\title{
The Credit Rating Industry: Competition and Regulation
}

\author{
Inauguraldissertation \\ zur \\ Erlangung des Doktorgrades \\ der Wirtschafts- und Sozialwissenschaftlichen Fakultät \\ der Universität zu Köln
}

\section{7}

\author{
vorgelegt von \\ Fabian Dittrich \\ aus Köln
}

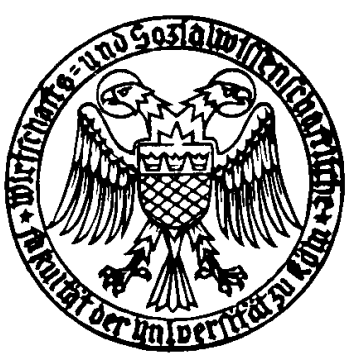


Referent:

Prof. Dr. Horst M. Schellhaaß

Korreferent:

Prof. Dr. Susanne Wied-Nebbeling

Tag der Promotion: 13. Juli 2007 


\section{Contents}

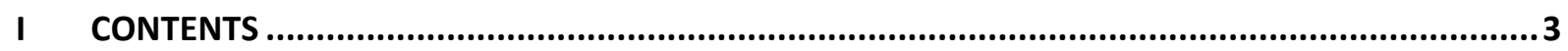

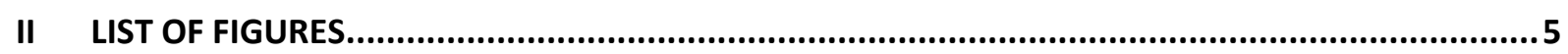

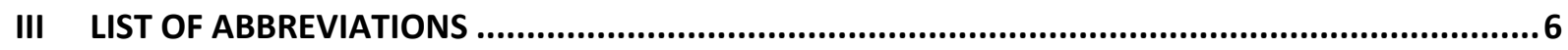

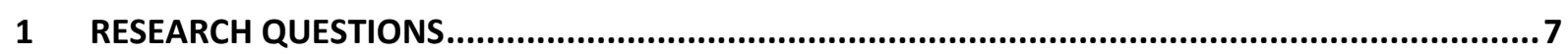

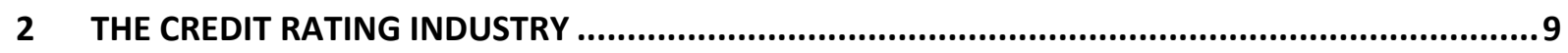

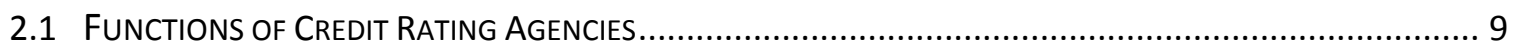

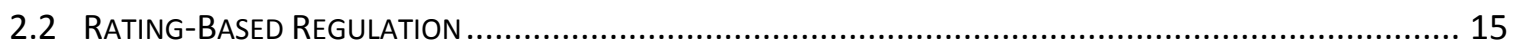

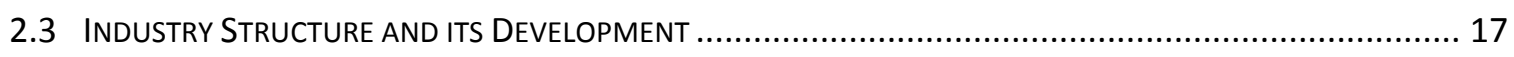

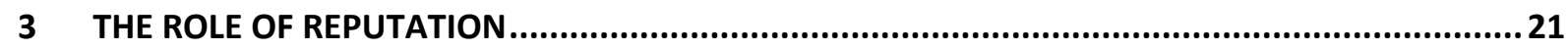

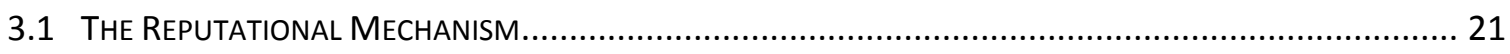

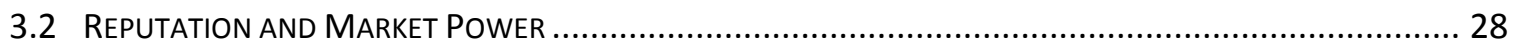

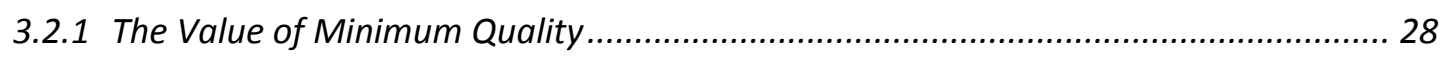

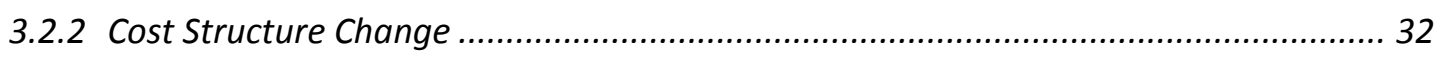

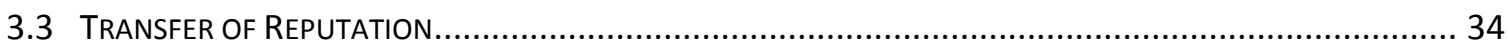

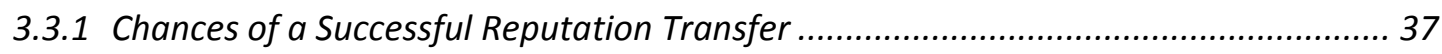

3.3.2 Market Potential of Reputable Non-Rating Newcomers ............................................ 40

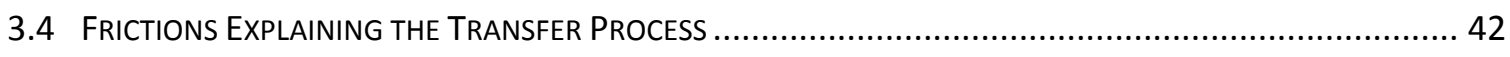

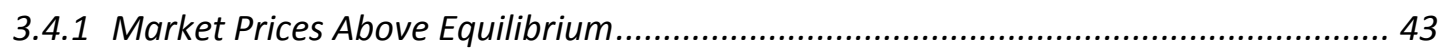

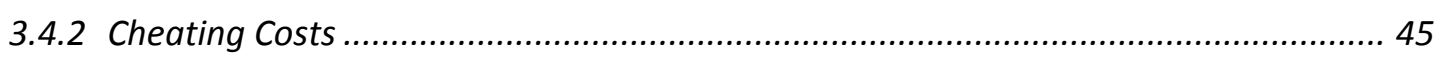

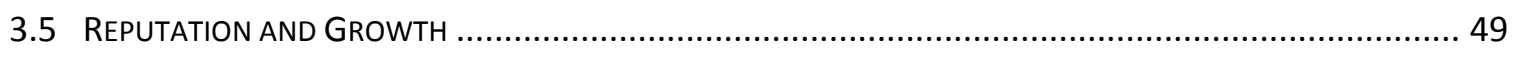

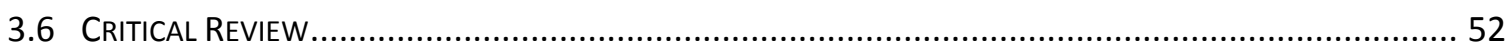

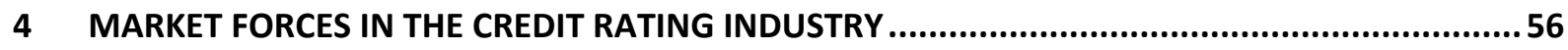

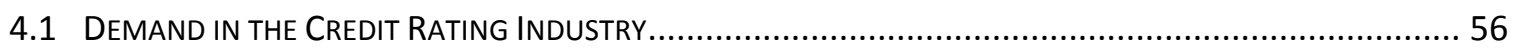

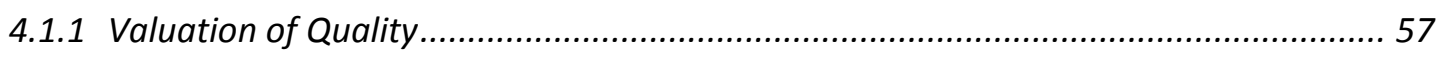

4.1.2 The Impact of Rating-based Regulation on Demand ................................................ 63

4.1.2.1 Information Value as Major Demand Driver............................................................. 63

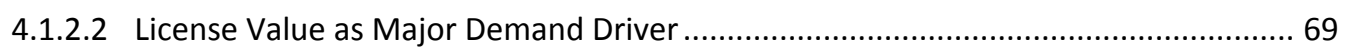

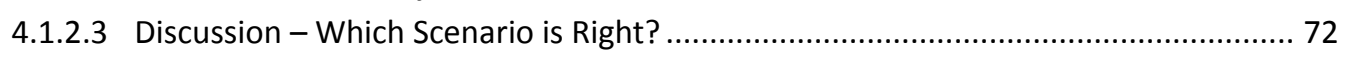

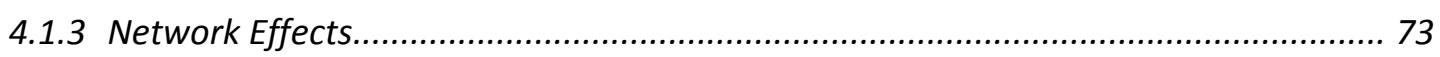

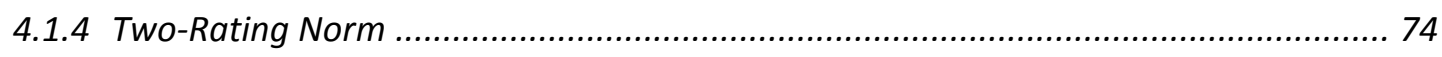

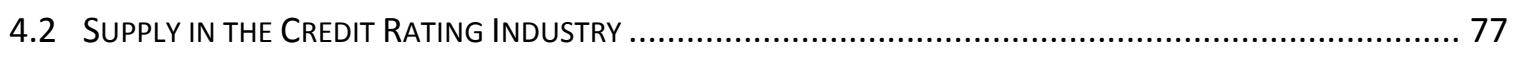

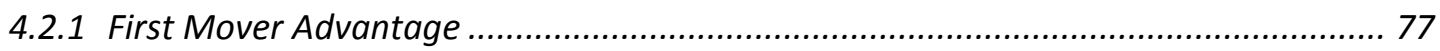

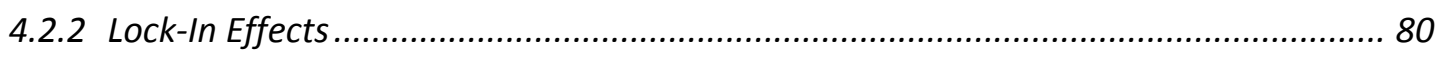

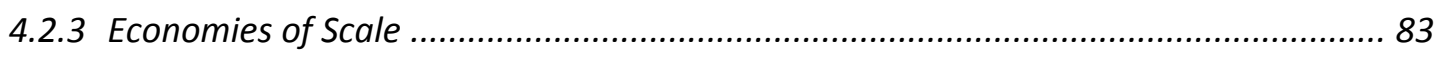

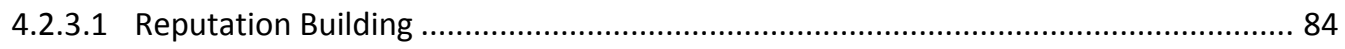

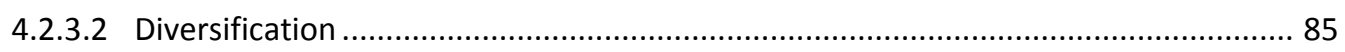

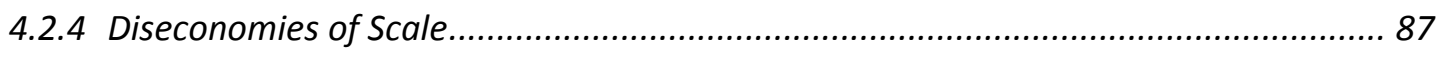

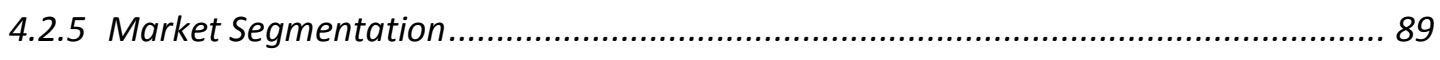

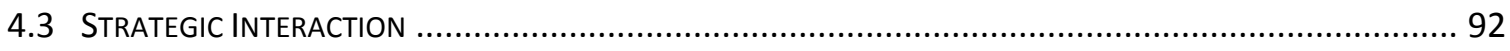

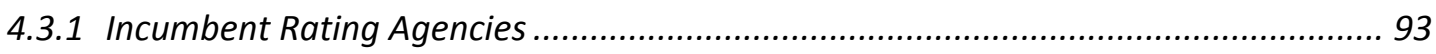




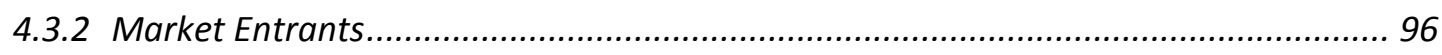

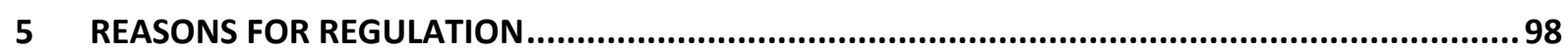

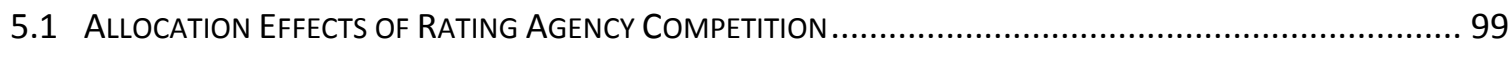

5.1.1 Monopoly Power and Inefficiency ...................................................................... 99

5.1.1.1 Static Efficiency ........................................................................................... 99

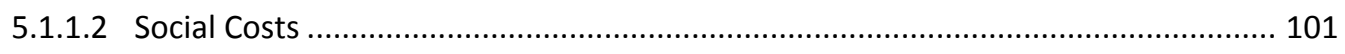

5.1.1.3 Dynamic Efficiency .................................................................................... 102

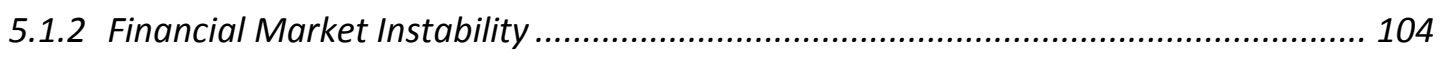

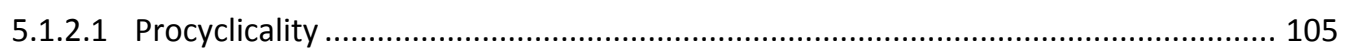

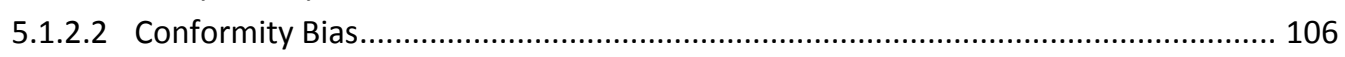

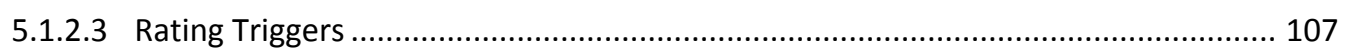

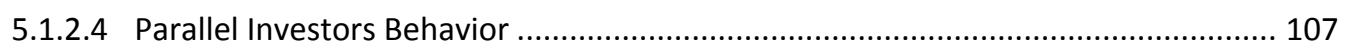

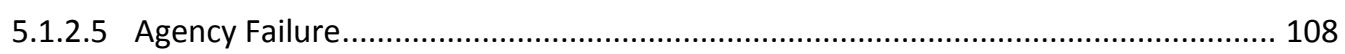

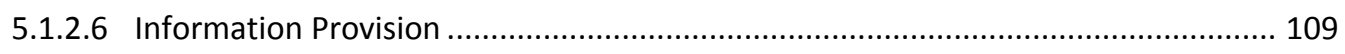

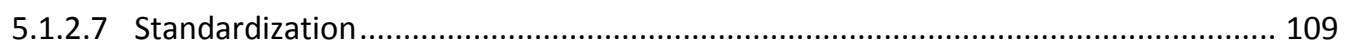

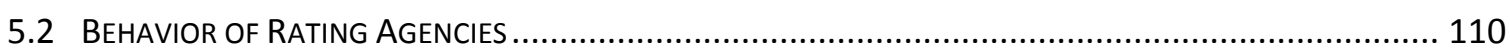

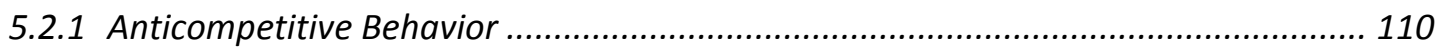

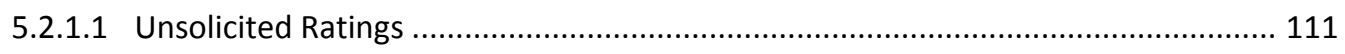

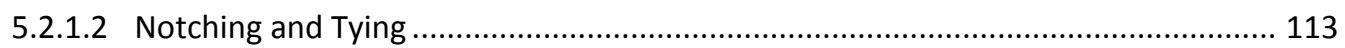

5.2.2 Abuse of Power - the Political Dimension .......................................................... 115

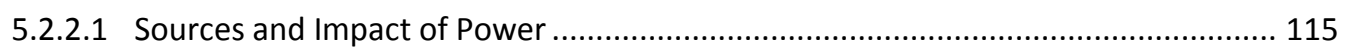

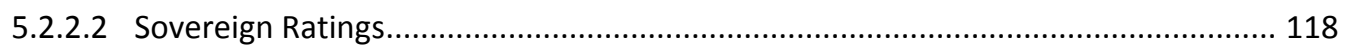

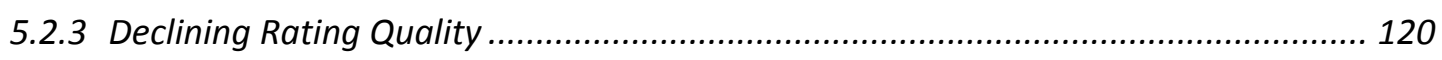

5.2.3.1 Factors Overriding Informational Quality ...................................................... 120

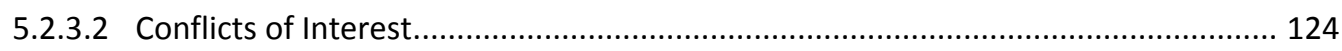

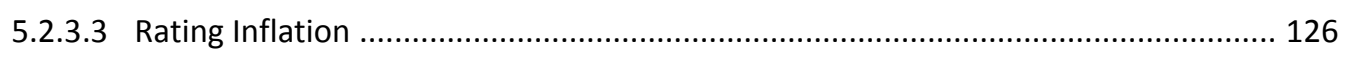

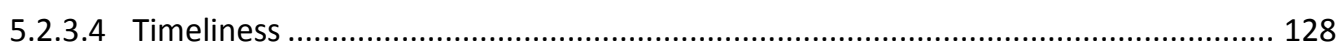

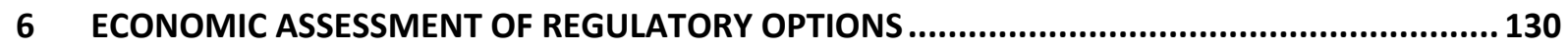

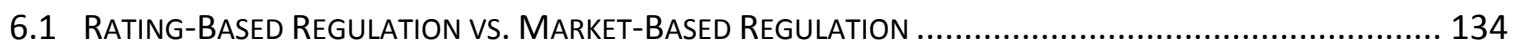

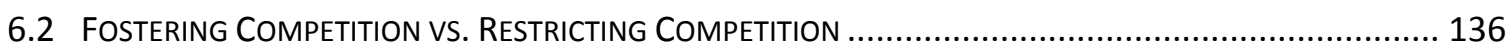

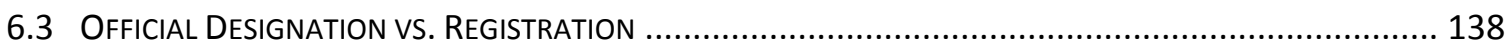

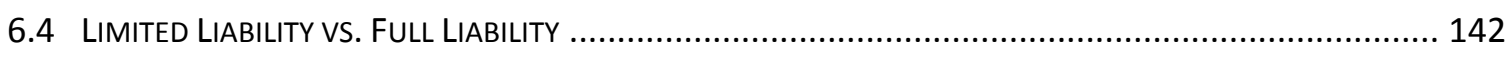

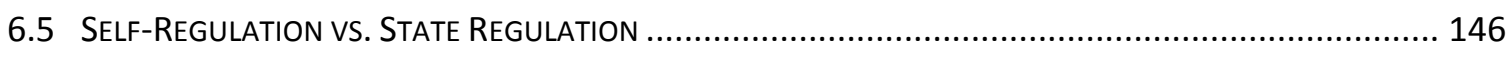

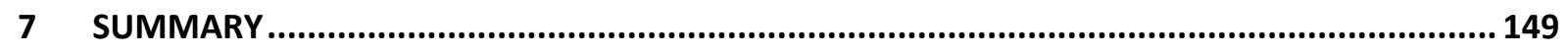

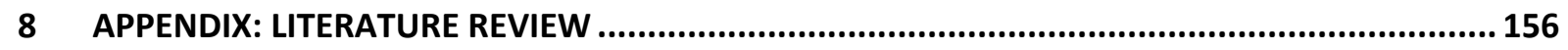

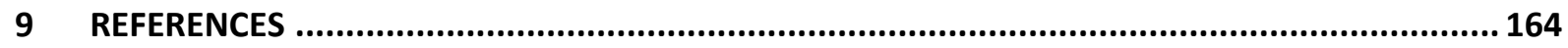




\section{List of Figures}

Figure 2.1: Information intermediation by credit rating agencies................................... 10

Figure 2.2: Functions of credit rating agencies ......................................................... 14

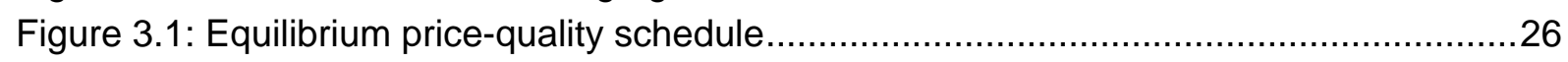

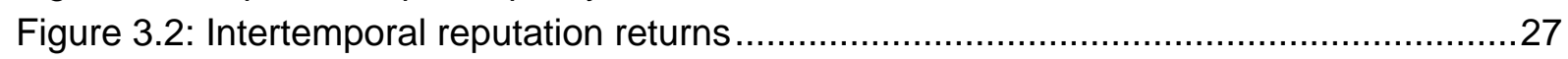

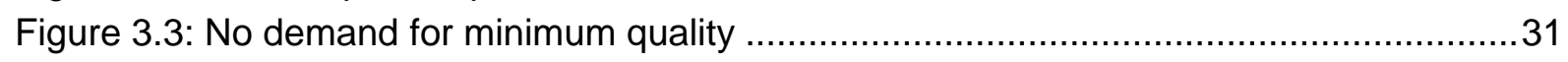

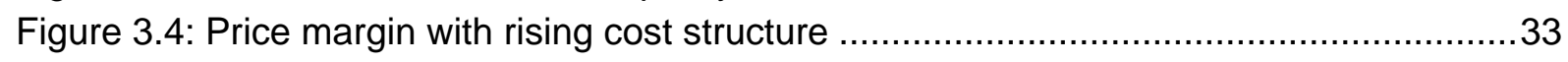

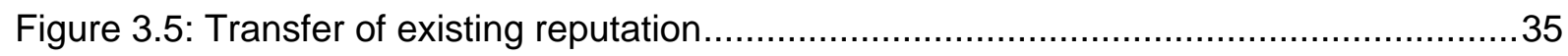

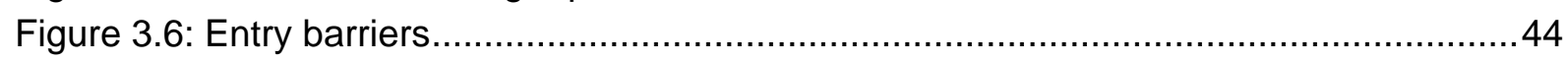

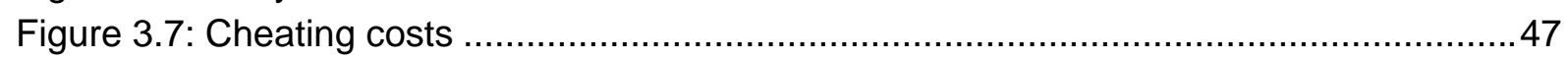

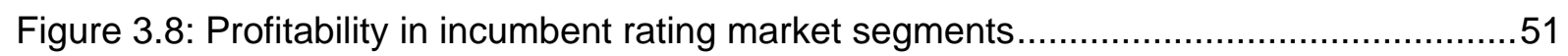

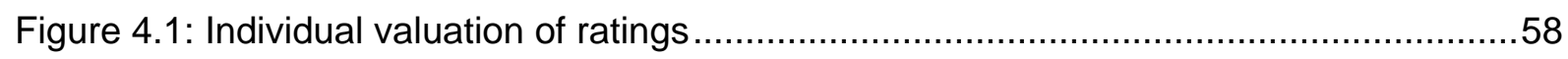

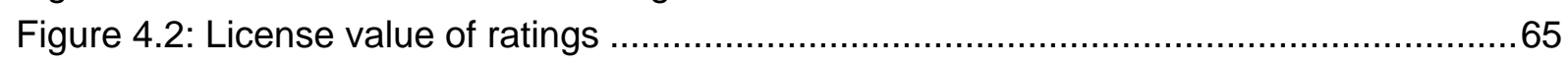

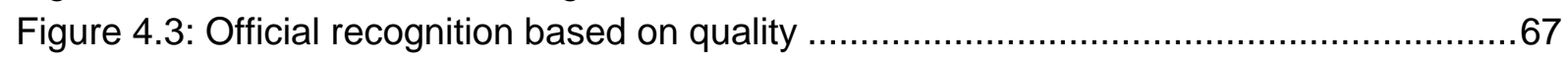

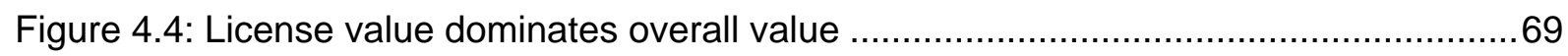

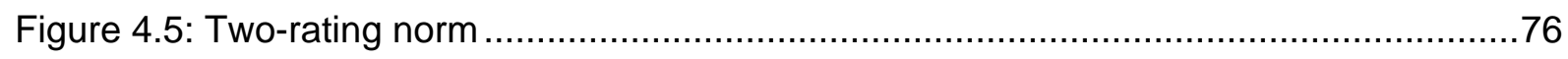

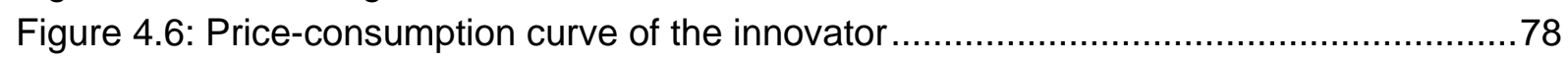

Figure 4.7: Price-consumption curve of the follower ...................................................... 79

Figure 4.8: Theoretical scope for credit rating market segmentation .................................. 89

Figure 4.9: Major elements influencing credit rating agency competition............................93

Figure 6.1: Summary of regulatory concerns .......................................................... 130

Figure 6.2: Credit rating agency regulation in the EU and USA .................................... 133

Figure 6.3: Credit ratings vs. market-based measures in credit risk-based regulation ........135

Figure 6.4: Business structure of rating agencies, equity analysts, and auditors................143

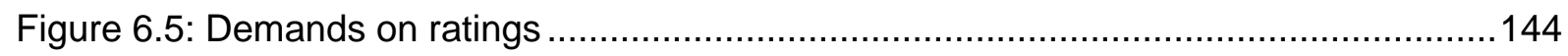

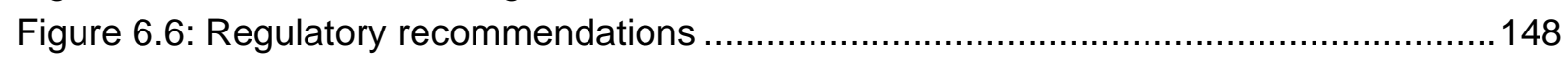




\section{List of Abbreviations}

$\begin{array}{ll}\text { BIS } & \text { Bank for International Settlements } \\ \text { CEBS } & \text { Committee of European Banking Supervisors } \\ \text { CESR } & \text { Committee of European Securities Regulators } \\ \text { CDS } & \text { Credit Default Swap } \\ \text { CRD } & \text { Capital Requirements Directive } \\ \text { e.g. } & \text { exempli gratia (for example) } \\ \text { et al. } & \text { et alia (and others) } \\ \text { ECAI } & \text { External Credit Assessment Institutions } \\ \text { Fitch } & \text { Fitch IBCA } \\ \text { i.e. } & \text { id est (that is) } \\ \text { IOSCO } & \text { International Organization of Security Commissions } \\ \text { Moody's } & \text { Moody's Investor Service } \\ \text { NRSRO } & \text { Nationally Recognized Statistical Rating Organizations } \\ \text { SEC } & \text { Securities and Exchange Commission } \\ \text { S\&P } & \text { Standard and Poor's' Rating }\end{array}$




\section{Research Questions}

Credit ratings have for a long time been an important and highly visible feature of financial markets. They regularly make headlines and are closely followed by the financial community. However, the credit rating agencies which issue these ratings have been on far fewer minds. Only after a series of big accounting scandals, Enron, WorldCom and Parmalat, to name but a few, has this highly concentrated industry received broader public attention. Although clear indications of trouble were visible for quite some time, in falling bond and stock prices, the rating agencies did not revise their favorable ratings for these companies until shortly before their bankruptcy.

Recent discussion has concentrated on the business model of credit rating agencies and on questions of regulation. For a tabular literature review see the appendix. Many contributions have drawn from a wide body of quantitative literature on the impact and quality of ratings. What has been missing is a thorough analysis of the underlying economics of the credit rating industry. Many scholars have discussed important principles, but have as yet not produced a detailed and coherent picture. This study closes the gap. A better understanding of credit rating economics will certainly help resolve important, open questions on regulation.

The study starts with an overview on the credit rating industry in chapter 2. Among other things, it contributes to the discussion by introducing a comprehensive framework for structuring the multiple rating agency functions. The focus of chapter 3 is on a detailed analysis of the reputation mechanism which lies at the heart of the credit rating business model. Although reputation is widely accepted as the key aspect of credit rating economics, there has been little explicit research on it. In particular, this study is the first to introduce a formal reputation model based on a simple framework by Shapiro (1983) which can be used to explain large parts of the industry. The basic question of how the reputation mechanism works, as well as adjacent issues such as the transfer of reputation, will be scrutinized.

Chapter 4 takes a wider look at the industry and identifies the forces behind credit rating supply and demand. Several authors such as Partnoy (1999) and Hill (2004) have already raised important questions. However, no comprehensive formal analysis of the issue exists so far. This study contributes important new aspects to the discussion, identifies the economic structure in the existing main arguments, links them, and generates several results as well as suggestions for further research. In large sections of chapter 4 the reputation mechanism is kept as a framework while the open research questions serve as a focal point. Regarding demand, scholars disagree on why ratings are so important. Is it merely their information value or is it because they are used by the state as a tool in 'rating-based regulation'? On the supply side the logical question is whether the high industry concentration is a 'natural' result of market forces or is it the result of state interference. The chapter concludes by analyzing the results from a classic industrial economics perspective and by drawing results for strategic interaction between rating agencies.

Chapter 5 provides a comprehensive review of potential reasons for regulating the credit rating industry. The area has already received substantial research attention, e.g., by Schwarcz (2001), Hill (2004), or Rousseau (2005), although as yet there is no comprehensive overview of the subject. In contrast to existing research, this study will build on the full-fledged analysis 
of the credit rating industry in chapters 3 and 4 . This allows for an economic evaluation of every major issue which is cited as a reason for state interference, including arguments from political scientists and sociologists such as Sinclair (2005), who often dominate practical discussion.

Finally, chapter 6 consolidates the results from chapters 3, 4, and especially 5 into an assessment of regulatory options concerning the credit rating industry. Since this topic has already received a great deal of attention from scholars such as Partnoy (2006), Blaurock (2006), or Bottini (1993), as well as from many regulatory bodies such as BIS (2004), or CESR (2005), the focus here is not on a detailed analysis but on the main economic principles that should guide the state in regulating the credit rating industry. Despite previous broad attention, only few authors have systematically dealt with this topic. This study reduces the state's scope to five options, i.e. the use of rating-based regulation, competition, official recognition, civil liability, and implementation methods. The economic analysis of these options leads to specific recommendations for the design of a regulatory regime against which the most recent regulatory initiatives by the US Congress (2006b) and the EU Parliament (2006) are compared. 


\section{The Credit Rating Industry}

\subsection{Functions of Credit Rating Agencies}

Credit rating agencies are in the business of predicting default probabilities for all kinds of debt securities and debt issuers ${ }^{1}$. A rating mirrors the likelihood of timely and complete payment of debt securities according to standardized quality categories ${ }^{2}$. The focus is not on absolute default probability, but on the relative riskiness of different debt securities. Furthermore, credit ratings typically mirror long-term developments and do not respond to short-term market fluctuations; new significant information is reflected in up- or downgrades. Both quantitative and qualitative rating methods are employed. In neo-institutional finance theory rating agencies can be depicted as information intermediaries. They are consulted in the course of a market transaction in order to overcome informational asymmetries between both market sides. In short, they create value by reducing information costs in the marketplace. Rating agencies are specialized in capital market transactions and are not active in the lending business.

Apart from information intermediation, credit ratings are today generally associated with a second major function: ratings serve as a regulatory tool in financial market oversight - one speaks of 'rating-based regulation'. This is often called the certification function. In this view, rating agencies not only assign a credit evaluation but they also issue a 'license' to access the capital markets or to lower regulatory burdens (Partnoy 1999, pp. 683-88). The certification function has its counterpart in the private sector. Here ratings serve as a risk management yardstick at institutions such as banks or investment funds (e.g., ECB 2004, pp. 8-9). Credit ratings often determine the range of eligible assets or are sometimes used as 'rating triggers'. It often makes sense to differentiate between the information and the certification function. However, the underlying hypothesis is that without good information provision, ratings are not useful for regulation and risk management ${ }^{3}$. Therefore, it is advisable to concentrate initially on the economics of information provision.

Every credit contract constitutes a principal-agent relationship. In the process of granting a credit, the issuer or agent usually has information (hidden information) superior to the investor, the principal. The issuer, however, is not able to cheaply convey his information about his own credit risk to the investor. Because he may profit from supplying the investor with wrong information, investors will generally not trust the reliability of such information. Thus they require a risk premium which increases the cost of the transaction, i.e. the interest rate paid by the issuer will rise. Issuers with a low credit risk but also low returns might not be able to obtain any credit (adverse selection). Rating agencies try to ease this dilemma by providing investors with a screening instrument in order to reduce the informational asymmetry and reveal hidden information. This in turn lowers the risk premium required by the investors.

\footnotetext{
For a widely accepted definition of 'ratings' and 'rating agencies' see IOSCO (2004, p. 3).

Such categories are, e.g., 'AAA' or 'B'. For an overview of the main categorizations see, e.g., Sinclair (2005, pp. 36-39). Ratings of BBB (or an equivalent) or higher are 'investment grade', below one speaks of 'speculative grade' or 'junk level'. Ratings are usually published with a commentary.

3 Partnoy (1999) challenges this hypothesis. From his point of view ratings can fulfill the certification function without being informative. The actual link between the two functions will be scrutinize in section 4.1.
} 
Furthermore, credit ratings also function as a monitoring mechanism during the debt security's lifetime, easing the moral hazard situation after a credit has been granted. In the absence of monitoring, an issuer may act opportunistically, taking risk prone decisions in his own favor while lowering the investor's expected return. The issuer's actions are costly to observe (hidden actions). Credit rating agencies invest heavily in monitoring these actions and issue periodic updates to their initial ratings. A simple model of the credit rating industry with the focus on the information intermediation function can be seen in Figure 2.1:

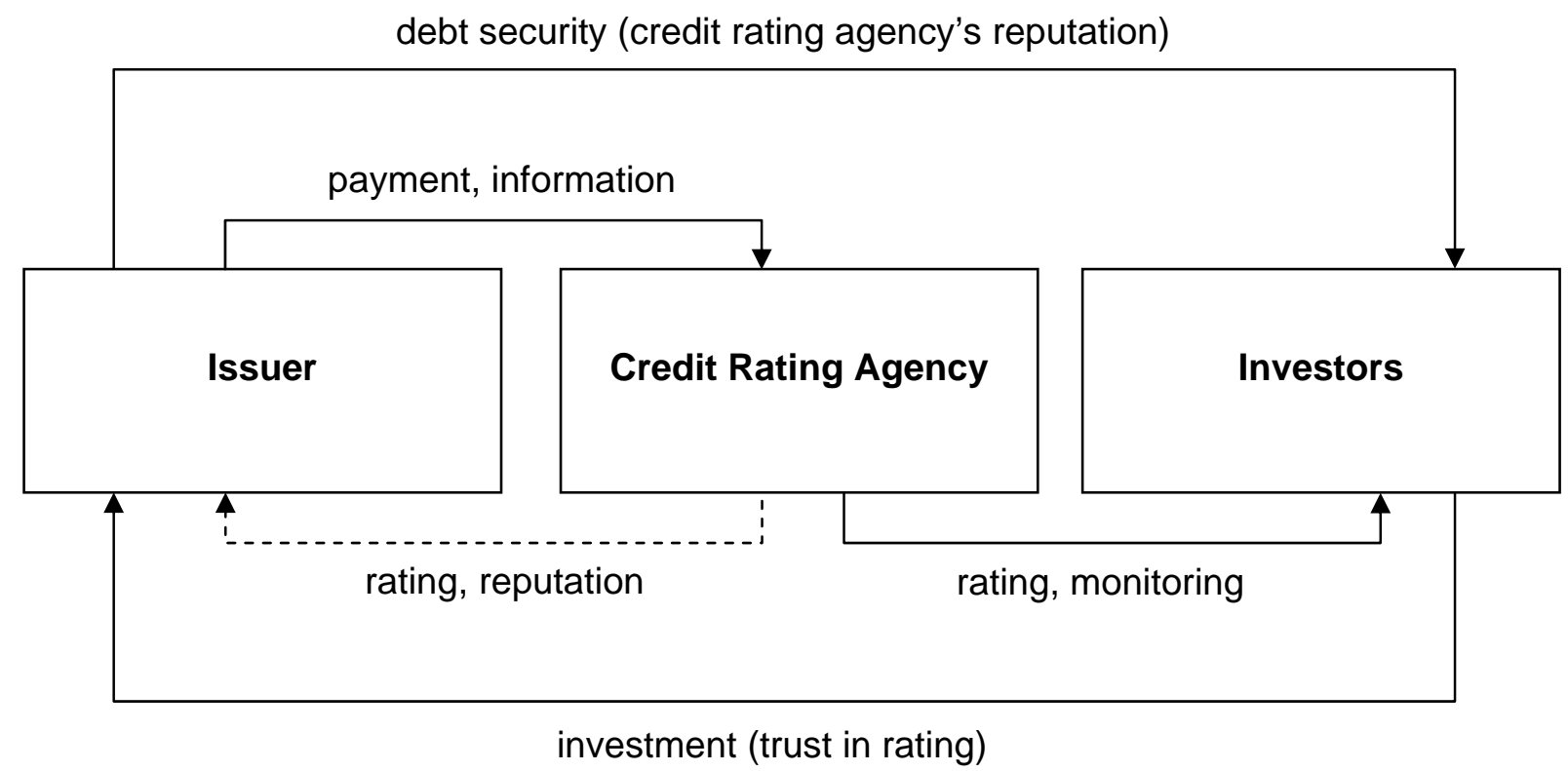

Figure 2.1: Information intermediation by credit rating agencies

The issuer sells a debt security to the investor. The investment received for a given debt security will be higher in proportion to the assumed creditworthiness of the issuer. At this point the rating agency comes into the game. It receives payment and information from the issuer. In return, the information is scrutinized by the agency and condensed into a rating of the issuer's creditworthiness. The rating is then communicated to the investors. The investors are convinced by the rating because the agency is trustworthy. As a result, their opinion of the issuer's creditworthiness becomes much more certain. Therefore, they are willing to accept a lower risk premium for their investment than they would if operating without a rating. As long as the price paid by the issuer to the rating agency is lower than the value of interest payments saved, the issuer will buy the rating. Over the lifetime of a debt security, the rating agency will usually monitor it and update the rating as a service to investors who want to buy or sell the bond on the secondary market. Issuers also benefit from monitoring and typically pay regular fees for the service. They acquire a favorable reputation in the market if they are willingly to operate under the credit rating agency's ongoing scrutiny.

The basic good produced by credit rating agencies can be described from the issuers' perspective as a signaling service. In an analytical process the agencies gather financial and other data and publish a neutral opinion about the true credit quality of an issuer or a debt security. These opinions are indicators covering the potential for credit loss resulting from delays in payment or the failure to pay. Note that other risks associated with fixed income securities 
such as exchange rate risks or interest rate risks are not covered by credit ratings (Moody's 1991, pp. 73, 83-84). Furthermore, rating agencies cannot cover the risk of fraud, as they rely on information provided by the issuers. In an investment decision, credit ratings thus can only be one input factor among others. Institutional investors often use them as checks against their own internal research.

Looking at the signaling service in more detail, one finds two adjunct components. On the one hand, there is the actual generation and provision of information as described above. Closely connected to the pure information value of ratings is the 'reputation value', which is also indicated in Figure 2.1. Market participants will trust the quality of ratings because of an agency's reputation. From this point of view, the reputation itself is the rating agencies' product. Independent of the actual rating, simply being rated serves as a positive signal to capital markets (Chemmanur and Fulghieri 1994, p. 59). The issuers buy a share in the agency's good reputation in order to increase their own reputation in the eyes of the investors. Especially little known issuers buy ratings to build up their own market reputation (Jappelli and Pagano 2000 , p. 8). To be rated by one of the broadly acknowledged credit rating agencies shows that an issuer takes the issue of creditworthiness seriously and is working together with a highly professional external partner. For established issuers who are reputable themselves, ratings can be an instrument to distinguish themselves from other market participants. Credit ratings generally play "an important role for companies when evaluating counterparties (...)" in nearly every business aspect (AFTE 2004, p. 5) In a 1998 study 60 percent of surveyed issuers said ratings also play a role in their marketing (Fight 2001, p. 5, 169).

In this respect, ratings not only convey credit information, they convey the rating agencies overall reputation for integrity onto the issuer ${ }^{4}$ as well. Quite like an auditor, a rating agency's expertise serves as a bond. The reputation value is not only relevant for marketing, but plays an integral part in many financial market transactions. Structured debt securities, e.g., are especially designed to receive a certain rating (risk profile). The actual rating acts as an approval of the debt security's construction. Of course, the reputation value is dependent on a high informational quality of the underlying rating service. Therefore, one does not need to differentiate between the information and the reputation value in most cases - they jointly result from the information intermediation function.

In general, issuers with a high credit rating from a reputable agency will be able to attract many investors and sell their debt securities at a relatively small cost. They have to pay lower interest rates than issuers with a low credit rating. Of course it can be assumed that large sophisticated investors are able to generate similar information through their own research. This, however, would mean a duplication of efforts, as the same information would be produced many times over. The credit rating agencies, on the other hand, generate the credit risk information only once, exploiting vast economies of scale in information production (Grundmann and Kerber 2001, p. 269). This is a major reason why the creation of credit in-

4 Cook et al. (2003) examine the value of reputation empirically in the bank lending market. In a sample of 618 lending institutions the study finds that reputable banks can generally extract a certification premium from its clients which rises with the banks reputation. As details on loans are not published, the premium can hardly be traced back to a specific information factor. Thus, the study is a strong indication for an actual and significant reputation value in markets with information asymmetries. 
formation is generally pooled by specialized agencies. Diamond (1984) shows in a formal model that the monitoring of credit contracts is most efficiently delegated to some form of financial intermediary. In the actual market place large institutional investors still do their own credit research, but they use credit ratings as a vital input (Ellis 1998, p. 39).

Empirical evidence on the information value of credit ratings is mixed. For an overview see Boot et al. (2006 p. 101-03), Micu et al. (2006 pp. 3-6), and Norden and Weber (2004 p. 2816-17). It has been shown that there is a very high correlation between ratings of the major agencies and default rates. Credit ratings also have some explanatory power for a debt security's market price ${ }^{5}$. However, it is not clear to what extent credit ratings bring new information to the market. Kliger and Sarig (2000) show that there is definitely at least a small independent informational effect: when Moody's revised its rating categories in 1982, bond prices reacted although there were no changes in underlying risks or regulatory benefits. To quantify the information value, researchers usually concentrate on the question whether credit rating changes have an impact on market prices. By concentrating on rating changes, aspects other than credit risk that have an impact on market prices are largely eliminated. Early studies from the 1970s produced conflicting conclusions. They either showed significant reactions to rating changes or no reactions at all. Generally, the quantification of the informational effect is complicated by potential changes in the regulatory status of bonds which might also impact credit spreads. The crucial concept here is the 'price pressure hypothesis' (Micu et al. 2006, p. 5).

Newer studies often broaden their focus beyond debt securities' market prices. They also look at the reaction of a company's stock price to a rating change. Such appraisals, however, face an even greater risk of distortion by the license value of ratings. If a rating adjustment changes an issuer's regulatory status, this can have a strong impact on the equity value, e.g., by lower reporting costs or increasing financial flexibility. It is a principal finding that the stock price reacts significantly to a rating downgrade, but to a much lesser extent to an upgrade. Reactions are stronger for issues of low credit quality compared to issues in the top rating categories. Other researchers have observed different reactions of stock and bond prices depending whether they were triggered by the agencies' motive for a rating change or by the issuer's asset structure. Although there have been a great number of studies, the exact information value of credit ratings remains an open question.

Since the late 1990s, researchers have a new tool to single out the information value of ratings: credit default swaps (CDS). The price of these financial instruments is exclusively determined by the available information on the probabilities of default and loss in the case of default. Consequently, prices of CDS only react to rating changes if they bring new information to the market. Norden and Weber (2004), Hull et al. (2004), and Micu et al. (2006) are among the first scholars to study the impact of ratings from Moody's, S\&P and Fitch on CDS. All sorts of rating announcements can cause statistically significant reactions of CDS prices. The strongest reaction is seen for negative rating reviews from Moody's and S\&P. On average, spreads implied by CDS prices climbed 10 basis points on the announcement day.

5 It is a logical result that credit ratings only partly explain bond spreads, as these reflect other factors than credit risk such as liquidity or taxes, as well. 
Reactions for other negative events have been far smaller. Studies differ depending on reactions to positive rating events or rating events from Fitch. Generally, the reactions of CDS for bonds rated around the investment grade boundary are strongest, i.e. prices have been influenced by a change in the regulatory status. In sum, available CDS studies suggest a small independent information value of credit ratings. To neutralize regulatory effects, future studies might concentrate instead on bonds rated below the investment grade boundary or on ratings from non-recognized agencies.

Given the weak empirical evidence on the information value, Partnoy (1999) argues that today's ratings in most cases only reflect information already incorporated into the debt securities' market prices. The market reacts to the change in the regulatory status rather than to credit risk information. The rating itself is the information and the value of ratings is simply derived from the influence on a debt security's regulatory status. Hill (2004, p. 65-72) discusses the issue in detail and gives several reasons why Partnoy's extreme view has deficiencies. Admittedly, the evidence cited can not quantify the relative importance of information provision versus the regulatory value.

Statements by issuers and investors are also not clear on this issue. In a survey around $90 \%$ of the 41 issuers questioned believe that ratings are very or at least somewhat relevant for a broad access to capital and cheaper costs of funding (TBMA 2006, p. 4-8). But it is not evident if this results from information provision or rating-based regulation. For over $80 \%$ of investors questioned ratings are relevant in their value for internal risk management. But at the same time over half of the investors questioned state that their own internal research is more important to them than credit ratings, while only five percent say ratings are more important. This finding may well reflect the simplicity of ratings, which makes them an easy to use tool, whereas it provides no indication of their absolute information value. Future surveys should strive to differentiate between the information and regulatory value of ratings.

Apart from the information/reputation and the certification function, credit ratings fulfill additional economic roles. It is often mentioned that the relative nature of the rating agencies' risk assessment creates a value by itself, because risky investments of all possible classes and countries can easily be compared (e.g., Moody's 1991, p. 75). Some sociologists such as Kerwer (2002a) and Sinclair $(2000,2005)$ have put this into a wider framework. They reason that credit rating agencies create a value through standardizing the credit assessment process, regardless of the information value of the ratings. The rating agencies constitute the credit relationship itself and thus lower general uncertainties between issuers and investors. One can argue analogous to Campbell and Kracaw (1979) that rating agencies as financial intermediaries provide a mechanism to release private information to the market while maintaining confidentiality about the information itself. During the rating process, an issuer's management is routinely consulted for non-public information. Jorion and Zhu Liu; et al. 2005 find empirical evidence that US ratings have gained information value since 2000 , when regulation FD provided rating agencies with special access to private information. Yet another proposed function of credit rating agencies studied by Boot et al. (2006) is the provision of a coordination mechanism or 'focal point' to resolve situations where multiple equilibriums in firm investment decisions can be obtained. 
Figure 2.2 summarizes the major functions of credit rating agencies in three groups. First, the information function: credit rating agencies intermediate informational asymmetries between issuers and investors by generating information and by providing a reputational bond (regulators are also interested in the information). They also offer a mechanism for issuers to release private information. Investors and regulatory bodies profit from economies of scale in information production. Second, the certification function ${ }^{6}$ : states use credit ratings for ratingbased regulation, which affects investors and issuers alike. Ratings also serve as a private risk management tool. Third, the standardization function: credit ratings provide a framework for the process of issuing debt and investing into it. Investors can also use ratings for easy risk comparison.

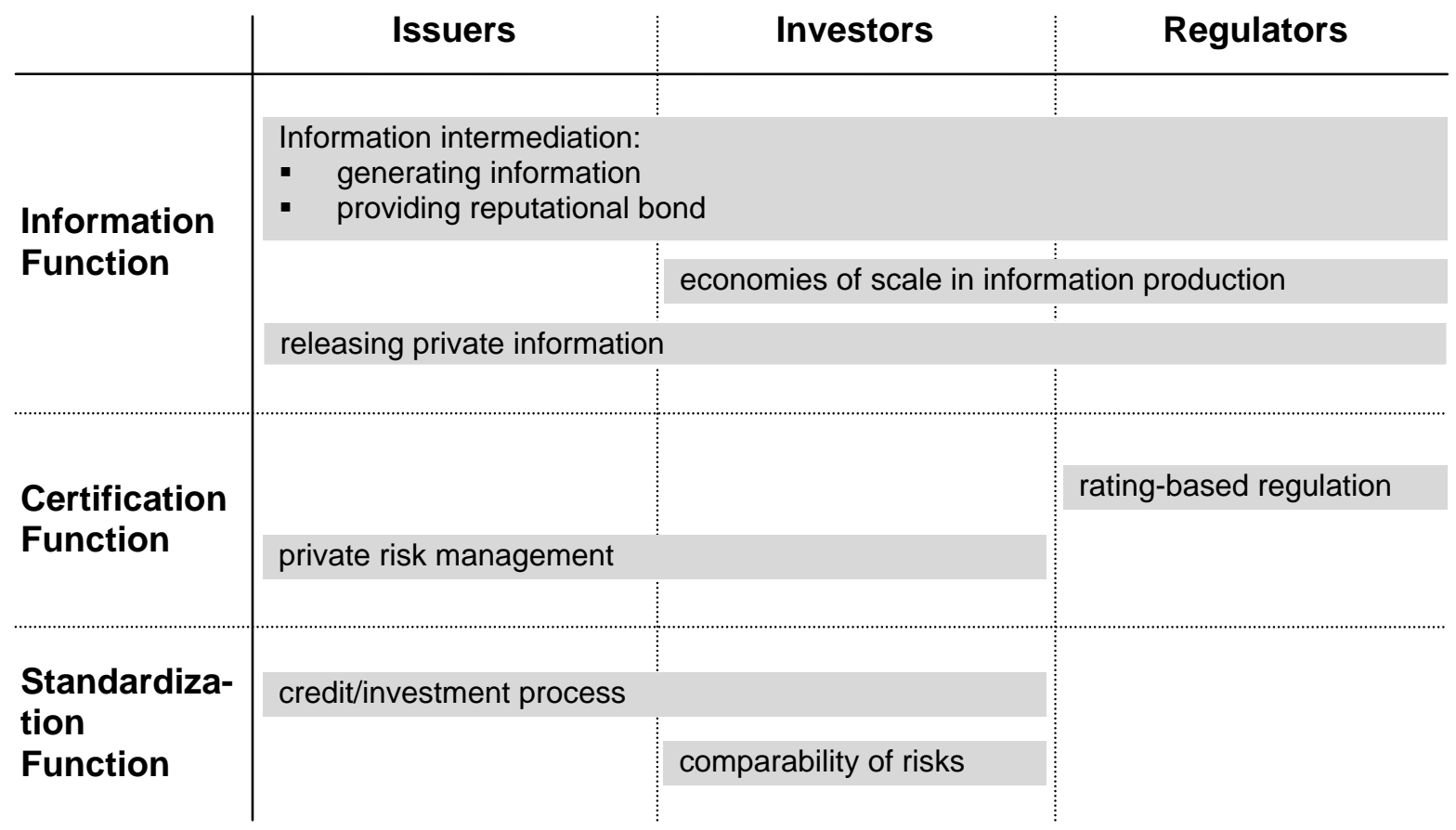

Figure 2.2: Functions of credit rating agencies

Credit rating agencies can be described as 'information gathering agencies' (Millon et al. 1985, pp. 1403-04). They acquire and process information but do not fund customers in the way 'funding financial intermediaries' such as banks do. The difference is crucial since rating agencies lack a crucial control mechanism: banks are 'accountable' for their credit analysis because they take a financial stake in the scrutinized assets. The higher the banks' share the greater in turn is their incentive to correctly acquire and process information (Campbell and Kracaw 1980, p. 864). Market participants can rely on the quality of the information without explicit monitoring.

The circumstances are different with credit rating agencies. They do not take any financial stakes in analyzed debt securities and thus do not have a direct financial incentive to provide

6 The reputation function, which has been described as integral part of the information function, might also be seen as certification. Here, the certification function has been more clearly defined: A rating serves as a real certificate only in that it is used for compliance with explicit public or private rules. The reputation function means less: A rating only attests that a debt security has undergone the rating agency's scrutiny. 
the best possible service. In other words, credit rating agencies and investors also find themselves in a moral hazard situation. Rating agencies may profit from sloppy analysis to save effort or they could issue manipulated ratings to either pressure or collude with issuers.

There are no mechanisms that directly monitor the quality of credit ratings for investors or for issuers. Both would need to take the same steps as the rating agencies in order to accurately assess the quality of the information. This, if possible at all, would mean a duplication of efforts, the avoidance of which is a major reason for the existence of rating agencies in the first place. Typical means to assure quality such as litigation or guarantees are not options for the credit rating industry. Although the quality of ratings is observable ex post, it is very difficult to hold rating agencies liable. In the USA, e.g., credit ratings have historically been treated as 'opinions' under the First Amendment to the Constitution (e.g., SEC 2003a, p. 4). Guarantees, on the other hand, are not applicable as rating quality is measured against statistical default rates. A certain amount of bonds in every class must default in order to reach high quality. For cases other than outright fraud, there is no basis to define guarantees for issuers or investors. However, there is a feasible indirect solution to the monitoring dilemma: reputation. Reputation will therefore be the focal point of chapter 3. It will analyze how reputation in principal ensures high quality, and which influence it has on the industry structure.

\subsection{Rating-Based Regulation}

The credit rating industry is characterized by the fact that states worldwide use private credit ratings as a reference point in rules and financial regulations - ratings gain a certification function (for an overview see Sinclair 2005, pp. 42-49). Financial regulation can have many purposes; most relevant for rating-based regulation is the protection against systematic risk (for an overview of regulatory goals see Balling 2004). The state intends to prevent the accumulation of too much risk at certain points in the financial system in order to prevent contagious events such as bank runs. The goal is financial stability, which can be defined as "the stability of the key institutions and markets that go to make up the financial system" (Crockett 1997 , p. 6). An important component of financial stability is confidence in the system by all participants, which can be described as a public good (Dumez and Jeunema 1997, pp. 4-5). The state aims to increase confidence since everybody profits through reduced transaction costs and increased volumes. There is also a consumer protection side to it, expressed, e.g., by rules limiting risk taking by pension funds.

From a practical point of view it is easy to understand why ratings are an attractive instrument in financial regulation. First of all, credit ratings have proven efficient in their high correlation between risk categories and default rates, regardless of whether they convey new information ${ }^{7}$. Second, credit ratings are readily available at no direct cost to all market participants. This is especially true for today's common electronic publication. Third, the need for continued detailed oversight can be kept at a minimum by matching market recognition and regulatory recognition of rating agencies (Brookfield and Ormrod 2000, p. 315). Fourth, ratings are based on reputation and thoroughness, an ideal instrument to increase confidence.

A general deficiency as a regulatory instrument is the relative nature of ratings. In many circumstances it would be more adequate to regulate the absolute level of risk. 
In sum, ratings are a simple instrument to influence the behavior of participants in financial markets.

By 2002 there were "at least eight federal statutes and 47 federal regulations, along with over 100 state laws and regulations, reference NRSRO ratings as a benchmark" in the USA (US Senate 2002, p. 102). Most EU member states use ratings for a variety of purposes, too (CESR 2005, §§ 183-86 and Blaurock 2006, pp.8-9). There is also rating-based regulation in many other countries (BIS 2000, pp. 41-44).

Rating-based regulation can be grouped into three areas (Adams et al. 1999, p. 200): disclosure requirements, investment restrictions, and capital requirements. In the first area, credit ratings serve to define disclosure requirements. An appropriate credit rating may lower legislative obligations, or may even be a path to completely avoid supervision. Ratings can also be a requirement for issuing special financial products. The goal is to free low-risk companies from unnecessary regulatory scrutiny. Secondly, regulators use credit ratings to impose investment restrictions on certain financial institutions. By prohibiting the holding of unrated or low-rated investments, the riskiness of the overall portfolio can be limited. The third category comprises all rules concerning capital requirements. Private credit ratings are used in this context to determine the riskiness of single assets and the appropriate capital needed to insure against default. The state's goal is to prevent financial market instability. In all three categories rating-based regulation has in common that a (high) credit rating either allows a security to be bought by certain financial institutions, or the cost of holding it to be lowered. For the analysis in this study the fact that ratings carry an additional value other than informational or reputational is of crucial relevance.

Partnoy (1999) and the SEC (2005) provide a good overview of past and current ratingbased regulation in the USA. Ratings were first incorporated into substantive regulation in the United States in the 1930s as a by-product of the then dominant safety-and-soundness regulation that was intended to preserve the systematic stability of the banking system and to protect liability holders (e.g., White 2002. p. 51). Most rules were investment restrictions for reserve banks, trust funds and saving banks. The term 'investment grade', which refers to securities rate BBB (or an equivalent rating) or higher, was coined during that time by US regulation (S\&P 2006, p. 13). 1940 to 1973 was a period with no major introduction of further rating-based regulations.

However, after a credit crisis in the early 1970s new rules explicitly referring to private credit ratings were adopted in 1973. For the first time the SEC also introduced a standard definition for ratings (SEC 2005, pp. 5-11). Only ratings from 'Nationally Recognized Statistical Rating Organizations' (NRSROs) can be used to comply with rating-based regulations in the USA. The NRSRO designation was important as regulations could now explicitly refer to these recognized rating agencies. Since 1975 there have been a large number of new rules, releases and regulations in the USA referring to NRSRO credit ratings in areas such as securities, insurance, banking, pension or real estate. Rating-based regulation has spread during this time to many other countries as well.

The importance of private credit ratings in regulatory regimes worldwide has further increased with the Basle II Capital Accord issued by the Basle Committee on Banking Supervi- 
sion in June 2004 (BIS 2004). Most countries worldwide are expected to introduce a financial oversight framework based on Basle II, to take effect from 2007. The proposals, among other things, introduce a regime of differentiated capital requirements for commercial loans based on their credit risk. The credit risk assessment can either be provided by internal rating systems, or by a standardized approach using external credit ratings. Presumably, only bigger banks in developed countries have the capacity to create and use internal rating systems. Therefore, credit rating agencies could see a boost in the importance of their service worldwide. With the implementation of Basle II, credit ratings for the first time directly influence not only an issuer's access to capital markets but potentially also its cost of commercial loans (Jackson 2001, p. 321) ${ }^{8}$.

Rating-based regulation, in sum, is a major force in the credit rating industry. It makes sense to explicitly differentiate between the industry's 'natural' structure and the impact of ratingbased regulation. Such a division is useful in order to clearly understand the basic economic mechanisms. Further, it simplifies the analysis of the role of the state. We will see that ratingbased regulation is essentially increasing demand for ratings, while potentially restricting supply through official recognition. While the analysis is explicitly directed at rating-based regulation, it is in large parts also applicable to private arrangements that use credit ratings such as voluntary investment restrictions of investment funds. Admittedly, the frictions of private arrangements should be lower, as internal investment procedures can be changed with greater ease. There is also no direct regulatory barrier to entry.

\subsection{Industry Structure and its Development}

The credit rating industry is today dominated by two global players: Moody's Investor Service (Moody's) and Standard and Poor's Rating (S\&P). These two rating agencies hold a near duopoly. With Fitch IBCA (Fitch) there is only one more but considerably smaller global player that is owned by a French conglomerate (for a short profile of the three companies see Smith and Walter 2002, pp. 298-301, for a more extensive analysis of the wider industry see Fight 2001, pp. 13-99). Together with the 'niche agencies' Dominion Bond Rating Service and AM Best, as of 2007 the three market leaders are the only NRSROs in the USA. From 2008 on, however, the situation is likely to change dramatically since any rating agency with a credible client base can register as NRSRO in the USA under the 'Credit Rating Agency Reform Act of 2006' (US Congress 2006b).

Practically all bonds traded today in the USA are rated by Moody's and S\&P and also a large majority of international issues are also rated by them (e.g., Hill 2004, p. 48). In 2005 Fitch rated 66 percent of all debt securities worldwide (Fimalac Group 2006, p. 33). This means that the absolute market penetration of Moody's, S\&P, and also Fitch is very high. The same is true for their relative standing: in 2005 Moody's and S\&P shared about 77 percent of

8 Indirectly, credit ratings have been important for all kinds of credit for some time: In a survey of 230 senior level financial professionals in 2004 nearly 80 percent stated that their credit providers - including banks - require them to have a rating from S\&P, Moody's or both (AFP 2004, p. 3). 
worldwide credit rating revenues while Fitch held another 15 percent $^{9}$. It is noteworthy that these three general purpose rating agencies have always been the market leaders since the inception of the industry. Moody's was founded in 1909, the Poor's Publishing company and the Standard Statistics Company that merged to S\&P in 1941 started in 1916 and respectively 1922, and the Fitch Publishing Company began its rating business in 1924 (White 2002, pp. 44).

Fight (2001, pp. 6-11) and Sylla (2002) provide a good outline of the historic development of the industry. From its beginning in the early twentieth century, the credit rating market was for many decades limited to the USA. The country was predestined for credit ratings because of its grand railroad development projects under private auspices, and because of the predominant bond financing in a large and rapidly expanding economy. The credit rating market expanded with increasing speed between 1909 and the 1930s. In the 1940s, 50s, and 60s the rating agencies faced weak demand in an environment of low volatility, a healthy economy and few defaults (Partnoy 1999, pp. 647-48). A second period of rapid and increasing growth began in the mid 1970s and lasts until today. Both periods of expansion have seen high volatility and many defaults in the bond markets, as well as an increase in rating-based regulations. Especially the second wave of expansion was significant. S\&P, for instance, had only 30 professionals working in its industrial group in 1980, a number that rose to 800 by 1995 (p. 650). The expansion was accompanied by an internationalization and later globalization of the rating market. In the 1960 s and 1970 s first issues of sovereign states were rated by the US agencies. In the 1980s Moody's and S\&P started to rate domestic bonds in Europe and Japan. In quick succession both companies opened local offices in Europe, Japan, and later in many emerging markets. In certain cases they also acquired local rating agencies that have mainly been founded during the 1980 s and 1990s.

We can outline five factors which have driven industry growth especially since the 1970s (Gras 2003, pp. 11-14). First, there have been structural changes in financial markets. The number of participants and anonymity have increased, while investment strategies have become more complex and diversified. Second, disintermediation shifted credit from banks to capital markets and new complex credit products have been created through securitization. Third, individual countries have increasingly financed themselves through the credit markets. Sovereign ratings, in turn, have been the basis for local companies to be scrutinized by rating agencies. Fourth, American approaches in capital markets have set the standard worldwide. One important aspect of today's globalized financial markets is credit ratings. Fifth, ratingbased regulation has increased in the USA and since the 1990s in many other developed and developing countries. All five factors favor credit rating agencies either by increasing complexity and informational asymmetries or by raising the number of available debt securities and regulatory induced demand respectively.

9 The market share data is estimated on the basis of the 2005 Annual Reports of Moody's Corporation, McGraw-Hill Companies (S\&P), and Fimalac Group (Fitch), as well as on revenue data of several larger second tier rating agencies. An exchange rate of 1.28 US Dollar per Euro and 116 Yen per US Dollar was used. Note that the large market share differences between the two leaders and Fitch is influenced by differences in rating fees. Fitch rates a relatively higher share of world wide debt securities than implied by market share; its average fees must consequently be lower. For older estimates from 2001 see Hill (2004, p. 60). Despite the enormous industry growth since the late 1990ies, Moody's and S\&P have only slightly lost ground to rivals. 
In the USA at any given time there have never been more than five general purpose rating agencies. In virtually all other countries there have been and are even less competitors (White 2002, p. 33). As the company histories of Moody's, S\&P, and Fitch show, most US and many domestic agencies of other countries that managed to build up a strong reputation eventually merged or were acquired by one of the market leaders. Altogether there have only been few entries to the credit rating market - US nationally and internationally - in which most companies maintained a narrow focus on a market niche, such as an individual industry or country (BIS 2000, pp. 21-39). No national rating agency has so far managed to reach a worldwide standing anywhere near the three market leaders. It is remarkable that the number of general purpose agencies has remained at its historical levels, although the world market for ratings has grown exponentially since the 1970s.

The increase in market size has been accompanied by many product innovations. Whereas ratings were confined to US domestic industrial bonds for many decades, the market generated several new rating products since the 1970s. Examples are sovereign ratings, bank loan ratings, or issuer and bank financial strength ratings (BIS 2000, pp. 97-99). The most important new class of ratings is structured finance products, which make up a major part of the rating business today. Moody's generates over $40 \%$ of revenues from structured finance ratings, for Fitch it is the most important business and growth driver (Fimalac Group 2006, pp. 32-33 and Moody's Corporation 2006, p. 7). There have also been several technical innovations. Most notably, rating scales have been expanded or adapted for newly rated debtclasses such as commercial paper; watch lists as well as plus and minus additions were introduced. Since the late 1990s the leading agencies have begun to offer consulting services as well. In general the rating industry has been quite innovative in recent decades despite concerns about excessive conservatism in a low competitive environment (Schwarcz 2001, p. 307). The main innovators tend to be smaller agencies such as Fitch, which can use their leaner organizational structures to move quickly into new segments of the market (Fight 2001, pp. 48-49). New rating products have become attractive through their usually high complexity, which also makes it easier to command premium prices.

Credit rating agencies traditionally generated their revenues by selling publications to investors. In the early 1970s, however, all major agencies changed their business model and started to charge issuers for the ratings. One reason cited is the emergence at that time of low cost copiers (e.g., Cantor and Packer 1994, p. 3). On closer inspection, however, establishing intellectual property rights does not seem to be the main problem, as other information providers did not change their fee structure at that time. The reason lies much more in a structural change in demand, as the growing mutual fund industry required a broad and well monitored supply of ratings (Chen 2004, pp. 40-41). The traditional subscription fees could not offset the increasing costs while at the same time the direct value in the eyes of the issuers was increasing. It simply makes sense economically to charge the issuers instead of the investors. The cost for the rating is proportionally spread to the investors according to the fraction they hold by a reduction in the yield of the debt security (Partnoy 1999, p. 654).

If issuers request a rating, they have to pay a yearly fee that increases with the issue size. Larger issues tend to be more complex to analyze and - more importantly - they pose a larger risk to the rating agencies' reputation (Herring and Reeve 1986, p. 68 and Schwarcz 2001, p. 302). As of November 2002, e.g., Moody's charges 0.033 percent for the first $\$ 500$ 
million of par value of corporate debt and an additional 0.02 percent above. The minimum fee is $\$ 33,000$, the maximum $\$ 275,000$ (Covitz and Harrison 2003, p. 7, citing an official Moody's document; see also Partnoy 2006, p. 69 and AMF 2005, pp. 16-17). Smaller agencies charge considerably less (e.g., Jewell and Livingston 2000, p. 71). Some rating agencies assign unsolicited ratings without using private information, for which issuers are asked but not bound to pay (e.g., White 2002, pp. 47-48).

Rating agencies were not especially profitable until the 1970s. Their financial performance, however, has increased enormously since then, both in absolute and in relative terms (Partnoy 2006, pp. 62-68). Moody's has traditionally been the most profitable agency. On credit rating revenues of $\$ 1.590$ billion in 2005, Moody's Investor Service generated operating profits of $\$ 935$ million, which yields an operating margin of 58 percent (Moody's Corporation 2006, p. 91). Exact data on S\&P is not available, since the rating business is part of a larger financial services business. For about similar revenues the operating margin is also likely to be above 50 percent (McGraw-Hill Companies 2006, p. 70 and own estimates). Fitch generated a significantly lower - but in absolute terms still remarkable - operating margin of 31 percent on revenues of $€ 477$ million and operating profits of $€ 149$ million in 2005 (Fimalac Group 2006, p. 112) ${ }^{10}$.

10 As a comparison, the operating margin of Microsoft in 2005 was 37 percent (Microsoft Corporation 2005, p. 5). 


\section{The Role of Reputation}

"A firm has a good reputation if consumers believe its products to be of high quality" (Shapiro 1983, p. 659). Reputation is typically relevant in multi period relations with asymmetric information in which consumers cannot easily observe the quality of the product or service ex ante. Nelson (1970) categorizes these products and services as 'experience goods'. In contrast to 'search goods', consumers would have to incur high costs to learn about the true qualities of experience goods ex ante. It is the simplest way to consume a unit of the experience good and make further purchases dependent on the information gained after the first transaction. Further, the observations made from experience must not be easily verifiable. Otherwise there would be no need for reputation as any deviation from a contract involving an experience good could be judged by a court (Kreps 1990, p. 116). Such a scenario applies to the rating context: investors cannot asses the quality of a given rating ex ante but have to rely on ex post information about the quality of past credit ratings. While the average quality can be perfectly monitored, there is no way to determine the quality of a single rating because of its nature as probability.

The basic idea behind the reputation mechanism in the rating market is simple: rating agencies can easily be monitored ex post by correlating the rating assessments with actual defaults. Agencies with a strong correlation build up reputation with issuers and investors for their accurate risk assessments. Because of the good reputation, investors believe in the rating quality ex ante and value the agencies analysis highly. The issuers in turn seek ratings from agencies with high reputation, because their ratings promise the largest reduction in borrowing costs. Thus, reputable rating agencies can demand a high price for their rating assessment, generating above market returns compared with a situation without reputation. In any period, rating agencies could deceive issuers and investors by an unsound analysis, either to save costs or to generate extra fees through favorable ratings ${ }^{11}$. The rating agency would earn an extra profit in the period of deceit, but would lose the rents generated from its reputation in the following periods. If this onetime gain cannot offset the reduced profits in the future, rating agencies will always produce high quality ratings in order to keep and strengthen their reputational capital.

The reputational capital view is nearly universally accepted in the credit rating literature. See, for instance, Schwarcz (2002, p. 14), or Mann (1999) for a general discussion of verification institutions in financing transactions. While some scholars see only little flaws in the reputation mechanism (e.g., Brookfield and Ormrod 2000, p. 326, or Smith and Walter 2002, pp. 314-15) others identify different areas of concern (e.g., Partnoy 1999, pp. 655-83, or Sinclair 2000, p. 495).

\subsection{The Reputational Mechanism}

Among the early scholars concerned with the build-up of reputation Shapiro (1983) describes the reputation mechanism in the most intuitive way. His model analyzes the build-up and implications of firm specific reputation in a competitive product market with free entry and

11 Some examples of deceit or 'milking' can be found in Strausz (2005, p. 46). 
quality choice by firms (see Shapiro 1983, pp. 659-79 for the whole subchapter) ${ }^{12}$. The only deviation from perfect competition is the incompletely informed group of consumers. In the rating context considered here, the firms are the credit rating agencies, the product is the rating service, and the consumers are the issuers. The issuers are assumed to pursue a high quality signaling service as their only goal concerning their rating.

Shapiro derives equilibrium from dynamically modeling reputation as an asset. After an initial period of investing into reputation, firms earn a premium on this reputation in subsequent periods, so they earn zero profits ex ante. In particular his model looks at an unlimited time frame divided into discrete periods $T$. The one period interest rate $r$ is assumed to be constant over time. Reputation is built up in relation to a single quality measure $q$ that covers all information imperfections in the market. The quality of an agency's ratings in a given period can only be observed after the lifespan of the underlying debt securities. The length of a period $T$ is thus assumed to be equal to the maturity of the rated debt security. Specifically, the described world consists of a large number of issuers that all issue revolving debt notes. Every period they decide whether or not to seek a rating from one of the rating agencies, the actual quality of which can only be observed ex post.

In the rating context, quality $q$ can most easily be interpreted as the correlation between defaults and rating categories. There should be more defaults during a given time period for every lower rating category. The higher the correlation, the better the relative ranking of credit risks and therefore the better the signaling service. For an overview on default studies see BIS (2000, pp. 126-31). Default studies are conducted by the rating agencies themselves as well as by independent scholars ${ }^{13}$. A high correlation shows that the ratings were factually correct and that there has been no manipulation, e.g., resulting from conflicts of interest. In other words, high quality is based on both expertise and independence (Hill 2004, p. 75). Most correlation studies include transition matrices displaying shifts of ratings between the rating categories. A high quality rating service would imply that there are few drastic rating changes. Transition studies are especially important because they capture the rating quality of debt securities that do not default.

There is, of course, more to a rating's quality than a high correlation with defaults, for the correlation does not constitute a causal link. A high quality rating should also bring new information to the market. As already discussed, the information value of ratings is the object of many empirical studies. In principle, the information value can be measured for every rating right after its issuance through its market impact. Since the absolute information value is so small and unstable, however, a complete picture can only be gained ex post through a

12 Chemmanur and Fulghieri $(1994, p .59)$ suggest that it is more appropriate in a service context to use a framework with incomplete quality information on the intermediary's side. This idea derived from an investment banking model, however, does not apply to the rating context. Rating quality purely reflects the quality of the fundamental credit analysis which is measured statistically and not on a case by case basis. As the agencies have full information about their analytical quality, Shapiro's model developed for product markets is appropriate.

13 This definition of quality is only applicable to a pool of ratings. Concerning a single rating, quality could be defined as standard deviation of the given rating from the 'true rating'. Theoretically, such a concept is illogical, however, for the true rating would not be a probability of default, but a certain statement: A debt security either defaults in a given time period or it does not. Therefore, the quality of a single rating can only be approximated by input factors, notably the level of scrutiny during the fundamental rating analysis. 
large enough data sample. The market might simply not react to single ratings while the fundamental credit analysis is still of a high quality. Throughout this work the proven correlation studies shall therefore serve as quality measure ${ }^{14}$.

Ex ante the issuers are able to observe if at least a minimum quality $q_{0}$ is provided. This assumption is unproblematic in the case of most physical products, but needs some further thoughts in a service context. There are two principle mechanisms to observe minimum quality. Under an input oriented argumentation, the provision of a minimum quality level can be assumed because of the production technology used. Rating agencies provide a fundamental credit analysis that necessarily employs knowledgeable employees and specialized data sources. There are several points of contact in the regular rating process, where employees of the rating agency meet with the management of the issuer, so that input factors (especially employees) can be observed (Moody's 1991, pp. 87-100). This complexity of the service makes the difference to products and simple services. When buying canned soup, e.g., one has no information about input factors and production technology, so minimum quality can only be observed from what one sees. When buying ratings, on the other hand, issuers always learn a certain amount about the production technology used. Thus it is realistic that issuers can use input factors as a proxy for minimum quality. International efforts to guarantee high rating standards largely build on this mechanism (IOSCO 2004) ${ }^{15}$.

Especially established agencies can hardly camouflage their production technology. They might try to use their observable production factors secretly for different purposes in adjoining businesses. However, there is already detailed information on the issuers' side about the rating process. Big shifts would be detected. In addition, the three market leaders do not have major adjacent businesses where they could easily use these resources (e.g., Fight 2001, pp. 13-99). In order to comply with the model assumptions, one has to rule out any sunk or multi-period fixed costs. This assumption is not unrealistic, either: the production technology of credit rating agencies is heavily dependent on knowledge of the different industries and analytical techniques. This knowledge is not firm specific and should thus trade on the market at cost. There are, however, firm specific credit risk models.

From an output oriented perspective, one can argue that recently issued ratings are proof for the minimum quality. The minimum quality can be observed once a rating is issued, e.g., by comparing the rating with market prices of the underlying debt instrument or other readily available data such as company reports. This is especially true in a world with cheap information technology and strict disclosure requirements. Ratings and market data generally need to be 'in line', as financial markets are very efficient. Being in line with the market, however, only shows that an agency is not wrong on a broad scale while one cannot say ex ante if its analysis is superior. Market prices are not a perfect mirror of credit quality, as factors such as taxes or liquidity also play a role (ECB 2004, pp. 10-11). In other words, a compari-

14 Further quality measures could focus on short-term aspects such as the frequency of rating reviews or the timeliness of reactions to unexpected events. However, default studies already cover such aspects to some extent. Defaults are recorded for different time periods such as one year or ten years. If the agency is slow, one year default rates will reveal this, since too many highly rated issues default.

15 In case input factors are centrally checked by a regulatory body, there is more (confidential) information available than observed by the issuers. Therefore, input factors can be used to guarantee a quality above $q_{0}$, e.g., in state licensing. 
son with market data only allows checking for a minimum quality. As long as it is possible to check a large enough number of ratings against market data, the mechanism works to reliably detect a negative deviation from $q_{0}$. If the rating agency were to decide not to provide at least minimum quality, e.g., by arbitrary, sham ratings, all issuers would quickly observe this behavior and stop buying further ratings from this agency. In the following it is assumed that the input oriented method always works to verify minimum quality. In addition, minimum quality can be checked against market data, if available.

In order to focus the analysis on the quality aspect, it is presumed that each agency provides a given number of ratings. For simplicity, the quantity is set at unity, so one can abstract from fixed costs. As a result the costs of supplying ratings of quality $q_{i}$ can be denoted by $c\left(q_{i}\right)=c_{i}$, where $\frac{d c_{i}}{d q_{i}} \geq 0$ and $\frac{d^{2} c_{i}}{d q_{i}^{2}}>0$. The index $i$ covers all possible quality levels. The cost structure is also valid for ratings at $q_{0}$ and below. It is assumed that all providers have access to the same technology. Hence, there are many potential rating agencies operating under the same cost function and acting as price takers. In its nature, the cost function is unspecific to the level of quality for any $q_{i}>q_{0}$, i.e. there are no sunk costs that signal a certain level of quality. At any given date $t$, each agency faces perfectly elastic demand which is only dependent on its reputation $R_{t}$ at that date ${ }^{16}$. Accordingly, the price that can be charged is denoted as $p\left(R_{t}\right)$. Reputation can thus be interpreted as quality expected by the issuers.

Regarding the information structure of the rating business, one can realistically assume that the issuers can distribute ex post information about product quality among themselves for free, while it is not possible to assess quality ex ante ${ }^{17}$. As described, correlation and other empirical studies are an adequate measure of quality that is readily available at no or little cost. Rating agencies that choose a lower than contracted quality will thus be punished through a decline in the issuers' willingness to pay in subsequent periods. The immediate and complete diffusion of quality information results in the adjustment equation (see Shapiro 1983, pp. 664-67 for the equations of the basic model):

$$
R_{t}=q_{t-1}
$$

The demand side of the market is comprised of a large number of issuers with heterogeneous preferences. They differ both in their willingness to pay and in their taste for quality. In equilibrium, two conditions must be fulfilled regarding the demand side: (a) every issuer knowing $p\left(q_{i}\right)=p_{i}$ chooses his most preferred price-quality combination on a given pricequality schedule, and (b) the market clears at every quality level. Any price-quality combination not demanded by the issuers will not be supplied by the rating agencies.

16 The assumption of perfectly elastic demand is crucial in that it rules out price competition per se. If the assumption is relaxed there exist cases where a high quality equilibrium will not sustain without central regulation (Kranton 2003, p. 386). The matter will be discussed in section 3.6.

17 As the number of ratings is fixed to 1 , the free distribution of quality information does not provide for a competitive advantage in form of 'free riding' on existing reputation. In case a reputable rating agency increases output in the basic model, it needs to build up new reputation for these activities. 
The equilibrium price-quality schedule is derived by two conditions regarding the supply side: (c) firms with reputation $R$ must find it optimal to supply ratings of quality $q=R$ rather than to deviate from issuer's expectations, and (d) no entries occur to the rating industry. Shapiro describes a situation fulfilling all conditions (a), (b), (c), and (d) as 'reputation equilibrium'. Considering condition (c) one has to posit a state in which the rating agencies have no incentive to milk their reputation. Milking in the rating context means that a high quality incumbent secretly reduces its effort and costs. He could, e.g., cancel subscriptions to data sources, or reduce the depth of the analysis in order to save labor costs. The issuers cannot observe this behavior as long as a minimum level of input factors is still employed. The contact to the agency looks normal and the observable rating quality is unchanged. Only after the lifespan of the ratings can the reduced quality be detected. In practice much easier and probably more relevant form of milking is not to decrease costs but to increase revenue by issuing favorable ratings or pressuring issuers with too low ratings. A manipulated rating from a reputable agency might be very valuable while it cannot be rightly identified by other market participants.

In any period an agency with reputation $R=q_{i}>q_{0}$ could lower its quality to the minimum level yielding a onetime profit of $p_{i}-c_{0}$. In the subsequent periods the agency either exits the market or generates zero profits producing minimum quality as $p_{0}=c_{0}$. Alternatively, the agency could maintain its quality forever, generating a constant flow of profits of $\left(p_{i}-c_{i}\right)$ with a present value of $\frac{1+r}{r} \cdot\left(p_{i}-c_{i}\right)$. In order for milking to not be attractive, $\frac{1+r}{r} \cdot\left(p_{i}-c_{i}\right) \geq p_{i}-c_{0}$ must hold ${ }^{18}$. I.e. the present value of future reputation premiums generated from continuous high quality ratings on the left side of the equation must be larger than the onetime profit which could be generated from cheating in any given period on the right side of the equation. After transformation one derives the 'no-milking condition':

$$
p_{i} \geq c_{i}+r \cdot\left(c_{i}-c_{0}\right)
$$

Equation (3.2) puts a lower bound on prices at which an equilibrium can be sustained. Conversely, 'the no-entry condition' (d) puts an upper bound on prices. An entry at the quality level $q_{i}>q_{0}$ is unattractive if non-positive profits are expected ex ante. As a new rating agency has no reputation, it can only sell its service at an introduction price of $p_{e}=p_{0}$ for minimum quality which is readily observable. In his first period the new competitor will thus generate a negative profit of $p_{e}-c_{i}$ with $p_{e}=p_{0}=c_{0}$, whereas he can expect profits of $\left(p_{i}-c_{i}\right)$ in all following periods. In order to prevent entries the present value of all expected profits must be non-positive: $p_{e}-c_{i}+\frac{1}{r} \cdot\left(p_{i}-c_{i}\right) \leq 0$. After transformation one derives the no-entry condition $p_{i} \leq c_{i}+r \cdot\left(c_{i}-p_{e}\right)$ which can be written as: 


$$
p_{i} \leq c_{i}+r \cdot\left(c_{i}-c_{0}\right)
$$

The two conditions (3.2) and (3.3) determine the equilibrium price-quality schedule:

$$
p_{i}=c_{i}+r \cdot\left(c_{i}-c_{0}\right)
$$

Figure 3.1 shows the equilibrium price-quality schedule and illustrates a firm that has chosen $q_{i}=q_{1}$ :

$$
\begin{aligned}
& \text { costs } c\left(q_{i}\right)=c_{i} \\
& \text { price } p\left(q_{i}\right)=p_{i}=c_{i}+r \cdot\left(c_{i}-c_{0}\right)
\end{aligned}
$$

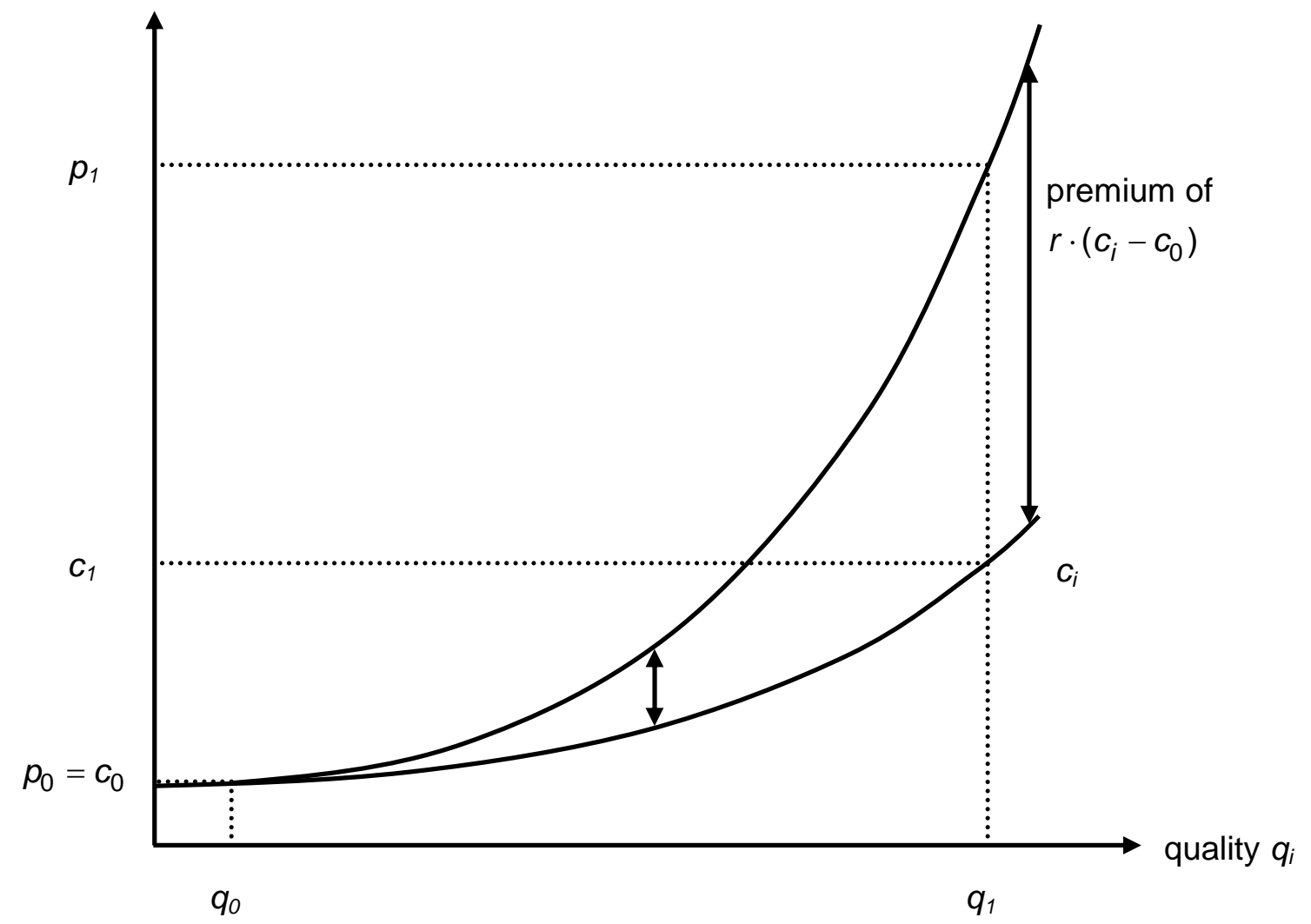

Figure 3.1: Equilibrium price-quality schedule (according to Shapiro 1983, p. 668) ${ }^{19}$

All ratings with a quality in excess of the minimum quality sell at a premium of $r \cdot\left(c_{i}-c_{0}\right)$. This premium can be interpreted as return on a one-time information cost of $c_{i}-c_{0}$ in the first period or alternatively as return on the asset value of the reputation that has been built up in the introduction period at a cost of $c_{i}-c_{0}$. One can also understand $r \cdot\left(c_{i}-c_{0}\right)$ as an annuity paid every period on a loan with unlimited maturity that was raised in $t=0$ to build up reputation. 
A point of critique in this simple framework is the basic assumption (3.1) which stated the immediate adjustment of reputation after one period, i.e. $R_{t}=q_{t-1}$. Typically, there is no such black-white behavior of issuers in real markets. A new rating agency might only be able to raise prices slowly and issuers might perceive reputation differently while time lapses. Instead of one period of loss followed by constant gains in all following periods, rating agencies will likely see several periods of losses. At a certain point the agency breaks even in the sense that investments into reputation equal reputation premiums earned. From this point on, the earned premiums surpass new investments into reputation. Figure 3.2 illustrates this:

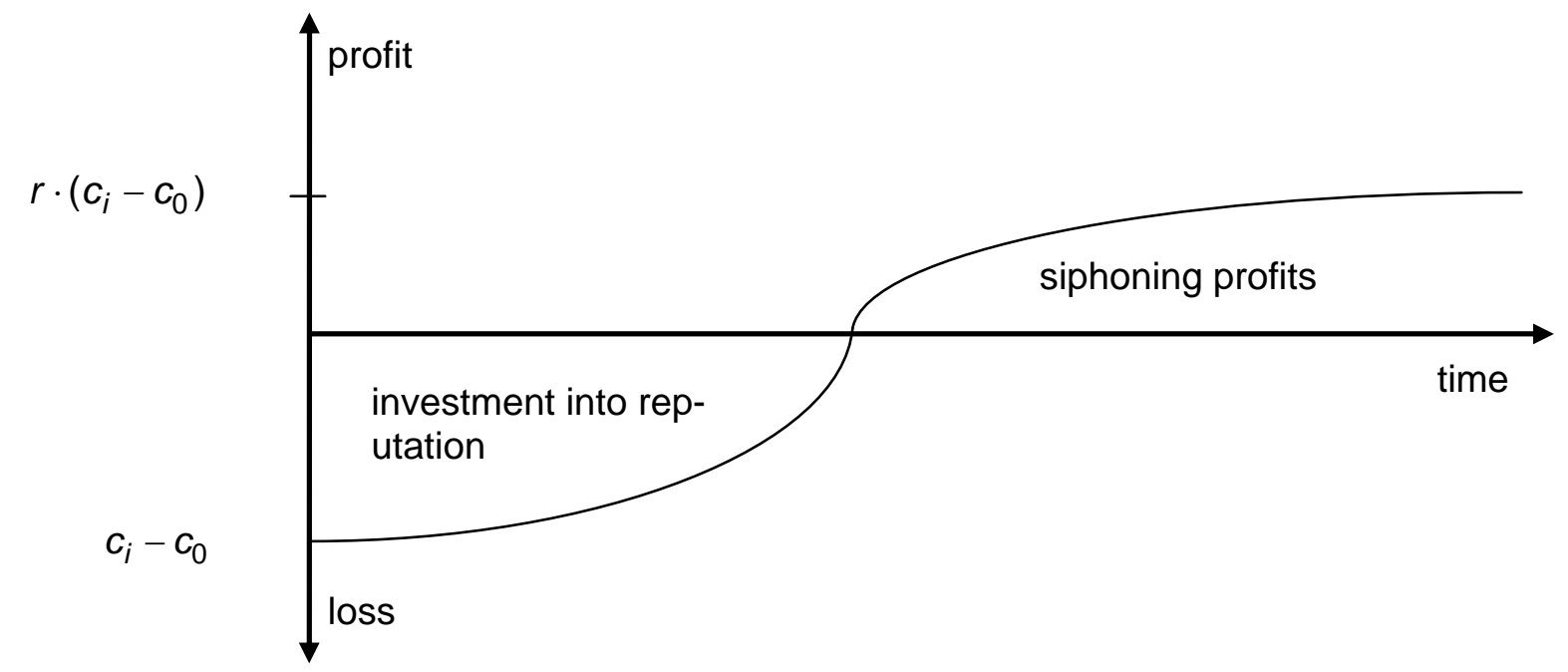

Figure 3.2: Intertemporal reputation returns (according to Shapiro 1983, p. 669)

Such a picture corresponds with what one expects from real markets: initially, there is an investment period, followed by a siphoning phase. Ex ante, the expected profits from the inter-temporal reputation returns are zero. This is the necessary equilibrium condition for no entries. It becomes clear that such a view on the reputation building process does not alter the mechanism itself. Rating agencies initially deliver high quality ratings below cost, but can raise prices above cost in later stages. The possible gains from cheating are thereby more than offset by gains from continuous high quality production.

In the model, the investment into reputation consists only of the price discount in the first period. In reality, important parts of it may also be other factors such as marketing costs. An unknown agency might need to approach potential customers individually, while issuers will turn to highly reputable agencies on their own. Other costs could accumulate in connection with demonstrating high quality. Technically, correlation studies can easily be done, but still require substantial effort. Newcomers might need to produce such studies by themselves so that quality information can spread among their clients and in the market. Even the well established agencies such as Moody's and S\&P regularly issue such reports. Given their company size, however, the cost should not be substantial to them. Other potential burdens for newcomers might come with capacity building. For simplicity, such factors will be abstracted from and all information costs are assumed to accrue in the form of the initial price discount in the entry period. 


\subsection{Reputation and Market Power}

Shapiro's analysis challenges several informal notions concerning reputation predominant in particular in the rating context. Many authors attribute market power to the leading rating agencies simply because of the fact that they feature a high reputation (e.g., Partnoy 1999, p. 620). This argumentation, however, is questionable, if reputation is seen as an asset that yields no first-mover-advantages. It can be built up through an initial investment which yields a stream of profits in future periods. Reputation thus does not carry more or less market power than any other asset. From the same line of reasoning one can argue against the statement that reputation itself is a barrier to entry (CESR 2004, § 58). A barrier to entry is any cost differential between firms already in an industry and firms that are planning to enter (Stigler 1968, p. 67$)^{20}$. As long as it is possible to sell subsidized high quality ratings at an introduction price of $p_{e}=p_{0}$, any newcomer can enter the market. Reputation in this case is merely an investment to entry, but no barrier to entry. Given the availability of a milking strategy, it is also always possible to exit the market without a loss. Consequently, there are no sunk costs involved in the basic reputation mechanism.

In the light of the small number of competitors in the credit rating industry throughout its history, the profitability, and the importance of reputation, it is obvious that some factors will prevent the competitive outcome described in the basic model. The question is how exactly the actual industry situation influences the function of the reputation mechanism. Most importantly, one needs to clarify whether the reliance on reputation could indeed be a barrier to entry as well as a source of abnormal profits in the credit rating business.

\subsubsection{The Value of Minimum Quality}

In order to build up reputation, new entrants need to sell ratings in the initial period at a price level $p_{e}$ that ensures the issuers will not be cheated. This condition is met by the price $p_{0}$ for minimum quality. Any agency providing ratings below this level would immediately be recognized. On the other hand, an agency providing higher than minimum quality cannot be recognized ex ante. Even though the average quality of new agencies is likely above $q_{0}$, no issuer would pay more than $p_{0}$, because at any price $p_{e}>p_{0}$ a newcomer could generate a riskless profit. However, cheating must not be profitable. New entrants thus can either provide minimum quality ratings at cost or higher quality ratings below cost with the expectation of according profits as return to their reputation in the future.

The price for minimum quality is a crucial variable in the reputation model as it determines the initial investment of a high quality producer. The reputation premium is directly dependent on the entry price: $r \cdot\left(c_{i}-p_{e}\right)$. A deviation from the perfect competitive results of the basic model will occur when the achievable entry price changes over time. Given the historical industry development, just such as situation has occurred. Today the value of minimum quality

20 Stigler's definition is one of the clearest but tightest definitions of entry barriers. Capital requirements and especially sunk costs are no-entry barriers from his point of view. However, sunk costs are an exit barrier, because they cannot be recovered. In turn, exit barriers potentially act as entry barriers, as incumbents may use the sunk costs to make threats of aggressive post entry behavior more credible (for an overview on barriers to entry definitions see McAfee et al. 2004, p. 461-65). 
is zero because freely available market data provides the same information as cheaply produced ratings. The argumentation behind this idea is straight forward: if the value of a credit rating is mainly informational and the information carried by minimum quality ratings can easily be checked against freely available information, the rating does not carry much value. Instead of relying on a rating, the investors could directly look at the available market data without incurring major costs. Therefore, no issuer will buy a low quality rating, as it brings no advantages. This argumentation is particularly plausible today, as the pool of freely available information such as bond quotes or mandatory business reports is very large and easily accessible through the internet.

The same reasoning did not apply to the infancy of the credit rating industry. In the first half of the $19^{\text {th }}$ century freely available information was very limited since modern information production and sharing means such as copying machines, computers or the internet were not available. In addition, strict disclosure laws, which are common today, were only gradually introduced since the 1930s (Sylla 2002, p. 25). Therefore, one can conclude that there has been demand at $q_{0}$ because minimum quality credit ratings originally did carry valuable information. This statement is also supported by the fact that for many decades the investors directly paid the agencies for the information value of the ratings which can be seen as a proof that ratings - even of newcomers - were valuable (Partnoy 1999, p. 640).

A low quality rating can of course be produced through a fundamental credit analysis with real analytical effort at the cost of $c_{0}$, but today the information generated is not better than what is freely available ${ }^{21}$. With respect to the model one can speak of a 'competitor' offering ratings of quality $q_{0}$ at its marginal cost of $O^{22}$. In the very low quality segment up to the level of $q_{0}$, rating agencies can never compete with market information. It has been argued above that the minimum quality of rating agencies can always be checked against input factors. If a rating agency sells a rating, it needs, e.g., analysts with contact to the issuer or a management team negotiating the deal. These are costs that cannot be avoided. As a result, a credit rating agency offering a fundamental credit analysis always acts on a positive cost curve, even if it produces 'worthless' information at the minimum quality level. The two key points of these ideas are firstly that up to $q_{0}$ all demand will be satisfied by freely available information, while secondly a rating agency producing quality $q_{0}$ has to always incur the positive cost $c_{0}$ nonetheless.

In reality, it is likely that a new rating agency producing ratings through an observable fundamental credit analysis provides a quality higher than minimum quality. Issuers and investors are therefore likely to assume an average quality above $q_{0}$ which might be high enough to offer them a substantial value compared to the free market information. Hence, issuers expecting a higher average quality are willing to pay a positive price even though only minimum quality is verifiable. The Shapiro model says only that rational issuers will not pay more than costs in order to prevent hit and run strategies. However, it is plausible that the addition

21 This is not necessarily true for structured finance products which are usually not publicly traded. Information about them is difficult to generate. In such circumstances the line of thought below does not hold. As a result it should be comparably attractive to enter segments such as structured finance, for here it is easiest to generate revenues as an unknown rating agency.

22 Of course, there are at least some costs such as the opportunity cost of looking up information. For ease of analysis such costs are disregarded here. The results hold for any $p_{e}<c_{0}$. 
of free information at the minimum quality level will reduce the valuation for lower quality ratings. Relevant for the following analysis are cases in which issuers are only willing to pay entry prices below the cost for minimum quality. For the purpose of simple analysis the extreme case of $p_{e}=0$ is assumed. Structurally, the same results hold for any $p_{e}<c_{0}$.

What does a changed willingness to pay for ratings of newcomers mean for the reputation equilibrium? If one first looks at the no-milking condition (3.2) for established high quality producers, one can see that it remains unchanged at $p_{i} \geq c_{i}+r \cdot\left(c_{i}-c_{0}\right)$. An agency still has to decide either to offer constantly high quality at a profit $\left(p_{i}-c_{i}\right)$ per period or to lower its quality to the minimum level yielding a one-time profit of $p_{i}-c_{0}$. Crucial is the fact that issuers can check minimum quality against the agency's input factors. An established reputable rating agency simply cannot close shop and provide its client with information read in a newspaper. Even if the issuer cannot see ex ante if the rating information is indeed better than the freely available market information, the cheating profit is still limited to $p_{i}-c_{0}$.

Looking at the no-entry condition (3.3) one arrives at a deviation from reputation equilibrium. No issuer will assign a positive value to ratings issued by new entrants which can in turn only realize a new introduction price of $\hat{p}_{e}=0$. This is because of the quality uncertainty. Even if a newcomer provides high quality, it can only be checked after a certain time. The issuers observe if quality is at least $q_{0}$, nothing more. As this information is freely available, no one will ever be willing to pay a positive price to a newcomer. There is also no possibility to raise $q_{0}$ to a level where it has value, since the mechanisms to evaluate minimum quality have not changed. The no-entry-condition $p_{i} \leq c_{i}+r \cdot\left(c_{i}-p_{e}\right)$ for high quality newcomers changes in turn to $\hat{p}_{i} \leq c_{i}+r \cdot\left(c_{i}-0\right)$, as the introduction price $\hat{p}_{e}$ would no longer match the minimum cost level $c_{0}$. The new no-entry-condition for quality levels above $q_{0}$ in the absence of any positive demand for ratings at or below minimum quality can be rewritten as:

$$
\hat{p}_{i} \leq(1+r) \cdot c_{i}
$$

As argued, the no-milking-condition (3.2) does not change. Transformed one can rewrite the condition as:

$$
p_{i} \geq(1+r) \cdot c_{i}-r \cdot c_{0}
$$

Comparing the two equations one can see that there is no longer a definite equilibrium price. The market price can now be anywhere between $p_{i}$ and $\hat{p}_{i}$ in a range of $r \cdot c_{0}$. The actual price level will develop according to the nature of the competition in the industry. Figure 3.3 displays the interrelation with reference to a firm that has chosen $q_{i}=q_{1}$ : 


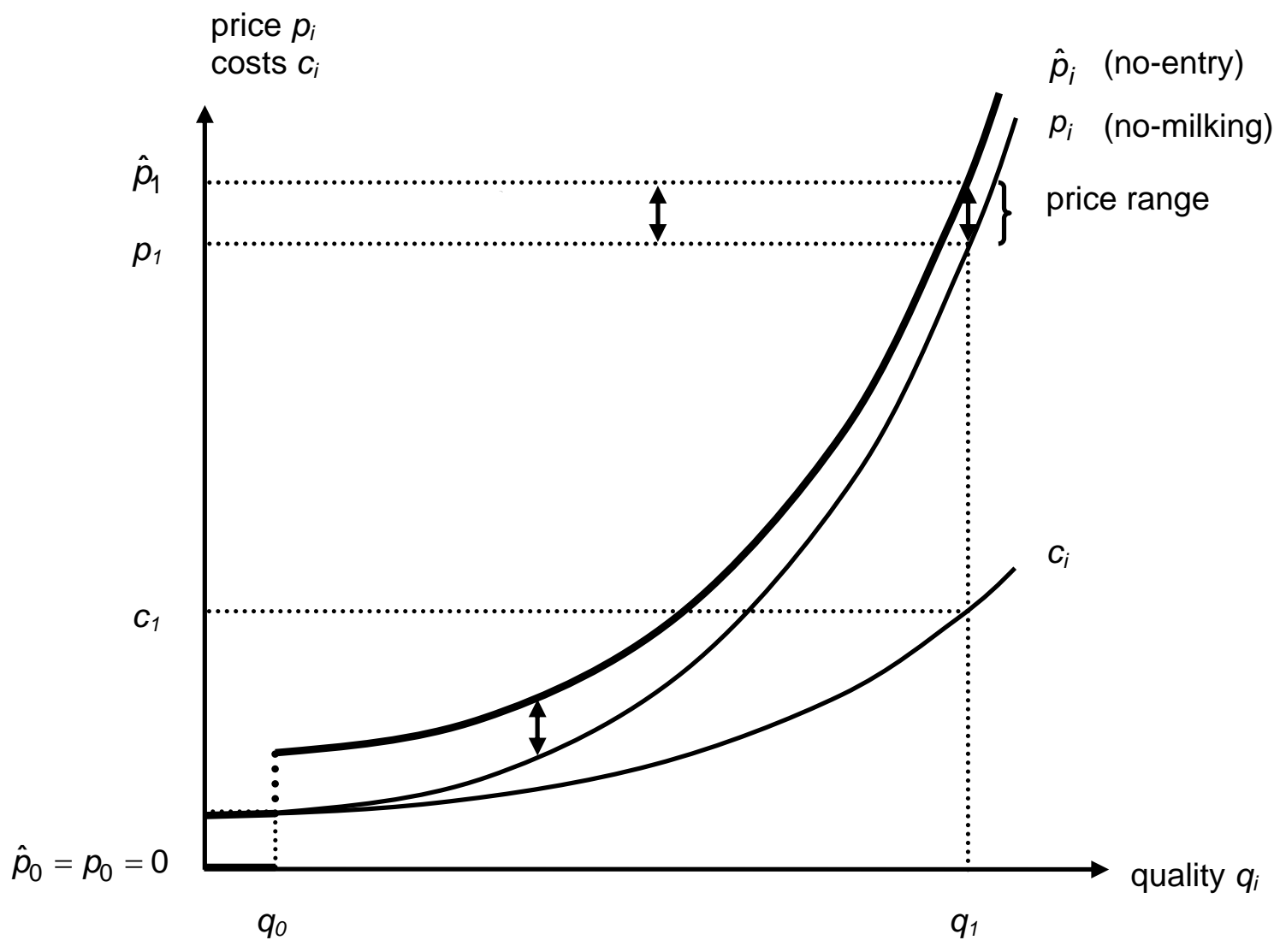

Figure 3.3: No demand for minimum quality

In bold print one can see the new no-entry path. A newcomer needs to receive a market price of $\hat{p}_{i}$ so that a high quality entry strategy at any point above $q_{0}$ can be profitable in the first place. Anywhere below this path the initial investment into reputation would be larger than the discounted value of all future premiums. Below $\hat{p}_{i}$ is the original equilibrium path $p_{i}$. However, it has lost its equilibrium property. It now only constitutes a lower price barrier for the incumbents who have been in the industry since before minimum quality lost its value. At any price below this path it would be more profitable - as before - to reap one-time cheating profits than to continue offering high quality. In the lower left corner one can see the following: at any directly observable quality, i.e. at any quality lower or equal to $q_{0}$, the price is 0 for newcomers and incumbents alike because the informational content of such ratings can be freely read from available market data. The cost of producing such ratings, however, stays on the original cost path because a minimum number of input factors must be sustained by a rating agency. Obviously, there will never be a market for ratings on these quality levels, as costs are above price.

One can read two important results off Figure 3.3. Firstly, newcomers to the credit rating market today face a barrier to entry. They have to incur costs that the incumbents never had to incur. In the entry period they receive nothing for their high but unknown quality ratings, while the incumbents received $c_{0}$ when they entered the industry. In other words, the build-up of reputation has become more expensive over time. Although newcomers and incumbents only need the same reputational capital in order to make a high quality strategy credible, the investment needed to generate this capital has increased. The second result directly follows 
from the first. The initial market players have acquired an 'early-mover-advantage' over time. The market price can vary in a range of $r \cdot c_{0}$ above the no-milking path $p_{i}$. Depending on the competition between the incumbents there might well be market prices above $p_{i}$. At such levels incumbents make economic profits exceeding their cost of capital. The argument is the same as above: they entered the industry under the old no-entry condition, generating a positive price in the entry period. Thus, their investment into reputation was comparably smaller than the one needed by newcomers today. Thus, the incumbents already break even at a lower price. In an open market, economic profits would attract entry, but today newcomers operate under different conditions.

The analysis is supported by actual market developments. The incumbents have been in the market since the early $19^{\text {th }}$ century, while the number of successful newcomers has been small. No one has managed to independently reach the reputation of the incumbents. Further, the credit rating industry has become very profitable over time. This is a clear indicator of entry barriers preventing current and potential competition from influencing the rating industry. Although the model corresponds to the market development, one has to be careful about the results, as several other factors also play a role. Rating-based regulation and official recognition, e.g., can have similar effects on the competitive environment. One can conclude, however, that there are 'natural' factors which have at least some explanatory power for today's credit rating market environment.

\subsubsection{Cost Structure Change}

It has been shown that a shift in the value of minimum quality over time is plausible. A second possible parameter change concerns the cost structure. The relative cost of services - such as credit ratings - has generally increased over time as productivity gains in physical production were larger than in services. Put differently, knowledge has gained more weight compared to physical production in many areas, leading to a relative price increase of knowledge. With specific regard to the credit rating market one can note that the complexity of corporations and especially of financial transactions has risen. Although there are better analytical tools today than at the inception of the industry, the provision of high quality ratings is much more complex. New risks from international competition, from fast changing technology, or from complex legal positions need to be considered. Many complex financial regulations exist today that were not present decades ago. In sum, it seems realistic to assume higher production costs per rating today than at the inception of the industry.

For ease of analysis a general rise of the cost curve of a factor $\alpha>1$ is assumed. I.e. ratings of any quality level become proportionally more expensive, reflecting an evenly increase in factor costs. Alternatively to such a symmetric rise one could also argue for no or only a little cost increase on low quality levels but over proportional increases for higher qualities. This would especially reflect the rise in complexity. However, such a modeling would not structurally alter the analysis.

If the whole cost function $c_{i}$ has shifted up to $c_{i}^{\prime}=\alpha \cdot c_{i}$, the incumbents have to attain, analogous to the original model, a price of $p_{i}^{\prime} \geq c_{i}^{\prime}+r \cdot\left(c_{i}^{\prime}-c_{0}^{\prime}\right)$ in order not to have an incentive to milk their reputation. The potential newcomers must face a price of $p_{i}^{\prime} \leq c_{i}^{\prime}+r \cdot\left(c_{i}^{\prime}-c_{0}^{\prime}\right)$ in 
order not to enter. In equilibrium the market price must therefore be $p_{i}^{\prime}=c_{i}^{\prime}+r \cdot\left(c_{i}^{\prime}-c_{0}^{\prime}\right)$. From an equilibrium point of view, there is no difference to the basic model. However, the incumbents originally decided to enter the industry on the condition that $p_{i} \geq c_{i}+r \cdot\left(c_{i}-c_{0}\right)$, with $r \cdot\left(c_{i}-c_{0}\right)$ as return on the initial investment in reputation. Given that the incumbents keep their reputation constant at level $i$ over time, it follows that for generating zero profits today a price of $\pi_{i}=c_{i}^{\prime}+r \cdot\left(c_{i}-c_{0}\right)$ is needed. If $\left(c_{i}-c_{0}\right)<\left(c_{i}^{\prime}-c_{0}^{\prime}\right)$ holds, the price to be profitable is below the equilibrium price, i.e. $\pi_{i}<p_{i}^{\prime}$. Under the assumption of a general rise of the cost curve of a factor $\alpha>1$ the relationship holds as $\left(c_{i}^{\prime}-c_{0}^{\prime}\right)=\alpha \cdot\left(c_{i}-c_{0}\right)$ and thus $\left(c_{i}-c_{0}\right)<\alpha \cdot\left(c_{i}-c_{0}\right)$. Consequently, the incumbents generate a steady profit margin of $p_{i}^{\prime}-\pi_{i}=r \cdot\left(c_{i}^{\prime}-c_{i}+c_{0}-c_{0}^{\prime}\right)>0$ per period.

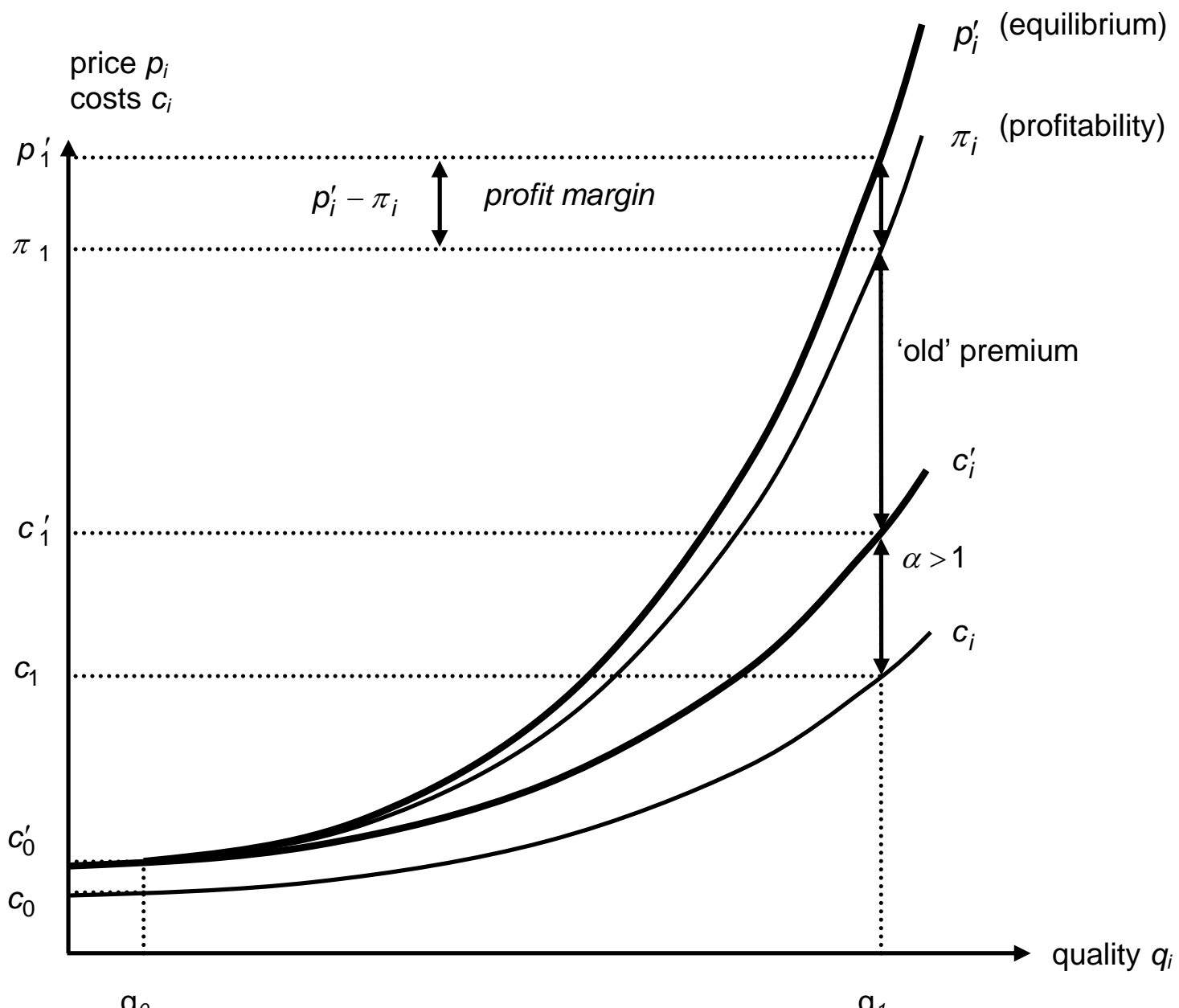

Figure 3.4: Price margin with rising cost structure

Figure 3.4 shows the situation discussed, again with reference to a firm that has chosen $q_{i}=q_{1}$. The 'old' cost curve $c_{i}$ has shifted upwards by the factor $\alpha>1$ to the new level of $c_{i}^{\prime}$ which is drawn in bold. Also in bold one sees the new equilibrium price path $p_{i}^{\prime}$. On this path newcomers just have no incentive to enter, while incumbents just have no incentive to milk their reputation. However, incumbents are profitable at the new equilibrium level because their investment into reputation was based on the original cost curve $c_{i}$ with an initial loss of 
$\left(c_{i}-c_{0}\right)$. The 'old' reputation premium of $r \cdot\left(c_{i}-c_{0}\right)$ is therefore still enough to make the incumbents break even. The profitability price path $\pi_{i}$ matches the new cost curve with the 'old' premium. All prices above this path provide for profits. In equilibrium the profit margin is $p_{i}^{\prime}-\pi_{i}$. The 'old' premium plus the profit margin equals the new premium $r \cdot\left(c_{i}^{\prime}-c_{0}^{\prime}\right)$ which is not drawn in the figure for the benefit of a better overview.

A cost structure shift as described above can provide an explanation for the incumbent's profitability today. Similar to the ceasing value of minimum quality, a cost structure shift translates into a relatively higher investment needed. Incumbents had to pay less for the same level of reputation than a newcomer would need to invest today. In other words, the value of existing reputation has increased over time. Technically, a cost structure change is a structural barrier to entry as newcomers have to defray higher costs than incumbents had to when they entered. Practically, however, newcomers are not hindered from entering the industry, as incumbents will increase prices to the new equilibrium level. Below that, it would be more profitable to reap one-time milking profits. Thus, no incumbent could credibly commit himself to lowering prices in order to deter entry; the additional profits might only be used in non-price competition. All in all, a potential rise of the cost curve is a logical mechanism explaining the incumbents' profitability, even if it provides no basis for a strategic entry barrier.

\subsection{Transfer of Reputation}

A key question of the reputation mechanism is the possibility of transferring an established reputation to new market segments or rating products. General research suggests that a transfer is altogether possible as long as no ambiguity towards reputation emerges (Kreps 1990, p. 130). In other words, a clear corporate culture must endure, otherwise the benefits from widening the scope of a reputable firm will quickly be outweighed in the consumers' eyes by a falling overall reputation for high quality. Transferring existing reputation is a twosided argument. On the one hand, it can be used to explain how a newcomer can generally reduce the investment to enter the credit rating market. On the other hand, it offers an explanation for long-time incumbents having a cost advantage over newcomers if they want to quickly enter a new market segment. This second case will be used to explain the model.

Over time several new rating market segments, such as structured finance products have developed. Because new segments usually promise strong growth and profits, they are attractive to incumbent agencies and newcomers alike. In order to succeed, both have to build up reputation for the new rating product. In the example of structured finance products, different methodologies and analytical tools are needed compared to classic commercial bond ratings. According to the basic Shapiro model, the cost of reaching a reputation level of $i$ in the new market segment is solely dependent on the entry price $p_{e}$. The entry price reflects the observable minimum quality, which is the same for everybody. In principal, one thus has a level playing field. However, established rating agencies can often leverage their existing rating business in order to gain a competitive advantage over newcomers who are not yet seen as reliable for any credit ratings: the established agencies transfer their reputation (Jendges 1996, pp. 103-08). The key argument goes as follows: an incumbent is able to convey to the issuers in the new market segment through his existing reputation that he will 
provide at least a quality level of $q_{0 r}>q_{0}$. This idea is shown in Figure 3.5, implemented into the basic model:

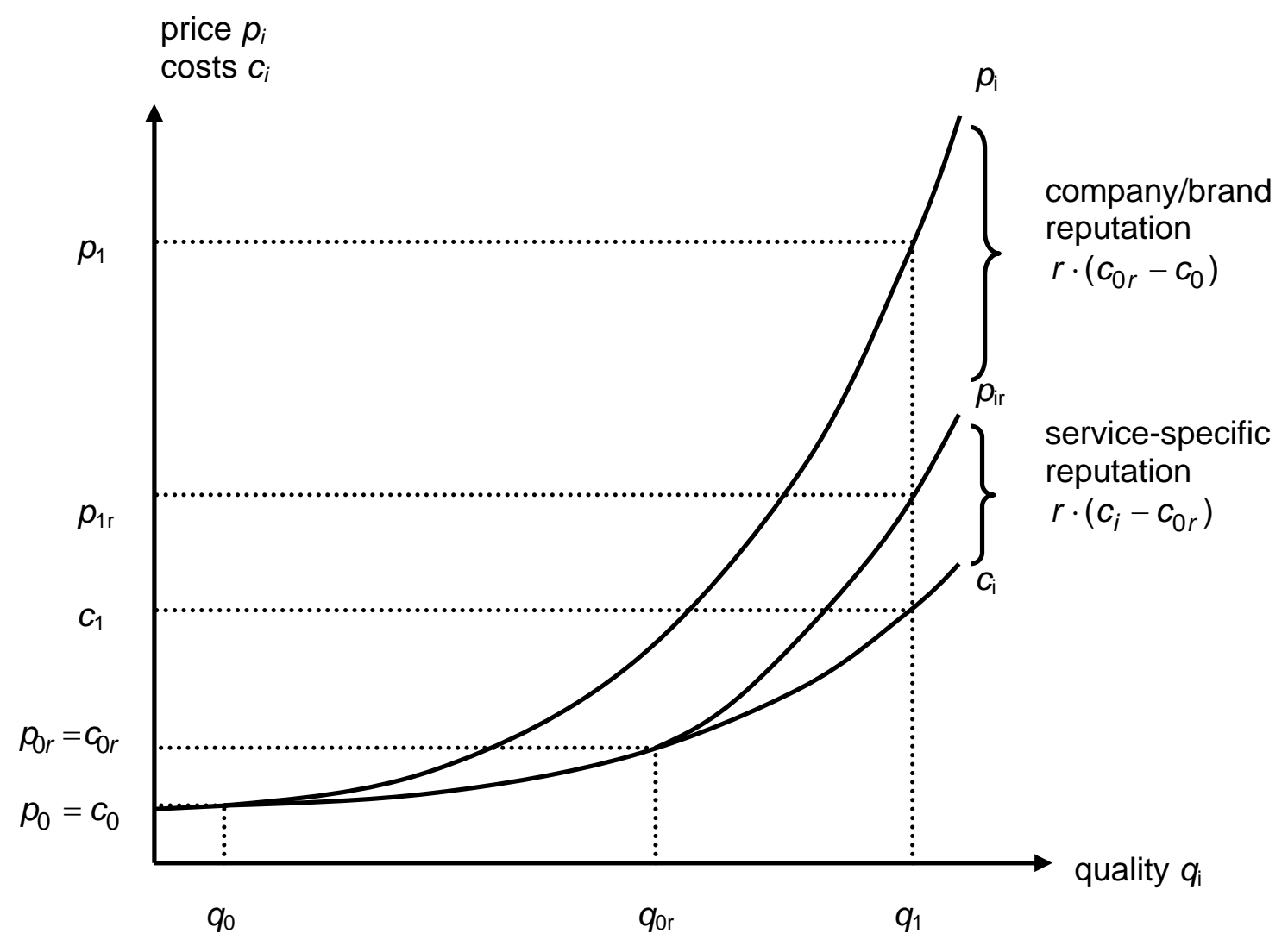

Figure 3.5: Transfer of existing reputation (Jendges 1996, p. 107)

The upper price path $p_{i}$ has here not changed in comparison to the basic case, it simply describes an unknown newcomer. The lower price path $p_{i r}$ is applicable to rating agencies successfully transferring reputation from their existing rating business. They are thus able to reduce the ex ante quality uncertainty from $q_{0} q_{1}$ to $q_{0 r} q_{1}$. Up to a quality of $q_{0 r}$ they can sell at cost, because issuers believe that the actual quality will never run below this level. Only between $q_{o r}$ and $q_{1}$, will the transferring agency need to build up reputation according to the basic model.

Reputation is usually connected to a brand name as a vehicle. Market participants associate a certain product class, different quality characteristics and an overall image with it. Relevant for transferring reputation, however, are only those quality characteristics that apply to the new product as well. One speaks of company or brand reputation. Brand reputation can usually make up only a part of the reputation for providing a high quality level. The other part of the reputation is very specific to the new product and must be generated by investments in a way described above (Aaker 1992, pp. 269-70). This is the reason why issuers still have to pay a lasting premium. As a rule of thumb, the assumed minimum quality $q_{\text {or }}$ will be higher, the closer the existing rating service characteristics match the ones of the new service and the greater the overall image of the entrant is. The usual reputation premium on $r\left(c_{i}-c_{0}\right)$ is reduced to a premium for reputation specific to the rating service $r\left(c_{i}-c_{0 r}\right)$. The remaining 
part of the original premium $r\left(c_{0 r}-c_{0}\right)$ ceases to exist, generating a competitive advantage for firms already reputable in related markets. In Figure 3.5 one sees both cases of a reputable entrant and an unknown entrant. In equilibrium an unknown entrant would need to sell at $p_{i}$ whereas a reputable entrant would sell at $p_{i r}$, well below the other entrant's price.

Of course, a competitive advantage without any difference in production technology or demand structure for reputable and unknown newcomers causes problems in the competitive equilibrium model. For now, the idea of a competitive advantage resulting from existing reputation will be adopted. The actual structure of the competitive advantage will be modeled in the following section.

How does the mechanism work in detail? Although directly unobservable, the issuers believe the new ratings to be of quality $q_{o r}$ because of their prior experience with the agency in other market segments. Thus they are willing to pay a price of $p_{o r}$ in the initial stage. Two mechanisms help to make the new minimum quality credible. The stronger one is a negative spillover on reputation in incumbent market segments. If the agency sells the new ratings at a quality level below $q_{\text {or, }}$ the affected issuers will draw negative inferences on the agency's complete business. In fact, all the agency's clients of the incumbent business are able to observe the low quality of the new ratings as well. They, too, are likely to reduce their willingness to pay because they fear a generally reduced quality. In case of a milking strategy with a price $p_{1 r}$ but quality $q_{o r}$, only the new rating business is affected as merely reputation specific to the new rating service is milked, whereas the brand reputation covering also the incumbent rating activities is untouched. By contrast, in the case of a milking quality $q_{0}$, quality characteristics applicable to all credit ratings are negatively affected. As a consequence, participants in incumbent market segments will expect a decreasing quality of their ratings as well and limit the price they are willing to pay for unobservable quality. As this effect is potentially very large compared to the new business, this threat is assumed to be binding. Thus a quality below $q_{\text {or }}$ will never be produced.

The second mechanism is based on expertise in production technology. The issuers connect certain quality characteristics of existing credit ratings directly to the new kind of ratings. They anticipate that characteristics applicable to both will have the same specification in either product. This idea is based on the assumption that existing production technologies or capacities are also used for 'old' and 'new' ratings, leading to the same level of quality in the respective characteristics. The entrants would need to impose costs in order to deviate from a high quality level. This argumentation, however, is problematic in the model settings. It implies a production technology specific to a quality level beyond $q_{0}$. Since quality level-specific production technologies above $q_{0}$ and sunk costs have been ruled out, the focus will be on the mechanism described first.

Incumbent agencies that successfully transfer reputation are able to offer their new rating service at the introduction price of $p_{e}=p_{0 r}$ in the first period. In turn, they cannot provide lower quality than $q_{\text {or }}$ once they are established. Otherwise their incumbent businesses would be harmed. For a high quality strategy to be profitable, the one-time cheating profits of 
$p_{1}-p_{0 r}$ must be smaller than the present value of all future premiums $\frac{1+r}{r} \cdot\left(p_{i r}-c_{i}\right)$. One thus arrives at a new no-milking condition:

$$
p_{i r} \geq c_{i}+r \cdot\left(c_{i}-c_{0 r}\right)
$$

If there are several incumbent rating agencies that could all enter the new segment via a reputation transfer, expected profits, i.e. the initial loss plus the discounted premiums, must not be above zero for additional competitors: $p_{e}-c_{i}+\frac{1}{r} \cdot\left(p_{i r}-c_{i}\right) \leq 0$. One now arrives at a new no-entry-condition:

$$
p_{i r} \leq c_{i}+r \cdot\left(c_{i}-c_{0 r}\right)
$$

Both conditions are similar to the conditions (3.2) and (3.3) in the basic model, with the only difference being that the introduction price and the lowest possible quality in a milking attempt both rise to $c_{0 r}$. By combining the two conditions one arrives at the new equilibrium price path $p_{i r}$ :

$$
p_{i r}=c_{i}+r \cdot\left(c_{i}-c_{0 r}\right)
$$

The equilibrium (3.9) builds on the assumption that there are several reputable potential entrants assuring the new no-entry condition. If there is only a single suitable reputable entrant, the original no-entry condition for unknown firms $p_{i} \leq c_{i}+r \cdot\left(c_{i}-c_{0}\right)$ is relevant. Unknown newcomers will only enter the new market segment if prices above $p_{i}$ look realistic. The monopolistic entrant thus has a pricing margin of $r\left(c_{0 r}-c_{0}\right)$ which corresponds to the company reputation in Figure 3.5. Without competitive pressure he will hold his price close to the original level $p_{i}$, creating positive economic profits. In any event the successful transfer of reputation by incumbents is an entry barrier for unknown newcomers as the market price can be below their profitability level $p_{i}$.

\subsubsection{Chances of a Successful Reputation Transfer}

The theoretical basis for the transfer of reputation is rather strong. One now needs to consider if the credit rating industry's specific conditions make the concept a practically viable strategy. If one looks at the historical evidence it seems to be rather easy for incumbents to transfer reputation to emerging market segments. Over time the rating business has expanded from railroad bonds to diverse areas such as foreign debt, commercial paper or structured finance. In practically all these segments the original incumbents are still the market leaders today - they must have had a competitive advantage over unknown newcomers. From a detailed practical point of view there are four areas of limitation which generally might impede a reputation transfer: the transferability of reputation itself, possible conflicts of interest, a limited discrimination between brand and service-specific reputation, and the necessity of an innovative element. The key is certainly the transferability itself. 
The central premise for a successful transfer of reputation is the general acceptance of such a transfer. The issuers need to believe in a higher quality $q_{\text {or }}$ than the observable minimum quality $q_{0}$. Is the issuer indeed likely to deliver a superior quality in the new field? Such a belief must be based on similarities between the incumbent rating business and the segment to be entered. Issuers must have the justifiable opinion that agencies doing reliable business in one segment will also do reliable business in another segment. Such trust can develop when the two rating services are very similar and share important key elements. In other words, company reputation needs to be of high relevance. It has been explained that the track record for high quality is the one decisive element in a rating service. Incumbents exhibit such a track record in at least one segment of the rating market. This makes it possible that customers accept a transfer of reputation, since the agency has proven its general abilities. The rating agencies actively support this impression by using the same rating scales for different rating products. While the new ratings might be analytically quite different to existing ones, they suggest similarity by choosing the same scale for the outcome. In sum the general transferability of reputation is certainly given.

The second area of potential limitation to a transfer process is conflicts of interest ${ }^{23}$. Even if issuers believe that an agency is technically able to provide high quality, there might be conflicts of interest between the two market segments preventing high quality in the new segment. This is especially true if a dodgy behavior in one segment can create business in the other segment. Generally, potential conflicts of interest are imminent to the credit rating business (e.g. Smith and Walter 2002, p. 289). It is always possible to argue that there is an incentive to award a favorable rating for one debt security in order to gain business for other debt securities of the same issuer. This holds true even if there is only a single debt security. In this case, the incentive of a favorable rating would then be to gain business in future periods. Because there are structurally no new conflicts of interest, the issue is not likely to play a major role in a reputation transfer in the eyes of the investors. The strategic alignment of the transferring agency stays focused. It is easy for the investors to understand that a high integrity in the new segment of the rating market is vital for the success of the whole company.

A third problem limiting the prospects of success is the perception of the different parts of reputation. In some cases it might not be possible for investors and other market participants to judge if a drop to $q_{\text {or }}$ from a higher level $q_{i}$ is relevant to the agency's other businesses, although it should actually not be relevant at all. In extreme circumstances any deviation from $q_{i}$ could harm its reputation in other segments, even if the issuers and investors originally expected merely a minimum quality of $q_{\text {or }}$ resulting from its existing reputation. Once a high quality level $i$ is reached, a drop to a lower level potentially affects all other businesses. Therefore, a milking strategy on the $q_{o r}$-level bears a financial risk. In the worst case scenario even small accidental deviations from the implicitly contracted quality $i$ would have severe negative effects. Thus the strategy of transferring reputation becomes incalculable.

The danger of a limited discrimination between brand and service-specific reputation is of a strong nature in the case of reputable incumbents. Existing and new rating products are likely

23 The issue will be discussed in more detail in subsection 5.2.3.2. 
to be very close in their characteristics. Issuers might wisely withdraw business in the existing segments in case of a lower than expected quality of new rating products. If there are quality problems in the new segment, investors will question the credibility of the whole rating agency, not only the credibility of the specific new rating service. This is a major hazard. However, such risks are inherent to the reputation-based business model of the rating agencies. Small deviations from expected quality can lead to a major loss of reputational capital, be it in one or in several segments of the rating market. Management is hence used to deal with such risks and there are internal institutional checks and balances. Or incumbents might cautiously enter new segments under different brands through joint ventures and acquisitions (e.g., Smith and Walter 2002, pp. 301-02). In sum, the absolute increase in risk should in most cases not be large, as the risk is already present even without a reputation transfer. On the other hand, the increased risk of random quality problems can be dealt with by internal quality management measures which are already present.

The last area of practical concern is the need for an innovative element. One has to differentiate between new and existing market segments. The first mover in a new segment is per se innovative, so there is no problem. Later entrants, however, do need some kind of innovative element to be successful (Kroeber-Riel and Weinberg 1996, pp. 280, 291 and Jendges 1996, p. 111). This could be a special product feature, ease of use or an accompanying service. Pure me-too products usually have a difficult stand in experience good markets as they can only compete on price. Even if they manage to efficiently build up reputation, they need to offer the same value at a lower price in order to lure away customers from earlier entrants. In the credit rating business, the need for an innovative element might become a bottleneck, if the market does not demand many different rating characteristics other than high informational quality. The first or second player might easily enter, while further entrants have difficulties in differentiating. Incumbents can try to offer a superior service during the rating process. This, however, does not help if demand is driven by investors who only care for the best possible rating and not for the issuer's convenience during the rating process. In young market segments with only small players, the innovative element provided by a veteran agency might be its reputation itself. An incumbent can be the first agency in a rating segment that has generally proven to be able to offer high quality.

Altogether, the appraisal of the areas of limitation shows that a transfer of reputation to new segments of the rating market is a possible strategy for incumbent agencies. The theoretical analysis cannot quantify the strategy's impact, though. Artus et al. (1993) are some of the few authors trying to empirically measure this effect. They analyzed S\&P's market entry into France in 1990 through a joint venture with Agence d'Evaluation Financiere, a young but leading local credit rating agency. The study finds hardly any impact of S\&P's ratings on interest rate spreads shortly after its entry in 1991. Consequently, the assumed entry quality $q_{\text {or }}$ was not much higher than $q_{0}$ which by definition has no impact on market prices. Although it is only a single example, the paper shows that a transfer strategy is likely to bring only limited benefits to incumbents. But even if the ability is limited, it might still be a competitive advantage towards outsiders not active in the rating business at all. 


\subsubsection{Market Potential of Reputable Non-Rating Newcomers}

So far the transfer of reputation has been modeled from the perspective of an already reputable rating agency moving into new market segments. However, reputable companies from non-rating businesses might also use the strategy to enter the rating market. Technically, the same mechanism applies. Because of their high company reputation they might persuade issuers to believe in an increased minimum quality of $q_{\text {or }}$. If one again first looks at the historical evidence, it seems to be difficult for external entrants to transfer reputation to credit ratings. If it were easy, there would have been many attempts of entry as well as constant price pressure on existing agencies over time. However, in the credit rating industry's history, incumbent agencies never have been under significant competitive pressure from outside entrants trying to leverage their reputation acquired in non-rating markets. The BIS (2000, $p$. 21-22), e.g., lists the owners of 29 mostly global and regional rating agencies. While some are from the financial community, no agency is dominated by a single owner who could leverage his brand name. Thus there might be factors at work which make such a competitive strategy per se difficult or even impossible.

Looking at the central question of transferability itself, one can see that only companies that offer services with similar characteristics can be seriously considered. The firms most likely to be able to transfer a meaningful amount of reputation to the credit rating business are from the larger financial community. Banks, auditors or insurance companies are some examples. They have sophisticated analytical skills, experience in finance, as well as a high level of professionalism and confidentiality; all characteristics that are required to be successful in the credit rating business. The key element of a successful rating service, however, is its track record. Investors only believe in the quality of ratings after they have seen proof for it over a longer period of time, regardless of how qualified the new entrant might be judged by the track record in his traditional markets. Put differently, reputation in the rating business is strongly connected to output. A good reputation regarding input, on the other hand, is not central. Issuers want to see that a company has proven to be generally able to rate before they will believe in an unseen increased minimum quality. Therefore, a meaningful transfer of reputation to the rating market is likely to be very difficult.

In addition, there are potentially very strong conflicts of interest for entrants from the financial community. They might have an incentive to provide artificially high ratings in order to acquire business from a rated organization in other markets. An insurance company, e.g., might rate the bonds of a client favorably in order to secure large insurance contracts with the same company. From a theoretical point of view this argumentation is weak, as favorable ratings would be detected after the lifespan of the debt securities with potentially strong negative effects for the agency. Investors would stop valuing the ratings, so no issuer would have any incentive to buy them anymore. Furthermore, the incumbent businesses might also be harmed. The general company reputation for high quality service is at stake. In this example fewer clients would contract with the insurer in its core business. Because of these potential dangers, it would be irrational to provide artificially high ratings, as it is irrational for incumbent agencies. The sensible strategic options remain either to provide constantly high quality or to broadly milk reputation. Conflicts of interest might at most trigger cases of individual fraud. Single people or divisions of a company might try to secretly profit from provid- 
ing rigged ratings. However, such risks are inherent to most financial businesses and companies have internal measures to prevent them.

In sum, conflicts of interest should not be a major issue for reputable entrants, as there is no room for deceit in a reputation-based business model. But from a practical perspective the mere existence of these potential conflicts of interest can pose a problem since not all investors can be expected to judge rationally. A finding supporting this thesis is the multitude of measures for rating agencies to actively convince investors of their integrity (Covitz and Harrison 2003, p. 8). A potential conflict of interest is already a threat to the build-up of reputation towards the investors. Even if all issuers do not expect any misconduct on the part of the new rating agency, they know that some investors will become wary when they buy ratings from an entrant who could abuse the ratings to assist its other businesses. For the investors who do not trust in the ratings of a new agency, the issuers cannot realize any benefits associated with these ratings. Therefore, rational issuers will also take potential conflicts of interest into account. Since such conflicts are stronger for reputable newcomers with adjacent businesses, the transfer strategy becomes comparably more difficult than for incumbents.

The remaining two areas of practical concern require less thought. The danger of a limited discrimination between brand and service-specific reputation is also present, but to a lesser extent compared with incumbent rating agencies. The new rating service is less similar to the existing outside business. Any likely reputable outside entrant should feature a risk management system preventing large, random quality variations. In regard to the need for an innovative element the same argumentation as above applies. A first mover is per se innovative, for later entrants it will be more difficult to innovate.

If one combines these findings, one can see that external companies have practically little chance to successfully transfer reputation to the credit rating business. The key is simply the difficulty to convince issuers and investors that the new rating service shares enough characteristics with the existing business so that a higher assumed minimum quality of $q_{o r}$ is justified. Limitations to a transfer strategy might also arise if some investors have quality concerns because of potential conflicts of interest. If one compares the possibilities for reputable rating agencies and companies whose reputation is based on other financial businesses, the result is clear: it is only possible for the former to use this strategy. Incumbent rating agencies might be able to offer their new service at a low equilibrium price $p_{i r}$. Even if the difference to $p_{i}$ is small, outside entrants cannot compete at this price level. They always need to build up more product-specific reputation than incumbent rating agencies. In any case, they have a cost disadvantage which acts as entry barrier.

Experimental research from Alpert and Kamins (2004) shows that market leading incumbents who are able to successfully assert their status in the eyes of customers have a competitive advantage in the transfer of reputation ${ }^{24}$. Specifically, the advantage lies in the customers' positive perception of the incumbent's ability to be a successful market leader in an adjoining market. In the reputation model, this corresponds to a high $q_{\text {or }}$ assumed by issuers and in-

24 Although the study uses household panels as the research method, the results are likely to hold for the credit rating market. The investors - the ultimate consumers of ratings - include many 'unsophisticated' individuals and small institutions that can be expected to act similarly to the households. 
vestors. These experimental findings support the implications for the credit rating market. The leading companies - and thus in general the biggest companies - are most likely to transfer reputation ${ }^{25}$.

Both experimental and empirical research on the credit rating market is supportive. As cited, there are no reports on successful examples of outside companies leveraging their reputation (BIS 2000, pp. 21-22). The three major rating agencies, on the other hand, have all leveraged their reputation to expand into emerging foreign markets (Smith and Walter 2002, pp. 301-02). As discussed above, a very cautious management is needed in this process. Negative impact onto the existing rating business resulting from quality problems beyond the management's control in new market segments must be prevented. This explains why the leading rating agencies are expanding into more risky emerging international credit rating markets through local partners. Only after several years can these partners become an authorized local branch operating under the incumbent's name.

\subsection{Frictions Explaining the Transfer Process}

In the reputation transfer process it has so far been argued that the new minimum quality $q_{0}$ is binding because of negative spillover effects on existing markets. This is plausible from a practical perspective. From a theoretical point of view, however, the transfer of reputation cannot be explained within the perfectly competitive world of the model. Equation (3.1) above posited the diffusion of information within a market only after one period, i.e. $R_{t}=q_{t-1}$. It describes a time lag which also applies to information diffusion between different market segments. Clients in the incumbent segment will only learn about the actual quality in the new segment after one period. Consequently, they can consider a milking strategy in the new market segment in their buying decisions on the incumbent market only after one period as well. In other words, negative spillover effects are delayed by one period. Therefore, there will always be a profitable cheating strategy: a reputable rating agency could offer its services in a new market segment at the observable minimum quality $q_{0}$ but charge a price of $p_{0 r}$ reflecting the minimum quality $q_{\text {or }}$ assumed by the issuers. This would yield a positive onetime profit of $p_{0 r}-c_{0}$. If the company were at the same time to pursue a milking strategy in all its other segments, there would be a strictly positive profit overall. By definition, in equilibrium the milking strategy merely produces zero profits on the other segments. This was precisely the calculation used to arrive at equilibrium. Given this profitable strategy, the threat of a negative spillover cannot be binding, i.e. issuers would not believe in the higher minimum quality in the new segment.

This result conflicts with many real examples for the successful transfer of reputation. Apparently, there are practical factors preventing a profitable milking strategy in the transfer process. Theoretically only frictions surrounding the reputation mechanism can explain this phenomenon. The real rating market does not feature a distinct equilibrium price, but a range of possible market prices exist.

25 This is also consistent with the concept of cheating costs to be introduced in section 3.4. Market leaders have the largest cheating costs which they can pledge against the issuers trust. 


\subsubsection{Market Prices Above Equilibrium}

The simplest friction which can explain a successful transfer of reputation is market prices above equilibrium or respectively above the no-milking price. If incumbent agencies produce long-term economic profits, they have a strong incentive to stay in business, because a milking strategy can only produce zero profits. When the profits are substantial, they override any inducement to cheat in a new rating market segment. The basis for market prices above equilibrium are deviations from perfect competition. In particular there must be a protection from outside competition in the form of entry barriers. Only if incumbent agencies do not have to fear new entries to their industry, do they in principal have the leeway for durable price increases. As analyzed above, one entry barrier results from a changing value of minimum quality. Generally relevant for entry barriers is the fact that potential entrants must bear costs the incumbents never had to bear.

Let us assume a fixed cost $\gamma$ in the first period for new entrants. The cost curve for providing ratings remains unchanged from gamma at $c_{i}$ because $\gamma$ is only the cost to enter which is unconnected to actually producing ratings. The no-milking condition $p_{i} \geq c_{i}+r \cdot\left(c_{i}-c_{0}\right)$ does not change either, for it only regards current and future profits of a reputable incumbent and not the entry cost. The no-entry condition, on the other hand, is affected. The investment into reputation is increased by $\gamma$ to $c_{i}-p_{e}+\gamma$ (with $p_{e}=c_{0}$ ) compared to what the incumbents had to pay. As above, entry is unprofitable if the discounted premiums are smaller than the initial investment, i.e. $\frac{1}{r} \cdot\left(p_{i}-c_{i}\right) \leq c_{i}-c_{0}+\gamma$. After conversion one arrives at a new noentry condition:

$$
\hat{p}_{i} \leq c_{i}+r \cdot\left(c_{i}-c_{0}\right)+r \cdot \gamma
$$

Similar to Figure 3.3 one arrives at a state where the no-entry price is above the no-milking price by a margin of $r \cdot \gamma$. Figure 3.6 depicts the situation with reference to an agency that has chosen the quality level $q_{1}$. One can see the familiar cost curve $c_{i}$ which is determinative for the no-milking price path $p_{i}$. In the basic model $p_{i}$ is the equilibrium price level. Here, however, there is a possible price range of $r \cdot \gamma$ between $p_{i}$ and $\hat{p}_{i}$. The reason is the entry cost of $\gamma$, which is displayed in the form of the broken line. All new entrants must bear this cost. As a result, they must generate higher reputation premiums than incumbents in order to cover their increased investment. At the price level of $\hat{p}_{i}$, potential entrants would break even. The entry cost does not depend on quality. Therefore, $\hat{p}_{i}$ can simply be derived by moving $p_{i}$ upwards about $r \cdot \gamma$. 


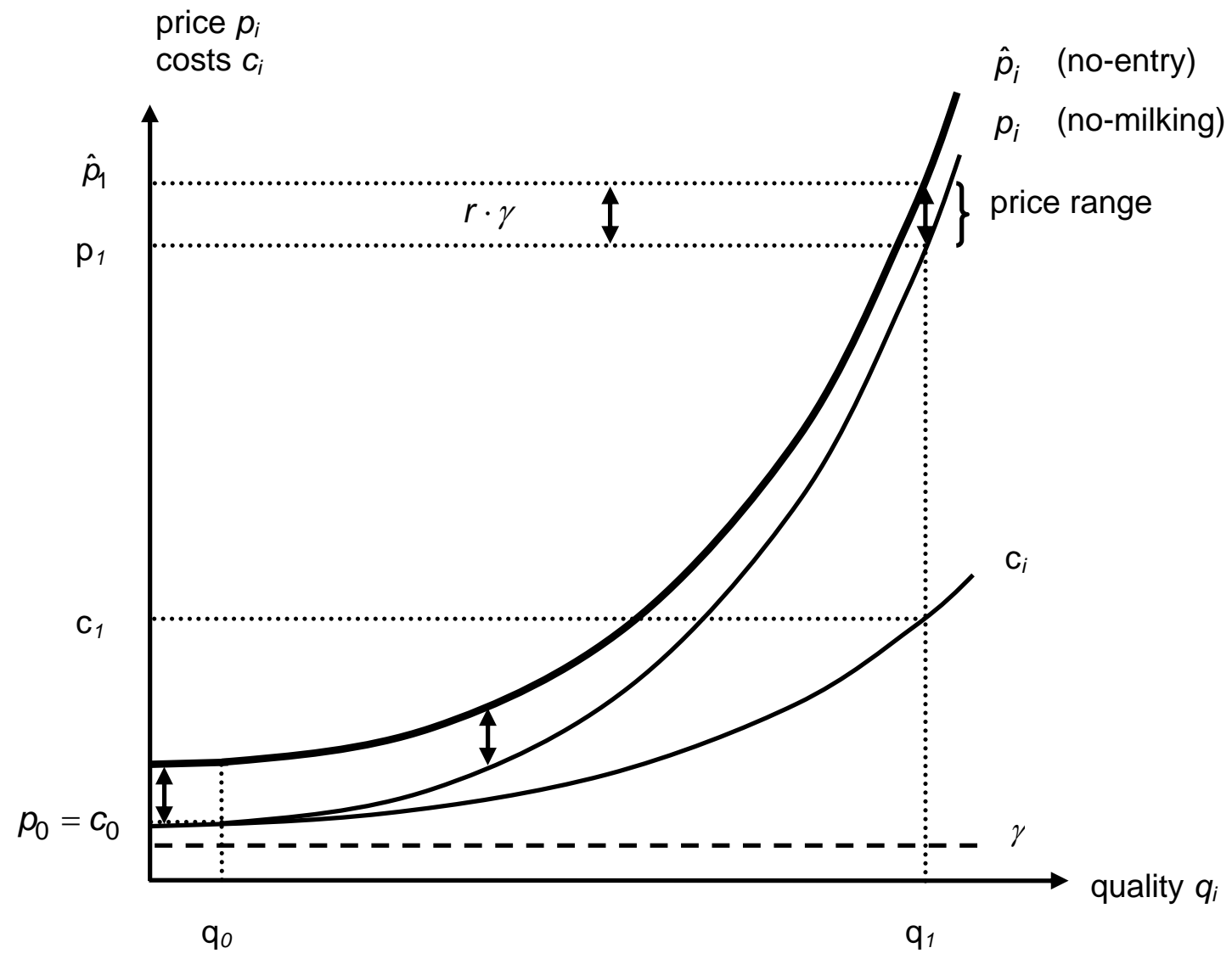

Figure 3.6: Entry barriers

If a rating market segment is indeed protected from new entrants, it is possible that the incumbents generate lasting profits. Let us assume that an established rating agency is active in $j$ segments, producing regular profits of $\gamma_{j}$ in each. The sum of these profits must be weighed against the potential gain from a milking strategy in the context of a reputation transfer. While the agency can successfully dupe issuers in the new segment, it will risk all of its future profits in its existing businesses. Only if this potential loss is a substantial pledge, will issuers initially accept a transfer of reputation. Specifically a successful transfer requires that the sum of the profits is larger than the one-time cheating profit $p_{0 r}-c_{0}$ in the new market segment:

$$
\sum_{j=1}^{n} r \cdot \gamma_{j} \geq p_{0 r}-c_{0}
$$

The strategy to cheat in all market segments simultaneously is not only viable in the period of transfer, but in any period because there is never an immediate way to control the higher minimum quality $q_{o r}$ in the new segment. This means a reputable company can only expand via the transfer of reputation on a fixed and limited scale because profits from incumbent segments must be permanently pledged.

However, if it is possible to increase the price in the new segment from a level of $p_{i r}$ to $p_{i}$, the pledge of economic profits from other market segments is no longer necessary. At $p_{i}$ the 
highest possible milking profits with a milking quality of $c_{0}$ are by definition offset by the gains of continuous high quality production. A price increase to $p_{i}$ is in principle possible, because after the reputation for high quality has been established in period $t$, issuers know about it from period $t+1$ on. If the competition allows for it (e.g., if there is only one agency in the market able to enter via a reputation transfer strategy) the price in period $t+1$ can be increased to the level $p_{i}$. In this case, the new market segment turns its structure into an incumbent segment with reputation described in the basic model, with the exception that positive economic profits are generated, as there has been no full initial investment into reputation. The originally pledged profits from incumbent segments can then again serve as insurance for further reputation transfers. Note that the profits generated in the new segment at a price of $p_{i}$ cannot be used as a pledge for a reputation transfer to other segments. These profits arise because of the reduced investment into reputation, not because the market price rises above the no-milking price. At $p_{i}$ a rating agency is indifferent between milking and continuously providing high quality; the discounted profits are the same for either option.

One can conclude that rating agencies creating economic profits can credibly transfer their reputation to new rating market segments. Admittedly, the size of profits sets a limit to the speed of expansion. The profits can only be pledged once and are bound until the price in the new segment rises at least to a level equivalent to a 'normal' reputation equilibrium. The result is a sequential expansion of the credit rating business, because issuers and investors will only accept unproven minimum quality on a limited scale at any given time. If the new market segment is very large compared to the existing business, even the biggest incumbents are likely to be unable to prevent substantial new investments into reputation. However, the bigger the company the larger is the potential scope for reputation transfers.

\subsubsection{Cheating Costs}

So far the possibility of a credible reputation transfer has been ascribed to entry barriers which open up the way for sustained profits. On the other hand, frictions in the reputation mechanism can also be modeled as exit barriers. Specifically sunk exit costs in the form of cheating costs $h_{i}$ ( $h$ for hiding) are relevant. Cheating costs also break with the original perfectly competitive assumption. However, they fit well into the picture one expects from an actual industry. Cheating costs mean that an established agency cannot abruptly lower its quality to $q_{0}$ without being detected. It needs to incur costs to disguise its action, keeping the quality drop hidden from the issuers until they discover this after the end of the period. The assumptions of quality uncertainty beyond $q_{0}$ and a production technology not specific to a quality level beyond $q_{0}$ are still valid. Cheating costs simply accommodate the fact that surrounding factors other than the actual informational quality may hint at a milking strategy.

In the rating process there are several points of contact between the agency and the issuers. It has been argued that these contacts work as a guarantee for minimum quality as the issuers learn about some of the available input factors (e.g., personnel). However, issuers cannot learn more than this from what they see. Hence, a milking strategy cannot be detected. While the personnel externally representing the agency stay the same, the internal analytical process might be altered in order to save effort. I.e. employees could be shifted to other projects. Such a strategy seems practical in a single case, but on a broad scale there are obvious problems. In order to significantly save costs, an agency must eliminate personnel or 
shift them to different businesses or markets. As a result, it is not possible to sustain the agency's known standards in client relations. If there are significant changes, at least some issuers will detect this and spread the information. While it is not possible to detect an actual quality reduction, broad scale changes in external relations clearly suggest a big shift behind the scenes. This can only mean a reduction in quality as an upward shift would be gradual and be inclined to involve additional personnel. All taken together one can conclude that high quality incumbents need to keep more personnel for milking as would be needed to just produce minimum quality. This is equivalent to an extra cost accruing in milking. (Newcomers in their entry period, on the other hand, face no such restrictions as they could plan with minimal input factors from the outset.)

Considerable cheating cost can also be expected in the process of preventing a leakage of internal information concerning the quality reduction. If the issuers learn from a credible source such as a discontent senior employee about the milking strategy, they will immediately stop buying ratings. A rating agency pursuing the milking strategy must internally set incentives to prevent such a conduct. However, there is of course no absolute safety for the agency. In this respect cheating costs can be modeled as a probability of leakage, with the interesting feature that the expected loss increases over-proportionally with size. This is because a single point of leakage affects the whole company. If a few issuers learn about the milking attempt, the information will spread quickly. This conforms to the basic assumption $R_{t}=q_{t-1}$ in equation (3.1) which precludes that quality information quickly spreads among clients once available. Further, the higher the drop in quality, the likelier a leakage is as its 'value' rises. This explains why cheating costs are best modeled against quality. As a result one can conclude that cheating costs rise with the complexity of the business. Large, reputable rating agencies have an absolute and also relative higher amount of cheating costs.

If a reputable company chooses to cheat its customers in period $t$, a cost of $h_{i}$ for hiding its action dependent on the quality offered in $t-1$ is assumed. As a result, the no-milking condition (3.2) changes. The possible cheating profit is reduced to $p_{i}-c_{0}-h_{i}$ while the discounted benefit of high quality production is unchanged at $\frac{1+r}{r} \cdot\left(p_{i}-c_{i}\right)$. For stable high quality production, cheating profits must be smaller than the honorable alternative. Therefore, one arrives at a new no-milking condition for cheating costs:

$$
p_{i}^{h} \geq c_{i}+r \cdot\left(c_{i}-c_{0}\right)-r \cdot h_{i}
$$

The no-entry condition (3.3) remains unchanged at $p_{i} \leq c_{i}+r \cdot\left(c_{i}-c_{0}\right)^{26}$. Thus for an agency that has chosen the quality $i=1$ one ends up with a pricing power margin of $r \cdot h_{i}$, which is displayed in Figure 3.7:

${ }^{26}$ At this point it is assumed that entrants consider a high quality strategy at the equilibrium price as the stable market outcome. 


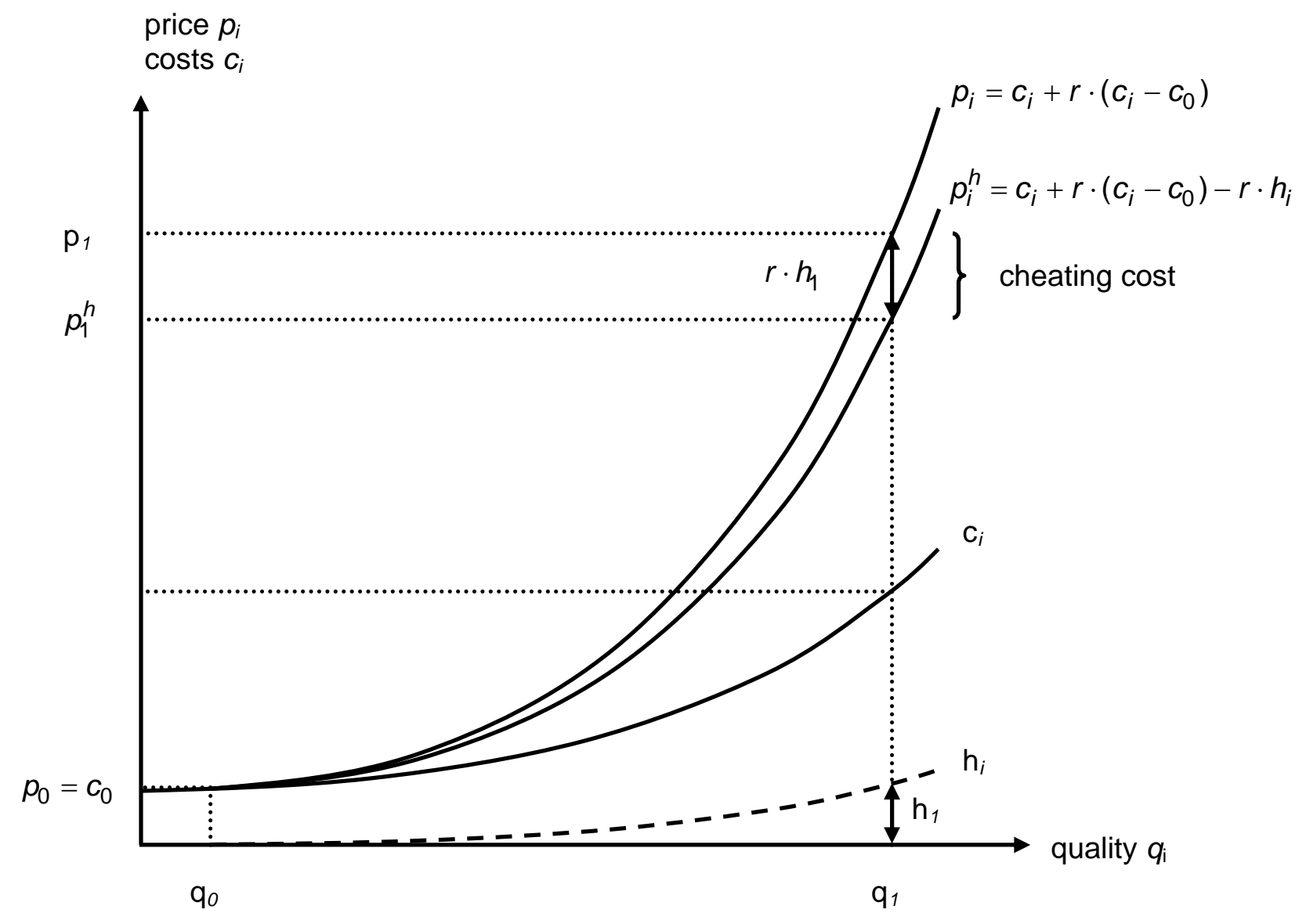

Figure 3.7: Cheating costs

The figure shows the familiar cost curve $c_{i}$ and the equilibrium price level $p_{i}$. In the lower part one sees the broken cheating cost curve $h_{i}$. As argued, cheating costs only accrue with milking and must be deducted from the milking profit of $p_{i}-c_{0}$. This is why it becomes less profitable to cheat. The price path $p_{i}^{h}$ describes at which price a reputable agency is indifferent between high quality production and milking. This path must not be mistaken as equilibrium the zero profit equilibrium is still described by $p_{i}$. What one sees, however, is that reputable agencies will be less likely to milk their reputation when cheating costs are included. Down to a market price of $p_{i}-r \cdot h_{i}$ high quality production is superior to milking.

If the market price stays at $p_{i}$, there is room for transferring reputation ${ }^{27}$. In order to cheat, the incumbent has cheating cost $r \cdot h_{i}$ per market segment $j$ he is active in. As long as the sum of all cheating costs is higher than the value of the transferred company reputation $p_{0 r}-c_{0}$ in the new segment, it is unprofitable to choose the milking strategy:

$$
\sum_{j=1}^{n} r \cdot h_{i j} \geq p_{0 r}-c_{0}
$$


Again, the strategy to cheat on all segments simultaneously is viable in any period. The pledge of cheating costs therefore needs to be permanent. Only if the market price in the new rating segment rises from $p_{i r}$ to $p_{i}$, can issuers safely expect no-milking attempts. Similar to the case of economic profits, incumbent agencies can only expand via the transfer of reputation on a fixed and limited scale. The analysis of cheating costs also bears another interesting result: the higher the current quality and the bigger the rating agency, the higher are the costs for hiding a milking strategy. Therefore, Moody's, S\&P and Fitch are able to transfer much more reputation than small competitors, thus strengthening their competitive position.

Cheating costs have just been identified as the source of a competitive advantage of incumbents, because they make possible the credible commitment not to cheat when transferring reputation. Laterally reversed, each competitive advantage of an incumbent is a disadvantage for potential entrants. Cheating costs can therefore also be described in the framework of entry barriers.

Thus far Stigler's definition of entry barriers as cost differentials has been used. If one neglects the time dimension, the introduction of cheating costs $h_{i}$ in this sense does not constitute a barrier to entry. Any company could follow an incumbents' development path: entering the original rating market, building up reputation, and then using this reputation to enter other rating markets on competitive terms. But in a shorter time horizon the picture looks different. If an incumbent transfers reputation to a new rating market, a newcomer could not follow easily. The incumbents moving to a new market need a price level of $p_{\text {ir }}$ to be profitable, whereas a newcomer would need to charge $p_{i}>p_{i r}$. In other words, there exists a cost difference between unknown newcomers and reputable incumbents, for the short-term investment into reputation is larger for the newcomers. Thus, cheating costs can be the basis for shortterm entry barriers to innovative rating market segments. Specifically, 'short-term' means at least the length of one period $T$ that is needed to build up reputation in the original segment which can then be transferred in the next period. With long-term commercial bond ratings, e.g., a single period might comprise several years to verify informational quality. In the actual market this is a substantial amount of time which might well exceed the planning horizon of most businesses. In other words, the 'short-term' is already so long that the entry barrier is absolute. Because of the long planning horizon companies will not take the risk.

It has just been shown that cheating profits and the resulting advantage in transferring reputation are a relevant barrier to entry under the strict definition of entry barriers as cost differentials (Stigler). In a wider context, there is a second very important dimension to the issue if one looks at entry barriers as "a rent derived from incumbency" (Gilbert 1989, p. 478). Cheating costs can be interpreted as rents which are lost in comparison to a continuous high quality strategy. This reflects their nature as sunk costs. Consequently one can argue that cheating costs $h_{i}$ allow strategic pricing to deter new entries (McAfee et al. 2004, p. 463). If a newcomer seems likely to enter an established market segment, incumbents could lower their price to a level of $p_{i}^{h}$. Because a part of the investment in reputation has effectively become a sunk cost that cannot be recovered upon exiting the industry, issuers will not suspect a 
milking attempt by such a price move ${ }^{28}$. At $p_{i}^{h}$ entrants face expected losses ex ante, so they would not enter in the first place. One can therefore claim that cheating costs are much more than a barrier to entry for unknown firms in innovative market segments. They are potentially the basis for a general entry barrier into any established market segment if incumbents can indeed credibly commit themselves to a post entry price below $p_{i}$ (the likelihood of such behavior will be analyzed in section 4.3).

\subsection{Reputation and Growth}

Shapiro's model and its various expansions have thus far completely eliminated the aspects of quantity and growth. It was assumed that every agency produces the optimal quantity 1 which does not change in later periods. However, the credit rating market has multiplied its size over time. A lot of this growth came from new rating products, but the classic industrial bond ratings also increased substantially (e.g., Fight 2001, p. 7). Within the basic model such a quantity expansion is only possible if reputation is developed for every new unit of production capacity. From a practical point of view this assumption is unrealistic: Moody's and S\&P's reputation for high quality is widely known. Every new issuer who seeks a rating in one of the established market segments will rely on this information. There is no need for an initial discount for the large incumbents to overcome an informational asymmetry. Only lesser known competitors, who are not generally accepted in the market as high quality producers, will need to build up reputation in the eyes of each new customer.

There are two principal categories of growth. Either industry growth is expected in $t=0$ or it comes as a surprise in later periods. If there is constant growth expected ex ante, the model changes only slightly. The no-milking-condition (3.2) has been derived by equating the discounted future premiums $\frac{1+r}{r} \cdot\left(p_{i}-c_{i}\right)$ with one-time milking profits $\left(p_{i}-c_{0}\right)$. With anticipated constant growth, there are additional contributions to profit whose present value $\Pi$ has to be added to the discounted future premiums ex ante. Since growth is assumed to be constant, $\Pi$ is the same in any given period. As a result, the quality assuring price path $p_{i}$ will move downwards to $p_{i} \geq c_{i}+r \cdot\left(c_{i}-c_{0}\right)-\Pi$. Similarly, the no-entry price falls to the same level, since entrants can expect higher profits and are willing to enter at lower market prices. Thus the quality assuring price in a scenario with anticipated constant growth is $p_{i}=c_{i}+r \cdot\left(c_{i}-c_{0}\right)-\Pi$. There are no changes to any of the model mechanics which have been explained in this chapter.

Analytically more difficult is the case of unexpected and inconstant growth. It is a realistic assumption that rating agencies and issuers did not anticipate the industry's massive expansion over time. Growth came at least in part as a surprise and it has been erratic. Within the equilibrium reputation framework it is difficult to integrate an unstable environment ex ante, because incumbents and newcomers take different development paths. The key problem lies

28 This of course implies that no cheating costs are 'pledged' in some new market segment as part of a transfer strategy. Otherwise it would be profitable to exit the threatened existing market with no disadvantage compared to continuous production, but reaping milking profits in the new market. 
in the inflexibility of the price path $p_{i}$ which cannot fall easily. The no-milking price has the informational asymmetry $\left(p_{i}-c_{0}\right)$ as input which does not change with the quantity of ratings supplied. Clearly, if the number of ratings grows, the sum of milking profits rises proportionally. As a consequence, the sum of reputation premiums must also rise proportionally. This is exactly the case when the premium per rating is constant, reflecting the unchanged informational asymmetry. In other words, the no-milking price and therefore the whole price path $p_{i}$ cannot fall. Contrary to the case of constant growth there is no assurance that future premiums will rise so that today's no-milking price falls.

Since unexpected growth is a reality, the question arises as to what happens with the additional profit contributions? The answer ultimately is dependent on market power and issuer rationality. There are two possible cases: either the issuers acquire the benefits from a spreading reputation, or the rating agencies do. If new issuers take the high quality of an agency for granted in an existing market segment, they do not hesitate to pay a price $p_{i}$. At this price, the agency generates profits because there has been no investment into reputation. A rational issuer knows this fact. Although there is no quality uncertainty, he will demand a price discount in the first period. In a competitive market new issuers will in fact be granted the price discount since profit seeking rating agencies will underbid each other as long as profits can be generated. Although there is no longer a quality uncertainty in this scenario, the price mechanism of the reputation framework stays intact as discussed. Instead of an initial discount reflecting the quality uncertainty rating agencies grant a discount to gain new clients $^{29}$.

The picture looks differently in a world of frictions and market power. If there is little competitive pressure between the incumbents, issuers who seek a high quality rating might have no other choice than to directly pay $p_{i}$. The credit rating market today seems to resemble such a situation. Price discounts of Moody's or S\&P for new issuers are at least not known to the author.

The described scenario can be built into the reputation framework by applying reasoning similar to the transfer model above. In contrast to new market segments, there is no 'remaining' quality uncertainty in existing market segments when buying from one of the long-term incumbents. New issuers will directly believe in the high quality of the big market leading agencies, i.e. they believe $q_{0 r}=q_{1}$. The complete reputation premium is covered by company/brand reputation. Technically, the experience good resembles in these settings a search good. Contrary to the transfer model, the equilibrium price path will not change because the minimum quality is still assumed to be $q_{0}$. The incumbents can reap the full milking profits by lowering their quality from $q_{1}$ to $q_{0}$. Thus they must earn at least a market price of $p_{1}$ per rating in order to have an incentive to constantly provide high quality. At this price, however, incumbents realize positive profits. Figure 3.8 shows this situation in a simple two stage model: 


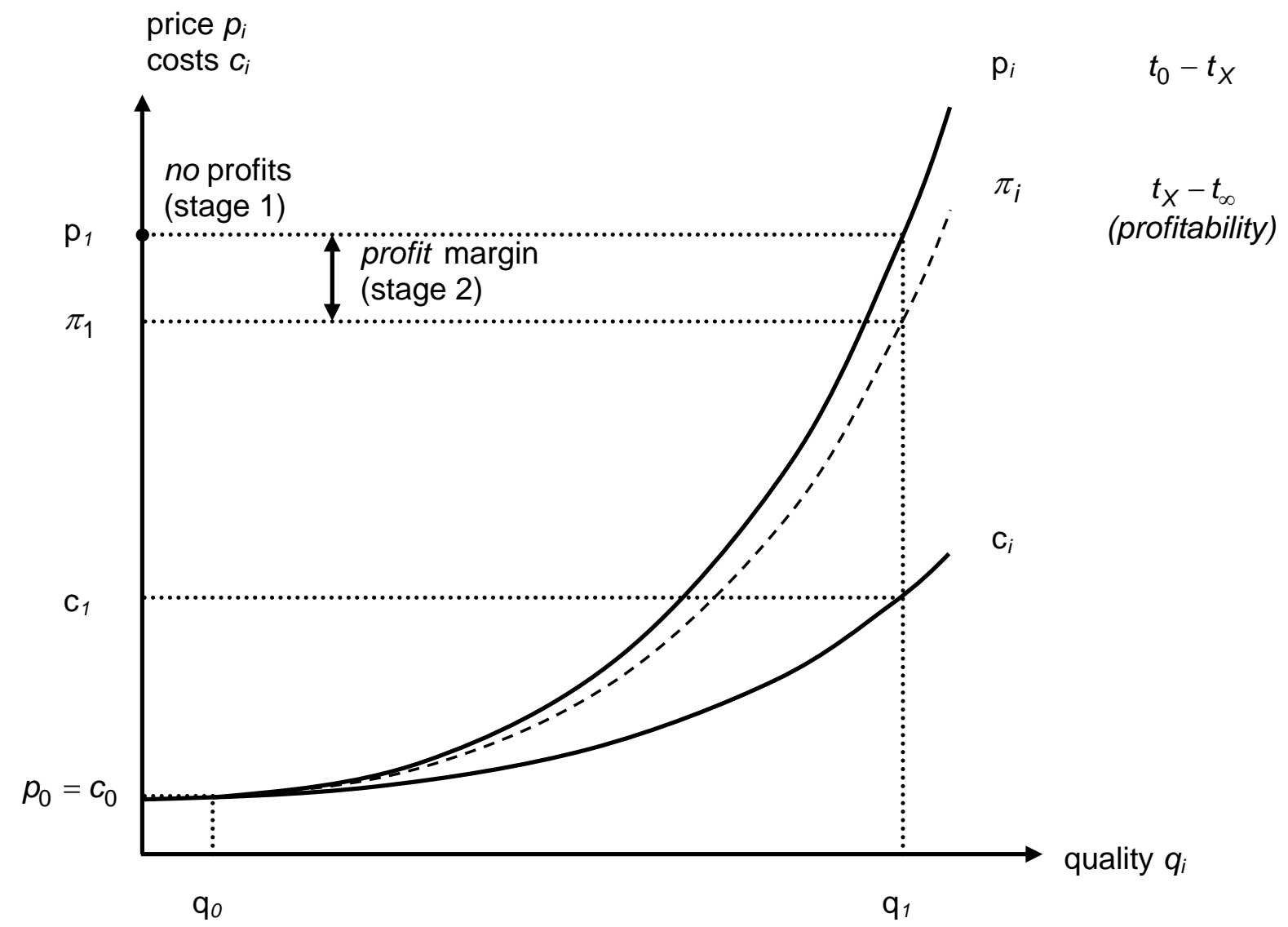

Figure 3.8: Profitability in incumbent rating market segments

One sees a high quality credit rating agency providing a rating service at $q_{1}$ realizing an equilibrium price of $p_{1}$ while always having costs of $c_{1}$. The market price is the same in all stages because at any point below $p_{1}$ milking would be profitable. As analyzed, this is because the detectable minimum quality does not change. In the first stage from period 0 to $X$, the rating agency has no general market reputation. That means its clients believe in the high quality only after they have tested it. For every new issuer the agency has to build up reputation. No economic profits are generated. In period $X$ the agency succeeds in building up a widespread reputation for high quality ratings in the market. Everybody believes that the agency always provides $q_{1}$. In period $X$ a certain number of new issuers sign up. For these issuers no initial price discount is necessary. Therefore, the premiums generated from these new ratings are direct profits. Overall, the rating agency would only need to generate a price level of $\pi_{1}$ to compensate for its initial investments. Consequently, at $p_{1}$ a constant profit margin of $p_{1}-\pi_{1}$ is generated. Again, the price will not fall below $p_{1}$ because it would be more profitable to cheat at such a level ${ }^{30}$. In the example the market is saturated after period $X$, so stage 2 describes the final state of the industry.

This phenomenon is in its essence a fixed cost degression. The initial loss of $p_{0}-c_{1}$ for developing reputation can be spread to more units over time. Since growth is not constant and 
unsure in its nature, it is not calculated in ex ante. Instead, a rational issuer would demand a onetime discount in $t=X$ equaling the agencies discounted profits. This does not happen for the reasons described. In a competitive environment, such profits should in the long run attract other companies to the credit rating industry. In principal, every new entrant could follow the incumbents' development path. This, however, is unrealistic in the credit rating market. As argued already, newcomers to existing market segments necessarily start under different conditions. As latecomers, they hardly have a chance to establish themselves as well known market leaders that could profit in the mid to long-term from their reputation being spread for free. It takes several years until period $X$ is reached. In saturated or even declining segments this might not be possible at all. That means newcomers might never reach general market acceptance to leverage their reputation towards new customers in a way the incumbents do. Only in new market segments might the expectation of a spreading reputation and high profits play a role. But because of the long time horizon - it took the incumbents several decades to reach their position - and the general uncertainty about market developments, it seems unlikely that entrants to a new market segment can expect such effects.

Since reputation-based growth has been modeled as a special case of the transfer model, one again needs to think about obstacles to such a strategy. The four areas scrutinized above change in the case of internal expansion in an established market segment. Structurally, no new conflicts of interest will arise, and there is no danger of a limited discrimination between brand and service-specific reputation as all reputation refers to the established market segment. An innovative element is not necessary because the issuers are seeking not a new but an established and well known service. That leaves the transferability of reputation as the only restriction. An agency must have a market-wide reputation for high quality ratings. Every new issuer has to trust the incumbent to an extent that he clearly believes he is receiving the quality contracted for. In such a case internal growth is possible without further substantial investments into reputation - bar competitive pressure.

\subsection{Critical Review}

The analysis has thus far shown that the reputation mechanism within the credit rating industry is effective: It makes high quality offerings possible despite the experience good characteristics of ratings. An undesirable outcome of the reputation mechanism might be barriers to entry and abnormal profits. However, this does not limit the quality assurance function of reputation which is pivotal to the business model of credit rating agencies. Regulatory authorities rely on it, too. Therefore, it is fundamental to check for possible failures of the reputation mechanism which might have been overlooked in the model thus far. The reputation mechanism may fail especially in extreme circumstances.

First of all, there is a general critique on the model's assumptions. In reality there are never perfectly competitive situations. However, the different variations of the basic Shapiro framework above all deal with deviations from a competitive situation. Market prices are indeed unlikely to match equilibrium prices, but in every case analyzed the reputation mechanism remains intact. Changes in 'untouched' parameters such as the interest $r$ or the length of a period $T$ do not alter the mechanism either. Regarding different values for $T$ an agency must build up reputation for ratings of all different maturities. The analysis has largely eliminated quantity, because of the argument that reputation needs to be built up for every unit, i.e. is- 
suer. The more realistic scenario that rating agencies grow and reputation freely spreads to new issuers has also been dealt with. In all these cases reputation allows for a sustained supply of high quality ratings.

Probably the most critical point in the reputation model is consumer rationality (Shapiro 1983, pp. 663, 667). Issuers are assumed to price ratings strictly on their quality over the past period which is why agencies have no control over price. In particular it is argued that issuers do not buy from agencies demanding a price below equilibrium, because at such a price producing high quality is not profitable in the long run. Demand is perfectly elastic. This view, however, excludes the possibility of setting prices dynamically in a strategic firm interaction. Kranton (2003) contemplates the possibility of firms temporarily lowering prices in order to increase market share. The consumers buying decision is ultimately driven by the expectation of future quality which can be assured if losses in the current period are offset by gains through an increased quantity in the future.

If the decrease in current period profits from a lower price is offset by an increase in current and future market share and the dispersion of market share decreases, issuers should rationally be willing to buy ratings below the quality assuring price (Kranton 2003, p. 392). The argument can be explained with the help of Figure 3.8: an established agency (in stage 1) might temporarily lower its price below $p_{i}$ in order to attract a higher market share. In all following periods it again charges $p_{i}$. If one assumes for simplicity's sake that there is no loss of the additional market share, the agency will generate a profit margin, for the additional premiums are generated without additional investments into reputation. However, there have been costs in the form of lost premiums in the period of reduced prices. If these costs are smaller than the additional discounted profits, the strategy is profitable. Rational issuers will therefore not suspect a milking attempt and rely on the high quality-low price combination.

Given this possibility of strategic pricing, it becomes obvious that equilibrium cannot persist under the assumptions made by Kranton. A rating agency has the incentive to temporarily reduce prices, especially if competitors have acquired a large market share. The lower prices would draw away issuers from competing rating agencies. Once prices are returned to the normal level, additional profits are generated from the new issuers. However, this strategy would be attractive for any reputable rating agency. The market would hence see constant price pressure and attempts to undercut each other; a return to high prices would be impossible. Therefore, high quality could only be guaranteed under central (price) regulation, e.g., of an industry association (Kranton 2003, pp. 399-400). In general, the possibility of profitable strategic pricing is indeed an obstacle to consumer enforced high quality standards. The key question is whether the assumptions that allow such behavior hold for the credit rating market. On a practical level the question can be easily answered with no, as there are several high quality producers in the market.

To answer the question analytically, consumer behavior needs to be analyzed in detail. Are issuers readily willing to move from one rating agency to another because of price? Once prices return to a high level, will they remain with the new agency or return to the old one? These issues will be scrutinized in the analysis of demand and supply in chapter 4 . One will see that issuers are price insensitive. They have incentives to stay with their traditional agency in order to offer continuity to the investors. An agency would need to offer a very low price 
to attract additional issuers, while it cannot be certain to hold them if they have a longstanding rating history with another agency. In other words, the investment to acquire new issuers is high, against which the return is unsure. The credit rating industry's market structure generally makes strategic cooperation attractive. In sum, strategic pricing is no threat to the reputation mechanism in the credit rating industry, while it might well be in other industries.

To date there have been no major rating agencies deliberately milking their reputation, especially no long-established players at the top end of the market. Could this suggest flaws in the concept of the reputation mechanism? Real markets should at least produce some companies milking their reputation. For several reasons the question can be answered with no. First of all, if milking is indeed profitable for a reputable company, it would not wait but directly milk and exit the market. Therefore, young companies are more likely to milk than old companies. Long established players have obviously never found the milking strategy to be attractive which suggests structural factors that make milking unattractive. For the big rating agencies, e.g., it has proven to be profitable to take the honorable, high-road strategy for nearly a century.

The most obvious structural issue making milking unattractive is cheating costs, which were introduced above in the context of reputation transfers. For practical reasons it is not possible to simply choose the milking strategy. Especially for big and long established players cheating costs are likely to be substantial. Even if reputation premiums did not cover the calculative cost per period, reputable companies would not exit via milking - their investment into reputation has become partly sunk. The other important structural issue is profits. If entry barriers are present, market prices tend to be higher than equilibrium prices. Even if market prices fluctuate they likely do this at a level where the quality strategy is clearly superior to milking. Also, the profitability of the milking strategy is highly dependent on assumptions about future prices. In real business life there is of course no certainty. A manager might easily make a mistake if he decides to exit the market by milking. Only if prospects are very bad, can milking be a viable strategic option. Furthermore, if prospects are indeed very bad, some issuers and investors will also be aware of this fact. It will consequently become more difficult to hide a cheating strategy.

If one drops the assumption of perfect ex post monitoring, models will suggest a failure of the reputation mechanism only if there is a monopolistic rating agency (Hörner 2002, pp. 64445). Once the monopolistic agency has established a reputation for high quality, issuers will assign single instances of low quality to 'bad luck' and continue to buy ratings from the agency. In turn the agency will have the incentive to reduce quality in order to profit from these wrong expectations. Given such model assumptions, a high quality equilibrium can only persist under competition that provides the issuers with an outside option: in the case of low quality they will play it safe and choose another high quality producer. While the failure of the reputation mechanism is analytically clear, the respective assumptions do not hold for the credit rating market. Big rating agencies with a large number of ratings every period can be monitored at virtual perfection. If there are hundreds or thousands of ratings in a correlation study, systematical quality deviations in a given period will surely be identified. For smaller agencies, single instances of 'bad luck' might distort correlation studies. However, a small rating agency is unlikely to be a monopolist. 
Kuhner (2001) shows that the reputation mechanism might also fail in situations of financial crisis. He defines a financial crisis by the inability of investors to distinguish between 'healthy' and 'unhealthy' issuers and the fact that investors withdraw their funds cumulatively. Neither healthy nor unhealthy issuers can survive an investors' exit. Under such circumstances ratings can hardly provide useful information to investors. Rating agencies in turn focus not on giving the best possible fundamental analysis but rather on not losing their reputation. They will provide arbitrarily low ratings because they assume that even healthy issuers will fail. Further, all agencies act in the same manner in order not to be exposed as the only agency that had wrong predictions. However, it must be clear that the failure of the reputation mechanism in such a scenario is not the reason for the financial crisis. The model simply suggests that credit rating agencies are unlikely to prevent or attenuate a financial crisis. The results are empirically supported: McNamara and Vaaler (2004) find that the three leading credit rating agencies were undifferentiated and overly pessimistic in the Asian Crisis of the late 1990s.

While the model critique presented is valid in some respects, it offers no starting point to question the principles of the reputation mechanism. The conclusion holds that reputation will always provide for a high quality in the credit rating market. A broader critique of the reputation mechanism would include factors overriding it, i.e. other things than rating quality determine reputation. The matter will be analyzed in section 5.2.3.1 where it becomes relevant. 


\section{Market Forces in the Credit Rating Industry}

\subsection{Demand in the Credit Rating Industry}

Credit ratings are ubiquitous in financial markets. Issuers attach great value to them - demand is high. In a 2005/2006 survey, two thirds of issuers stated that they receive good or very good value for the rating fees they pay, despite of the seemingly high prices reflected in the profitability of the big rating agencies (TBMA 2006, p. 20). From a microeconomic point of view the influence of demand on the industry structure is of special interest. We first need to analyze what kind of rating is valued by investors and issuers. A second important question is the impact of rating-based regulation. Further points of interest are network effects and the two ratings norm.

As above, the analysis will concentrate on an abstract evaluation of the underlying economic factors. The area also offers rich opportunities for empirical research, though. Previous studies are at variance about the impact of the different value drivers. Usually, researchers do not explicitly try to combine several value drivers into one model. The common approach of examining bond spreads tries to explain the information value of ratings ${ }^{31}$. If a rating makes investors feel more confident about the credit risk of an issue, they demand a lower risk premium. Given the fees of only about three basis points per rating, the potential value attached to them is very high since bonds can easily have spreads of several hundred basis points. If the interest paid on an issue were reduced through a rating from, for example, 6.5 percent to 6.4 percent, the savings in interest payments would outweigh common rating fees by a factor of three. A small market impact of the credit risk information carried by ratings - which is demonstrated by most studies - easily makes issuers willing to pay today's seemingly high rating fees. One focus of this section is therefore to find out about the structure of demand rather than its absolute value.

There is virtually no empirical research on the exact value of the regulatory recognition of credit rating agencies. Several studies focus on the impact of rating changes around the investment grade boundary (e.g., Johnson 2004). In principal they are concerned with the license value, as many rating-based regulations refer to it. However, the step of actively differentiating between the informational and regulatory effect has yet to be taken. Such studies are also complicated by private rules such as rating triggers which have similar effects on rating-based regulation. A promising approach is to study differences in CDS, bond, and stock price adjustments after rating events. Some regulatory benefits such as lower reporting costs for the issuer or an increased financial flexibility when issuing bonds have no direct effect on credit risk. They should therefore only be measurable in equity prices and not in bond and CDS prices. 


\subsubsection{Valuation of Quality}

Thus far the specifics of demand have been largely eliminated in the formal reputation model. In Shapiro's framework all rating agencies are assumed to produce the optimal quantity of 1. At any given quality level there are a certain number of agencies meeting stable market demand. There might also be no demand at all on certain quality levels. Demand is assumed to be fully elastic in the sense that no issuer would pay more than $p_{i}$ because with free entry there will always be an agency offering this price. On the other hand, issuers would not pay prices where milking is obviously the best solution. These assumptions helped to simplify the explanation of the reputation mechanism. Now a more realistic approach shall be taken. One needs to clarify in how far demand depends on quality. Which quality levels are desired by issuers? A second aspect is price. There is not a single equilibrium price but a range of possible prices. Which price are issuers willing to pay? It has already been argued that some kind of lower price boundary based on issuers' rationality is indeed a plausible assumption in the credit rating context. Specifically, a realistic no milking-price $p_{i}^{h}$ takes cheating (hiding) costs into account. Entry barriers, on the other hand, create room for prices above equilibrium. An upper price boundary $\hat{p}_{i}$ takes this into consideration.

Only if issuers are willing to pay a price between $p_{i}^{h}$ and $\hat{p}_{i}$ (the equilibrium price in the basic model) for a given quality $i$, do rating agencies have the chance to establish themselves on this level in the first place. The graphical analysis below will build on the basic model for convenience. Issuers will base their decision to buy ratings on price and quality, i.e. there exists a classic demand curve ${ }^{32}$. Here, quality solely refers to the informational quality. As indicated by the suffix $i$ for quality, there is a demand curve for every quality level. In a first step one needs to clarify which quality levels are most important to issuers. Particularly the willingness to pay for quality $q_{i}$, i.e. the valuation $v_{i}$, will be looked at. In a second step one also needs to analyze any possible interdependencies between different quality levels. Would issuers change a high quality rating for a lower quality rating at a lower price? For simplicity, the analysis initially concentrates on the valuation of an exemplary issuer.

It has been argued that today a minimum quality level can be observed by comparing ratings with market data and mandatory company reports. All investors will therefore not value $q_{0}$ ratings. There is obviously no demand for ratings below $q_{0}$, either, since ratings are even less informative than what investors already know. A positive valuation can only be expected for $q_{i}>q_{0}$. At quality levels slightly above $q_{0}$ investors only have small benefits over what is freely available. Consequently, there will be little willingness to pay. On the other hand, credit rating agencies must invest real and substantial effort to come up with ratings even slightly above minimum quality. It has been argued that they cannot simply take freely available information, but need to generate ratings through a fundamental credit analysis - the usual cost curve $c_{i}$ applies to any quality level. As a result, there will be a range of qualities above minimum quality, at which issuers are not willing to pay enough to even cover costs. The

32 Note that issuers need to incur costs to provide the rating agency with the information it needs for the analysis (Herring and Reeve 1986, p. 68). This is a third decision variable. For simplicity, it is abstracted from in this analysis. 
quality level where the valuation matches costs is $q_{x}$. Similarly, there is a point $q_{y}$ further up the quality spectrum, where a given issuer is willing to pay exactly the equilibrium price. Figure 4.1 illustrates the context:

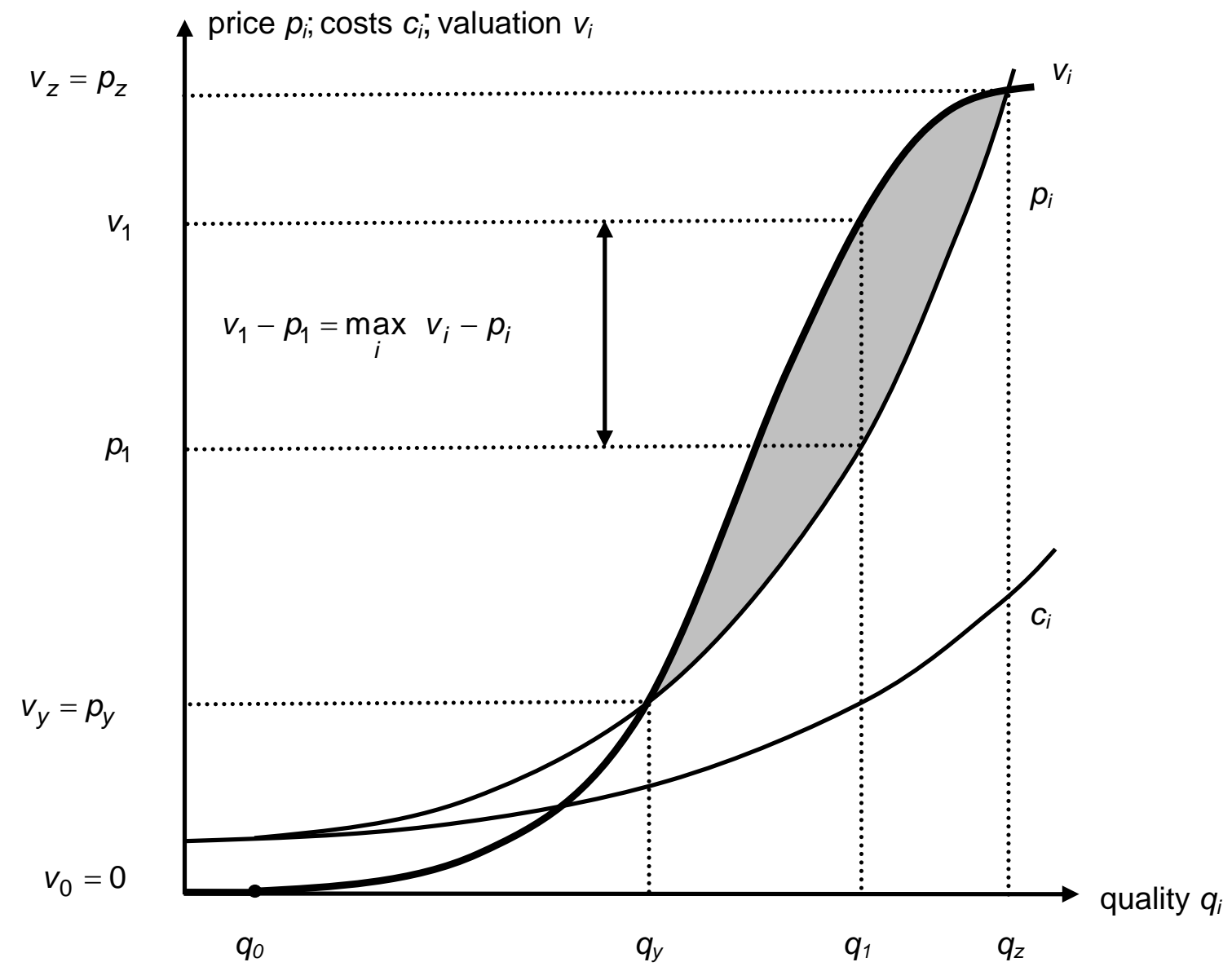

Figure 4.1: Individual valuation of ratings

One sees the familiar cost curve $c_{i}$ and the respective reputation equilibrium price path $p_{i}$. The valuation path $v_{i}$ is indicated in bold. It characterizes the willingness to pay by an exemplary investor depending on quality $q_{i}$ offered by a rating agency. The valuation for $q_{0}$ is zero and at $q_{y}$ it matches the equilibrium price. There is a second quality level $q_{z}$, where valuation matches the equilibrium price. This is because the costs to improve quality rise disproportionately at high quality levels, while the willingness to pay levels off at the same time, for additional informational quality does not have big benefits for the investors at this level. An actual rating market can only exist for qualities between $q_{y}$ and $q_{z}$ since only in this quality range is the valuation equal to or higher than price. The shaded area covers all possible market prices given that $p_{i}$ is the no-milking price. At $q_{1}$ the difference between the valuation and the equilibrium price is maximal:

$$
v_{1}-p_{1}=\max _{i} v_{i}-p_{i}
$$

Under strong rating agency competition, it would therefore be the quality level of choice of the depicted issuer because its rents will be maximized at $p_{1}$. In an anticompetitive market, a 
monopolistic agency would also choose the quality level, maximizing its monopoly profits at a price of $v_{1}$.

The valuation of ratings by an arbitrary issuer has just been described. The important question now is if such a valuation is applicable to all investors. In order to come up with a prediction of market demand one needs to look in more detail at the factors driving the issuers' and investors' valuation of ratings. The general assumption of a low willingness to pay for ratings slightly above $q_{0}$ seems unproblematic since ratings at this quality level do not offer substantial advantages over freely available information. At extremely high quality levels it is also plausible that costs rise over proportionately compared to the issuers' valuation because statistically measurable quality increases become marginal. One can therefore retain the general idea of an 's-shaped' individual valuation curve as depicted in Figure 4.1 for every issuer.

The motivation of issuers to buy ratings is driven by their desire to convey credit information about themselves. They also want to profit from the general reputation to be scrutinized by a rating agency, even if they have a bad credit risk. Basically, a rating works as a signal to outside parties, especially to investors. By its very nature the value of this signal in the investors' eyes is driven by informational quality. They want to be provided with the best possible information. The individual investor does not care about the rating costs when researching: he can choose from a wide array of possible investments and is likely to consider mostly those with a rating of high quality. As a result, there will be little willingness of issuers to buy low or medium ranged ratings, for many investors concentrate on securities rated by highly reputable agencies.

Another argument takes a similar line from the issuer's perspective. No issuer wants to buy ratings from a bad or even the 'worst' rating agency. As a signal, the rating needs to act positively on market participants. In its external presentation, no issuer can afford to be rated by a mediocre or even the worst agency, even if this agency offers decent quality on an absolute scale. Hence, issuers will try to avoid the agencies of the relatively lowest quality ${ }^{33}$. On the other hand, it is an advantage in external communication to be scrutinized by the best and most reputable rating agency. Since every issuer wants to buy ratings from the best and not the worst agency, the demand for ratings will be channelled to high quality levels. Only if the quality of all agencies in the market is high and close enough so that statistically significant statements about an agency's relative ranking are not possible, an issuer can be sure not to buy ratings from the relatively worst agency.

Both arguments support the idea of an s-shaped valuation curve. Investors want an absolutely high rating quality which directly translates into demand for high quality ratings by the issuers. Additionally, issuers care for a relatively good rating, what makes buying ratings of intermediate qualities even more unattractive. As soon as an issuer regards the rating quality as high, the willingness to pay will increase sharply, accounting for the steep part of the valuation curve depicted in Figure 4.1. A direct result from the course of the valuation curve

33 In normal (product) markets for personal use there is no such behavior. In fact, many customers often look for the best price, not the highest quality. 
is a low cross elasticity of demand between different quality levels $i$ and $j$ (where $x$ is the quantity or number of ratings sold):

$$
\eta_{x_{i}, p_{j}}=\frac{\partial x_{i}}{\partial p_{j}} \cdot \frac{p_{j}}{x_{i}}
$$

Especially in their decision to buy high quality ratings, issuers pay not much attention to the price of low or midrange quality. Such ratings are bad substitutes for high quality ratings. As argued, demand concentrates on comparably high quality ratings such as $q_{1}$, no matter how lower quality ratings such as $q_{0}$ might be priced - the cross elasticity between these two quality levels is zero:

$$
\eta_{x_{1}, p_{0}}=\frac{\partial x_{1}}{\partial p_{0}} \cdot \frac{p_{0}}{x_{1}}=0
$$

The argument helps us to narrow down the range of possible rating qualities to the high quality levels. To come up with an actual demand curve for high quality ratings one now needs to clarify the direct price elasticity of demand, i.e. the quantity change which can be expected when the price changes. A key question is how different issuers value a rating of a given quality.

For relatively unknown issuers trying to reach many investors - which is the largest group in a worldwide debt market - the valuation of ratings will be similar. Exactly because ratings are directed at many investors, there exists a common mechanism of valuation. Each issuer essentially caters to the same pool of investors which have been dubbed as 'financial markets'. A debt security rated by a high quality agency bears lower interest rates than a comparable unrated debt security. This interest rate spread is identical for comparable issuers. Of course, an issuer's absolute benefit of a rating varies with the volume of the debt security. A large issue benefits more from a rating than a small one. From a per unit perspective, however, a rating has an identical value for every issuer. The drafted valuation $v_{i}$ can be interpreted as common valuation structure for a rating referring to a standardized debt security.

Differences in individual valuations might arise in connection with the reputation value of ratings. A part of the interest rate spread is derived from the general value to be scrutinized by a high quality agency. A household name issuer with a reputation for sound financials might be able to generate high demand for its debt securities without a rating. This might especially be true for small issues in 'home markets'. A good example is the sports car producer Porsche AG which successfully issued several unrated bonds in the past. However, such a strong position is an exemption in international financial markets and should only affect few issuers. Anyway, such issuers can often profit from ratings as a marketing instrument to distinguish themselves from other issuers - or to not fall behind (Fight 2001, p. 5). One can conclude that the individual valuation $v_{i}$ of a given rating fluctuates in dependence of the reputation value for the issuer, although these fluctuations should be limited for a large majority of them. Issuers also value ratings as an instrument to release private information to the market without directly disclosing it. It is difficult to empirically quantify such an effect. How- 
ever, it should cause no major disparity in rating valuations, as all issuers can be expected to have some private information which benefits investors if released 'securely'.

Another source of value for credit ratings is standardization (Kerwer 2002a, pp. 297-99). Credit ratings define the process of issuing debt. This is most important for institutional investors with guidelines and practices for day to day investment decisions which premise ratings of certain high quality agencies (Hill 2004, p. 61). Ratings that comply with such investment processes enjoy an increased value. Investors have to incur higher transaction costs when buying bonds either unrated or rated by 'not accepted' agencies. Therefore, they are less likely to invest in such bonds if there are many appropriately rated alternatives. The effect is independent from issuers, as the cost differential occurs on the investors' site. Naturally, such a standardization value is limited to a few high quality rating agencies that have comparable rating methods. While this is no argument for valuation differentials between the different issuers, it once more reinforces the s-shape of the valuation curve independent of quality. Ratings of agencies with little reputation cause higher transaction costs for investors than ratings of high quality agencies ${ }^{34}$. Independent from the information value, issuers will concentrate on high quality ratings fulfilling (or setting) the standard.

The direct alternative to buying ratings is not buying ratings. Therefore, the valuation path $v_{i}$ can at a maximum reflect the interest rate spread of rated versus non-rated debt securities. However, the valuation might also be limited by alternatives to debt securities. In all developed financial markets issuers have access to standard bank lending. If it is cheaper to raise a bank credit than to issue an unrated bond, these financing costs determine $v_{i}$. Within a national market, the bank credit conditions are comparable for all issuers. Therefore, the influence on the valuation should be similar for everyone. Difference can only be explained between national markets. If there is no strong national bank credit market, issuers often have little chance other than international debt issues to access substantial capital. This is true for many developing markets without a grown financial system. In countries where banks traditionally hold a large portion of assets compared to other institutional investors such as mutual funds, bank lending often is more attractive compared to rated bond issues. Baliga and Polak (2004) analyze the case of Germany which traditionally has a strong lending business. An important reason is that credit and investment standards are more aligned to bank lending in such countries, especially because of historically developed monitoring structures. For issuers seeking manageable debt, transaction costs with banks can be so low that they assign but small value even to high quality ratings. In this case the spread achieved in the credit market for a rated bond is higher than the interest demanded by a bank.

Taken together, the absolute valuation of ratings by different issuers is very similar, because ratings are used in frictionless international debt markets. Ratings on comparable debt securities result in the same interest rate spread. A part of the value is derived from common standards in international financial markets. Large valuation differentials might exist in national markets where bank lending is the standard. If one looks at credit ratings as a global market, however, one can safely conclude that there is a common valuation curve $v_{i}$ applying

34 There can of course also be high quality/highly reputable smaller agencies which do not comply with investment standards and thus do not enjoy a transaction cost advantage. 
to most issuers. Therefore, the market for high quality ratings has a low direct elasticity of demand in the relevant range where $x$ is the quantity or number of ratings sold:

$$
\eta_{x, p}=\frac{\partial x}{\partial p} \cdot \frac{p}{x}
$$

If the valuation of ratings is similar for all issuers, they will react to prices in the same way. For all market prices below the common valuation $v_{i}$ most issuers will buy a rating, for all prices above only few will buy a rating ${ }^{35}$. As long as $v_{i}$ is above $p_{i}$ or respectively the range of possible market prices $p_{i}^{h} \hat{p}_{i}$, the quantity sold will (virtually) be the same for any price, i.e. the direct elasticity of demand is zero:

$$
\eta_{x_{i}, p_{i}}=\frac{\partial x_{i}}{\partial p_{i}} \cdot \frac{p_{i}}{x_{i}}=0 \quad \text { for } v_{i}>p_{i}
$$

The analysis has been simplified by concentrating on a standardized debt security of a given size. The conclusion was that the valuation of ratings is comparable per unit of debt issued. As a direct result, issuers will have a higher willingness to pay for large debt securities. The demand function becomes elastic under fixed prices per rating. At a high price only big issues are profitable, while at a low price ratings for small issues also make sense. The effect gets attenuated because rating costs increase in tendency with size: the complexity of the analysis grows and also 'risk costs' rise (Herring and Reeve 1986, p. 68 and Schwarcz 2001, p. 302). Therefore, the equilibrium price schedule also rises with issue size. The actual pricing policy seen in the market corresponds to the guideline: yearly rating fees are dependent on issue size within a range, e.g., $\$ 33,000$ to $\$ 50,000$ as the minimum fee and up to $\$ 300,000$ as the maximum fee for corporate debt ratings (Partnoy 2006, p. 69) ${ }^{36}$. Because of the degression of the fixed minimum fee, ratings for large debt securities are always relatively cheaper than for small issues, though. Rating fees for very large issues (roughly above $\$ 1$ billion for Moody's, e.g.) are constant. In sum, differences in issue size will therefore increase the demand function's elasticity at least to a certain extent.

One can conclude that demand in the credit rating industry will focus on high quality levels and that the issuer's valuation of ratings is similar, i.e. the direct demand elasticity is low. These results have been confirmed empirically: nearly all international debt securities today feature a credit rating. This striking market penetration corresponds to a low elasticity of demand. However, it might also be a result of rating-based regulation, which will be discussed below. Moody's, S\&P and Fitch have all been historically active in the very high quality segment. There are either no or only negligible players at lower quality levels. In general, the nature of demand poses an entry barrier to the credit rating industry. As all issuers concentrate on established companies, they are unlikely to look at newcomers with a low reputation.

Graphically, the demand curve is steep over a certain price range (i.e. the quantity does not change much with a rising/falling price), but has a break at a certain price where it becomes very flat (i.e. the quantity quickly goes towards zero with only slightly rising prices).

36 It is difficult to empirically analyze if the rising price schedule purely reflects costs. Under limited competition rating agencies are able to reap extra profits from issuers with a high willingness to pay for large issues. 
The oldest incumbents have an inherent advantage (Hill 2004, p. 45) ${ }^{37}$. Even if newcomers offer a high quality service over several years - which is the basis for a high reputation - issuers might simply not be aware of this development because they focus on agencies which already have a high status (Podolny 1993, p. 832).

\subsubsection{The Impact of Rating-based Regulation on Demand}

The demand for ratings has been modeled so that it will be driven by the issuers' desire to convey information about their creditworthiness to investors. A second major driver of demand is rating-based regulation. This is most obvious in the case of disclosure requirements where an appropriate credit rating may lower legislative requirements. Issuers have an incentive to buy a rating simply to reduce reporting costs, completely independent of the information value for investors. Rules concerning investment restrictions and capital requirements have a similar effect. They help to lower financing costs and increase financial flexibility, as issuers can reach a larger pool of potential investors with an appropriate rating. In a nutshell, ratings receive an additional value other than informational: they provide a 'license' for accessing certain areas of the financial markets, or to avoid regulatory burdens (Partnoy 1999, p. 683).

The license value of ratings is generally accepted. Open to question, however, is its importance. The regular or 'reputational capital' view regards the license value as an addition to the information and reputation value (e.g., Hill 2004, pp. 66-68). Overall, the information value is still decisive in the willingness to pay for ratings. Some authors see the relationship the other way around (especially Partnoy 1999, p. 683; see also Kerwer 2002a, p. 306). From this perspective the license value is the main or even the only driver in buying a credit rating today. One can speak here of the 'regulatory license' view. The information value has deteriorated over time because of more readily available risk measures. There is no detailed empirical research on the question, while the general hypothesis that the market impact of ratings is primarily driven by rating-based regulation has existed for quite some time (e.g., West 1973, p. 168). Only anecdotal evidence is cited for the actual importance of the license value compared to the information value (Hill 2004, p. 72). There are, however, examples of large bond price movements induced by a change in the regulatory status (e.g., Gerke and Mager 2005, p. 204). Since the reputational capital view is the standard view of most researchers it will be dealt with first. The structural differences to the regulatory license view will be analyzed in a second step.

\subsubsection{Information Value as Major Demand Driver}

To understand the structural impact of rating-based regulation one first needs to clarify its relation to quality. Does the license value fluctuate with informational quality or does it remain constant? From an ex post perspective the picture is clear: a given rating invariably features the same license value independent of the analytical quality behind it. An AAA rating, e.g., always has the same regulatory benefits attached to it, no matter which agency issued it. From an ex ante perspective, however, the valuation might to some extent depend on the

37 A long time series of ratings is not only the basis for a high reputation, it may also feature direct additional advantages. Historical data may give hints about the absolute credit risk, for instance. 
informational quality. If one assumes that an issuer has perfect knowledge about his fair rating, a lower rating quality can be interpreted as a higher fluctuation margin of the actual rating received compared to the fair rating. This is important in cases where a small rating difference has a significant impact on the license value, e.g., in cases where the actual creditworthiness is slightly above or below investment grade ${ }^{38}$. An issuer with a fair rating below investment grade profits from a high fluctuation margin because his chance of receiving a (wrong) investment grade rating increases. The respective benefits more than compensate for the similarly increased chance of getting a too low rating, because there is not much difference between being rated one or two notches below investment grade. Issuers with a fair rating slightly above investment grade prefer high quality ratings for the same reason in the reverse situation. Consequently, both assign different license values to the same quality ratings.

In the analysis here, such differences in the license value $v_{L}$ are neutralized, because there are only few points on the rating scale where one will see such big differences in regulatory benefits as at the investment grade boundary. For most issuers regulatory benefits are similar for any likely rating from a reliable agency, i.e. the fluctuation margin of $i$ does not matter at all: $\frac{\partial v_{L}}{\partial i}=0$. A rating of minimum quality has exactly the same license value as a high quality rating. By contrast, the value of the signaling service is solely derived from its informational quality, i.e. the accuracy in describing the financial soundness of the rated debt security and issuer: $\frac{\partial v_{i}}{\partial i}>0$. The unobservable analytical quality $i$ is reflected by an agency's reputation. This is the reason why thus far only demand for high quality ratings of reputable agencies has been identified. This situation changes when one considers rating-based regulation. The individual valuation for recognized ratings rises for all quality levels. In Figure 4.2 the constant license value is assumed to be $v_{L}$ for a given debt security and all rating agencies are recognized by the state.

The figure shows the familiar cost curve $c_{i}$ and equilibrium price path $p_{i}$. The broken line in the lower part represents the license value $v_{L}$ which is constant for all quality levels. The broken s-shaped curve is the original valuation curve $v_{i}$. The bold curve $v_{i}+v_{L}$ is the sum of the two broken valuation curves. It represents the issuer's willingness to pay for an officially recognized rating of quality $q_{i}$. In the depicted case the increase in the valuation through $v_{L}$ is so large that at any quality below $q_{z}$ the valuation curve is above the equilibrium price path $p_{i}$. The shaded area indicates all possible price quality combinations at which a market for ratings could emerge. Contrary to the analysis without rating-based regulation, one now sees demand for low qualities as well, since the willingness to pay is larger than costs. The area left of $q_{0}$ (shaded in light gray) indicates strategies where rating agencies arbitrarily make up artificially high ratings without inducing any corresponding costs.

38 The investment grade boundary has a considerable impact, as many rules refer to it (ECB 2004, p.12). 


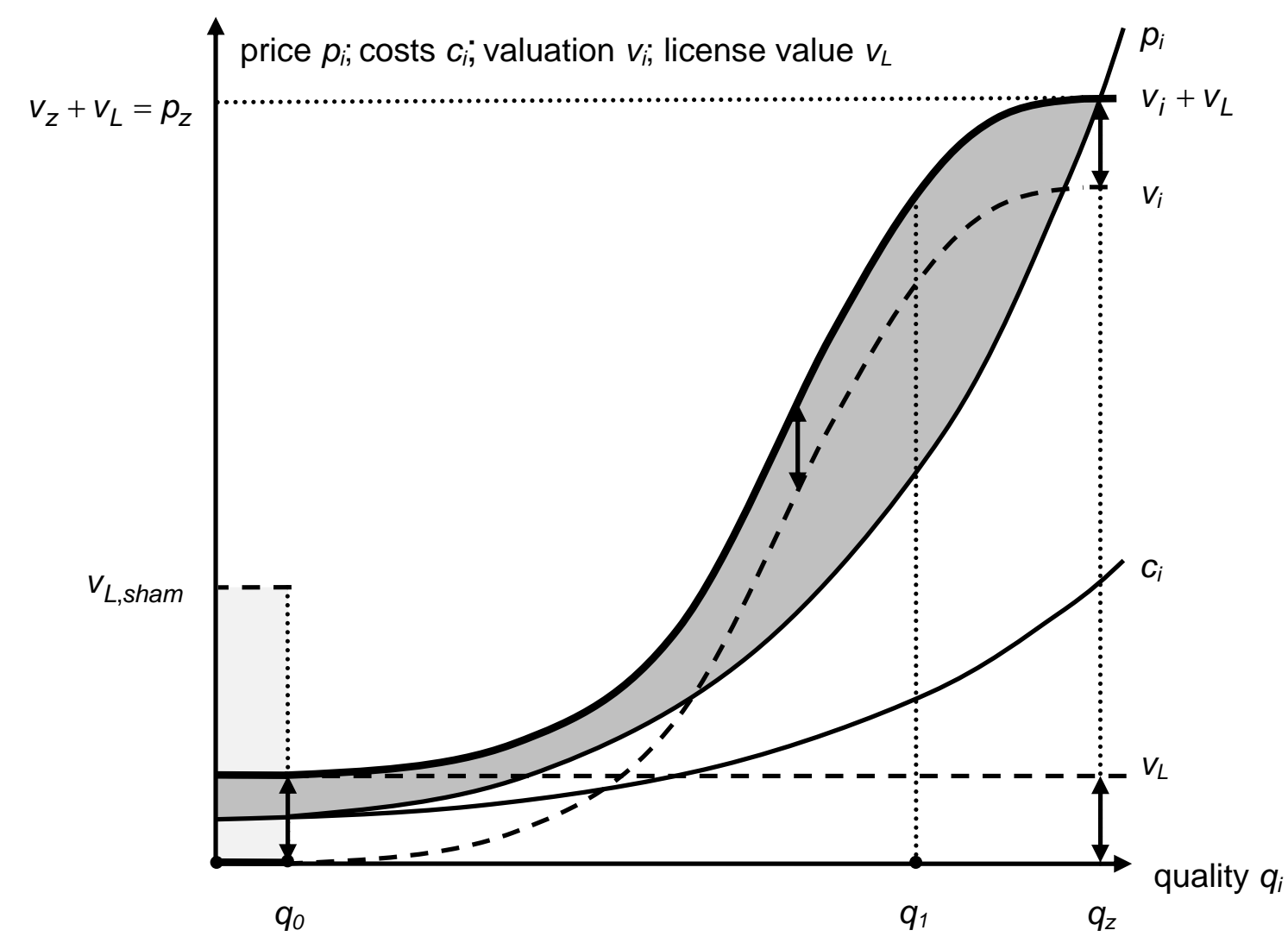

Figure 4.2: License value of ratings

The low quality area is of particular importance. Below $q_{0}$, reputation is no longer involved. It is evident that ratings are artificial, i.e. they bear no information value and are only useful in the light of regulatory restrictions. An AAA rating for a high risk bond is an example. Rating agencies operating in the very low quality area will choose whatever rating is most profitable for them, because they do not have a reputation to lose. Such sham ratings might be attractive for issuers with a bad effective creditworthiness. Neglecting any impact on the issuer's own image, some will request artificially high ratings which secure them rating related benefits of $v_{L, \text { sham }}$. A sham rating does not reflect the issuers' credit-worthiness, but is exclusively aimed at maximized benefits in connection with rating-based regulation. Consequently, the license value $v_{L, \text { sham }}$ is above the 'honorable' license value $v_{L}$. It increases with the difference between the honorable rating and the sham rating. In essence, an AAA sham rating takes all regulatory restrictions attached to a debt security.

Clearly, sham ratings are not in the interest of the state because all rating-based regulation is explicitly or implicitly directed at influencing the behavior of financial market participants. If it is possible to shop for arbitrary ratings at very low cost, there is no longer any incentive for the respective issuers to actually change their manner of doing business. Investors, too, could circumvent rules directed at them. This dilemma poses the question if the market will 
prevent the pure avoidance of regulatory burdens or if a direct intervention into the credit rating market is necessary ${ }^{39}$.

Certain issuers have an incentive to avoid very low quality ratings despite of their apparent benefits. They have to fear large reputation costs concerning their own reputation. Investors, customers and partners might get alienated by evident attempts to avoid regulation by 'shopping for ratings'. For such issuers the broken valuation curve $v_{i}$ becomes negative below $q_{0}$ (not depicted). An artificially high rating does no good and is harmful to the issuer in that it has a negative impact on its business. Potentially, borrowing costs might even increase because investors become unsure about which information on the issuer is right. Possible gains from the license value $v_{L, \text { sham }}$ are easily offset by these negative effects. In sum, issuers with such an incentive structure are unlikely to buy ratings of very low quality. They still enjoy the highest rents at $q_{1}$. Even if sham ratings offer a positive net value, high quality ratings offer a far higher value.

Issuers with few investors, customers and partners or little market contact in general might not have such an incentive structure. This is especially relevant for ratings of debt securities directed at a few acquainted investors, such as many structured finance issues. There might be only little or even no informational asymmetries between the involved parties. The valuation curve $v_{i}$ would be flat at zero and all parties would prefer to contract without regulatory restrictions. In a world without rating-based regulation there would never be demand for ratings from such issuers, which is why they haven't been included in the previous analysis. Under rating-based regulation, however, some structured debt securities might need a (good) rating in order to become viable. The constant license value $v_{L}$ applies as described for any rating quality level. At the very low quality level, however, artificially high ratings even provide for an especially high license value $v_{L, \text { sham }}$. Naturally, the respective issuers will go for the cheapest and most favorable ratings, as they have little to lose in terms of reputation but a lot to gain through avoidance of regulatory burdens.

One can summarize the main impact on the rating quality demanded as follows. Issuers who are interested in the informational and reputation value of ratings will stick to high quality ratings. Potential benefits of sham ratings are offset by their own reputation losses. Among the honorable alternatives their preference for quality $q_{1}$ remains untouched, as the valuation curve $v_{i}$ moves upwards at about the same amount $v_{L}$ for all qualities. For the very low quality level, however, there will be additional issuers merely interested in avoiding regulative costs by buying artificially high ratings.

This is problematic in the eyes of the state. Issuers who buy high quality ratings because they are interested in their own reputation for prudence, are most likely to act cautiously as well in compliance with governmental expectations. By contrast, restrictions on debt securities shifting risks between a small number of parties might be of a key interest to the state. Financial institutions might accumulate too much risk through issues with sham ratings and

39 For private rules in risk management the answer is clear: No one would use clearly identifiable sham ratings, because they rather distort things than give valuable information. Even if issuers buy sham ratings, they will be (at best) ignored by investors. 
endanger financial market stability. It is precisely those parties that the state wants to influence most who are likely to avoid the regulation. The market offers no mechanism to prevent this. Therefore, it is easy to understand that virtually all researchers see the need for regulatory control of the rating market in connection with rating-based regulation. The most plausible way is to restrict the ratings that are open to a certain group of recognized high quality rating agencies, which is the traditional approach taken by the SEC with its NRSRO designation and the Basle II guidelines. The impact on demand created by rating-based regulation is answered with rules restricting supply.

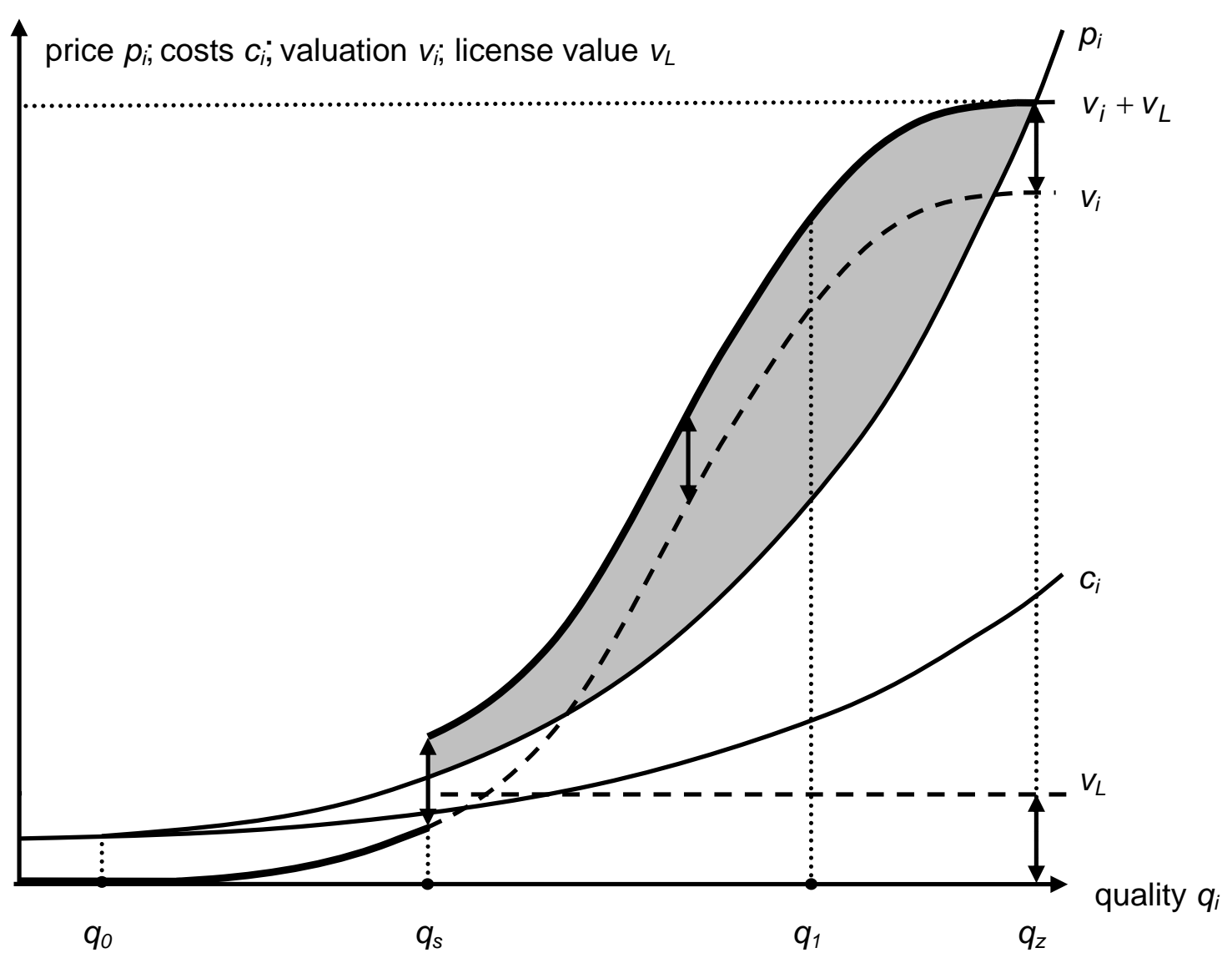

Figure 4.3: Official recognition based on quality

In Figure 4.3 one sees the impact of a regime that only recognizes agencies that have a proven track record in delivering at least a quality level of $q_{s}$ (s for state). Below $q_{s}$ demand is not affected by benefits derived from rating-based regulation and a market cannot evolve as the valuation $v_{i}$ is at every point below the equilibrium price $p_{i}$. Under such a regime the described problems are not present, as very low quality ratings do not offer any benefits to issuers. However, the possible scope of the market has broadened from the quality range $q_{y} q_{z}$ from Figure 4.1 to $q_{s} q_{z}$ now. The two previous Figures 4.1 and 4.2 allow for a comparison between a situation without rating-based regulation and with such regulation, but with universal recognition of all agencies. In all three cases one can see that an honorable issuer maximizes his rents at high qualities, notably $q_{1}$. The discussed group of issuers - exclusively concerned with the license value of ratings - will strive for the cheapest available recognized rating (as $v_{s}$ is below $p_{s}$ in the depicted case, no such market would evolve, however). Empirically there is some evidence for such behavior: Fitch, which ranks lowest among the three 
big recognized agencies and has the lowest prices, has a significantly higher proportion of structured finance ratings than Moody's (Fisch 2004, footnote 23). This might reflect the higher proportion of debt securities with few involved parties and little informational asymmetries among structured finance ratings compared to regular bond ratings. Here, price possibly counts for more relatively than reputation.

One has seen that rating-based regulation creates a constant license value. But an important question remains unanswered: Do different issuers assign the same (constant) license value to a given rating for a comparable issue? If rating-based regulation eases disclosure requirements, the savings in reporting costs will be similar for everybody. All issuers can in this way reduce certain administrative tasks. But with capital requirements based on ratings, the benefits for investors are also very similar. A certain rating reduces the capital costs of holding a debt security by a fixed amount. Investors are therefore willing to accept a lower interest rate on the rated security. From the issuers' point of view, a lower interest rate directly translates into a higher willingness to pay for a rating. If one assumes that all issuers have the same structure of investors, the license value derived from capital requirements is identical. Such an assumption is not unrealistic in an open financial market, as a regulated debt security will always be held by investors who have the highest relative advantage in holding the respective security. A similar reasoning applies to rating-based investment restrictions. If a certain rating enables a debt security to be bought by additional investors, the interest rate will tend to fall. In sum, the question if all issuers assign the same license value to a comparable rating can be answered in the affirmative.

The analysis has so far concentrated on a rating for a given debt security, independent of its size. Taking this additional factor into account one finds that some parts of the license value depend on issue size while others do not. Most importantly, a (good) recognized rating lowers interest rates compared to a non-recognized rating, because more investors are allowed to hold a security and liquidity is high. Of course, the interest rate reduction applies to every unit issued, i.e. this part of a rating's license value is proportional to issue size. By contrast, benefits for reduced reporting needs accruing to the issuer are largely fixed. A small debt issue profits more on a per unit base than does a large issue. This is the first time one finds a value driver for ratings that is independent of issue size. The policy of split prices (base minimum fee plus fee depending on issue size) of the major officially recognized rating agencies corresponds in this respect to the actual valuation of ratings dependent on size.

It is not easy to empirically quantify the different value drivers, but the actual price structure might be well aligned with the willingness to pay for different issue sizes. While in a competitive market the split price structure can only be explained as reflection of costs, in a protected market price discrimination could also be an explanation. I.e. the prices do not reflect costs but rather the individual willingness to pay in order to maximize the agencies' profits. Note, however, that these theoretical considerations would require thorough empirical analysis to either verify or refute them. Important here is the fact that one can largely neutralize the size of debt securities in the valuation analysis because it is in fact neutralized by the actual pricing policy.

Overall, the license value of a recognized rating is very similar for all issuers. This is important for demand elasticity. Thus far it has been concluded that demand is very inelastic over 
a large part of the price range. This result does not change qualitatively with rating-based regulation. The whole demand function for a given rating quality moves upwards, while the elasticity remains largely unchanged. In addition, the cross elasticity between different rating qualities is not affected as the s-shape of all individual valuation curves remains similar. Even if low quality ratings now acquire a certain value, they are still a poor substitute for high quality ratings since the difference in value remains unchanged.

\subsubsection{License Value as Major Demand Driver}

Thus far, the license value $v_{L}$ has been considered to be limited compared to the information and reputation value $v_{i}$. The only substantial problem of rating-based regulation was arbitrarily high sham ratings which undermine its purpose. However, official recognition based on quality is an effective solution to the problem. Empirically, however, the proportion between the two different value drivers has not proven. That is why one also needs to look at the second possible, significant case put forward by Partnoy (1999, p. 683). The informational/reputation value $v_{i}$ might have suffered substantial deterioration over time. In this case, the license value $v_{L}$ is decisive for the issuers' overall willingness to pay for ratings. Specifically, a situation is assumed where $v_{i}$ is in fact so insignificant that there would be no market for ratings without rating-based regulation. Figure 4.4 illustrates the scenario:

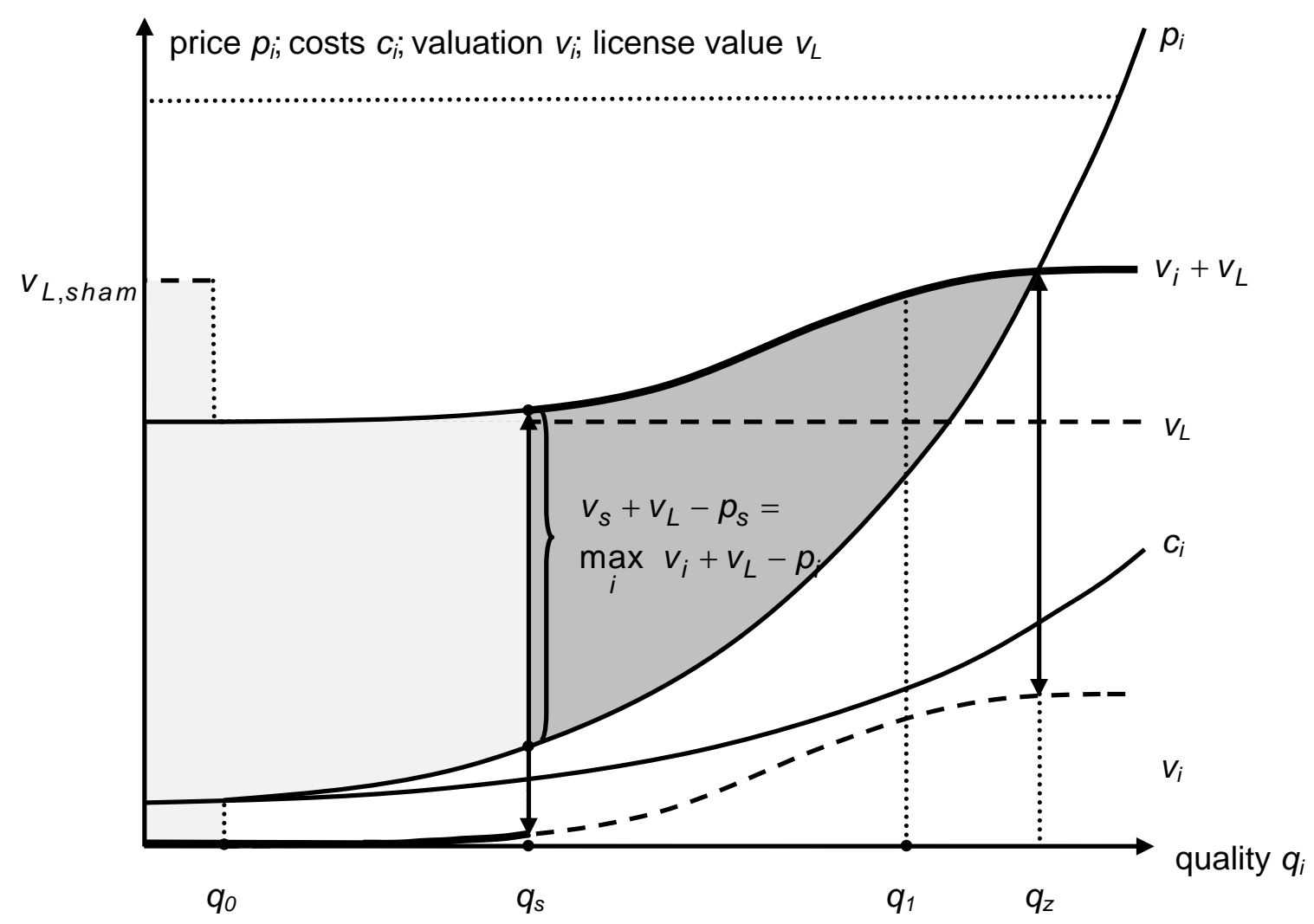

Figure 4.4: License value dominates overall value

As always, one sees the familiar cost curve $c_{i}$ and the equilibrium price path $p_{i}$ indicating the supply side of the market. Only at or above $p_{i}$ can a market for ratings evolve. However, in this scenario issuers assign only a limited informational and reputation value to ratings. The broken valuation curve $v_{i}$ is well below the equilibrium price path. In the absence of rating- 
based regulation there would be no credit rating market at all. The benefits derived from rating-based regulation, however, are substantial, as represented by the broken line $v_{L}$. The overall willingness to pay for ratings dependent on quality is represented by $v_{i}+v_{L}$.

In the absence of official recognition, a market might evolve at any price-quality combination in the shaded area, because the willingness to pay is higher than the quality assuring price. In the very low quality area to left of $q_{0}$ there might again be the possibility of sham ratings at no costs providing an extra high value $v_{L, s h a m}$. Along the lines of the argumentation above, in this scenario there is also a need for official recognition based on quality. In this figure only agencies with an informational quality higher than $q_{s}$ are recognized. As a result, the valuation to the left of the threshold is exclusively driven by the information value, while to the right of $q_{s}$ the license value also applies. The two lines in bold represent the overall willingness to pay under the respective regulatory regime depending on quality.

One can see that in the recognized regime the area of possible price-quality combinations becomes limited to the darker shaded area between $q_{s}$ and $q_{z}$. The highest difference between the equilibrium price and the valuation stands at $q_{s}$ :

$$
v_{S}+v_{L}-p_{S}=\max _{i} v_{i}+v_{L}-p_{i}
$$

One no longer sees a maximum at $q_{1}$ somewhere within the range of possible qualities, but the minimum quality needed for recognition directly sets the most desired quality. This is because the gap between the valuation of the informational quality and the price for the respective ratings widens with rising quality ${ }^{40}$. Issuers aim to minimize this 'loss'. They no longer care about quality but only about the value of the license. In a competitive market they choose the cheapest recognized rating. A monopolistic agency would go for the same quality level as it can extract the highest rent at $q_{s}$.

From an economic perspective this result is interesting in that it creates antithetic conclusions. On the one hand, rating agencies need to offer a stable high quality in order to secure state recognition. The license is comparable to an asset which can be withdrawn by the state in the case of violations (Shapiro 1986, note 6). A recognized agency faces risk costs of losing its license $r\left(q_{i}\right)=r_{i}$ which increase with falling quality. This risk should prompt the agency to act responsibly by offering high quality. Without recognition it would immediately lose all its business. On the other hand, credit rating agencies strive to keep production costs as low as possible, which corresponds to a low quality. The lower the costs, the better is an agency's competitive position. Profits per rating of a monopolistic agency $v_{i}-p_{i}+v_{L}$ are maximized at $i=s$. The market will not 'care' about a relatively low informational quality as long as an agency is officially recognized.

If one compares the situation to the reputational capital scenario where the informational quality is the main value driver, one finds a crucial difference. While the motive to provide high quality in order to stay in business remains in principal intact, the profit incentive is con-

40 Mathematically, $p_{i}$ is at any point steeper than $v_{i}$. 
trary. A lower quality is more profitable than a higher quality. A rating agency does not strive to be better than other agencies, but a lower informational quality gives a competitive advantage. As analyzed, rating agencies would choose the extreme outcome $i=s$ in a frictionless environment, i.e. the lowest possible quality which enables state recognition. However, the real recognition process carries certain risks. Assuming the recognition will immediately be lost below $q_{s}$; rating agencies will therefore adjust their quality to a level $i^{*} \geq s$ where the marginal risk costs $r_{i}$ of losing state recognition equals the marginal gain from further lowering quality:

$$
\begin{aligned}
& \pi_{i}=\left(v_{i}-p_{i}\right)+v_{L}-r_{i} \rightarrow \max _{i} \\
& \Rightarrow \frac{d\left(v_{i}-p_{i}\right)}{d i}=\frac{d\left(r_{i}\right)}{d i}
\end{aligned}
$$

The optimal quality level $i^{*}$ depends on the specifics of the recognition regime. It will be the lower, the more exact (little risk of recognition loss by unintentional events) and the less strict (e.g., no loss of recognition even slightly below $q_{s}$ ) the regime is. In any event, as long as there is a notable quality difference between $q_{1}$ and $q_{s}$, one will see a quality deterioration in the credit rating market compared to the reputational capital scenario. Again, all agencies will settle for a similar quality level. First, the optimal level according to (4.7) is equal for every agency. Secondly, if one considers interdependencies of the risk costs $r_{i}$ between different agencies in a game theory framework, no recognized agency would want to have the lowest reputation in a quality region where state recognition is not guaranteed. It is safest for the individual agency if all agencies operate on the same quality level, as the state would not withdraw recognition from all at once.

The main result of the analysis is simple: the rating quality of recognized agencies will be lower if demand is driven purely by the license value compared to the regular scenario where informational quality is decisive. The reputation mechanism does not provide for a high quality (Partnoy 1999, pp. 655-56). In fact it no longer plays a role at all for market participants. The demand for information/reputation provision by ratings is not sufficient to provide for the existence of a market. In this respect, the 'failure' of the reputation mechanism is no problem for private market participants, as there is not sufficient informational asymmetry to justify the information costs induced by it. For private market participants ratings are merely an instrument to free themselves from restrictions. However, the failure of the reputation mechanism is certainly relevant for the regulator. The goal of rating-based regulation is to increase the informational quality in the market and thereby to reduce systematic risk. Whereas private actors have better tools - e.g., ratings from smaller non-recognized agencies - for their own risk management, the state relies on a mediocre tool. Hence, regulation is not as effective as possible - it might even have a negative influence on markets through inaccurate governance. In addition, the state creates an anticompetitive environment through official recognition, which is a concern voiced by Partnoy (Partnoy 1999, p. 655). A small group of companies is granted market power and high profits. 


\subsubsection{Discussion - Which Scenario is Right?}

The impact of the above scenario on the reputation mechanism and therefore on the whole credit rating industry is substantial. But the question remains as to how important these thoughts are in reality. Is the license value the major demand driver? In a world of many sophisticated institutional investors with their own in-house research, this might be true. Credit risk information is generated by internal research, while credit ratings are only a burden limiting their flexibility. Anecdotal evidence from one survey (TBMA 2006, p. 4) conflicts with this consideration, as over $80 \%$ of surveyed institutional investors indicate that ratings are relevant in their internal risk management efforts. Jewell and Livingston (1999 and 2000) show that third and fourth ratings of NRSROs are valued by the market even in the non-investment grade area where no regulatory benefits accrue. Hill (2004, p. 65-72) actively disputes the regulatory license view. If reputation did not matter, all issuers would buy the cheapest available ratings from Fitch or one of the smaller recognized agencies. The major price differences between the NRSROs cannot be explained by Partnoy's view. As certain regulations only require a single rating, at least some issuers should have an incentive not to buy two, which is the norm for big debt securities.

If Partnoy is right, Moody's and S\&P should not be able to sell ratings to issuers in jurisdictions without rating-based regulation. A finding from the $E U$, where rating-based regulation has been traditionally less important than in the USA, is that Moody's and S\&P are nonetheless the dominant players (CESR 2005, § 246). This suggests a general competitive advantage of the market leaders' unrelated to rating-based regulation. However, the small absolute size of the European rating market can be interpreted in support of Partnoy, i.e. even the leading agencies have no chance to gain a strong hold in the market. There is a similar anecdotal finding for Middle Eastern banks, many of which refinance themselves domestically (Poon and Firth 2005, p. 1746). Although there are certainly at least some informational asymmetries involved, such banks seldom choose to become rated.

Indications of the importance of rating-based regulation might be derived from reactions of rating agencies' stock prices to important changes in the regulatory framework. The Credit Rating Agency Reform Act in the USA, which was introduced and discussed in mid to late 2005 , is such an event (U.S. House $2005 a$ and 2005 b). Since it permits many additional rating agencies to quickly receive official recognition, it clearly weakens Moody's and S\&P's position from the perspective of rating-based regulation. However, Moody's stock price outperformed the market and appreciated significantly in mid/late 2005 and early 2006. A detailed analysis of Moody's falling stock price in mid/late 2006 when the Act was finally passed might provide more insights into this question.

One problematic point in this analysis is the fact that ratings and especially rating downgrades become information by themselves under rating-based regulation (Hill 2004, p. 69). This is a reason why market participants pay attention to recognized ratings even if they contain no other information. Available empirical studies do not actively differentiate between a self-induced and a 'real' information value. The information value attested to ratings today might purely reflect the regulatory status. Another point in favor of Partnoy's argumentation is the standardization of investment processes. Private market participants might stick to their 
grown investment processes geared towards Moody's and S\&P ratings, even if the information value has deteriorated over time.

Such a transaction costs argument, on the other hand, is inconsistent with the use of ratings in non standardized private contracts. If there are better measures of credit risk, they might be preferable, for instance, to classic rating triggers. In sum, the pure regulatory license view is clearly too drastic. Given the evidence cited, the information and reputation value plays an important if not decisive role in the valuation of ratings. Regulators relying on rating-based regulations should nonetheless watch the issue closely. There is clearly a sizable regulatory value attached to ratings today and conditions might shift over time with a gradually falling quality $q_{1}$. For researchers, too, the area is one of the most promising fields for future empirical research.

Regulators should also care for a different reason. Even if the regulatory value is not decisive, it might easily run above $p_{s}$. This means that the benefits of the license alone justify rating costs. While 'normal' issuers still buy high quality because of the added benefits of reputation, the group of issuers interested in sham ratings will opt for the cheapest ratings. Although outright sham ratings are not possible, it might still be a benefit for certain issuers to buy ratings which are not of the highest quality.

\subsubsection{Network Effects}

The demand for ratings is also influenced by direct network effects or, in general terms, demand side economies of scale ${ }^{41}$. Credit ratings do not focus on specifying a certain absolute risk of default but provide investors with a comparative risk evaluation. Thus, risky financial instruments from diverse areas such as structured finance products or sovereign debt can be compared, whereas the absolute risk of the rating categories changes over time (e.g., BIS $2000,126-127)$. The leading agencies actively seek to minimize differences in default probabilities of similar ratings between different segments of the credit rating market (Ammer and Packer 2000, pp. 11-12). This is why an important aspect of a rating's information value can only be derived in the context of other ratings. All of these ratings must be based on the same methodology and displayed on an identical scale. Only if each rating category includes securities of identical credit risk does a comparison makes sense. In a 1998 survey, 90 percent of institutional investors cite 'rating consistency' as the most important factor for determining their impression of rating accuracy (Baker and Mansi 2002, p. 1387).

The utility of every single investor rises with each additional rating. From a technical point of view, the market features direct positive external economies in consumption. Given that there are $n$ ratings, investors can make $n \cdot(n-1)$ direct comparisons. If an additional issuer decides to buy a rating, $(n+1) \cdot n$ direct comparisons are possible. Thus a single new rating creates $2 n$ new feasibilities (Economides 1996, p. 679). As the information value of every possible comparison is zero or larger, investors do always profit from an increase in the absolute number of ratings. The stronger this network effect is, the higher will be the demand

41 Network effects are often explicitly considered by firms in their strategy and can therefore also be described as a supply side factor. However, network effects are no factor in the production function. They only realize with the decision of issuers to buy ratings. Therefore they are considered as demand side effect. 
for an agency's ratings. Thus, network effects provide for important demand side economies of scale. Because investors prefer ratings from larger agencies, issuers are most likely to buy from the leading agencies. Network effects can be a driver of industry concentration.

The three major rating agencies Moody's, S\&P, and Fitch all feature very similar rating symbols and scales (e.g., Johnson 2004, p. 27). The economic reason behind this striking similarity is simple. If investors recognize two agencies' ratings as being based on compatible scales and methodologies, they can compare the ratings of both companies. The network size rises and therefore the investors' valuation of the ratings increases. Network markets tend to standardize. In the credit rating market the standard was set by the original incumbents who have used the same rating symbols since the inception of the industry early in the 20th century. The rating scales were expanded over time, but not substantially altered.

Given the possibility of compatibility and standardization, the argument of network effects as a driver of high concentration weakens. If every agency can effectively join the network of existing ratings by using standardized methods and scales, there is no advantage in featuring a large rating base by itself. Further, if a small agency joins a large rating network, its customers profit much more than the users of the existing network from the increased overall size. Thus, compatibility is a strategy which especially benefits small agencies such as industry newcomers.

However, there are two important obstacles to compatibility and standardization for newcomers. First, it is questionable if newcomers can offer exactly the same quality as the incumbents. This is decisive for comparing ratings. It is also questionable if investors will immediately accept a newcomer's ratings as fully compatible, even if the informational quality is proven to be high after the first period in the market. Such a performance extends the time needed to fully catch up with the incumbents in terms of reputation. Second, newcomers will have difficulties in generating demand for non-innovative ratings. In order to ensure compatibility, rating scales and rating methods must be similar. Under these conditions a newcomer's ratings would offer no more value than the ratings of incumbents. On the contrary, because of the short track record the value is likely to be lower. Hence, the demand will concentrate on the established agencies. In a nutshell, newcomers face a tradeoff between compatibility and innovation while full compatibility is hard to achieve anyway.

\subsubsection{Two-Rating Norm}

In the market for big international debt securities a 'two-rating norm' has developed over time, i.e. a majority of big bond issues is simultaneously rated by Moody's and S\&P (Hill 2004 , p. 61). The two-rating norm is a major factor determining demand and can be attributed to several factors. Two questions must be asked: Why do issuers buy two ratings, and why are these invariably the ratings of Moody's and S\&P?

The simplest reason for investors to want more than one rating is additional information. If two ratings convey more information than one, investors prefer debt securities featuring two ratings, just as they use many research opinions in equity investment decisions. Empirically, studies have indeed documented an additional information value of a second rating (e.g., Hsueh and Kidwell 1998, p. 52). While the additional value is not necessarily very high, in- 
vestors still prefer it because they do not directly carry the rating costs. As their perceived risk is lower when investing in a bond with two ratings, they are willing to accept a lower interest rate. If issuers expect the decrease in interest rates to be sufficient, they will incur the costs for a second rating only for the reason of increased information. Overall, the increased information value is unlikely to be the only reason for buying two ratings because the bulk of information comes from the first rating. It is no surprise that most other factors leading to the two-rating norm build on the certification dimension rather than the information function of ratings.

One of the most obvious arguments for the two-rating norm is rating-based regulation. Certain rules require at least two ratings (e.g., Partnoy 1999, pp. 692-706). Mutual funds, e.g., may only purchase commercial paper with at least two (good) NRSRO ratings. Issuers in turn need to buy two ratings in order to reach their core investors. Given the large number of rating-based regulations, it is plausible that practically all issues benefit to a certain extent from a second rating, even if the phenomenon itself cannot be fully explained. Rating-based regulation also provides a partial answer to the second question of why it is invariably the ratings of Moody's and S\&P: investors often have the regulators' obligation to use ratings consistently. Banks using external credit ratings for risk assessments, for instance, are required by $\S 94$ of the Basle II framework to use the same agencies' ratings for each kind of claim without 'cherry-picking' (BIS 2004, p. 24). They will hence try to concentrate on a few agencies with broad coverage. For big international issues, Moody's and S\&P are the two apparent players.

A more subtle argument is the signaling or reputation value of a second rating (Hill 2004, p. 63). Some issuers tended to use a second rating only to expose themselves to double scrutiny. Even if the actual additional information for investors is limited, an issuer shows that there is nothing to hide. A second identical rating, e.g., can dispel an investor's fear of exertion of influence on the rating agency, which is far more difficult to duplicate. Once a critical mass of issues had been rated with two ratings - for whatever reason - investors began to demand double scrutiny from all issuers. As many are willing to expose themselves to double scrutiny, issuers with only a single rating might arouse the market's suspicion for their deviating behavior. The two-rating norm is in this respect self-enforcing. Issuers must either comply or explain. But explaining why they are not willing to expose themselves to double scrutiny is difficult. The argument of lower costs hardly stands against any suspicion of wrongdoings. In doubt, investors will only look at issues with two ratings.

Hill (2004, p. 60-62) discusses further reasons for the two-rating norm, explaining especially its endurance once established. Many investors have investment guidelines and practices tailored to bonds rated by both Moody's and S\&P. Investment managers do not have an incentive to deviate from the standard in day-to-day business, as it would mean extra effort for them. They are locked in to doing business the way it has been traditionally done; transaction costs are lowest by sticking to bonds rated by Moody's and S\&P. Such investment guidelines can explain both questions (why two ratings and why those from Moody's and S\&P). In many cases the guidelines are in fact strict rules, i.e. deviating from the two-rating norm can com- 
pletely lock out issuers from a significant number of investors ${ }^{42}$. Internal investment rules are another argument explaining why the two market leaders are chosen. Ratings from Moody's and S\&P are commonly accepted as an important measure in an investor's due diligence process. In the event of litigation they can point to their precautionary use of ratings. Another argument is the use of Moody's and S\&P ratings in investment benchmarks. Many quantitatively oriented investors emulate their benchmark index, which means buying debt securities rated by the two agencies.

Further factors discussed above contribute to the two-rating norm. Ratings by Moody's and S\&P are regarded as equivalent and therefore compatible in the sense of network effects. Investors have a low preference for 'incompatible' ratings, which might be based on different standards. It is natural for issuers to pick the two leading and comparable agencies. Moody's and S\&P also feature the highest absolute reputation in the market. Since investors prefer ratings of the most reputable agencies, issuers stick to the top players in the market. A survey of 205 institutional investors supports these findings: Moody's and S\&P are perceived as equal in terms of quality and they are significantly ahead in market reputation compared to all other agencies. Investors and issuers alike clearly see Moody's and S\&P as the top two agencies (Ellis 1998, p. 41). Figure 4.5 summarizes the reasons for the two-rating norm:

\section{Why two ratings?}

\section{Why Moody's and S\&P?}

- Additional information

- Rating-based regulations requiring two ratings

- 'Double scrutiny' as standard

- Investment guidelines

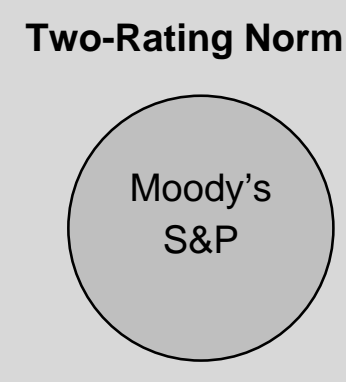

- Highest reputation

- Investment benchmark

- Accepted as due diligence

- Compatible rating methods

- Investment guidelines

Figure 4.5: Two-rating norm

In many respects the two-rating norm is a culmination of the different demand drivers. On the one hand, it guarantees Moody's and S\&P a comfortable business, as everybody buys their ratings. On the other hand, it provides protection from smaller agencies since it is inherently difficult for them to break into the main business. When additional agencies are used it is usually as tie-breakers in the event of a split rating from the two market leaders (e.g., Jewell and Livingston 1999, p. 1). In general, however, Jewell and Livingston see a 'trend' towards third ratings, although the reasons to buy additional ratings are not clear (p. 4-5). Cantor and Packer (1996), e.g., find a significantly higher rate of third ratings only for big issues for which they are relatively cheap. 'Rating shopping', i.e. the hope of getting better additional ratings to comply with regulations where only the best rating counts, seems to play no role. Whatever the reasons for additional ratings are, a broad trend could ease the restraints on competi-

42 In a study published in 1998, e.g., among the 205 institutional investors questioned 23 percent have internal guidelines strictly demanding 2 ratings. 80 percent of these investors say the ratings must be from Moody's and S\&P (Ellis 1998, p. 39-40). In a broader study of 387 US mutual funds, 43 percent of respondents strictly demand two ratings (Baker and et al. 2002, p. 1377-1378). 
tion set by the two-rating norm. In the 'worst case', a new three-rating norm with Fitch as the third agency would develop. In a more competitive scenario, various smaller agencies might establish reputations for reliable third ratings and eventually make inroads into Moody's and S\&P's primary ratings business.

\subsection{Supply in the Credit Rating Industry}

Thus far the market environment for credit rating agencies has been analyzed with a focus on the reputation mechanism and the drivers of demand. To acquire the complete picture one needs to look more closely at the economics on the supply side (e.g., Dodd and Setty 2003 , p. 7). Which factors determine the organizational structure of rating agencies and of the industry structure as a whole? Is it purely the frictions in the reputation mechanism and the concentration of demand on the high quality level, or are there other variables to be considered? At the center of these questions lies the high industry concentration. The focus is on special industry features that might naturally lead to a high concentration, even if the entry barriers discussed above and demand side effects are absent.

\subsubsection{First Mover Advantage}

Being first to market is an advantage in the credit rating industry; and all the more so in the early days of the industry when the agencies and their rating quality were not generally known. Today it still plays a role in innovative new market segments. The mechanism will be explored via a model from Schmalensee (1982).

A new and innovative credit rating market segment is considered. Two identical rating agencies subsequently enter the market in periods $t=0$ and $t=1$. As simplifying assumption the first agency does not react once the second agency enters ${ }^{43}$. Both offer the same high quality $q_{1}$. The issuers, however, are not able to ascertain the quality ex ante, for ratings are an experience good. Both rating agencies therefore need to offer each new issuer an initial discount in order to compensate his risk as to the true quality. In $t=0$ the first agency ('the innovator') only faces uninformed issuers as no one has yet had the chance to acquire experience with the innovator. In $t=1$ the innovator faces two groups of issuers. Issuers who have already bought ratings in $t=0$ are now informed about the true quality $q_{1}$ whereas everybody else is still uninformed. Also in $t=1$ the second rating agency ('the follower') enters the market. The true quality of the follower is unknown to all issuers. In $t=2$ and all later periods both rating agencies face two groups of issuers, one informed and the other one uninformed about their quality.

Figure 4.6 shows the price-consumption curve the innovator faces. Since his true rating quality is unknown, he needs to grant a risk-premium as a discount. For uninformed issuers the demand curve $E G$ applies. At an introduction price of $O H$ the innovator can sell $O C$ ratings in $t=0$. In $t=1$ the primal clients are aware of the high quality and no longer demand a risk premium - for them the demand curve DA applies. The quantity OC can now be sold at a

43 This is unproblematic for the model results, as such a behavior is to the advantage of the second agency. The second agency will nevertheless have a competitive disadvantage. 
price of OF. Additional issuers, however, still need to be persuaded of the high quality through a price discount, i.e. the demand curve $B G$ applies. The complete price-consumption curve for the innovator from $t=1$ on is $D A B G$.

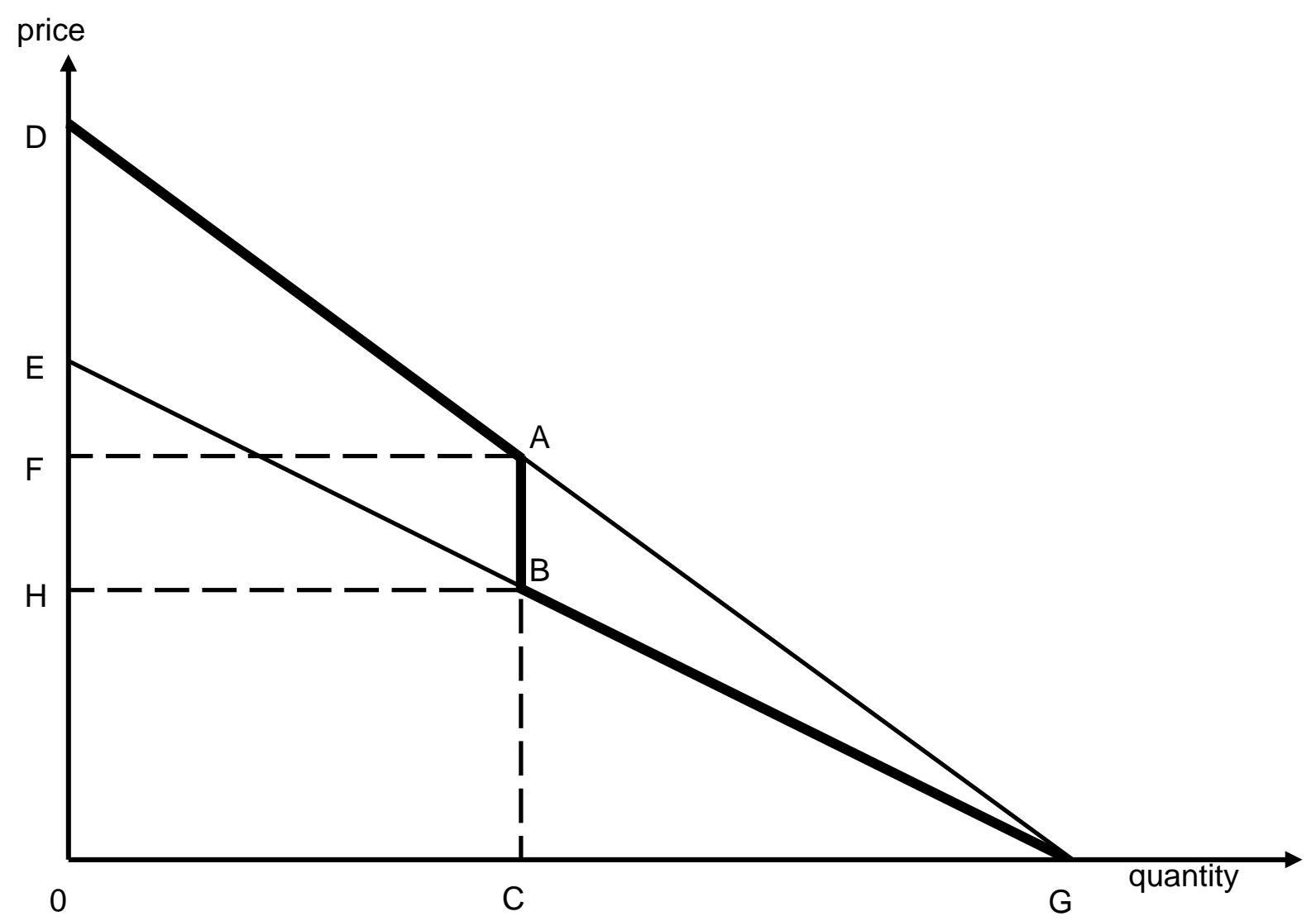

Figure 4.6: Price-consumption curve of the innovator (according to Schmalensee 1982, p. 343)

In $t=1$ the follower enters the market with an identical rating service of quality $q_{1}$. However, none of the issuers is aware of the high quality. As assumed above, the innovator does not react to the entry. The follower faces two groups of issuers. One group - with a generally high willingness to pay - is aware of the innovator's but not of the follower's high quality. The second group is aware of neither agency's quality. Consequently, the demand curve of the uninformed group is $B G$, the same as for the innovator. The innovators clients, in contrast, will only switch to the follower if they are compensated for the substitution risk of changing brands. For the marginal issuer the follower must offer a price of $\mathrm{OH}$ to make him switch. The discount $A B$ equals the opportunity cost of the marginal issuer to switch to an agency of unknown quality which must be subtracted from the innovator's price $O F$. In general, the opportunity cost of switching is the difference between DA and EB. The follower must underbid the innovator's fixed price $O F$ by this amount to make issuers switch. The issuers who were most likely in $t=0$ to buy a rating from the innovator are now least likely to switch because they have the highest opportunity costs.

Figure 4.7 illustrates the situation of the follower, given a price of $O F$ of the innovator. The curve $A B K$ indirectly illustrates how many of the issuers (which are already informed about the innovators quality) would change to the follower. $K B$ can be interpreted as follows: a cus- 
tomer will only switch if the price of the follower compensates for his individual opportunity cost. At a price of $\mathrm{OH}$ only the marginal issuer switches. At a price of $O M, C N$ issuers will begin to switch. The switching cost of the marginal issuer at this price is $V U$ or respectively $Q L$ representing the price discount the follower needs to offer. At a price of $O K$ all issuers $C O$ would switch, as even the highest opportunity cost of $D E$ is covered by the discount $F K$. At any price below $\mathrm{OH}$ the follower will also attract issuers unaware of the innovators' quality; the demand curve $B G$ applies. At $O M$, e.g., the follower will not only attract $C N$ issuers from the innovator, but also other $C P$ issuers will buy their first time rating from the follower. Both effects are combined in the HZG curve, which is the price-consumption curve of the follower in $t=1$.

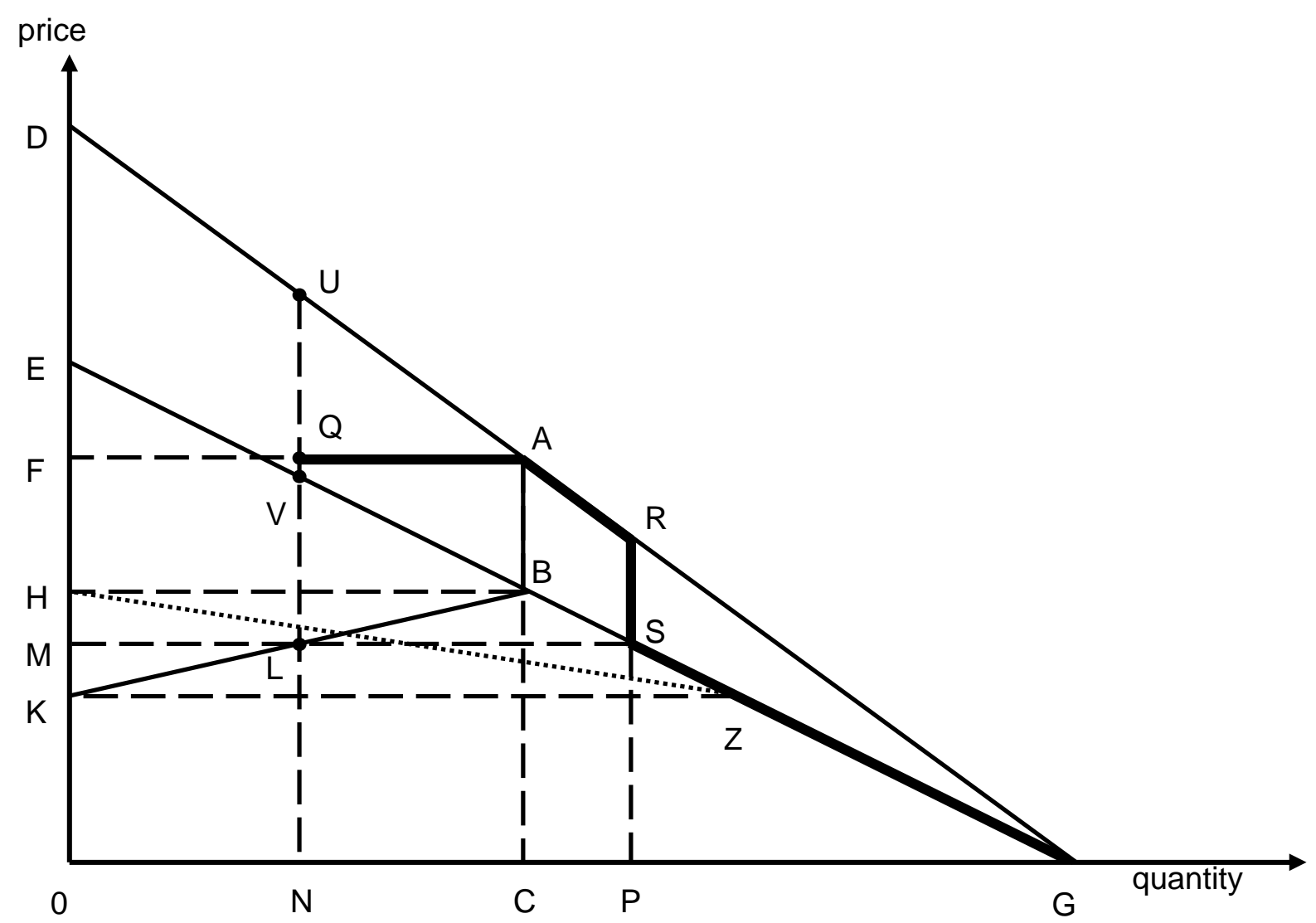

Figure 4.7: Price-consumption curve of the follower (according to Wendorf 1994, p. 101)

How does the situation look in $t \geq 2$ with prices in $t=1$ of $O F$ for the innovator and $O M$ for the follower? The follower has attracted $\mathrm{CN}$ issuers away from the innovator. After assuring themselves of the commensurately high quality, these issuers are now willing to pay a price up to $O F$. A higher price is not possible, as all issuers would change to the then cheaper innovator offering his ratings per assumption always at $O F$. The first time buyers of ratings $C P$ are now also aware of the higher quality, and their willingness to pay rises from $B S$ to $A R$. Consequently, the price-consumption curve of the follower is QARSG; the partition QAR refers to the informed and the partition SG refers to the uninformed issuers. Note that at prices between $O K$ and $O M$ further issuers will switch from the innovator to the follower according to 
curve $K L$. For graphical clarity, this aspect is not included in the price-consumption curve QARSG ${ }^{44}$.

This short graphical analysis indicates that a lack of knowledge on rating quality leads to different results in the entry periods of the innovating and the following rating agency ${ }^{45}$. Both agencies have to overcome the same informational asymmetry - there is no difference here. The crucial point is that the issuers buying from the innovator face higher opportunity costs in $t=1$ than in $t=0$. Graphically spoken, the innovator has the competitive advantage to deduct the risk premium from the demand curve of aware clients $D G$. The follower has the competitive disadvantage that he must deduct the risk premium from the market price of the innovator. The innovator can gain $\mathrm{OC}$ clients with a price of $\mathrm{OH}$, while the follower must offer a price of $O K$ to acquire the same amount of clients. $K H$ is therefore a measure of the competitive advantage of the innovating rating agency against the following rating agency. The innovator is more efficient in overcoming the informational asymmetry. In the Shapiro framework the higher investments of the follower translate into a higher equilibrium price compared to the innovator - a competitive disadvantage for the follower.

The first mover advantage plays a significant role in today's credit rating markets. Moody's and S\&P enjoy a market wide reputation for high quality. An unknown newcomer must provide good reasons to make issuers leave their traditional agency. Because informational quality cannot be proven, price is the main variable to compete on. If one considers these results in the reputation framework, one can see that entry becomes more difficult for newcomers. They not only need to provide the discount $c_{i}-p_{e}$ to overcome the informational asymmetry, they also need to compensate for the additional risk in leaving a proven high quality rating agency. The first mover advantage acts as a classic entry barrier to the rating market, as described in Figure 3.6. The sum of all additional risk compensations is $\gamma$; the investment to enter the market increases to $c_{i}-p_{e}+\gamma$. With a strategy comparable to reputable incumbents, newcomers have to incur costs which the original players never had to pay for, i.e. they cannot follow the incumbents' development path. Empirical evidence from the bank credit market, e.g., suggests that more than a quarter of a customer's added value for a bank is derived from opportunity costs of switching to an unknown competitor (Kim et al. 2003 , p. 25). Of course, the informational asymmetries between banking and credit rating are very different. The example shows, however, which magnitude a first mover advantage can achieve.

\subsubsection{Lock-In Effects}

The first mover advantage is based on the opportunity cost when switching from a known to an unknown credit rating agency. After the entry period all informational asymmetries are overcome. Issuers who have contracted with both agencies can freely change between the two based on the cheapest price. This means that the competitive disadvantage of newcomers is confined to a single period. From a broader perspective, however, similar effects are always present. Issuers are in some cases locked-in to their rating agency permanently, not-

\footnotetext{
44 This aspect is included in Wendorf (1994, p. 101).

45 For a similar mathematical analysis see Schmalensee (1982).
} 
ably in connection with the reputation value of ratings. Lock-in describes "the cost of switching to a different service" (Shy 2001, p. 4) ${ }^{46}$. The term originates from the discussion on technology adoption and is used as an explanation for cases where an inferior technology establishes itself in the market. Here, lock-in simply describes the case in which an issuer has a disadvantage when changing to a different established rating agency, independent of its knowledge on the other agency's quality. Lock-in can therefore be seen as a dilation of the first-mover advantage.

Looking at two rating agencies of the same size with similar reputation for equally high quality, there is prima facie no difference in the objective value of the ratings from each agency. However, from the issuers' point of view there is a difference, because a part of a rating's value is derived from the general reputation of the issuing agency. With a rating, an issuer devotes himself to the high professional standards of the agency, which are generally accepted in the market. The lock-in happens at this point. Investors will ask why an issuer switches away from a highly reputable agency known for its analysis. An equally reputable agency would bring in the same level of analysis and would therefore not offer a better service. Investors are only able to observe the agencies past quality, but they are not able to observe the specific contacts and relations between the issuers and the agencies. As there is no observable reason for a change they might fear an unobservable reason. One obvious motive for changing agencies is the attempt to receive a better rating, i.e. rating shopping (Cantor and Packer 1996, p. 2). Even if the issuer has purely honest motives, it is impossible to prevent such reasoning by investors. Switching comparable agencies might thus lower the trust in the issuer, likely resulting in increased borrowing costs.

If all players in the market behave entirely rational, the argument above of course fails. Every investor knows that a reputable rating agency would not involve itself in rating shopping, because it would lose its high reputation over time. The fear of fraud is therefore unjustified. However, real markets are not frictionless. The functioning of the reputation mechanism might be marginally impaired. Even if it functions flawlessly, some investors might simply suspect it of not working properly. The critical literature on credit rating agencies is a good indicator that this is actually the case. If an issuer changes its long established agency for no obvious reason, at least some investors will suspect that there is a hidden reason (Hill 2003, p. 1153). Naturally, such suspicion is not to the advantage of the issuer.

Generally, the lock-in is most important at the top-end of the market, especially for Moody's and S\&P. The two agencies are reputable for the highest quality and have no competitors that could exceed them. Any issuer switching away from Moody's or S\&P arouses suspicion of rating shopping, as he can at most receive a service of comparable scrutiny. The effect is strongest towards less proven newcomers. Changing to an agency of lesser reputation (which is derived from informational quality) the suspicion of rating shopping is especially strong. But also a change from Moody's to S\&P and vice versa should be seen as a certain lock-in effect, as already argued above.

46 In case issuers actively consider future switching costs as a variable in their buying decision, it can also be described as a demand side effect. However, lock-in is a variable which can directly be influenced by rating agencies in their production function. It is realized with every single issuer and therefore considered as a supply side effect. 
Going down the quality spectrum to a medium quality agency, the lock-in mechanism is in part canceled. A switch to an equally or less reputable agency will still arouse suspicion. However, if an issuer changes to a rating agency with considerably higher reputation, such a reaction will not take place. In contrast, investors will appreciate the move to a higher quality provider, and the reputation of the issuer will increase accordingly. No one will suspect an issuer of shopping for a better rating when he changes from a relatively little know agency to Moody's or S\&P. Lock-in is therefore only a protection against competition from lower quality rating agencies, but it does not help in competing against more reputable players. Thus, the phenomenon only benefits the largest and oldest, high quality incumbents. Formally, switching costs can be denoted as $w_{i j}$. The index $i$ stands for the reputation of the current agency and the index $j$ for the reputation of the new agency. One can summarize the analysis of $w_{i j}$ as follows:

$$
\begin{array}{ll}
w_{i j}>0 & \text { for } i \geq j \\
w_{i j}=0 & \text { for } i<j
\end{array}
$$

In order to make an issuer switch his rating agency, he must be offered a price that compensates for the switching cost. Contrary to the analysis on the first mover advantage, this is independent of the available information on the different agencies. Even an issuer with a single rating from S\&P or Moody's who has been rated by the other agency in the past, faces switching costs. In general, switching costs establish market power. There are two ways that switching costs can affect competition: rating agencies might lower prices to attract further issuers or they might increase prices to extract additional rents from existing customers (Klemperer 1995, p. 515).

A simple example of two agencies with identical reputation $i=j$, identical prices $p_{i}=p_{j}=p$ and identical switching costs $w_{i j}=w_{j i}=w$ will clarify the matter. To attract issuers from the competitor, both agencies would need to offer a discounted price of $p-w$ to compensate for the switching cost if the other agency's price stays constant. On the other hand, both agencies could raise their price above the equilibrium level of $p$ to $p+w$ given a constant price of the competitor. At such a price level it would of course be more difficult to attract new issuers who as yet have no rating and therefore face no switching costs. In a saturated market segment, on the other hand, this disadvantage is negligible. Hence, switching costs are a good argument to explain the high price level one sees in large saturated market segments, such as in industrial bonds. While prices would need to be reduced by the full amount $w$ to attract issuers from the competitor, prices can be raised incrementally without losing any customers. This is a favorable strategic situation for increasing rather than lowering prices.

There are other factors leading possibly to lock-in which are independent of the relative reputation of agencies. Issuers with many short-term notes who also have outstanding long-term debt might be afraid of receiving a worse service in their remaining long-term ratings if they change their agency. But the argument is difficult, since any 'punishment' would be reflected negatively in rating quality (see section 5.2.1). Transaction costs also play a role for the lockin. Issuers become used to their rating agency and establish process standards to handle the 
relationship optimally. However, these factors should have little impact compared to the reputation-based lock-in and are not unique to the credit rating industry.

\subsubsection{Economies of Scale}

The analysis of demand has shown that issuers favor big, high quality rating agencies. The opposite approach is to ask if big rating agencies are more efficient than small ones. Traditionally, this question has concentrated on production technology. In industries with constantly high concentration the cost structure is often the major driver behind this phenomenon. In extreme cases the cost function takes the form of a natural monopoly. A sufficient condition for natural monopoly is the subadditivity of costs $c$ in the relevant range of market demand (Train 1991, p. 12). A single company must be able to produce the market demand $x$ more cost-efficient than two or more companies: $c(x)<\sum_{i=1}^{n} c\left(x_{i}\right)$ for $n \geq 2$ with $\sum_{i=1}^{n} x_{i}=x$. The output $x$ can be interpreted as the number of ratings provided by the market. Although the economies of scale model builds on identical output units, it does not seem problematic to treat the rating process behind the different ratings as equal. Thus the focus is on the number of ratings produced by a company ${ }^{47}$.

Thus far no fixed costs in the production process of ratings have been assumed ${ }^{48}$. The fundamental credit analysis is heavily based on human capital, exhibiting general analytical skills and industry knowledge (e.g., Moody's 1991 pp. 87-100). In principle, these inputs are not specific to a single firm and can be bought on the market for separate periods. The absence of (major) fixed costs is already atypical for a natural monopoly. Decisive, however, is the impact of the output's size on average cost. The rating process usually involves only few individuals. Indeed many of these individuals are specialized in certain segments, such as countries, industries or financial products, but this does not constitute a major problem for small rating agencies. As long as their ratings remain focused on narrow areas, they have no substantial cost disadvantage over bigger companies.

Economies of scale may arise, on the other hand, from production factors such as access to databases, for instance. Usually, it is on average cheaper if more people within an institution use the same database. However, given the importance of human capital the overall impact on production costs from these factors should be limited,. One can conclude that the production function of credit rating agencies does not exhibit major economies of scale. On the contrary, it seems quite easy for small companies to compete with bigger ones on costs. The production technology features constant returns to scale (Strausz 2005, p. 55). However, size matters in reputation building and risk diversification.

47 Focusing on a single rating as an information product, it is obvious that it does not make sense to produce exactly the same information twice. In the more realistic case of small differences in ratings on the same underlying object, consumer preferences would need to get actively modeled in order to identify the optimal number of agencies rating the same debt issue.

48 The provision of an individual rating does have a fixed cost component which is reflected by the mixed rating price consisting of a base fee and fees depending on issue size. Physically setting up a rating agency, however, bears little fixed costs as described. 


\subsubsection{Reputation Building}

The ideas above cover the informational quality of ratings. One also needs to look at the second part of value derived from ratings, i.e. the reputation value. An unproven newcomer must generate trust among the issuers along the lines of the Shapiro framework. There needs to be an initial investment with later returns on reputation. In principal, a growing reputation requires new investments for every unit of output. Hence, there is no room for economies of scale in reputation building in the equilibrium model. In reality, the picture looks different. While the actual production of ratings does not feature scale economies, the development of reputation certainly does.

The advantages of old, big agencies over young small ones become most apparent in models where quality information explicitly spreads to non-customers (e.g., Fishman and Rob 2002, pp. 1-19). There is still a detection lag $R_{t}=q_{t-1}$, but contrary to Shapiro the information about past quality diffuses gradually in the complete market - reputation building here is a dynamic process. The longer a rating agency is in the market with a high quality, the larger its potential customer base will grow. Thus it can generate higher profits than smaller rivals. This in turn is an incentive for high investments to protect the superior reputation recognized by the issuers. Being long established and big, therefore, becomes a quality signal by itself.

Starting from the familiar Shapiro model similar results have been drawn in developing the ideas on growth within the reputation framework and the transfer of reputation. Once a crucial reputation base is established relative to a specific market segment, new clients can be attracted without further investments in reputation. The high price becomes a quality assuring signal. This idea is the basis for many examinations of brand names and reputation (e.g., Nelson 1970). It has been explained in the reputation framework in section 3.5. Issuers are certain about the agencies abilities to deliver high quality, so they are willing to pay a high price. The price is in fact so high that milking is not attractive for the agencies.

In a frictionless world, issuers would nonetheless expect an initial price discount because they know that a high price means profits for the rating agency even in the first period. Any profits would be dissipated by competition. However, such a phenomenon is not seen in the credit rating industry. Because competition and issuers rationality is limited, the established rating agencies can spread their reputation to new clients without major costs. New issuers pay a quality assuring price based on the experience others have had with the agency. In economic terms the process is very simple. The reputation for a specific market can be depicted as a fixed investment which can be spread to more and more units from a certain point on. There is no direct cost for rating agencies to cast many reputational bonds at the same time (Mann 1999, p. 27). Many authors see a major driver of concentration in this effect (e.g., Dodd and Setty 2003, p. 7).

Strausz (2005) derives similar results in his model of "the threat of capture in certification markets'. Although the certification process itself features constant returns to scale, "honest" (high quality) certification in his model exhibits increasing returns to scale. As reasoned above, Strausz allows (in contrast to Shapiro) for different output-sizes per company. Crucial is the amount of future rents a certifier can generate. The higher these rents are, the lesser is the threat of capture (milking). Thus, a large company can set its price in equilibrium lower 
than a small company - in fact, a monopolistic producer will be the optimal outcome ${ }^{49}$. The model results are based on the assumption that consumers communicate a certifier's reputation among themselves. Any certifier needs to incur the same cost to establish its reputation, but the total amount of future rents depends on firm size. Thus, quite intuitively, the most efficient outcome is to have only one company incurring the costs to establish a reputation.

It seems hardly possible to empirically test the critical reputation base. Rating agencies which are only active in a very specific segment need a comparably small investment in absolute terms. In contrast, big 'full service' rating agencies such as the three market leaders today require much higher investments. Given a fixed market size, the bigger company always has an advantage. This is derived from the idea that all agencies need to incur the same investments to reach the critical reputation base.

Whereas it is obvious that reputation building within a market segment features economies of scale, the analysis of reputation transfer has also shown scale economies in developing reputation in different adjoining market segments. Because of the frictions in the form of cheating costs $h_{i}$ per market $j$, a competitive advantage arises for already proven firms. If equation (3.13) $\sum_{j=1}^{n} r \cdot h_{i j} \geq r \cdot\left(p_{0 r}-c_{0}\right)$ holds, i.e. if the costs of cheating are higher than the value of the reputation transferred, it is possible for a rating agency to transfer its reputation to new rating products. The larger a rating agency is, the more reputation can be transferred. Seminal new rating segments such as structured finance products may be so capacious that only very large agencies can use a transfer strategy.

One can see that the build-up of reputation is heavily based on size not only within existing market segments but also when entering new segments. Larger rating agencies can enter more quickly and on a broader scale than smaller companies or newcomers. This naturally favors the big players in the market. Especially important is the case when an agency can increase its price from $p_{i r}$ to $p_{i}$ over time. In comparison to a competitor unable to use the transfer strategy, the agency in question reaches the same level of reputation with a smaller investment. This advantage is directly based on the agency's size. As above, the result does not hold in a competitive market. A fully rational issuer would expect a one-time price reduction in order to acquire the profits resulting from a price increase from $p_{i r}$ to $p_{i}$. Under real market conditions with limited competition and rationality, however, the result is plausible.

\subsubsection{Diversification}

Reputation is the rating agencies' main asset, which must be carefully protected. Company size helps the rating agencies to dissipate risks to the reputation base. In principal, reputation can be negatively impacted in two ways. On the one hand, correct ratings might be wrongly perceived. Accidental events can lead to unexpected defaults distorting short-term and even long-term correlation statistics. On the other hand, an agency might indeed provide some low quality ratings because of internal quality problems. This could most notably be employees trying to benefit privately from bringing in low effort. While the business strategy aims to de-

49 In his analysis Strausz blinds out the possibility of cheating. Thus a real price competition is possible. 
liver high quality, the implementation is imperfect in some cases. This is harmful for the agency's good reputation.

Models without a perfect ex post measurement of quality (contrary to Shapiro's framework) incorporate the risk that investors wrongly perceive a high quality as $10 w^{50}$. If the incorrect perception is substantial, this might easily endanger the entire reputation base and therefore the business. If it is not substantial the wrong perception might lower the agency's income but not force it out of the market. In the case of risk averse agencies or individual analysts who prefer a stable income, it might be concluded that especially small competitors want to grow or merge in order to diversify risk. Ramakrishnan and Thakor (1984), for instance, support this view in a general model on financial information intermediaries. For a small rating agency with only a low absolute number of ratings even one badly perceived rating might threaten the whole business because the statistical impact of a single rating is significant. The statistical impact of single ratings for large rating agencies is negligible. Further, unusual events are likely to cancel each other out. In other words, the average quality of small agencies might be substantially influenced by chance, whereas the average quality of large companies would remain unaffected by such unsystematic risk. Overall, the risk-costs of a wrong perception of quality fall with agency size, but this effect is declining. At a certain size, further growth will probably have no effects on risk diversification. This is a promising area for empirical research.

The risk diversification effect in the credit rating industry is more pronounced than in other experience good markets because of the special nature of ratings and their quality measurement. From an output oriented position the quality of a single rating is not defined. A debt security either defaults in a given period or it does not, and its rating merely states a probability for this. Even if a top rated issue defaults, one gets no information about whether the scrutinized rating class was right. In other words, default is not a bad thing as a certain number of defaults in every rating class is needed to guarantee a high quality risk classification $^{51}$. Only in the context of other ratings, can quality be measured. If there are ten issues rated $\mathrm{BBB}$ and ten issues rated $\mathrm{BB}$, more issues from the second group should default than from the first. Clearly, a few 'unexpected' defaults, which could not have been foreseen even by the most prudent analysis, would heavily impact the sample of ten ratings. In a sample of say 1,000 ratings, however, chance should have no impact. If correlation studies are flawed, it suggests a bad rating quality. This thought leads to the second factor which might have a negative impact on reputation: sporadic low quality ratings by single rating analysts.

In the presence of perfect internal monitoring (as in the Shapiro model) this is of course not a concern. Moral hazard is effectively prevented as no individual within the rating agency has the chance to privately benefit by investing only low effort but realizing a high average return $^{52}$. The low effort would immediately be detected. Thus, exclusively high quality will be produced. Without internal monitoring, on the other hand, some ratings are inevitably of poor

\footnotetext{
50 This idea was already discussed as part of reputation transfers risks in section 3.3.

51 The difference becomes clear if one takes, e.g., an investment bank underwriting IPOs: The investment bank calculates a capital value and future profits. If the actual values depart from the projected, the quality was low. Further, the projections can be directly compared with those of competing equity analysts. For a rating, this is not possible: If an issue does not default, one cannot say ex post which of several different ratings was best.

52 The possibility of outright fraud is ruled out here.
} 
quality. This has two effects. First, the average quality measured against long-term correlation statistics will suffer, dragging down the reputation premium. Second, a random accumulation of low quality ratings in a certain time period or rating category might lead to notable distortions in correlation studies. If distortions are significant and interpreted by investors as a milking attempt, the whole reputation base is in danger. One can see that agency size helps to diversify this second risk in the same manner as the risk of a wrong quality perception.

A lapsing average quality must be taken care of by internal risk management efforts. The structure of the prevalent rating process suggests a very strong internal monitoring: analysis and rating decisions are separated and split between different persons in committees (e.g., Moody's 1991, p. 88). Also the fact that thus far no major rating agency has ever been brought down over a scandal speaks for the prudence of rating agencies. Although the internal monitoring is strong on an absolute scale, it is certainly not perfect. But even without perfect internal monitoring there are mechanisms to mitigate moral hazard through diversification $^{53}$. It is possible to assign an individual analyst to several different rating teams. If the full effort of every individual is needed to produce high quality, there exists an indirect measure to monitor effort by statistically correlating the outcome of the individual's rating projects with quality. If an analyst can be assigned to enough different projects, it might also be the case that his actual utility is negatively influenced as the benefits of low effort are more than offset by the decrease in compensation (Ramakrishnan and Thakor 1984, pp. 424-25). From these considerations one might conclude that internal monitoring becomes easier/cheaper with agency size. The bigger an agency, the easier it is to assign analysts to several projects. In addition, fixed costs of risk management systems can be offset.

\subsubsection{Diseconomies of Scale}

Whereas it is obvious to point to economies of scale in the credit rating market, there are also diseconomies of scale. At the heart of this argumentation lies the possibility of serious criminal negligence or fraud. The best illustration is the failure of the auditor Arthur Andersen in 2001 over an accounting scandal at the energy company Enron (e.g., US Senate 2002, pp. 24-29). As Enron's accountant, Arthur Andersen was shown to have published a dodgy analysis of the company's financials, in many cases not disclosing the illegal behavior but helping to cover it over. In 2002 Andersen was convicted of criminal charges for the shredding of documents, although this verdict was dropped in 2005 (e.g., Lane 2005). Further, Andersen's independence was questioned by market participants because of its high consulting revenues from Enron. The Enron case was such a major challenge to Andersen's integrity that all major clients and the public abruptly lost faith in the company. Expressed in the reputation framework, the onetime delivery of minimum quality to a single client was enough to destroy the company's entire reputational capital ${ }^{54}$. There was no time for a systematic milking strategy to create extraordinary profits on a broad scale. There are also ex-

53 Under quite general assumptions moral hazard can also be prevented by costly direct internal monitoring creating a positive net result (Diamond 1984, p. 395-402). The diversification argument is not needed under this line of argumentation.

54 One can speak of minimum quality, as the service quality was obviously high enough not to be directly identified as dodgy by market participants. 
amples from the investment banking industry, where cases of fraud by single employees have lead to a severe loss of reputation of the whole company (Podolny 1993, p. 861).

This risk applies to any reputation-based business model, not least to credit rating agencies. A major scandal can prove fatal (Smith and Walter 2002, p. 293). Very importantly, clients may in many cases not differentiate between the reputation in different market segments once an agency is firmly settled in a new field. If a rating agency delivers low quality in one segment, not only clients in this sector but also clients across the board will become wary. The potential loss of reputation through an individual transaction is far greater than the value of the transaction itself (Mann 1999, p. 27). The advantage of large companies using existing reputation to move into new market segments can easily backfire if reputation suffers. Arthur Andersen, for instance, was active not only in auditing big international firms, but also in tax services, in consulting, and in auditing midsized and large firms in many national markets. Except for the consulting activities, which were already formally separated from Arthur Andersen, all these businesses failed in the wake of the Enron scandal, either going out of business or being bought and re-branded by competitors.

It has already been argued that a deliberate milking strategy becomes dangerous if only carried out in a single market segment. Milking one segment can destroy the whole business, as in the Andersen case. However, management has control over such a strategy and will not pursue it if in doubt. If the ex post quality measure is not perfect, management cannot do much about it. But it has been shown that average quality levels out with size, so perceived, unintended deviations from high quality pose no threat to big honorable companies ${ }^{55}$. And moral hazard in the form of substandard effort can be prevented by an agency's internal structure, given a certain company size. Furthermore, substandard effort will most likely not lead to major quality reductions.

Fraud or serious criminal negligence, on the other hand, is a different and more dramatic event which cannot be completely prevented by internal monitoring. Fraudulent employees are usually not guilty of slack, on the contrary, they exert themselves to generate individual gains for themselves or a small group, while at the same time disguising their behavior. Given that the likelihood of fraud leading to the complete loss of reputation is significant and the same for all employees, it is obvious that the overall costs of fraud rises over proportionally with size. Imagine rating agency $A$ has $x$ employees and reputation $y$, agency $B$ has the size $2 x$ and the reputation $2 y$, and both agencies face a possibility of fraud of $f$ per employee each period. The calculative risk cost of $A$ per period is $a=f \cdot x \cdot y$, the calculative risk cost of $B$ is $b=f \cdot 2 x \cdot 2 y=4 a$. Double the size of $A$, rating agency $B$ faces four times the risk costs in the event of fraud or serious criminal negligence.

The high expected costs of fraud or serious criminal negligence, especially for large companies, are based on the assumption that one incident in an arbitrary market leads to the complete loss of reputation in all markets. Empirically the Arthur Andersen/Enron case is proof for

55 Some reputation models with noisy quality signals, i.e. a low quality perception by pure chance, allow in equilibrium for high quality firms leaving involuntarily the market which constitutes a complete loss of all investments in reputation (e.g., Hörner 2002). This result however seems far too strict in the case of real markets. 
that assumption, at least in the accounting business ${ }^{56}$. Credit rating is in many cases similar to accounting, especially because of the criticality of reputation for high quality and integrity. In principal, fraud in one market segment should not systematically impact quality in other segments as the provision of ratings itself is not altered by the criminal negligence of unrelated employees. A reaction such as in the Enron case is therefore irrational from a purely informational quality perspective. However, a rating from a reputable agency also conveys the agency's reputation itself onto the issuer. Being rated by Moody's or S\&P is a quality signal in itself regardless of the actual rating. If this general reputation of a rating agency is damaged through a case of fraud or serious criminal negligence, it is very likely to alienate the issuers. Being rated by a fraudulent agency will link an issuer to all 'negative talk' in the media and the financial community about the fraudulent rating agency. The actual information value of a rating becomes secondary As soon as some issuers decide against the established agency the 'negative talk' will increase. Investors will ask why an issuer is staying with a troubled agency when others have left.

\subsubsection{Market Segmentation}

In the credit rating market, three areas of segmentation are theoretically relevant: quality, geography and product class. Furthermore, the market can be split from the supply side into officially recognized and non-recognized agencies. Figure 4.8 displays the different areas. The subsequent analysis will now look closely at the question of whether a rating agency's practical possibilities to differentiate are as plentiful as indicated.

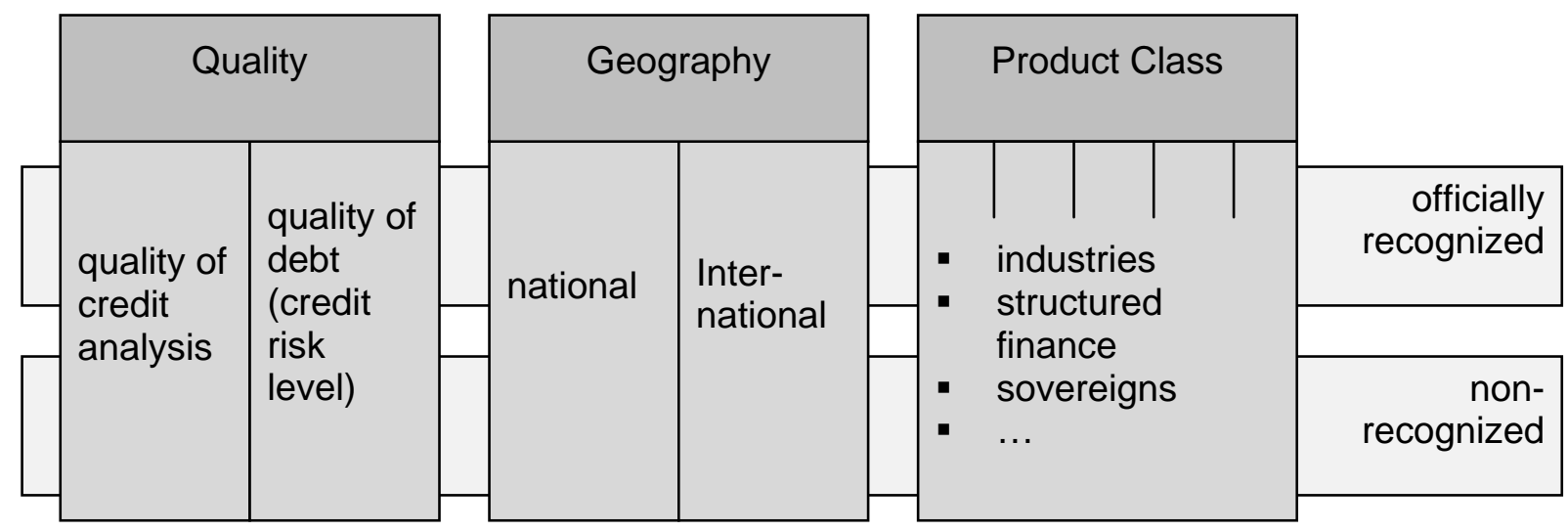

Figure 4.8: Theoretical scope for credit rating market segmentation

Most product and service markets feature distinct quality segments. A single brand or producer is usually only active on one quality level. As a result the number of competitors tends to be higher in markets with many quality segments. In the analysis of demand for credit ratings it has been concluded that issuers concentrate on agencies which offer ratings of high informational quality. From this perspective, there is only one possible quality segment. However, rating agencies not only face a quality choice regarding their analytical process but also regarding the issues they rate. This is inherent to the business model of all intermedia-

56 Like all big accountants at that time Arthur Andersen had seen several accounting scandals (US Senate 2002, p. 27). However, the weight of the Enron case made the public tip. Andersen would probably have failed even without its other 'smaller' scandals. 
ries, which in principal have to choose the quality of their service and the quality of their products or clients. A retailer, e.g., has to choose the range of products he offers and the quality of his sales service.

For credit rating agencies, this translates into the choice of analytical quality and credit risks. Agencies could conceivably focus on low or high credit risks. Such a specialization is obviously not plausible. Ratings are especially valuable as they make the comparison between low and high credit risks possible. Ex ante it is not always clear in which category an issue broadly falls; ex post default risks change and ratings are updated. Therefore, a specialization on certain risks is neither possible nor would it make sense. As unspectacular as this result may be, its implications are important. The argument becomes clear when the credit rating industry is compared with investment banking. Chemmanur and Fulghieri (1994) show in their model that the greater the reputation of an investment bank, the lower the riskiness of the issues it underwrites. They also cite empirical proof (p. 75). In investment banking, the underwriting of an issue is already a signal of its quality. Highly reputable investment banks will only accept highly reputable and secure clients. As a result, there is a distinct hierarchy between a relatively large number of investment banks (Podolny 1993, p. 857). Competition between the different players is limited to within the individual status levels.

The difference between credit rating agencies and investment banks lies in their business models. Investment banks are usually compensated on the basis of the actual offering price of an issue. If they achieve a higher price, they receive higher fees. The investment banks with the highest reputation generate the highest valuations, but also have the greatest risk of endangering their reputation if a valuation turns out to be too high ex post. Therefore, they choose financially sound clients that pose little risk (Chemmanur and Fulghieri 1994, pp. 5760 ). One or more investment banks - presumably all of a high analytical quality - compete in the different risk brackets. In the credit rating industry the strategic situation is different: the proceeds of rating agencies are independent of the actual rating, as they are calculated according to the face value of an issue. Rating agencies gain nothing when assigning a higher rating. Even the most reputable rating agencies can rate bad credit risks, as long as they issue a low rating. As a result, there is only a single segment for all risks within any given market segment, which leaves no room for a hierarchical market structure (Kerwer 2002b, p. 44).

Without the possibility of differentiating in terms of quality, rating agencies lack a key competitive variable available in other industries. While retailing, e.g., offers many possible combinations of quality sold and levels of service/choice of channel, all rating agencies are similar in these two dimensions. For newcomers it is hard to establish themselves in such a situation because it is difficult to differentiate from the incumbents. The same is true for the incumbents themselves, who have little leeway to differentiate from each other.

A classic variable to segment markets is geography. One can often clearly distinguish between local, regional, national and international markets. For credit ratings national and international markets are especially relevant because of potential differences in national financial regulations and standards. However, geographical differentiation faces a fundamental limitation: credit ratings assert their claim on the global comparability of risks. The information a rating conveys is the same everywhere. Laterally reversed, issuers are interested in a 
global reach. They want to have the largest possible basis of investors in order to attain the lowest possible interest rate. In other words, credit rating agencies cater to the needs of a largely global financial market. Once again, there is not much room to distinguish oneself - at least for issuers seeking global attention.

The picture looks different for issuers which are satisfied with placing their issues in certain national markets. These issuers should principally be willing to buy ratings from regional players who have no global reputation. The reach of a debt security is therefore a variable that allows market segmentation. It is possible to concentrate on issues in a certain country. The inherent problem of this competitive strategy is that an expansion is difficult. Because the reputation has a limited geographical reach, neither regional issues aiming at international markets nor international issuers can be attracted. A different national strategy aims to bring credit risk information to a certain group of outside investors. Fitch IBCA, e.g., originally concentrated on providing American investors with information on European bonds (Fight 2001, p. 49).

While the aspirations of the big rating agencies is international, the reality looks a bit different. During the rating process there is substantive personnel interaction between the issuer and the rating agency. In this respect, credit ratings are localized. Issuers require a contact person who is geographically and perhaps also culturally close. To acquire substantial business in a region, even an internationally reputable agency needs a local representation. The numerous national dependencies of Moody's and S\&P show that it is most profitable to be present in all important regions (e.g., Smith and Walter 2002, pp. 301-02). Such a regional presence in principal also opens up the market for regional issues. Even if issuers do not aim for diversified international investors, they do not lose by having an internationally reputable rating. The very way international rating agencies are organized therefore poses a direct competitive threat to national players. They might try to compete on superior regional knowledge based on their regional roots and on better adaptation to local investor needs - a strategy used, e.g., by the Japan Credit Rating Agency Ltd (e.g., Fight 2001, pp. 84-90). However, competing on better analysis is in principal difficult because the international players are obviously highly competitive in this. Otherwise they would risk their international reputation. Lacking the scope for a superior credit analysis, regional niche players will often have the best chance by competing on price and not on quality. Adapting to local investor needs might be the only plausible way of real product differentiation, as global agencies cannot change their worldwide standards. This 'protection', on the other hand, is also a limitation since other regions are more difficult to enter with a rating system specifically designed for a local market.

The third area of possible differentiation is in rated debt securities. An agency can concentrate on certain industries, financial products or areas such as sovereign ratings. The key to the strategy is to build up a reputation for superior credit analysis in a specialized field. Thomson Financial Bankwatch is an example for a successful specialized agency which only rated banks and their debt securities worldwide until it was acquired and absorbed by Fitch in 2000 (Fight 2001, pp. 60-71 and Hill 2004, p. 47). The strategy of concentrating on a certain industry suffers from the same problems as geographical specialization. General purpose rating agencies all work on a similar very high level of fundamental credit analysis. By the very nature of demand they must be as good as anybody else in the market. Therefore, spe- 
cialized players will have a difficult time positioning themselves in terms of superior credit analysis. Further, general purpose agencies always have the advantage of a broader basis of ratings for comparison of debt products.

A fourth area of market segmentation not found in other industries is official recognition. An agency's ratings are either recognized or not recognized for compliance with rating-based regulations. Unlike quality, geography, and product class, recognition is usually not a strategic variable for firms, since it cannot be influenced directly. Only under registration systems such as in the USA from 2008 onwards, will official recognition be a real choice for rating agencies. As already indicated, recognized agencies have an advantage over unrecognized ones in the form of the license value their ratings carry. Unrecognized agencies therefore have a disadvantage per se. Their virtues, on the other hand, are higher flexibility and less market impact. Moody's, S\&P, and Fitch, e.g., are suspected of not having downgraded Enron in 2001, in part because of the devastating consequences a downgrade would have had through rating triggers and the impact of rating-based regulations (Hill 2004, pp. 69-71). Smaller agencies do not have to consider such outcomes and can focus entirely on providing the best possible credit analysis. Off Wall Street Consulting Group, e.g., correctly classified Enron as bad debt six months before the NRSRO agencies did (US Senate 2002, p. 119).

Compared to most other industries the possibility for differentiation by means of market segmentation is limited. There is only demand for the highest analytical quality from agencies which rate all levels of credit risk and the market is in principal global. In sum, it is often correct to speak of a single market for credit ratings which is only divided by official recognition. It is difficult to use special regional or industry knowledge for differentiation since successful general purpose rating agencies must also possess the respective skills. Nonetheless, a niche strategy seems to be the most promising for entrants. The large majority of smaller rating agencies focuses on a certain country and/or industry (BIS 2000, pp. 21-22). The market leaders, too, vary in strength in some segments, a fact that often results from first mover advantages. Moody's, e.g., is traditionally stronger in Asia compared to S\&P, which leads in Latin America (e.g., BIS 2000, pp. 2, 33).

\subsection{Strategic Interaction}

Following the analysis of the reputation mechanism against actual industry background it has become clear that reputation equilibrium is primarily a theoretical construct which helps to understand the operation of the credit rating market. The result of a distinct price, a distinct output and a distinct number of competitors is not borne out in reality. There is no large number of equal rating agencies producing the same quality and quantity (which was set at 1 in Shapiro's model), rather, the market is highly concentrated. The historical shift in quality demanded and other frictions such as the general presence of cheating costs or lock-in create a range of possible market prices. In addition, the market for credit ratings is cornered by several demand and supply side factors that lead to a high concentration. Figure 4.9 provides an overview of the major elements that have been scrutinized in the course of chapters 3 and 4 : 

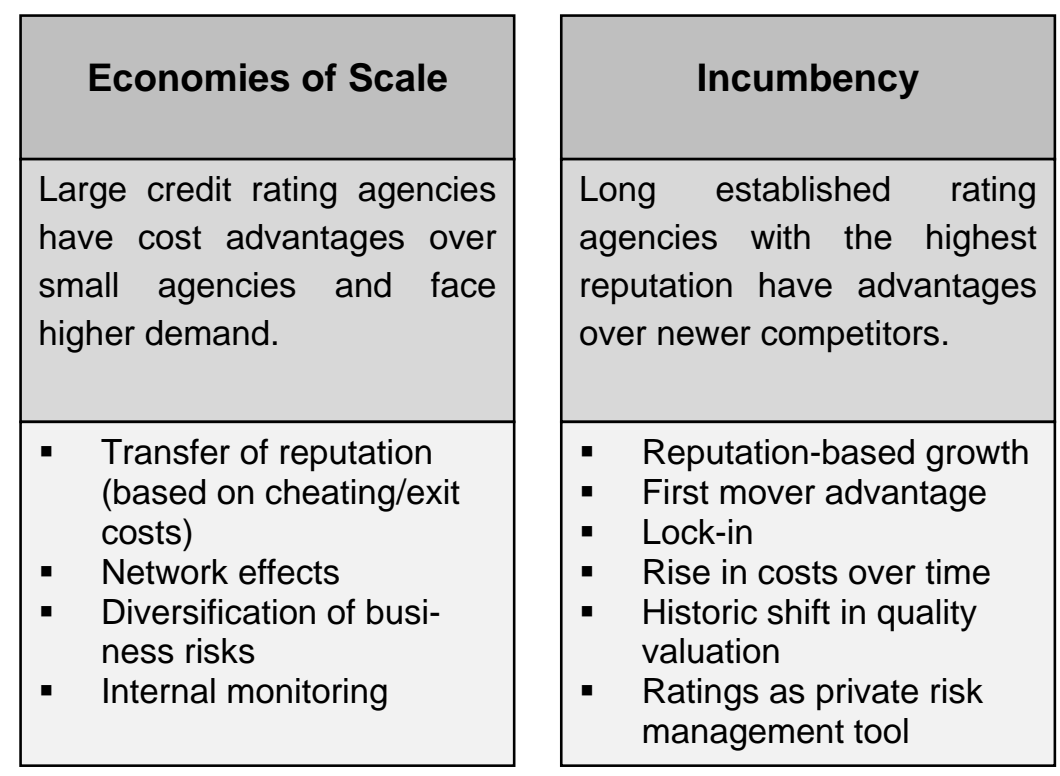

\section{Other Limitations of Competition}

Factors such as official recognition and the structure of demand limit the strategic options of rating agencies.

- Official recognition/ratingbased regulation

- Two-rating norm

- Few market segments

- No quality differentiation possible

Figure 4.9: Major elements influencing credit rating agency competition

Incumbent agencies have first mover advantages, while new players face entry barriers. Big agencies have an advantage over small ones in reputation building and risk costs, and investors generally prefer the market leaders. These underlying economic factors apply everywhere, be it in national markets or specialized branches. Therefore, it is not surprising that virtually all segments of the credit rating market have a high concentration with only a few sizable players (BIS 2000, pp. 21-32). Moody's, S\&P and to a certain extent Fitch dominate the market for big international debt securities.

In economic terms, the analyzed structural factors provide for a duopoly or close oligopoly situation. The actual price and quality in the credit rating market is not determined by the rules of perfect competition but by strategic interaction between the agencies ${ }^{57}$. Therefore, one needs to analyze how exactly rating agencies interact. The focus now will be a theoretical analysis of the strategic incentives resulting from the industry structure. Several ideas already discussed will be linked here. Details of the agencies' business models - although a very interesting field of research - will be largely overlooked. Instead, the results of standard industrial economics will be applied. Two key areas will be analyzed. On the one hand, one needs to ask what happens between the incumbents. Will competition ever succeed in driving down prices? On the other hand, the question of entrants is important. If newcomers do succeed in entering the market, how can they best compete against incumbents and how will the incumbents themselves react?

\subsubsection{Incumbent Rating Agencies}

Incumbents can set their price between an upper boundary $\hat{p}_{i}$ influenced by factors such as lock-in and a lower boundary $p_{i}^{h}$ determined by costs for hiding a cheating strategy. The equilibrium price $p_{i}$ of the basic model is just one possibility within this price range. As dis-

57 Strategic interaction describes situations where one market participant explicitly considers the actions of other market participants (e.g., Samuelson and Nordhaus 1998, p.172). 
cussed in section 3.6, issuers would expect cheating at prices below $p_{i}^{h}$ and not buy ratings ${ }^{58}$. Above $\hat{p}_{i}$ new rating agencies are likely to enter.

The price for a given rating can fluctuate within the defined range. An agency has to consider the immediate effect on quantity sold and its competitors' reactions. The issue has been analyzed in section 4.1. Because the direct price elasticity of demand is low in the credit rating market, lower prices barely increase the absolute size of the market. All issuers interested in ratings have a similar valuation, because it is derived from their use in an anonymous financial market. If one issuer buys a rating at the market price, most other issuers are willing to pay the same. The market penetration of established credit rating products is therefore by definition high. This picture is supported by empirical evidence: S\&P, e.g., rated 99.2 percent of publicly traded debt in the USA in 2003 (U.S. House 2003, p. 219). Even if prices were to generally fall, only comparably few new ratings could be sold, for most issues are already rated.

In non-growing segments of the rating market additional business can only come from issuers changing their rating agency, i.e. from increasing market share on the competitors' cost. As ratings of low or mid-range quality are bad substitutes for high quality ratings, high quality incumbents will act irrespective of other quality segments - the cross-price elasticity of demand will be low. Empirically, studies find the two leading firms acting on the same quality level, while Fitch, too, is only marginally different when corrected for selection bias (e.g., Jewell and Livingston 1999, p. 42). Therefore, price competition among incumbent agencies is in principal possible. Specifically, the prospects of price competition are nonetheless bad: lock-in effects may prevent many issuers from changing agencies even in the case of a noticeable price difference. For Moody's and S\&P the strategy is entirely impractical in many segments, because of their high market penetration. Both rate, e.g., nearly all publicly traded US industrial bonds. A share of 100 percent of clients cannot be increased. Only in certain market segments, such as in Asia or South America are there differences in market share that could be exploited (e.g., BIS 2000, p. 2). Fitch or smaller recognized agencies could try to lure away issuers from the two bigger rivals with lower prices. Apart from general lock-in, however, they face the two-rating norm. Strong demand side forces push business towards Moody's and S\&P. Even Fitch, which is widely regarded as a reputable full service agency, is hardly ever used as single rating without parallel ratings from one or both of the market leaders.

Overall it is extremely difficult for incumbents to acquire business through price reduction. Even if Moody's or S\&P could lower the price enough to lure away issuers from their rival in a not fully penetrated segment, they would face direct sanctions: the other agency would also lower its price to prevent an exodus of its customers. The result would generally be lower prices with unchanged market shares. Profits would be lower for both agencies; especially the 'aggressive' agency that lowered prices first would suffer. From a strategic perspective it

58

The only possibility to safely reduce the effective price below the no-milking threshold is through non-price competition. Klein and Leffler (1981), e.g., build their reputation model not on initial investments into reputation but on non-price competition such as advertising and other company specific investments to dissipate profits at high quality-sustaining prices. Rating agencies might also offer free ancillary services which can only be offered by incurring additional costs. 
is virtually impossible for the leading incumbents to profit from reducing prices. On the contrary, increasing prices is a promising option. In the same way that switching costs prevent issuers from changing their agency when prices fall, issuers will not switch when prices rise moderately. If the second agency follows all price increases, profits for both will rise. Prices can be increased as long as there is no other choice for issuers in the high quality sector. Fitch's price and other recognized agencies represent such an outside option. Although Fitch charges much lower fees than Moody's and S\&P, the agency is not able to substantially lure away business from its rivals. This demonstrates just how protected the position of Moody's and $S \& P$ is.

In factual, Moody's and S\&P operate in many segments of the rating market as a duopoly. On closer inspection the duopoly can even be interpreted as a monopoly in that there is no real competition between the two because of the two-rating norm. They both hold nearly 40 percent of the market and maximize their joint and individual profits by setting the highest possible price. Specifically, the upper price barrier $\hat{p}_{i}$ is set by the price where issuers would switch away to Fitch or a new competitor. The economic incentive for Moody's and S\&P is to increase prices to this level ${ }^{59}$.

Standard industrial organization models support the analysis above (e.g., Tirole 1998, pp. 239-43). Companies only engage in price wars if detection lags and cost asymmetries allow for significant short run profits. In the credit rating industry such factors are admittedly not present. Since the industry is concentrated competitors will quickly learn about price moves by other agencies. Furthermore, the big rating agencies are in contact in all market segments. Price reductions in one segment could well trigger broader reactions of competitors. A crucial assumption of the competitive models of strategic interaction is an infinite crosselasticity of demand, i.e. the products are perfect substitutes. For an unrated issuer choosing between one of the market's leading incumbents this is true. But existing clients are locked-in to their agency, which reduces the effectiveness of price incentives from competing firms. The cross elasticity between different quality levels is also very low. All in all, structural factors do not lend themselves to price reductions. Basic industrial economics therefore predict tactic collusion between the incumbents, leading to a high price equilibrium.

In a collusive oligopoly, all rating agencies sell at the monopoly price in order to maximize profits (e.g., Samuelson and Nordhaus 1998, pp. 172-74 for the whole paragraph). The market will be divided with a fixed share for each agency. The classic obstacles to a collusive oligopoly are cheating, outside competition and regulation. The state will usually fight a market outcome similar to a monopolistic market. If one looks at the two internal threats to collusive oligopolies, one finds little relevance for the credit rating market: cheating on prices and quantities is virtually impossible. As ratings are easily observable, any deviation from 'business as usual' will be detected. Prices are certainly no secret between the players and shifts in market shares quickly become visible. Outside competition usually refers to foreign competitors. Today's credit rating market, however, is in its very nature global - parallel to the reach of financial markets. From this perspective there is no threat of already established rating agencies from other countries. Only Fitch or smaller agencies could be a threat to

59 Towards Fitch such a pricing behavior can be interpreted as limit pricing (e.g., Tirole 1998, p. 368). 
Moody's and S\&P. Their power, however, is limited. The outcome of tactic collusion is high prices, even if business-sustaining prices could be lower. This is exactly what can be seen in the credit rating market.

\subsubsection{Market Entrants}

In a strict sense, entrants are companies that have recently entered the rating market. The incumbents are the long established raters Moody's, S\&P, and Fitch. In a wider sense, however, Fitch acts in some market segments like an entrant, in that it has to cope with significantly larger and stronger rivals. It has already been made clear that the credit rating market is very difficult to enter. Because of historic shifts, the incumbents enjoy a real cost advantage over newcomers, who must pay more to reach the same level of reputation. In addition, the structure of demand is unfavorable to newcomers: issuers stick with the proven agencies and it is hard to offer them an innovative product. Entrants face the trade-off between ratings compatible to the market leaders and a differentiated product. Entering the rating market head on against Moody's and S\&P is all but impossible: reputation needs to be built up over many years and it is cheapest to transfer reputation to new segments/issuers over even longer periods of time. Further, state recognition can usually only be achieved after being established on the rating market for some years.

Realistically, entrants can only follow a niche strategy, initially concentrating on a special country, product class, or both. The Japan Credit Rating Agency, for instance, successfully entered the rating business by concentrating on the Japanese market and Thomson Financial Bankwatch built up a high reputation for its bank ratings (Fight 2001, pp. 60-61, 84). Such a strategy needs less capital than rating thousands of different issues from the outset. The entrant can concentrate his resources on building up reputation in a narrow filed. If he is catering to a limited and closely defined group of investors and issuers, it is much easier to generate attention than trying to cater to a worldwide clientele. A promising strategy is to focus on evolving innovative segments of the rating market. Smaller rating agencies are likely to move more quickly into new rating niches because of their leaner organizational structures (pp. 48-49). This is one of the few competitive advantages of small, young rating agencies. Fitch, e.g., early concentrated on structured finance products which might explain why the agency still has a comparably high market share in this segment.

If a small agency is successful in establishing a good reputation in a specialized niche, it can use its position as a basis for expansion. Thomson Financial Bankwatch is an example. Its market recognition for ratings of financial institutions was so high that it was awarded limited NRSRO status for its special field in 1992. In 1999 it was upgraded to a fully recognized NRSRO for all ratings (White 2002, p. 46 and endnote 23). The example shows how an agency can overcome the 'catch 22' situation in gaining official recognition by entering the market on a limited scale. Shortly after full recognition, however, Thomson Financial Bankwatch was acquired by Fitch. The case of Fitch itself shows the other possibility to gain recognition. IBCA, a London based rating agency, gained full NRSRO status by buying the recognized US agencies Fitch, Duff \& Phelps, and Thomson Financial Bankwatch (e.g., Fight 2001, pp. 45-47). The strength of the conglomerate - which operated under the most prominent brand name Fitch - results from the combination of the different reputations in special segments. 
One can conclude that there is some scope for newcomers despite the high entry barriers. This necessarily poses the strategic question for incumbents of how to react to entrants. Most obviously, Moody's and S\&P could lower their price to a certain extent to discourage entry from the outset. However, as prices in the credit rating industry have only a low commitment value (only a part of reputation is economically a sunk cost), the credibility of such threats is questionable. Price reductions might only be interpreted as attempts of incumbents to manipulate the information available about them (e.g., Tirole 1998, pp. 361-88). Indeed, a reputation of aggressively reacting to newcomers in any segment may well pay off despite short run losses in the form of a long-term reduction in entries (e.g., Milgrom and Roberts 1982, pp. 280-312). But if a newcomer is successful in establishing himself, he faces the same exit costs as the incumbents resulting from difficulties in hiding cheating. Such exit barriers weaken the incumbents' threat of aggressive post entry behavior.

From an overall strategic perspective it is questionable if incumbents in the credit rating business actively try to discourage entry by price policy. The structural entry barriers provide substantial advantages for the first movers. As a result, only very few newcomers will be able and willing to enter in the first place. It is not worth investing into a reputation for aggressive post entry behavior if the number of successful entrants is limited anyway. A superior strategy is to wait and see while keeping prices high. If a newcomer is indeed able to successfully build up a good reputation and client base, it seems most profitable for incumbents to simply buy the newcomer or to merge with it rather than to engage in a price war. After the 'grandfathering' of Moody's, S\&P, and Fitch as NRSRO in 1975, the next four recognized agencies Duff and Phelps, IBCA, Thomson Bankwatch, and McCarthy, Crisanti \& Maffei were all acquired and finally merged into the new Fitch (e.g., Dodd and Setty 2003, p. 7).

It has been more attractive for the investors of the smaller NRSRO agencies to sell out to a bigger entity rather than trying to break into the highly profitable market of Moody's and S\&P on their own. This underlines the difficulty and risk of smaller agencies competing in the credit rating market. On the other hand, larger agencies have an incentive to acquire small agencies simply to prevent potential competition. In many cases, however, buying successful entrants is more than competition prevention. It has always been part of Moody's and S\&P's business strategy to affiliate with or acquire small agencies in emerging segments and countries (e.g., Fight 2001, pp. 16, 32). Especially in unknown and volatile environments it is attractive to move into the business via small but already proven agencies. Only when their international reputation was firmly established, did Moody's and S\&P fully integrate smaller agencies under their brand. In conclusion, one can note that entrants as well as incumbents have incentives to join forces in the credit rating business. It is highly unlikely that a competitor to Moody's and S\&P could develop 'organically' into such a strong position. Fitch, the only agency in a position to compete against the two in all market segments, is a conglomeration of many smaller agencies. 


\section{Reasons for Regulation}

Chapters 3 and 4 have highlighted the special economics of the credit rating industry. The market is coined by limited competition and market power in that incumbents are able to generate sustained profits. Additionally, rating agencies hold an important 'gatekeeper' position in financial markets - not least because of rating-based regulation. The questions in the remaining two chapters are if, why, and how the state should interfere with the market. There has already been a great amount of analysis, debate, and regulatory action in recent years. For an overview see e.g., Schwarcz (2001), Hill (2004), or Rousseau (2005).

One of the main difficulties in the relationship between the state and the credit rating industry is the multiplicity of potential concerns. When considering rating agencies as normal companies from an antitrust perspective, monopoly power and efficiency arguments are of importance. Analytically less clear is the mostly political notion of 'power' which is attributed to rating agencies. From the perspective of rating-based regulation, the main goal is a functioning reputation mechanism providing for a high rating quality since the state explicitly relies on it. Rating agencies should also not exploit conflicts of interest, which is lastly also an issue of rating quality. In a wider framework, the efficiency and quality of not only the rating industry but also of the complete financial system must be considered. The state is anxious about structural risks. What combines all concerns from an economic perspective is the concept of 'market failure', i.e. situations where state interference can improve the well-being of society at large.

There are two scientific approaches for evaluating reasons for regulation: allocation and behavior. The allocation approach looks at the outcome of competition. It asks if there are quantity and quality reductions compared to a more competitive state. It also looks at the pace of innovations and structural effects of competition. The behavior approach, on the other hand, is based on the idea that specific actions of rating agencies can be harmful. This is especially the case when competitors are hindered and will usually involve the reduction of the rating quality. Hence, it is a key question if there are breaks in the market control of the industry creating scope for 'bad behavior'.

The behavior approach is academically straightforward. The state interferes to influence specific actions which in turn lead to a better (measurable) outcome. In a practical setting, though, it is sometimes difficult to prove criminal negligence since it is hard to single out the intent of specific actions. The allocation approach, on the other hand, is academically weaker than the behavior approach because it builds on a benchmark allocation for comparison. In order to evaluate a specific market outcome, the state needs to know what the outcome under optimal conditions would be. In practice it is often easy to survey the necessary data such as market share or quantity and it is also possible to define a benchmark. However, such structural considerations can be misleading since strategic aspects are often ignored.

Most regulatory bodies have been shifting away from allocation considerations to a more strategic approach by looking at the specific behavior of market participants. Nonetheless, the allocation approach can generate useful insights about the general state of competition in an industry. In political practice, too, the allocation approach has considerable weight. A good example is the American legislative initiative to reform the credit rating industry which 
passed the US House of Representatives as the 'Credit Rating Agency Duopoly Relief Act' (US Congress 2006a). It implies that the duopolistic market structure is the principal source of problems in the industry.

\subsection{Allocation Effects of Rating Agency Competition}

\subsubsection{Monopoly Power and Inefficiency}

Economic efficiency is one of the most basic concerns of the state. In the simplest form efficiency can be described as "absence of waste" (Samuelson and Nordhaus 1998, p. 744). The state aims to create market environments that enhance competitive processes which in turn strengthen efficiency - an area called antitrust (Viscusi et al. 2005, p. 61). Antitrust assumes that functioning markets provide the best economic results. Two different notions of efficiency are relevant (pp. 79-80). The first concept is 'static efficiency' ${ }^{\prime 60}$ : the state is concerned that the cost of producing a given output is as low as possible. Rating agencies should thus not be able to artificially limit the quantity or quality of ratings. The second area of concern is 'technical progress' or 'dynamic efficiency': the market should provide for continuous innovation. Antitrust policies boost efficiency if total economic surplus can be increased, i.e. the society in sum should gain.

The analysis of the rating industry's structure and conduct in chapters 3 and 4 has involved a picture of an anticompetitive market. It is characterized by high concentration and sizable entry barriers. This gives rise to antitrust concerns per se, because the theoretical outcome of such a structure is collusion (Viscusi et al. 2005, pp. 62-66). As shown, the incumbents' conduct can in most market segments indeed be described as in tactic collusion. Such a situation is the basis for welfare reductions, as the rating agencies can set prices above costs they hold market power. In the following the question will be analyzed whether the rating industry's performance does in fact give reason to antitrust concerns.

\subsubsection{Static Efficiency}

Monopolies are harmful if their price increases reduce quantities compared to a more competitive state ${ }^{61}$. Such behavior can lead to an overall loss of welfare commonly called deadweight loss. While the surplus of the producer rises, the surplus of consumers falls disproportionately so that the total surplus is lower than in a more competitive situation. It is important to stress that the state is not inherently concerned with prices. Given a constant quantity, the price only determines the distribution of welfare, not its absolute size. Therefore, prices only matter if they have an effect on quantity. A dead weight loss only exists if issuers consume

60 The notion of static efficiency should not be confused with 'market efficiency' which usually refers to 'informational efficiency'. The question is how good a market (e.g., a stock market) does incorporate new information, affecting in turn the allocation of capital. This concept is not relevant from an antitrust perspective. It is implicitly taken up in section 5.2 .3 on rating quality, though.

61 Welfare may be impacted by a reduction in quality, too, even if quantities stay unchanged. Rating agencies possessing market power might have an incentive to reduce quality in order to save costs. If the cost savings are smaller than the loss in utility for the issuers, welfare will be reduced. Quality concerns are indeed central in the rating industry. The real impact, however, does not lie in the cost savings but in issues such as uncompetitive behavior and consumer protection. Section 5.2.3 analyses the potential room for a quality reduction in detail. 
fewer ratings compared to a different industry structure and conduct (e.g., Tirole 1998, pp. 66-69).

A good indication for potential inefficiency is profitability. Large and constant profits suggest high prices which in turn usually means that fewer customers buy the product. The monopolist strikes the best balance between higher prices and fewer units. The reason for looking at profits and prices is the difficulty of measuring quantity effects. Most times it is not possible to clearly define the absolute size of a market and close substitutes make an analysis difficult. For the credit rating market, however, such practical limitations are less relevant. The absolute size of the credit rating market is in most segments defined by the number of debt issues that could in principal be rated. There are as well no credible alternatives to bond ratings. Either a bond is rated or it is not rated. As a result, both price and quantity can easily be measured.

On the one hand, as indicated by their sustained profitability the prices charged by Moody's, S\&P, and Fitch are well above costs (including reputation premiums). This could be a basis for antitrust concerns. On the other hand, however, Moody's and S\&P - the agencies with the highest prices - have a very high market penetration as well. In many segments such as US corporate bonds or sovereigns they virtually serve the complete market. Logically, there is no room for concerns about a reduced quantity with a 100 percent market penetration. The reason for this situation with high prices and high quantities is the low demand elasticity analyzed in section 4.1.1. Issuers are willing to pay prices above costs because they value ratings so highly. From a welfare point of view, one sees a transfer of surplus from the issuers to the rating agencies. Such a pattern is common for markets with a low demand elasticity (e.g., Tirole 1998, p. 67). However, total welfare is not affected because the gains and losses in welfare are proportionate. There is no dead-weight-loss as the number of ratings is not lower than in a more competitive situation.

The lack of a large number of competitors and many multiple ratings is also not an indication of a welfare loss. Superficially, one might argue that the absence of many big rating agencies indicates a suboptimal number of ratings. For instance, equity issues, in contrast to debt securities, are often covered by ten or more analysts. Of course, such an argument does not stand up to economic scrutiny. Issuers base their decision to buy additional ratings purely on their added value - the price of ratings already received is irrelevant. Issuers see no benefit in buying many additional ratings even if they are substantially cheaper than their first and second ratings from Moody's and S\&P. Otherwise Fitch would rate practically every issue, too. Rating agencies selling their ratings directly to investors typically have a difficult time to profitably offer additional ratings. In sum, the low absolute number of competitors is unlikely to reduce welfare.

There is, however, more to the question of static efficiency than to the analysis of the number of rated vs. unrated bonds. High rating prices might not directly reduce the number of ratings, but instead the number of bonds issued because rating fees are part of the cost of debt capital. Once the decision to issue debt has been taken, according to the analysis in section 4.1.1, every issuer will buy ratings since the realized cost reductions outweigh the high rating prices - ratings produce a net benefit. There are some issuers, however, who basically would like to issue debt but the overall costs in doing so is too high. If ratings were cheaper, 
though, the overall cost of debt capital would be just low enough to make a debt issue profitable for them.

The result is analytically robust: A lower cost of capital is good for society. But the practical relevance is questionable. First of all, it is doubtful whether the rating fee of about three hundreds of a percent will make any difference in a real capital allocation decision. Second, even if this were the case, the marginal issuers can hardly be identified so the effect is not measurable. Lastly, the capital allocation decision is taken in the context of all possible kinds of capital including bank credit, equity, and other forms of capital. A focus on bonds is too narrow to evaluate the overall efficiency of the allocation process. Given these practical considerations, the state cannot justify an intervention on the grounds of wanting to reduce the cost of capital. However, it is clear that lower rating fees will certainly do no harm. Therefore, the goal of a fee reduction can legitimately be part of a wider policy to increase competition in the industry. Even if nobody knows if there really is an effect, a better capital allocation would at least be a potential benefit.

The last efficiency consideration in connection with high prices is the so called ' $X$ inefficiencies' (Leibenstein 1966, pp. 392, 412). As competitive pressure is not high for Moody's and S\&P, the production of ratings might not be optimal. I.e. the market leaders incur unnecessary costs. Especially incomplete labor contracts and the division of management and ownership may be a source for such inefficiencies in the rating business. Employees and management might pursue private goals contrary to the profit maximization aim of the owners. While such effects are certainly relevant, it is all but impossible to quantify their impact. Furthermore, the rating agencies business model implies strong internal quality controls, which should also detect major X-inefficiencies. Enhanced competition would certainly be beneficial from this perspective, too, but there is no basis for justifying antitrust measures.

\subsubsection{Social Costs}

There is potential for social costs in the credit rating industry, which often are described as rent-seeking-costs (e.g., Posner 1975, pp. 807-09). These costs are wasted from a welfare point of view as they do not create any utility by themselves. Classic examples are lobbying efforts, overcapacities or early entries. In the rating industry social costs are inherently present within the reputation mechanism. In order to overcome the informational asymmetries between issuers and investors there needs to be an investment in reputation which is compensated later by prices above costs. The investment is partly wasted since a high quality rating is produced, while the users of this rating assume a lower value $\left(q_{0}\right)$ than it actually has. Specifically, investors might incur costs to acquire information which they already have in the form of the entrants' ratings. Of course the state cannot do anything about these informational imperfections in the market. On the contrary, the reputation mechanism is an efficient instrument in overcoming existing informational asymmetries - the state could hardly do better. In order to enjoy the benefits of high quality ratings one has to accept this secondbest solution. Without ratings, overall welfare would be lower.

Thinking further, there might be additional - and thus avoidable - social costs, notably in connection with the first mover advantage. If agencies race to develop their reputations, they cannot rely on efficient strategies such as reputation transfers between market segments. 
This means that they have to provide many ratings for only little or no compensation in order to quickly create a reliable track record. It was argued that such investments into reputation today are very expensive for newcomers. Especially if they want to establish their reputation on a broad scale, a lot of economic waste can be expected. They incur costs for high quality ratings which are initially not followed by the market. From a welfare perspective it does not matter if the newcomers receive fees for their ratings. Relevant is only the disregard of the ratings by market participants. Apart from waste created through inefficient reputation building, there is further waste when young agencies fail to establish themselves on the market. The benefits of a good reputation are reduced if an agency is absorbed by another reputable player. In a case of market exit/bankruptcy all investments are lost outright- although this has traditionally played no major role in the credit rating industry.

Here, too, the state has little room to act. The kind of waste described is hard to quantify and there are no tools to prevent private companies from entering the rating market. Even a strict state licensing - which seems to be a far too drastic measure anyway - is impossible as rating agencies can act from any geographical location as service providers. The issue of licensing is relevant, though, in the context of regulatory recognition. Admittedly, not as a measure to prevent waste, but as a mechanism to potentially increase waste. Since official recognition creates an economic value for a rating agency, there is an incentive to generate costs in reaching this beneficial status. Similar to the argumentation in the previous paragraph, this is especially relevant if the number of recognized agencies is limited, leading to a race for recognition. Unproductive lobbying costs might also be involved.

\subsubsection{Dynamic Efficiency}

Besides static efficiency and the absence of waste it is also desirable to have a technologically progressive credit rating market. Financial markets are changing quickly, so rating agencies must be swift in adapting to new developments and in creating new services. The quality of existing services must also be enhanced. There is no general answer in terms of industrial organization as to what kind of market structure is best suited to ensure dynamic efficiency. Schwarcz (2001, p. 307), e.g., voices concerns about too little innovation by credit rating agencies in an anticompetitive environment. This corresponds to the idea of the 'replacement effect'. Monopolies have few incentives to innovate if they just replace existing business (e.g., Tirole 1998, p. 392). Moody's and S\&P cannot acquire much new business in corporate ratings, e.g., because they already serve the entire market. The pressure to innovate processes to increase market share is low. Nonetheless, the development of the credit rating industry has lead to many product innovations in recent decades (e.g., expansion of rating scales, new market segments/services). In order to find out if there were a reason for regulatory concern, one needs to analyze the incentives to innovate in more detail.

It is helpful to highlight the role of credit rating agencies as information intermediaries. Their services are only valuable in the framework of particular informational asymmetries in financial markets. This means rating agencies cater to a very specific demand. While other companies can develop completely new products or services which 'create' their own market, rating agencies have to fulfill set needs. The argument bears important consequences for product innovations (new services) in the core rating business: rating agencies must be innovative along financial markets, but they cannot be innovative on their own. The emergence of 
structured finance products is a good example. When issuers started creating asset backed securities, they needed credible outside help to evaluate or audit the risks involved. In fact, the whole rationale of such products is to structure assets in order to achieve a certain risk profile. Most structured finance products could not exist without credit ratings. However, it was not an innovation of the credit rating agencies themselves that created their present single most important market segment - and it could have never been. They were simply following the demand of financial market participants. This applies to ratings for collateralized debt obligations (CDOs), as well, which have been criticized as instruments of pure regulatory/rating arbitrage without any economic value (Partnoy 2006, pp. 73-80). Rating agencies were simply following the needs of investment banks.

The emergence of structured finance ratings is also an interesting case study in product innovation dynamics connected to firm size and reputation. Generally, one can assume that any need for ratings by financial market participants will be met, since it means new business and profits for rating agencies. Rating agencies irrespective of size and age will gain a relative advantage over competitors by establishing a good reputation by being first with a new rating service. However, big reputable rating agencies face a trade-off. They risk their high reputation for incumbent rating services when they enter new risky market segments. Rating methodologies had not yet been perfected when structured finance products were introduced and the business environment was blurry. Smaller, younger agencies face this tradeoff to a much lesser extent. They have less to lose by entering an unknown business environment. In addition small agencies have the advantage of leaner organizational structures and are thus quicker to adapt to new needs. From this perspective, start-ups would be best suited to provide completely new rating services.

Obviously, start-ups have not played a major role in structured finance ratings. In fact, there is no segment in today's credit rating market other than some single countries/regions where real start-ups have acquired a strong market position. The simple reason is lack of reputation which has been described as the major entry barrier to the rating market. An unknown newcomer needs to build up a reputation from scratch, which takes a substantial amount of time - any advantages over incumbent players are quickly lost. Despite facing the trade-off between reputation concerns and a quick entry, incumbent agencies have the edge in transferring existing reputation to new rating services. Theoretically, the most successful innovators are rating agencies that meet the minimum reputation requirement for a quick entry, but face comparably small risk for their incumbent business. The structured finance example confirms this theory. Fitch - which was assembled from a number of relative small but reputable underdogs - has a comparably strong position in structured finance ratings today. Being first to market with new rating services is also the only realistic possibility to gain ground against Moody's and S\&P, which are well protected through the two-rating norm and switching costs in incumbent market segments.

In sum one can note that concerns about too few core product innovations are unjustified. If financial markets 'need' a new rating service, they will get it. The only potential for relative welfare loss is a slow pace of product innovations if there are no suitable entrants to a new segment other than Moody's, S\&P and, increasingly, Fitch. Most likely to bring new services quickly to the market are mid-sized agencies that already have a reputation. Outside pressure plays a small role because entry barriers are too high for start-ups. 
A different issue in terms of product innovations is non-core innovations or ancillary services. Rating agencies can develop completely new services around their core ratings business. An example is rating advisory services. Rating agencies consult issuers prior to a rating on their probable rating and how they could improve this. Such services are not necessarily dictated by specific demand from financial markets, so a competitive environment should benefit. The importance of this aspect is limited, however, following the reputation-based business model. Rating advisory services, e.g., create obvious conflicts of interest which can be harmful to reputation. Credit rating agencies themselves are aware of this problem and critically evaluate their own attempts in the area (IOSCO 2003a, p. 11). In order to protect their integrity, rating agencies are unlikely to engage substantially in adjacent non-rating services.

Another aspect of dynamic efficiency is process innovation, i.e. the improvement of existing rating services. From a welfare perspective it is desirable that companies become better over time. If costs decrease, prices will also deteriorate in a competitive market leading to a higher quantity and increased welfare. The credit rating industry is different from this textbook view in two respects: there is not necessarily strong competition and the demand function is inelastic in the relevant range. Especially the second aspect is relevant here. If credit rating agencies manage to lower their costs, no additional ratings will be sold because a price reduction has no meaningful quantity effect apart from a potential rise in bond issues due to lower costs of capital. Given the lack of competition, prices will not change at all. The result of process innovations is simply increased profits for the rating agencies. The welfare gain is largely confined to these extra profits. In its structure, the problem is identical to the Xinefficiencies described above.

Also relevant is the fact that the production technology does not offer room for drastic process innovations in the first place. There is generally less potential for improvement in services than in physical production. The rating process is heavily based on human capital. Process innovations are confined to improved obtaining and utilizing data. A substitution of human capital for more data seems unlikely because data-based services such as credit scoring cater to different needs. Another area of process innovations is the relationship between issuers and rating agencies. Issuers often "complain about the inordinate amount of time and resources involved obtaining or renewing a rating" (Ellis 1998, p. 38). They have to incur wasteful efforts in order to satisfy the information needs of rating agencies. The rating agencies' costs to change such practices might be much lower than the benefits for issuers. Without competitive pressure, however, rating agencies are unlikely to change their methods. From a welfare perspective it is thus desirable to have smaller but reputable rating agencies that use process innovations to gain a competitive advantage. Incumbents are then likely to follow. Overall, however, concerns about innovation alone provide no convincing reason for state interference.

\subsubsection{Financial Market Instability}

Common goals of financial regulation have been described in the context of rating-based regulation in section 2.2. Ratings are used to limit systematic risk and to increase confidence in financial markets. These goals also apply on a much broader level: credit rating agencies are a part of the financial markets themselves. The state is concerned with the direct impact of ratings on financial markets since the actions of rating agencies can influence the behavior 
of market participants. Curiously, rating-based regulation plays the role of an amplifier: some market participants only react to ratings because they are forced to by rating-based regulations. While the individual action is intended by the regulatory rationale, the collective action of many market players might have an adverse effect.

In this section, different patterns that structurally influence the financial system in connection with credit ratings will be briefly analyzed. However, these patterns cannot be described as externalities, as is often claimed in practical and academic discussions. Externalities are only present when someone's production or utility function includes real variables whose values are determined by the action of rating agencies without the agencies' attention to these effects (Baumol and Oates 1998, pp. 17-18). This definition explicitly rules out purely monetary effects. Nonetheless, the patterns analyzed potentially have an unaccounted for effect on the allocation of capital and might lead to disruptions in financial markets. It is the state's incentive to guarantee robust markets and smooth transactions.

\subsubsection{Procyclicality}

Credit rating agencies are usually not quick in changing ratings. One major reason is the 'through-the-cycle' approach (e.g., Altman and Rijken 2004, pp. 2680-83; also see the discussion on timeliness in section 5.2.3.4). Ratings are intended to measure default probabilities over long investment horizons, without considering short run market price movements ${ }^{62}$. This approach limits the danger of amplifying current markets trends (Löffler 2004, p. 719). In principle, the through-the-cycle approach should result in above average ratings in times of high credit risk and in below average ratings in times of low credit risk. Such a stabilizing effect is in the sense of the state, since excessive credit expansions and contractions become attenuated.

However, once a rating change occurs, it might conceivably happen near the extreme point of the cycle since the pressure to initiate a rating action has been building up over some time. One sees a 'rating overreaction' parallel to short run market developments. This means that in times of bad credit risk ratings will tend to be too low, in good times they will tend to be too high. This translates - from the state's point of view - into an undesirable credit expansion effect: credit expansion is hampered in bad times, but assisted in good times because ratings are directly linked to financing costs. The state's intention, on the other hand, would be to have the expansion effect the other way round in order to smooth economic cycles. This makes procyclicality a structural problem.

There has been a lot of debate on this issue (e.g., ECB 2004, pp.18-19). It is generally accepted that ratings move to some extent with the business cycle despite the through-thecycle approach, but it is questionable whether they are assigned in a procyclical manner. Several empirical studies support the thesis that rating agencies overreact. Amato and Furfine (2004), e.g., find a general procyclicality, especially for investment grade ratings, and

62 Sometimes it is argued that issuers and many investors explicitly demand such an approach. In case ratings are quickly downgraded, a difficult financial situation for an issuer might get worse, while otherwise a recovery might have been possible. Investors, on the other hand, might be forced by legal obligations to sell when everybody sells in case a downgrade quickly follows new information (Hill 2004, p. 69-70). 
Kräussl (2003b) finds procyclical effects in the Asian crisis of 1997-1998. Mora (2004), on the other hand, finds that ratings during the Asia Crisis were not procyclical but followed market developments and did not contribute to the crisis.

Excessive procyclicality can become a practical problem with rating-based regulation. Even if market participants privately accounted for the fluctuating absolute default probabilities connected to a specific rating, they could be forced by certain state rules to take counterproductive investment actions. In the long run, excessive procyclicality is unlikely to persist of course, because dramatically fluctuating absolute default probabilities would certainly harm reputation. The practical danger to financial market stability is therefore limited. In any event, the state has no plausible tool other than perhaps official recognition to affect the issue, since it would need to directly interfere with the rating methodology.

\subsubsection{Conformity Bias}

Moody's and S\&P employ very similar rating methodologies, leading to highly correlated ratings; systematic differences for 'third' ratings can be explained by a selection bias and slightly different methodologies (Cantor and Packer 1996). It is obvious that high quality ratings which reflect the same underlying fundamental information must be similar. However, in many cases it seems that ratings and especially rating changes are rather too similar. The Asian crisis of 1997/1998 is an example of very similar behavior of the rating agencies: rivals' downgrades were issued late and within a small time frame (Radelet and Sachs 1998, p. 68).

Critics attribute this phasing of the established agencies to the fear of getting out of line with their rivals' opinions (Economist 1997). Presumably, the relative reputation gain from being first with a drastic rating change that proves correct over time is smaller than the relative reputation loss from a drastic rating change that proves to be wrong. From this point of view it is safest for Moody's, S\&P and Fitch to stick closely to their rivals' opinions, limiting the potential reputation loss relative to each other. Although rational, this behavior poses a structural risk as the incentive for parallel rating actions is highest in times of crisis (Kuhner 2001, p. 20). The reputation mechanism is least effective when it is most needed (McNamara and Vaaler 2004, p. 699).

The general concerns are that excessively similar ratings have a diminished information value and that information diffusion becomes rigid as no agency wants to make a first move. The market would be better served by more differentiated ratings. Informational quality in form of correlation studies does not need to fall with more diverse ratings because of its nature as a statistical average. In fact, it might even rise. A certain heterogeneity of ratings reflects the 'true uncertainty' of the underlying information (Grundmann and Kerber 2001, pp. 274-75). Unfortunately, the conformity bias comes to a large extent with the credit rating business model. Conformity (or 'organizational isomorphism') helps to develop and maintain reputation (Deephouse 1996, pp. 1033-35). At the same time, however, the reputation mechanism limits the problem of conformity per se. Even if ratings are similar, they cannot be broadly wrong. Otherwise the agencies would lose their reputation. 


\subsubsection{Rating Triggers}

Private debt contracts often contain rating triggers (for an overview see CESR 2005, annex D and Nicholls 2005, pp. 16-20). The practice permits investors to take actions against an issuer if a rating falls below a specified threshold (e.g., ECB 2004, pp. 12-15). Investors might be able to demand higher interest rates or - in the most extreme form - to demand the immediate repayment of downgraded debt securities. Rating triggers function as safeguards for investors protecting them from an unexpected deterioration of creditworthiness. Issuers in return receive better credit conditions. However, rating triggers also pose a threat and produce unintended negative consequences. A downgrade by itself indicates a worsening financial situation which might then be amplified by obligations resulting from rating triggers. One speaks of 'credit cliff' situations (p. 14). Downgrades in such situations tend to be very substantial because negative effects from rating triggers are factored in ex ante.

Especially in the short-term there is the risk of a liquidity crisis from unexpected debt repayments which might lead to serious problems or even to insolvency. Rating triggers accelerated the downfall of Enron, for instance (Moody's 2001b, p. 8). The credit rating agencies themselves have become well aware of the risk and have started to explicitly consider rating triggers as a risk factor (e.g., Moody's 2002). Alongside the danger of a downward financial spiral for a single issuer there exists a wider structural risk. If issuers have close financial ties with widespread rating triggers, liquidity problems caused by a single issuer might spill over to others. Analogous to bank run theories, a domino effect might begin knocking out several issuers.

Structural risks are inherent to rating triggers. However, full disclosure of triggers attenuates the problem as it makes visible all contingencies (ECB 2004, p. 15). Any trigger will be accounted for in debt and equity prices, and market participants will take explicit risk provisions. On the other hand, the number of triggers will probably fall with increased transparency since the true cost of rating triggers becomes more visible. Transparency helps to internalize parts of the structural risk, in that a part of the rating trigger costs is borne by the issuers. Even if they get better credit conditions due to a trigger, their equity market value might fall.

\subsubsection{Parallel Investors Behavior}

A further structural risk is parallel investor behavior induced by rating-based regulation and to a lesser extent by similar private rules. If a security is downgraded past a regulatory threshold, a large number of investors might be forced to sell in a short time period. This could lead to price-overreactions. One goal of rating-based regulation is to protect certain investors such as money market or pension funds from taking excessive risks. However, through the induced parallel behavior these investors are sometimes forced to take losses because they might have to sell when everybody is selling and prices are consequently low. Quotations often recover from such sell-offs. Those who profit from the rising quotations are the investors who are not covered by the regulation, whereas 'safeguarded' investors are stuck with their losses. This is a structural inefficiency in the system that increases the cost of ratingbased regulation for the regulated investors. 
The reliance on ratings exposes the state to such effects independent of informational quality. A highly reputable agency occasionally makes mistakes, too. The case of ThyssenKrupp, which will be discussed in section 5.2.2.1, is a good example. Although a downgrade from S\&P was neither reflected by general market opinion nor by other rating agencies, some investors were forced to sell. Consequently, ThyssenKrupp bonds recovered rather quickly after an initial loss, generating profits for unregulated investors who bought at low prices from regulated ones. The problem described cannot be fully avoided in a system with rating-based regulation, it can only be attenuated by its design. The time span before being forced to sell and clauses on which agency's ratings to use are important factors. Also important are the timeliness of rating revisions and watch list periods on the rating agencies side. The state should design rating-based regulations in a way that they respond to different rating classes. The heavy reliance on the investment grade boundary is the major source of parallel investor behavior. It is to be welcomed that the investment grade boundary falls into a single risk bracket for most individual claims under Basle II recommendations (BIS 2004, §§ 53-89).

\subsubsection{Agency Failure}

The credit rating business is built on trust. If it falters, an agency will quickly go out of business. The appraisal of the reputation mechanism in chapters 3 and 4 proves this argument from a theoretical perspective, the fall of Arthur Andersen after the Enron scandal is empirical evidence. While a deliberate milking strategy is implausible, agency failure might result from fraud or serious criminal negligence by a small group of agency employees. A single scandal then threatens the reputational capital of the whole agency. Even if the chance of Moody's or S\&P going out of business is small, it must be considered seriously since the result would be drastic.

Credit ratings for big international debt issues are dominated by the duopoly of Moody's and S\&P. A failure of one would move the market to monopoly, potentially reducing efficiency. More disturbingly, market demand cannot be met if Moody's or S\&P breaks down as the tworating norm firmly is build on precisely these two agencies. In the short run this would cause a serious disruption of financial markets as the issuance of many debt securities would at a minimum be delayed. In the worst case scenario the world's financial system might suffer from a liquidity and debt crisis, leading to global recession. Cementing the short-term risk is the supply side: even if there are other respected and officially recognized agencies such as Fitch, which could meet the demand created by the two-rating norm, they could not expand capacity quickly enough in such a crisis. After the breakdown of Arthur Andersen, its five global competitors quickly absorbed its client base, but in the credit rating market a single small player would need to stem the complete business of a much bigger company.

Given the substantial cost of a breakdown, the inevitable question is how likely it is. As argued, the prevalent rating process of Moody's and S\&P has strong internal controls (Moody's 1991, p. 88 and S\&P 2006, pp. 9-10). The agencies actively try to minimize the risk of fraud or serious criminal negligence, in order to protect their profits. A different argument is that issuers, investors, and states would not let one of the incumbents go out of business, precisely because no one could fill the gap (Sinclair 2000, p. 495). Especially the state has an outright interest to preserve the status of Moody's and S\&P, even in the case of a major scandal. They are considered 'too big to fail'. Continuous state support might be sufficient to 
make up for a (temporary) loss of investor and issuer confidence, but the state is not able to stem a large-scale loss of trust. One can conclude that an agency failure poses a substantial structural risk. On the other hand, the likelihood of such an event is difficult to predict, although it does seem to be very low. Overall, potential agency failure could best be attenuated by a larger number of reputable rating agency, so that the state should take steps to increase competition.

\subsubsection{Information Provision}

Hitherto the aspects of financial market stability discussed all involved potentially negative effects. However, there are also structural benefits to ratings. Credit rating agencies realize economies of scale in information production. They produce information once and make it available to many. Because leading agencies are centrally paid by the issuers, ratings are freely available. Sometimes even detailed background information is published. The obvious benefit of freely available ratings is the spread of credit risk information. Investors would need to incur high costs to generate this information privately; instead, they can freely use available ratings. One can speak here of positive monetary external effects as the price of the information effectively falls to zero. Some authors even speak of credit ratings as public goods (e.g., Smith and Walter 2002, p. 293). Most formal models on information sharing support the idea (Jappelli and Pagano 2000, pp. 14-16). Freely available ratings enhance market efficiency.

Rating agencies base their rating decisions not only on public information, but also on information they receive in discussions with management. In the USA, e.g., issuers are explicitly allowed to provide any credit rating agency with private information, although a selective disclosure is generally forbidden by 'Regulation FD' (e.g., SEC 2003a, p. 22). The private information is eventually released to the market via ratings. In doing this, only the expected results of an issuer's business or investment strategy are released to the market, while the operative details remain hidden. Consequently, competitors cannot gain much from the information. Investors, however, gain through better information on creditworthiness. ${ }^{63}$ The rating agencies' motive is of course to provide the best analysis possible in order to receive a high price from issuers. But one can still speak of a structural benefit, as it is not their goal per se to enhance the information available in the market. The advancement of overall informational quality comes as a 'side effect,' which should be protected by the state.

\subsubsection{Standardization}

A second structural benefit comes from the standardization function of credit ratings. Credit ratings "narrow the expectations of creditors and issuers to a well-understood or transparent set of norms shared amongst all parties" (Sinclair 2000, p. 496). It would be much more expensive if issuers were to provide credit information about themselves through changing systems and different methodologies. Investors would need to build up expertise in many different areas. The credit rating agencies are only concerned with standards insofar as they help save costs and strengthen their market position by increasing lock-in. The two-rating norm,

63 This is analogous to Campbell 1979, who argues that a mechanism to release private strategic information is valuable for the issuer. 
e.g., is certainly in the interest of Moody's and S\&P. But standards produce more benefits than rating agencies can internalize. The same is true for the network value of ratings. The state, in turn, should not take steps to limit standardization.

\subsection{Behavior of Rating Agencies}

\subsubsection{Anticompetitive Behavior}

Market power translates into the potential for anticompetitive behavior. From an economic perspective any rating action that hinders competitors by unfairly reducing their business opportunities is anticompetitive. An abuse of market power usually involves generating extra profits by pressuring issuers with (the threat of) excessively low ratings or not issuing ratings at all $^{64}$. Extra profits are typically generated simply through additional rating fees. However, only if issuers have no other choice than to contract with the powerful incumbents is there likely substantial harm to society. The state, in turn, should mainly be concerned with active attempts to hinder competitors. But regulatory bodies disagree on whether there is anticompetitive behavior in the credit rating industry. The EU Commission $(2005, p$. 7) says "There is no indication of any anticompetitive practices in this industry (...)". The US Credit Rating Agency Reform Act, on the other hand, is based in part on the accusation of "anticompetitive practices, such as notching, tying, and unsolicited rating" (U.S. House 2005b, p. 2).

Before looking at specific issues it might be helpful to limit the theoretical scope of anticompetitive behavior. First of all, rating agencies cannot employ contractual relations, i.e. there is no legal enforcement mechanism. Furthermore, per assumption the reputation mechanism is working well, i.e. rating quality is statistically measurable and a drop will be punished by market participants and the state through the loss of business and official recognition respective$1 y^{65}$. Under this precondition it is impossible for rating agencies to systematically issue excessively low ratings as a form of enforcement or punishment, and as a result any respective anticompetitive behavior is implausible. A plausible threat, on the other hand, is the refusal to issue ratings in order not to distort correlation and transition studies measuring rating quality.

A more difficult issue is the mere threat of excessively low ratings. As just discussed it cannot be systematically carried out without detection. If every issuer were to act entirely rationally, no one would respond to such a threat - it would be empty. However, it could be effective if it were only carried out once in a while. In this case the statistical rating quality only suffers marginally or not at all. In this respect, the small chance of actually receiving a too low rating already creates a 'psychological' threat for some issuers. They know that there is a real danger of suffering a big disadvantage by a rigged rating, but there is no way to gain solid evidence about an agency's misbehavior. The expected loss from falling victim to a rigged rating might be so high that many issuers would rather give in to a rating agency's demands. If a large enough number of issuers can be expected to behave in this way, fully rational issu-

64 The complement to market power is conflicts of interest, that is issuers and rating agencies collaborate to generate extra rents. This is not an uncompetitive behavior in its nature, as other rating agencies are not directly hindered. There is a short analysis on the matter in section 5.2.3.2.

65 It will be analyzed in the quality section 5.2.3.1 if there could be factors infringing on the reputation mechanism. If this is the case, the rating agencies threat would be boosted since they can safely issue some downward biased ratings. 
ers will also give in for the reason described above. They cannot prove anything against the agencies if they are the only ones actually receiving a too low rating. Seen from an economic perspective, the situation described is a problem of individual vs. collective action. If all issuers collectively did not react to the threat, there is no problem since there is neither something to be gained for the rating agencies, nor is there any effective sanction. However, if some individuals suspect that many other issuers are giving in to such threats, they will also chose to react to the agencies' demands. The equilibrium strategy thus tilts from 'nobody reacts' to 'everybody reacts'.

The threat of excessively low ratings might be especially strong for high risk issuers compared to low risk issuers. This makes sense as the high rating categories lie closely together in terms of default numbers and probabilities, whereas low categories on the junk bond level feature larger differences (e.g., BIS 2000, p. 127). High rating categories are more specific than low categories. A few bad credit risks in a high category may jeopardize the relative ranking of correlation studies, while a few good risks in bad categories only change the absolute number of defaults but not the relative ranking. In simple words, the measure for rating quality is less sensitive to rating actions in low rating categories. Similarly, potential reputation losses become smaller with lower rating categories, since getting ratings right is more difficult for high risk debt securities (Hill 2004, p. 77).

\subsubsection{Unsolicited Ratings}

An often controversially discussed topic is unsolicited ratings, Poon (2003, p. 593-96) gives a good overview ${ }^{66}$. They are neither authorized nor paid for by the issuer and are (largely) based on public information. Rating agencies might abuse unsolicited ratings as a threat to pressure issuers to pay for a 'proper' rating. Once a rating is paid for, the chance that an issuer buys a rating from a competitor is reduced. An unsolicited rating is 'feared' because it might put an issuer's credit risk in a worse light than it actually is - with the justification that it only reflects publicly available information. Moody's in particular has been accused of such behavior by individual issuers. The empirical evidence from a sample of unsolicited S\&P ratings is weak (p. 612-13): the fact that unsolicited ratings are generally low can be explained in large part by a negative selection bias, i.e. especially issuers with a bad credit risk choose not to pay for a rating. Although unsolicited ratings are on average still slightly below comparable solicited ratings, Poon finds this effect to be significant only for Japanese corporate bonds. Butler and Rodgers (2003) also find no abuse of unsolicited ratings. The same is true for Behr and Güttler (2006) who find not much difference between unsolicited and solicited ratings. The opinion of practitioners supports this view: in a survey of 102 institutional investors, 89 percent said that unsolicited and solicited ratings have the same quality (Ellis 1998, p. 40). In a comprehensive study on unsolicited bank ratings from Fitch, however, Poon and Firth (2005) find a somewhat larger downward bias than in Poon's 2003 study.

Theoretically, the incentive for rating agencies to pressure issuers with too low unsolicited ratings that are merely 'corrected' if paid for is not compelling. Since the quality of unsolicited

66 Most rating agencies have special terms for unsolicited ratings. Moody's speaks of 'investor-initiated ratings', S\&P of 'public information (pi) ratings', and Fitch of 'shadow ratings'. 
ratings as a subgroup can be measured ex post by correlation studies, any discrimination would be detected. In the best case, market participants would simply not value unsolicited ratings - so no pressure can be applied through them in the first place; in the worst case, the agency's general reputation would suffer. This danger outweighs the potential of limited additional profits. Even if all unsolicited ratings were systematically too low so that the rankordering of default risks is correct, reputation is endangered since market participants would clearly see the double standards. Why then issue unsolicited ratings at all? The standard answer is that investors expect big rating agencies to provide the complete picture, so they take the effort to issue unpaid ratings. For small agencies, on the other hand, unsolicited ratings are a way to build up their reputation, since not enough issuers are initially willing to pay (e.g., Poon 2003, p. 594). Therefore, it is not amazing that in fact the vast majority of unsolicited ratings, although not paid for, follow a rather normal rating procedure with at least some regular agency meetings (Fight 2001, p. 155). Rating agencies are clearly interested in delivering high quality ratings.

There might nonetheless be some limited room for rating agencies to abuse their powerful position. If the ratio of unsolicited to solicited ratings is insignificant, the statistical impact might not be observable in average rating data. Market participants understand this problem and have put pressure on Moody's in particular to change its practice, contrary to most other agencies, of not tagging unsolicited ratings. Fearing that its reputation might be damaged, Moody's began to tag all unsolicited ratings from 2000 on, so they could be scrutinized independent of their relative frequency (Moody's 1999). In addition, Moody's restricts its unsolicited ratings to speculative grade issues.

Despite transparency, a key problem remains: unsolicited ratings can work as an implicit threat which does not need to be carried out often, as discussed above. Issuers will be afraid of being disadvantaged by an unsolicited rating and will rather choose to cooperate and pay. Cantwell (1998) finds in his survey that about 90 percent of issuers whose initial rating was not requested subsequently paid for their rating (Fight 2001, p. 155). This means unsolicited ratings can indeed be a tool to gain additional business from unwilling issuers, but they offer no room for a lower quality. The 'psychological' threat can be upheld even with a small number of excessively low ratings. The cited empirical evidence that unsolicited ratings seem to be marginally too low on average supports this argument: the threat of a too low rating is apparently carried out in a few instances. This could be enough to force most issuers into 'compliance', i.e. making them pay. A second potential argument is that rigged ratings in lower rating categories - in which most unsolicited ratings fall - are a comparatively small threat to reputation.

There is no conclusive evidence on unsolicited ratings. Theoretically they are no threat to rational issuers. Indeed empirical research suggests that they are accurate. Practically, though, many issuers feel pressured by them. They choose to pay instead of receiving an unsolicited rating. However, rating agencies cannot openly threat issuers. A single case of such behavior - if made public - would be a serious harm to any agency's reputation. It is noteworthy that the US Justice Department has found no evidence of such behavior by Moody's in a three year investigation in the late 1990s (US Senate 2002, p. 103). At most, rating agencies could not take steps to remove the pressure felt by issuers. But even such 'blurring' of circumstances might be badly perceived by market participants, thus harming reputation. 
In sum, the danger of unsolicited ratings is real, but it seems overestimated by many critics of the practice. Drastic measures such as forbidding unsolicited ratings are certainly exaggerated. Of course, potential anticompetitive behavior of the market leaders against smaller reputable rating agencies could be prevented. However, banning unsolicited ratings would erect a high entry barrier since it is a widely used tool for newcomers to enter the rating business. It would also make investor-paid rating agencies technically impossible. More transparency and quality control, on the other hand, should help limit the danger of unsolicited ratings without hindering newcomers and hampering different business models.

\subsubsection{Notching and Tying}

A further potential abuse of market power is seen in the practice of 'notching' (U.S. House $2005 b$, p. 2). The term describes an established method of many rating agencies. Notching refers to "the practice of differentiating issues in relation to the issuer's fundamental creditworthiness", following a rather automatic procedure (S\&P 2006, p. 46). An issuer with a B rating, e.g., can receive different ratings on single debt issues notched up or down. A highly secured bond would receive a higher rating, such as $\mathrm{B}+$, an unsecured bond might be downgraded a notch to B-. There is of course nothing wrong with this practice.

Moody's and S\&P, however, have been accused of 'punitive notching', that is "automatically adjusting downward the ratings on structured finance bonds if they themselves did not originally rate those bonds" (Fitch Ratings 2002) ${ }^{67}$. Issuers fear such behavior and as a result choose to have all their bonds rated by the two market leaders rather than a competitor. The issuers' cost is limited to the price difference between Moody's/S\&P and the competitors, but for the competitors it means the loss of business or even market exclusion. Fitch indicated in an SEC hearing that the introduction of the practice in 2001 led to a substantial (in part temporary) drop in its commercial mortgage-backed securities market share, as many structured finance issuers chose to do all business with Moody's or S\&P rather than risking a notched down (unsolicited) rating (SEC 2003a, p. 24). Issuer and investor surveys also indicate concerns on punitive notching (for the results of a Fitch-sponsored study see Fitch Ratings 2002, for a small independent study see TBMA 2006, pp. 8, 10). A Moody's sponsored study by the National Economic Research Associates NERA (2003) finds no conclusive evidence of abusive notching but concerns remain.

In theory, punitive notching is a blunt sword. Notched down structured debt-securities can be easily identified by their high fraction of debt rated by other agencies than Moody's or S\&P, and most of these will be unsolicited, too. If the downward notching were to compensate more than a methodological difference between the agencies, the sub-sample of notched ratings would feature too few defaults. This is opposed to Moody's and S\&P's claim of the comparability of all risks - the double standards would lead to a costly loss in reputation. Even if punitive notching is a mere threat carried out in very few instances, there might be statistical evidence. Asset-backed securities commonly are designed to receive high ratings. Contrary to unsolicited ratings, punitively notched ratings would therefore accumulate at the

67 Fitch itself employs automatic notching of structured finance ratings, too, but to a lesser extent than Moody's and S\&P (Fitch Ratings 2002). 
bottom. In practice, however, the low risk nature of structured finance products creates a real potential for punitive notching. A notched down rating is likely to make some asset-backed securities all but impossible to issue. Consequently, issuers will do everything to get the desired rating or to prevent a notched down rating respectively. Moody's and S\&P's might even actively refuse to rate some asset-backed securities as it leaves no room for a statistical test of criminal negligence.

While the danger of punitive notching is real, the scope nonetheless seems to be limited. Issuers will only give in to pressure from Moody's and S\&P if the value of their structuredfinance ratings is clearly higher than the value of a Fitch rating. In other words, the larger the market power of Moody's and S\&P, the higher their potential for anticompetitive behavior. The value of Moody's and S\&P ratings depends, however, on their reputation. If there were a widespread fear of punitive notching - even if not statistically measurable - investors would value ratings from Moody's and S\&P less. This would make issuers confident in buying structured finance ratings from Fitch instead. If the two market leaders overdo it, Fitch and other agencies might actually benefit. Moody's and S\&P need to be very cautious if they do indeed use the anticompetitive practice of punitive notching. In any event, active steps against the practice on the part of the state are difficult, as restricting notching would essentially mean a direct influence on the rating methodology.

'Tying' is another alleged anticompetitive behavior of credit rating agencies (U.S. House $2005 \mathrm{~b}$, p. 2). It is a standard concept in antitrust economics which describes "the practice of a seller conditioning the purchase of one product on the purchase of another product" (Viscusi et al. 2005, p. 266). Specifically, an agency might only issue a rating if the issuer also buys ancillary services. Another form of tying would be conditioning one rating on others, so an issuer effectively needs to buy all his ratings from the same agency. In this sense notching is a form of tying. The concern about tying is that it hinders competitors from accessing the market and that the free choice of issuers is limited (p. 271).

Although at first sight it makes sense to tie ancillary services to ratings, upon closer inspection the prospects are limited. As argued in the innovation section 5.1.1.3, all non-rating services to issuers are in practice a potential harm to the agencies' reputation for independence. By tying services to ratings, this danger is magnified. Further, tying ancillary services is economically equivalent to a price increase. If issuers want a rating, they pay a higher price for the rating bundled with another service, independent of their valuation and desire for the additional service. Other rating agencies are not harmed by this behavior, but in fact helped in their core rating business since their ratings become relatively cheaper. An antitrust concern could then be found in a transfer of market power to the tied product. E.g., Moody's and S\&P might try to monopolize the market for rating advisory services. This, however, would hardly work, given their reputation-based business model. More relevant would be the case of exclusive rating contracts, i.e. tying a rating to other ratings for the same issuer. Here, a similar argumentation as with notching applies. 


\subsubsection{Abuse of Power - the Political Dimension}

The big credit rating agencies are quite famously attributed possessing enormous power (e.g., Partnoy 1999 , p. 620$)^{68}$. Their rating discretion allows them to influence not only the issuers' financing costs but to some extent they can also influence their clients' actual business behavior. Issuers often consider the impact on ratings as one important factor in strategic decisions. In a survey of 241 Japanese financial institutions over 90 percent of respondents either have a good rating as a direct management goal or at least often consider their rating in management meetings (JCIF 2001, p. 4). This importance of ratings is seen as a (political) power factor - which is of course not all that remote from the more specific economic concept of monopoly or market power which thus far has been at the center of the analysis $^{69}$.

From the economic perspective the concern with monopoly power is inefficiency and anticompetitive behavior, while its threat is a debatable issue. From a political perspective, on the other hand, rent-seeking behavior is not the root of the problem. Here, the mere existence of power is a source of irritation since rating agencies can be seen as quasi-public authorities (Sinclair 2001, p. 448). Politically it is not desirable that rating agencies can interfere with decisions of independent economic agents, e.g., through sovereign ratings. Governments want to set their own industrial policy agenda and prefer not to 'surrender power' to outside rating agencies. The power issue is of course analogous to the potential fields of anticompetitive behavior analyzed above - powerful rating agencies can abuse their position. To avoid repetition only specific examples will be considered.

\subsubsection{Sources and Impact of Power}

Politically the source of this power is a crucial question. There are two sources: reputation and rating-based regulation. From the reputation perspective the judgment of rating agencies has become so important that it substitutes decisions by issuers or investors, who align their behavior to what rating agencies think. Regulatory induced power is much more specific. Here, market participants have to take (undesirable) decisions due to specific rating-based regulations. Powerful rating agencies can exercise influence on issuers or investors to follow specific policies.

There are several documented cases where ratings explicitly moved prices of debt securities for regulatory reasons. One outstanding incidence is the downgrade of the German ThyssenKrupp group analyzed by Gerke and Mager (2005). Based on a revaluation of pension liabilities, S\&P downgraded several German companies in early 2003 without a prior watch list announcement. The downgrades were motivated purely by a change in the rating methodology and not by fundamentally new information. The case of ThyssenKrupp was special, as its debt was moved from investment grade to junk status. One exemplary bond of the

68 Partnoy quotes the journalist Thomas L. Friedman: "There are two superpowers in the world today in my opinion. There's the United States and there's Moody's Bond Rating Service. The United States can destroy you by dropping bombs, and Moody's can destroy you by downgrading your bonds. And believe me, it's not clear sometimes who's more powerful' (p. 620).

69 There has also been suspicion that politics influence rating agencies (Bottini 1993, p. 595-97). This idea corresponds to conflicts of interest analyzed below in section 5.2.3.2. 
group immediately lost six percentage points and the credit spread jumped by two full points. The loss was caused by institutional investors who had to sell their positions, as they were not allowed to hold junk bonds - mainly because of rating-based regulations. It took about two months until the quotation recovered half of the loss and only after nearly two years did the credit spread fully recover to its old investment grade level. The rating at that time remained at junk level with a positive outlook. This example clearly shows how rating agencies can influence quotations in the short run, even if they are based purely on a methodology change - i.e. there is no change in default risk. In the long run, however, markets return to an adequate valuation based on the best possible analysis of the available information.

The quotations of other affected companies changed on a less dramatic scale since their debt stayed investment grade. This demonstrates that rating agencies possess regulatory induced power since many relevant regulations in this example concern investment grade boundary. Independent of potential underlying information, the raters' opinion of investment grade or junk status can move markets. A rating change by itself becomes valuable information because it changes the regulatory status of a bond (Hill 2004, p. 68).

Although the ThyssenKrupp case illustrates the effect of regulatory induced power, it is not a case of abuse. S\&P certainly influenced market prices strongly in the short run. In the longer run, however, market prices deviated from S\&P's analysis and reverted to the old level consistent with the unchanged investment grade ratings of Moody's and Fitch. S\&P increased its ratings gradually back to investment grade over two years, albeit without market prices. The example encourages one to assume that S\&P had to follow market prices and the other agency's ratings. If S\&P had stuck to its lone junk rating, issuers and investors would certainly have questioned their rating quality, which could have impacted S\&P's reputation. The actual damage S\&P took from the affair was small - if any. The market obviously did not interpret S\&P's behavior as cheating. The systematic change in the rating method was aimed at improving the rating quality but ultimately proved to be deficient (Gerke et al. 2005, pp. 6061). One cannot speak of an abuse of power since there are neither indications of any kind of extra profits for S\&P nor indications of hindering competitors. Even if the goal had been to systematically discriminate against certain companies, the practice could only have been upheld in the short run, while at the same time endangering the long-term business.

The arguments concerning reputation induced power are more subtle than those just discussed. In the ThyssenKrupp example, S\&P de facto had the power to coerce. With its rating decision, certain investors were forced to sell. In the absence of rating-based regulation, rating agencies do not explicitly have such power. They cannot formally force an investor or issuer to do something. There is, however, clearly some form of pressure. In order to receive a high rating, issuers may well have to adapt their business conduct to the beliefs of the agency. The same is true for investors, since many use ratings as a risk management tool (e.g., ECB 2004, pp. 8-9). If a rating is altered, some investors may react simply because of internal guidelines, regardless of any underlying fundamental data. Such powers are naturally reserved to the most reputable agencies. Their long history as capable market leading agencies has out them into this position.

It is often difficult to differentiate between the two sources of market power. Perceived power is ultimately a mutual phenomenon. This makes it more difficult to argue on the free will of 
market participants. With their decision to buy ratings, e.g., issuers accept in principal the credit rating agencies' strong position. In the absence of rating-based regulation any such endorsement of power would merely be a procedure operating in the market on the free will of its participants. In reality, of course, an issuer might buy a rating purely to comply with regulation, although he distrusts the power of the rating agencies. Similarly, investors might adapt their internal rules to ratings by Moody's and S\&P only because they have to use these ratings anyway by law.

While the kind of power described is a fact, it is not of much use for rating agencies other than to generate 'normal' profits. It has been argued that it is difficult to threaten issuers with low ratings. A few low quality ratings might be enough to alienate investors, especially if there are specific clues of abusive behavior. Any abuse of power endangers the reputation base. Without reputation most power will immediately evaporate: issuers will not buy new ratings and the market will stop trusting in existing ones. Furthermore, the state is likely to withdraw its recognition. Seen in the reputation framework, the abuse of power is a milking strategy. It could only be profitable if carried out on a broad scale. However, if it were indeed more profitable to cheat than to produce high quality, the incumbents would long ago have milked and exited the market. The fact that rating agencies have enjoyed a constantly high reputation over a long time is proof that a systematic abuse of power has never been attractive. The economic reasons to abuse power are simply not convincing for rating agencies. Far from it, overall there is a strong incentive to avoid the impression that they are abusing their power.

However, all of this does not change the reality of power. With their actions rating agencies do influence market participants - often in direct and sometimes dramatic ways: "Mass layoffs by firms or a reduction of state expenditure by countries, e.g., by cutting essential public services, is a common sacrifice that rating agencies demand for avoiding downgrades" (Kerwer 2002b, p. 43) ${ }^{70}$. This quotation reflects the negative tenor especially of many sociologists towards the power of rating agencies. However, from an economic point of view the facts must be interpreted differently. By definition, rating agencies are aligned to what is deemed correct by financial markets. Otherwise they could not forecast default probabilities and would not enjoy a high reputation.

Credit rating agencies make risk assessments to their best knowledge. The basic rating methodology and important factors influencing rating decisions are widely published. (In the ThyssenKrupp example S\&P released detailed reasons for the downgrade.) If issuers respond to rating actions, they do not do this to fulfill the demands of rating agencies. They react in order to influence the real default risk of their debt securities. Any issuer will balance the benefits of an increased rating (i.e. a lower default probability) against the cost of an awkward decision to achieve these benefits. It is not Moody's or S\&P who require that expenditures be limited - the necessities of the financial markets are decisive. An issuer who wants to spend more money has to pay a higher price for it when his default probability rises. If the money spent is a worthwhile investment, there is of course no danger of a downgrade. The power of rating agencies is merely a catalyst making visible the demands of competition

70 For similar older criticism see (Bottini 1993, pp. 597-98). 
in a globalized economy. But the high visibility wrongly makes rating agencies a target for criticism. Their demands only display the realities of a market economy. They neither want to blackmail anybody nor are they the tool of a neoliberal elite.

Given that power cannot be systematically abused, that it is furthermore a dubious economic concept, and that in fact it does not exist in the pure political sense, the question arises whether it should be a general issue of discussion at all. From an economic perspective the answer is 'no'. Power is only relevant if the reputation mechanism fails. However, it is probably impossible to take the issue out of the political sphere, because rating agencies and their apparent power are easily visible and understandable. There will always be voices demanding the limitation the agencies' power. Of course, this makes little sense as power is not a bad thing if it cannot be abused. Further, power comes with the business model of rating agencies and cannot be abolished. The opinion of a reputable agency by definition counts in the market - it moves prices and influences decision makers if the credit risk is correctly reflected. Abolishing power would mean abolishing rating agencies. The matter is probably so intensely discussed since a part of market power is brought about through rating-based regulation. Rating agencies are quasi-regulatory bodies (e.g., Sinclair 2001, p. 448). The claim is to control this public power in private hands. Here, the state indeed has the possibility to limit the agencies' perceived power by limiting the use of rating-based regulation.

\subsubsection{Sovereign Ratings}

Sovereign ratings are probably the area most often cited in connection with the rating agencies power (for an overview see Ferri and Liu 2003 or Reisen 2003). They are an important factor in a sovereign's ability to access international capital markets. There are many examples of nations that criticize their sovereign ratings after downgrades have caused currencies and local debt and equity markets to depreciate (Sinclair 2000, pp. 496-98). However, actual credit spreads, especially on emerging market sovereign debt, have traditionally been on average somewhat below what sovereign ratings suggested, so it seems unlikely that rating actions caused the market movements (Cantor and Packer 1995, pp. 4-5). Nonetheless the rating agencies are criticized, mainly because of their high visibility.

The maximum rating of an issuer's foreign currency debt is often constricted by the country rating it operates in. This threshold is commonly called sovereign or country ceiling. The logic behind it is rather simple: an issuer with good credit risk receives a low rating on its foreign debt if the sovereign can impede international capital flows in time of distress. For a long time the sovereign ceiling was handled very strictly, acting "in virtually all cases as a 'sovereign ceiling' or cap on ratings of foreign-currency denominated securities (...)" (Moody's 1991, p. 158). After continued criticism and - more importantly - some statistical evidence, the sovereign ceiling rule was eased over time, while it still applies for most issuers (e.g., Moody's 2001a). Bonds from 38 companies were immediately considered for an upgrade when Moody's eased the rule in 2001. Interestingly, the unexpected methodology change here had practically no impact on bond or stock prices, suggesting the market did not consider the sovereign ceiling for the respective bonds in the first place (Mora and Aintablian 2005, pp. 12-13). This is another indicator that the rating agencies' power is overstated. 
Once again, in the short run the rating agencies might possess tremendous power. However, this power is safeguarded by the reputation mechanism as explained in different contexts above. No agency could systematically rate countries wrongly without losing its credibility and thus its power. The fact that the sovereign ceiling rule has been modified over time proves that the big rating agencies are responsive to quality concerns. If a rating cannot be understood by investors, even short run price movements might fail to appear. When sovereign ratings move national markets sustainably they can only reflect well scrutinized information. It is not a rating agency's action that puts issuers and the sovereign in an affected country into trouble - it is the financial situation and behavior of the sovereign itself. If there is no danger for national issuers by their government, the sovereign ceiling does not apply.

If sovereign ratings are generally of bad quality, rating agencies will simply not enjoy reputation for them, so their ratings will have no impact on market prices. Empirical research has proven this link: sovereign bond yields deviate more often from ratings than corporate bond yields since sovereign rating are deemed less precise (Cantor and Packer 1995, pp. 4-5). In fact, the market is more pessimistic than the rating agencies, which also contradicts a power abuse through too pessimistic ratings per se. However, problems could arise in connection with rating-based regulations. If rating agencies enjoy little reputation for sovereign ratings, they might arbitrarily set ratings without punishment from the market. If there are market participants that are forced to act according to specific regulations, rating agencies enjoy some power which could be abused. But overall this argument is weak. There are only few sovereigns, so real money could only be made from ratings for national corporate issuers. For these, the rating agencies enjoy a high reputation which they must protect.

One of the few plausible ways for a reputable agency to abuse its power connected to sovereign ratings is much more delicate. If a country is rated by several agencies it might make sense for a particular agency to systematically place its ratings at the top or the bottom of its competitor's ratings, depending on the potential scale of business in that country. Countries generating a lot of business would be rated above, countries of little significance below the competitors. On average, sovereign ratings would not be systematically higher or lower, neither would substantial absolute differences arise. Therefore, reputation should not be harmed. However, such a behavior might noticeably improve overall growth, because issuers are most likely to buy ratings from the agency that seems to be most positive on the country they operate in. Especially issuers with small issues that only seek a single international rating are likely to choose the most favorable agency - as long as its reputation is high.

Empirically, such a pattern can indeed be proven: the more an agency focuses its business on a given geographic region, the more favorable are the agency's sovereign ratings in that region (McNamara and Vaaler 2000, pp. 343-44). Of course, this correlation proves no wrongdoing. It might simply be that the agencies are most positive on the sovereigns they know best. Their special regional knowledge allows them to do without a general risk premium which needs to be applied to less known rating market segments in order minimize the risk to reputation. In any case it is difficult to spot the pattern in aggregated sovereign rating data. In a sample of 1997 - 2000 emerging market sovereign ratings from Moody's and S\&P, differences are usually small and neither of the agencies assigns systematically higher or lower ratings (Kräussl 2003a, pp. 36-41). In a broader sample including 81 rated sovereigns 
from June 2001, Moody's and S\&P differ in 28 cases, with Moody's assigning a higher rating in 11 and S\&P in 17 cases (Afonso 2003, pp. 58-60).

\subsubsection{Declining Rating Quality}

"Concern centers on the quality of credit ratings (...)", says the EU Commission (2005, p. 4). It uses the concern for quality as synonym for many specific worries about the credit rating industry - and rightly so, because quality is a synonym for the reputation mechanism.

In chapter 3 it has been concluded that the reputation mechanism is very robust. A reputable agency will never deviate from the high quality strategy; outright milking is not an option. What, however, if the reputation mechanism does not function properly? Then an agency will not be (fully) punished for a quality drop. The simplest reason for a rating agency to reduce quality is to save costs. More importantly, it has been shown above that a quality scope may lead to undesirable power abuses. Rating agencies could use too low ratings to hinder competitors and to make extra profits. This potential for anticompetitive behavior is reason enough to analyze the issue in detail.

Furthermore, the matter is also relevant from the perspective of rating-based regulation. The state is de facto a rating consumer relying on high quality. The goal of rating-based regulation is to limit the systematic risk in financial markets by controlling risk taking and capital adequacy. A key issue in guaranteeing financial stability is supporting the confidence of market participants, too. Both the direct limitation of risk and the indirect influence through confidence are dependent on a high rating quality. Only if ratings adequately describe default probabilities, will rating-based regulations efficiently control risks as intended. In the same way, a high quality is needed to maintain the confidence of market participants. Ratings are only regarded as a reliable tool as long as there is continuous evidence of their correctness. In other words, rating-based regulation has no use or even backfires in cases of a low informational quality. Therefore, rating quality is a major concern of the state. Analogous to consumer protection arguments the state must be protected from a low rating quality. This is especially the case if ratings are too high (contrary to the abuse of market power) as a result of collusion between issuers, investors, and rating agencies.

On a broader level - independent of rating-based regulation - the state is interested in a high rating quality per se to foster market efficiency (Rousseau 2005, p. 39). As credit ratings are part of the information pool available in financial markets, a low informational quality could distort capital allocation and produce an economic loss if the agencies' reputation (and therefore impact) remains high.

\subsubsection{Factors Overriding Informational Quality}

After having extensively shown the strength of the reputation mechanism it might seem eccentric to question it again. Despite all kind of frictions the basic economic incentives always stay in place. Empirically the enormous success of Moody's and S\&P and other reputable brands in many different markets is a proof. However, the credit rating industry is unique in that ratings have several different functions and are used by private and public actors alike. In this complex environment there might be external factors superposing reputation as un- 
derstood in the model. While the mechanism stays intact, an agency's reputation might be impacted by more than rating quality.

Sociologists and political scientists in particular try to explain how different internal and external factors in the credit rating industry could occur and influence reputation. Notably, it might be affected by 'market authority' (Sinclair 2000, p. 495). Market authority arises from reputation, but eventually exceeds it. Investors accept the big rating agencies as given authority as they would accept a law. The leading rating agencies do not need to persuade issuers and investors, but their assessments are accepted for their importance in coordinating international debt markets. While reputation may vary over time, authority exists on a fixed level. The Asian crisis is an example cited for this argument. The reputation of the big credit rating agencies should have fallen because of low quality ${ }^{71}$. However, the reputation was empirically not effected at all. Eventually, authority will of course fall if quality is constantly low. But the reputation mechanism fails over a range of higher quality levels. Issuers and investors do not differentiate if an agency produces flawless ratings or if it makes a number of mistakes. Market authority absorbs fluctuations in quality.

Connected to this argument is the view that rating agencies are standard setters (Kerwer 2002a, pp. 297-99). They act as 'coordination service firms', establishing a common understanding of creditworthiness. From this point of view rating agencies are not primarily information providers, but they offer a standard of creditworthiness that can be voluntarily adopted by the investors. The voluntary adoption is the crux of the argument. As standards are merely advice on action or on how to interpret information, the responsibility lies with the users, not the standard setter. It could thus happen that investors take the responsibility themselves for using low quality ratings, and do not blame the rating agencies. The latter could in turn permanently lower their quality. Lacking alternatives to credit ratings and being 'forced' by rating-based regulation, respectively, investors will continue to use standardized ratings with a continuous high willingness to pay.

The two arguments have in common that the issuers' decision to buy ratings is influenced by factors other than informational quality. A free decision purely based on quality, however, is the crucial assumption of the reputation mechanism. When issuers are not able or willing to react to quality changes, the reputation mechanism indeed fails to provide sustained high quality. The argument can be compared to reputations such as corporate culture. It has been said that "reputations grow and die hard", i.e. reputations are rather immutable (Kreps 1990, p. 128). This argument is based on an imperfect observation of actions and motives. If factors that are not as easily measurable, such as informational quality, become relevant in determining agency reputation, something similar could happen here. Rating agencies might keep their high reputation, initially acquired for superior ratings, even if their ongoing informational quality deteriorates.

The whole idea of the reputation model is built on the assumption $R_{t}=q_{t-1}$. That is, an agency's reputation equals the observed informational quality of the last period. The problem

71 The major agencies were slow to downgrade bonds, too many highly rated issues defaulted. On the other hand the rating changes were not very differentiated, so that many ratings were in fact too low (e.g., McNamara and Vaaler 2004). 
becomes clear if one assumes the extreme case $R_{t}=q_{\max }$, i.e. the reputation reflects the highest quality that has been delivered at any point in time, no matter what quality is currently produced. A rating agency would be able to generate milking profits every period, offering ratings at $q_{0}$ or even below, but charging $p_{\text {max }}$. Such a scenario practically means that issuers are forced to buy ratings of a specific agency, because rational issuers would stop buying ratings once a low quality is observed. Of course there is nothing to force issuers, but the matter becomes relevant in alleviated form if issuers buy ratings not purely on the basis of informational quality. The concept of market authority describes the situation well. The open question is how exactly it arises.

One of the most obvious candidates for creating market authority is state recognition for compliance with rating-based regulations. (For simplification other factors are initially ignored.) Interestingly, the intent of rating-based regulation to guarantee high standards of credit analysis is perverted by this concept since rating-based regulation becomes the reason for deteriorating informational quality. In principal, rating-based regulation is not connected with the reputation mechanism. Official recognition simply increases the issuers' willingness to pay for a rating, as has been shown during the analysis of demand in section 4.1.2. The reputation mechanism, on the other hand, is purely concerned with the informational quality of ratings which is untouched by rating-based regulation. Now, however, rating-based regulation is considered as an exemplary factor in influencing the issuers' and investors' perception of quality. The state's impact crystallizes in official recognition of a limited number of designated or registered credit rating agencies. By its very nature, official recognition creates a strong and visible break between designated and non-designated agencies. Issuers might initially want to buy a designated rating, while informational quality comes second. This corresponds to the regulatory license view already discussed in detail (Partnoy 1999, p. 683).

The idea of market authority established through official recognition fits well into the model of status-based competition (Kerwer 2002b, p. 44). Podolny (1993) argues that all firms in a market are hierarchically ordered on the basis of status. Status is a socially defined position based on a producer's perceived quality relative to its competitors. A higher status usually translates into better business opportunities and cost savings. Unlike the reputation model, status-based competition only assumes an imperfect link between quality and status/reputation. Inter alia, a company's status is impacted by its relations with others in the market. If, e.g., a rating agency serves the biggest and most reputable issuers, its status is considered high. Also ties to high status competitors or other third parties such as governments can increase status. State recognition clearly is a powerful driver of status. Under the approach taken by BASLE II recommendations and the past approach of the SEC, official recognition is per definition reserved for the most reputable rating agencies. The state reinforces the position of the best players.

The argument now goes that issuers reach their purchasing decision by looking at the perceived quality in the form of the status $s$ and not by looking purely at the informational quality $q$. Specifically, an issuer looking for the 'best' rating will not simply analyze available correlation, transition and impact studies to find out the agency with the historically best ratings. Instead, he will choose the agency which is generally considered to be number one in the market. The status of being the best agency is derived from several different factors as de- 
scribed above; reputation for high quality is only one among them. Certainly, the best agency will also be officially recognized by the state. The depicted issuer looking for the best rating will choose the agency which ranks highest compared to its competitors. The crux of the argument is that even if quality falls, the status of a given agency may remain unchanged because its ties with third parties - notably state recognition - legitimate its position in the market. The issuer might buy a rating of an informational quality which is inferior by a maximal margin of $\varepsilon$. This results in a changed adjustment equation:

$$
\begin{aligned}
& R_{t}=s_{t-1} \quad \text { for } q_{t^{*}}-q_{t-1} \leq \varepsilon \\
& R_{t}<s_{t-1} \text { for } q_{t^{*}}-q_{t-1}>\varepsilon
\end{aligned}
$$

Equation (5.1) simply says that an agencies reputation equals its status in the prior period under the condition that the informational quality has not deteriorated more than $\varepsilon$ compared to the quality level $q_{t^{*}}$ which was provided in the period the agency originally reached its high status level and official recognition, respectively. Reputation has become 'sticky'. Consequently, a high status rating agency can reduce its informational quality by about $\varepsilon$ without losing its status. This results in cost savings of $c\left(q_{t^{*}}\right)-c\left(q_{t^{*}}-\varepsilon\right)>0$ per period. More importantly, it opens room for either pressuring issuers or to collude with them in order to hinder competitors and increase profits.

Once again, the problem described is not a flaw in the reputation mechanism. The definition of rating quality is simply much narrower than the idea of status. The argumentation could be displayed by exchanging informational quality $q_{i}$ in the Shapiro framework by status $s$. The problem, however, is the measurability of status which is necessarily based on at least some qualitative factors. Even well established status rankings of investment banks leave some room for interpretation (Podolny 1993, pp. 848-66). In any case, status is always based on quality, while the link between status and quality is loose (pp. 831, 834). This means that a low quality producer can never have a high status. All status improving links - including state recognition - are based on quality. Therefore, status cannot fully override the reputation for quality which greatly limits the discussed problem. However, if issuers do indeed base their decisions on status, there is at least room for a limited quality deterioration in the market.

The idea of market authority has been developed in the framework of status-based competition. On a broader basis the concept fits well with insights gained from behavioral finance research (Baker and Mansi 2002, p. 1371). Shefrin (2000) gives a good overview on the field. Behavioral finance transfers results of psychological research to investment decisions, which are structurally similar to the decisions to buy ratings considered here. Issuers and investors do not act entirely rational and are affected by psychological factors. Most important are heuristic-driven biases (pp. 14-23). Market participants do not decide systematically but are guided by heuristics or 'rules of thumb' which simplify complex decisions. Issuers and investors are likely to judge an agency's reputation on stereotypes such as agency size - a bias called 'representativeness'. The biggest agency represents the highest reputation. Also relevant might be 'aversion to ambiguity'. Issuers and investors play it safe choosing well known Moody's or S\&P. Cheaper or better ratings from lesser known agency cannot compete because of the perceived quality risk. The arguments of behavioral finance essentially 
soften the assumption on issuer and investor rationality. If irrationality is present, the reputation mechanism might be impaired.

Apart from official recognition and irrationality there are other factors which might override the importance of rating quality. Specifically, network effects and the two-rating norm have been identified as demand drivers. Network effects emerge from the comparability of all ratings from the same agency. However, comparability necessarily builds on consistency. If informational quality varies over time and between debt security classes, ratings are no longer fully comparable. That means network effects are quality dependent and therefore not a good explanation for a potential quality deterioration. The two-rating norm, on the other hand, has quality independent components. Like every standard, it reduces transaction costs, e.g., by investment guidelines that are tailored to Moody's and S\&P ratings. As it is cheaper to use these ratings, issuers disregard a limited quality deterioration. But one cannot generalize this result to the lock-in effects described in the supply section. Lock-in in the rating industry is in large part quality-dependent. It is very costly to change to a rating agency with the same or even less reputation. The market will, however, appreciate a change to an agency providing ratings of better informational quality.

Looking at all the different factors, how much quality scope $\varepsilon$ do agencies have? Since there are quality independent factors such as parts of the two-rating norm determining status, $\varepsilon$ is certainly positive. A general irrationality of issuers and investors cannot be assumed, however, since many have the necessary analytical skills to judge ratings correctly. Further, official recognition - one of the most important status drivers - is at least indirectly dependent on informational quality because the state can in principal withdraw it.

In sum one can conclude that the hazards of a deficient reputation mechanism are substantial. On the other hand, it is unlikely that rating agencies have much quality scope in the long run since status is too much dependent on a high standard of analysis. In any event, the state should direct its policies at minimizing the quality scope $\varepsilon$. As it cannot abolish status or prevent issuers and investors from basing their decisions on it, the most sensible goal is to increase the dependence of status on quality, e.g., by linking official recognition more strongly to informational quality. Today, there is definitely still a grey zone that allows the most reputable rating agencies to remain unaffected by single scandals. The Asian Crisis, Enron, or WorldCom hurt Moody's and S\&P much less than many would have expected. Given this real quality scope, the question arises whether it is large enough for an outright abuse or if it simply allows the agencies to get away with some laxity. The following section will answer this question.

\subsubsection{Conflicts of Interest}

Section 5.2.1 did not find much evidence for an abuse of power in the form of excessively low ratings $-\varepsilon$ seems limited from this perspective. The counterpart to power abuses is conflicts of interest of which there are many within the rating agencies' business model (e.g., Smith and Walter 2002, pp. 309-11 or CESR 2005, §§ 42-86). An agency could use its quality scope to give arbitrarily high ratings to favored issuers to save costs and generate extra profits. Competitors, in turn, would lose their business opportunities through such rating actions. However, empirical studies find no evidence for conflicts of interest affecting business 
behavior (Covitz and Harrison 2003, p. 23 and Butler and Rodgers 2003, p. 19). The results suggest that profits from misusing the quality scope $\varepsilon$ are smaller than potential costs. This is the relevant result for the state.

Of course the absolute quality scope might be significant - i.e. rating agencies could make substantial profits by giving in to conflicts of interest - if the respective costs are high, too. Although rating agencies could in this scenario reduce quality substantially without losing status, they face even higher costs. There are several logical explanations that make it unattractive to be responsive to conflicts of interest. First, there is always the danger of increased regulatory scrutiny or even the loss of official recognition once the state detects a quality reduction. Second, it is difficult to extract substantial extra profits from issuers. Both, pressuring issuers with too low ratings and colluding on high ratings, are difficult to hide. Third, by using its quality scope an agency gives in to outside interests. Suspicion about such behavior will harm its reputation for neutrality and independence even if there is no hard individual or statistical evidence of dishonest business behavior. Last, if there is some kind of evidence for giving in to outside interests, lawsuits against rating agencies could be triggered. All this will eventually reduce status and destroy the scope to lower quality.

One can see that the incentives to uphold informational quality are strong - especially for recognized agencies. Rating agencies do not fall prey to short-term gains from using their quality scope but instead protect their long-term business. The four reasons cited can be condensed by the unique industry situation: "Most businesses are not scrutinized anywhere near as closely as are rating agencies, nor they are as potentially subject to loss of shareholder value in the case of misconduct" (Smith and Walter 2002, p. 310). The reputation mechanism prevents collusion between agencies and market participants.

This result stands against the continuous criticism of rating agencies lacking thoroughness because of their protected status. Especially in the Enron case rating agencies were criticized. US Congressman Paul Kanjorski, e.g., quotes from a Financial Services Committee meeting: "The monitoring and review of Enron's finances (...) fell far below the careful efforts one would have expected from organizations whose ratings hold so much importance" (U.S. House 2003, p. 2). Similar criticism has been voiced in connection with other scandals such as WorldCom and Parmalat, which were also rated investment grade only days before their collapse (e.g., AFP 2004, p. 1). Although they could not be blamed for legal wrongdoings, the large credit rating agencies did certainly do a bad job in all of these cases.

However, there are thousands of other ratings where the agencies apparently did a good job (Hill 2004, p. 44). The agencies are blamed for single highly visible cases, from which they hardly could have profited. On the contrary, the massive public debate that was triggered represents a substantial danger to their reputation. No wonder that rating agencies accepted the criticism and actively tried try to improve - exactly as the reputation mechanism predicts (e.g., Moody's 2003). Historically, rating agencies have always taken steps to limit potential conflicts of interest, e.g., by ensuring that they not receive a substantial portion of revenues from a single client or by installing internal monitoring systems and information walls (IOSCO 2003a, pp. 10-11). They obviously know that there is much more to lose by exploiting conflicts of interest than could be gained. The simple reason is that rating quality can be nearly perfectly measured ex post, thus revealing any major wrongdoing. 
One of the few conflicts of interest not captured through informational quality is the use of private information on issuers or upcoming rating actions for insider trading or other illegal activities. Here, however, large reputation costs occur if an insider trading scandal becomes public. Additionally, there is usually a strict legal framework dealing with the matter in general that also applies to credit rating agencies (e.g., CESR 2005, §§ 121-52).

Overall, conflicts of interest are an overestimated problem in the credit rating industry. In its long history, it has not seen a single major scandal that seriously damaged the reputation for independence and objectivity of a leading agency. Conflicts of interest probably get so much attention because they are so obvious. Of course, increasing transparency and reducing structural conflicts are welcome, but the absolute impact of such measures is likely to be small. While an abuse of power can work with only a few arbitrarily low ratings, colluding with issuers and investors would mean many factually wrong ratings. Consequently, rating agencies cannot make much money from giving in to outside interests because any large scale action will be detected ${ }^{72}$.

\subsubsection{Rating Inflation}

Credit ratings are in their nature a relative risk measure. A bond rated ' $\mathrm{B}$ ' is more risky than a bond rated 'A'. In most cases, however, the absolute default probability is relevant, too. The BIS (2000) discusses the issue in detail (pp. 126-31). A fund manager wants to know how likely a default is for a given bond and which loss given default he has to expect. Default studies conducted by the rating agencies and independent researchers quantify the ordinal ranking of credit ratings. There are absolute default probabilities attached to rating categories and recovery rates are estimated for different debt classes as well. It is a general finding that the absolute risk attached to rating categories changes over time. Rating agencies are better at predicting the relative riskiness than at predicting the absolute riskiness. This can be mainly ascribed to the 'through-the-cycle' approach (for an overview see Altman and Rijken 2004, pp. 2680-83). Rating agencies concentrate on giving a correct ordinal ranking and try to avoid unnecessary rating changes. Macroeconomic cycles are not fully reflected by typical credit ratings. Therefore, "default rates exhibit a cyclical character roughly consistent with the credit cycle" (p. 127).

The cyclicality of absolute default probabilities is ceteris paribus not in the interest of investors. They prefer stable values for better planning. However, changes in absolute rating probabilities are neither drastic nor abrupt. Sophisticated investors (who have several sources of credit information anyway) can therefore anticipate such fluctuations and adapt their behavior. Rating-based regulations, on the other hand, are hardly flexible since they directly refer to specific rating classes. This is a problem because the state is primarily concerned with absolute credit risk. Capital adequacy rules, e.g., aim to secure against real defaults. If the absolute probability rises but the rating remains constant, there is a suboptimal

72 What has been concluded for conflicts of interests applies in large parts to questions of fair presentation and rating methodologies, too (CESR 2005, §§ 87-120, 153-66). These issues are often displayed in the same way as conflicts of interests, in that agencies could save costs from lax internal standards. However, lax standards will result in low quality ratings which can be detected in correlation and impact studies. It is in the interest of rating agencies to have consistent, timely and fair methods. 
level of capital. The problem is cushioned because the changes in absolute rating probabilities are not drastic. Furthermore, some rating-based regulations such as investment restrictions might do harm if they are too sensitive to short-term absolute default probabilities. If credit risk rises temporarily, many pension funds, e.g., might need to sell assets which they will buy back after the credit risk returns to a normal level. The through-the-cycle approach prevents costly short-term distortions.

For the state, the danger of the relative nature of credit ratings lies somewhere else: i.e. in a 'credit rating inflation' (e.g., Hill 2004, pp. 77-78). Rating-based regulation aims at structural benefits, while the individual issuers and investors have to bear the costs. They have an incentive to avoid rating-based regulations. An across-the board rise in ratings would offer such an opportunity, because regulatory burdens decrease with a higher absolute rating class. The information value of ratings does not suffer thereby, for the ordinal ranking remains the same and only the absolute credit risk attached to rating categories rises. Consequently, investors - anticipating an adjustment of absolute default probabilities - experience a constant informational quality. The reputation damage of a rating inflation might be limited. On the other hand, there is an increased willingness to pay for inflated ratings from issuers because their financing costs decrease. This not only increases the market leaders' profits, but it also hinders competitors who have a harder time to deliver value to the issuers. The more important the regulatory value of ratings is, the higher the incentive for rating agencies to inflate ${ }^{73}$.

The theoretical danger of a rating inflation is apparent. Empirical research, however, contradicts the thesis. Ratings by Moody's and S\&P became systematically and steadily more conservative between 1978 and 1995 - a time during which many major rating-based regulations were introduced (Blume et al. 1998, p. 1403, 12). One explanation is that rating agencies are generally conservative to avoid any risk for their reputation, especially with innovative financial products (Schwarcz 2001, p. 306). This cannot explain the empirical finding, though, that Moody's is systematically more conservative than Egan Jones Ratings Company, a reputable but not officially recognized agency (Beaver et al. 2006, p. 332). Moody's seems to strive to satisfy its role as quasi-regulator which requires a certain level of conservatism. Obviously, Moody's finds it more profitable to be conservative than to inflate its ratings. The general reasons against exploiting conflicts of interest discussed in the subchapter just above apply. Especially increased regulatory scrutiny and investor law suits are relevant (Hill 2004, p. 78). If investors can prove that a rating agency helps issuers to avoid regulatory limitations, this is a good basis for legal action. In the extreme case the state might withdraw official recognition.

The fear of a rating inflation is not unfounded, though. It might become relevant if less reputable agencies receive state recognition. Since they have not invested a lot into reputation, a market exit would not destroy much value for them. Therefore, they might take the gamble of

73 Jackson (2001, pp. 321-22) discusses the issue from the perspective of the Basle II framework. Here, states themselves might have an incentive to free themselves from the international capital adequacy framework. They could effectively release issuers in their jurisdiction from the strict rules by recognizing agencies with inflated ratings. The problem becomes attenuated by Basle II implementation guidelines such as the CEBS recognition guideline which feature a detailed mapping process (CEBS 2006, § 121-173). 
losing recognition by inflating ratings to generate extra profits. To prevent such behavior a mapping process is necessary (e.g., BIS 2004, § 92). By mapping individual risk categories to a set of absolute risk weights, the relative level of ratings becomes ineffectual.

\subsubsection{Timeliness}

One of the oldest concerns regarding the quality of credit ratings is an alleged slowness of downgrades (for detailed examples from the 1980s and early 1990s see Bottini 1993, pp. 584-94). Rating agencies should be quicker in scrutinizing new information and changing ratings accordingly. In defense of the rating agencies one has to accept that ongoing monitoring is very costly (Hill 2004, p. 71). Therefore, it seems acceptable that rating changes at times lag behind market developments. A second factor relieving rating agencies is the unpredictability of certain events such as fraud or legal action which can cause sudden defaults. However, in cases such as Enron or WorldCom there were clear signs of trouble - not least in the form of falling bond and equity prices - which should have been taken up by all rating agencies. Nonetheless, the ratings by Moody's, S\&P and Fitch remained investment grade until a few days before default. Clearly, these ratings were of low quality at the time.

The problem of timeliness becomes complicated because of three factors. First, ratings serve different functions as shown in section 2.1. From the perspective of the information function, rating changes should be as timely as possible, even if they are to be corrected soon after. From the perspective of the certification function, ratings should be more stable, because changes in the regulatory status of a security cause transaction costs for regulated entities. Second, rating-based regulation and private equivalents such as rating triggers create a circularity (e.g., Nicholls 2005 p. 17). The consequences of downgrades in particular have a direct negative impact on issuers that might lead to further downgrades or even default. It is desirable that rating agencies are not too quick with rating actions, so that no avoidable 'chain reactions' are started. Third, issuers and investors have different needs from ratings (Hill 2004, pp. 70-71). Issuers favor slow downgrades and quick upgrades. Investors interested purely in the credit information - which should be the majority - generally favor quick rating actions, while investors subject to regulatory restrictions favor slow downgrades and quick upgrades. Whereas the first two factors describe the state's perspective (informational efficiency vs. costs of quick downgrades), the third factor describes a trade-off for the rating agencies in maintaining their reputation.

Survey results support the theoretical view: over 74 percent of investors believe rating changes are not timely, while 71 percent of issuers believe their ratings are up-to date (Baker and Mansi 2002, pp. 1389). Empirical research, too, is supportive. Beaver et al. (2006, p.304) find that "the properties of bond ratings are shaped by the institutional incentives placed on them by their clientele". As cited above, the study shows that Moody's is systematically more conservative than Egan Jones - a reputable agency not officially recognized in the USA. Specifically, Moody's is slower with rating changes, including downgrades. Moody's is concerned with satisfying its quasi-regulatory position in order to keep its high reputation. Eagan Jones only has the function of an information provider, so they serve their reputation best with timely rating actions. 
In the definition of rating quality used in the reputation model, timeliness plays no explicit role. This is because it is implicitly covered by correlation studies, which map defaults against ratings referencing to different time frames. One year default rates, e.g., should be lower than five year default rates. Of course there are no studies on very short time frames, say a one month default rate for long-term debt. Such studies would likely be very random. High profile failures like Enron, WorldCom or Parmalat discussed in public are probably the only one month defaults in the investment grade area. But already one year default studies show that the rating agencies get it right in general. In conclusion one can hold that timeliness is to a certain extent already part of rating quality as defined in the reputation framework and understood by the market. Rating agencies face a trade-off between quick and slow rating actions, especially when they are officially recognized. The state likewise has opposing incentives. Therefore, timeliness of rating actions should not be paramount in regulatory policy, but left to the rating agencies. They are as timely as it is best to maximize their reputation. After the Enron scandal, e.g., rating agencies often accelerated downgrades in response to market criticism, sometimes even so much that they were criticized for acting hastily (Hill 2004, pp. 70-71). 


\section{Economic Assessment of Regulatory Options}

After having analyzed the economics of the credit rating industry in chapters 3 and 4, and potential forms of market failure in chapter 5, the last step to consider is if and how these problems should be tackled by the state.

Figure 6.1 summarizes the results of chapter 5 . The column 'Impact' describes how large the impact is of an area of concern on the state's goals if the concern is indeed justified. The column 'Probability' gives an indication on the likelihood that a concern is justified or realized respectively. From the state's point of view, the focus should be on the areas which have a high impact and where it is likely that problems occur, i.e. on areas posing a high 'Threat'. The column 'Measure' contains the instruments which have been identified as most effective in attenuating the potential problems. It is the purpose of this chapter to show how the measures should be implemented. Operational details will be largely left aside and can be followed up in the cited literature.

\begin{tabular}{|c|c|c|c|c|c|}
\hline \multicolumn{2}{|l|}{ Area of concern } & \multirow{2}{*}{ Impact } & \multirow{2}{*}{\begin{tabular}{|c|} 
Probab. \\
(
\end{tabular}} & \multirow{2}{*}{ Threat } & \multirow{2}{*}{\begin{tabular}{|l} 
Measure \\
increase competition
\end{tabular}} \\
\hline Static efficiency & Reduced quantity & & & & \\
\hline & X-inefficiencies & () & (1) & 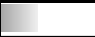 & increase competition \\
\hline Social costs & & () & () & 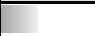 & easier official designation \\
\hline \multirow[t]{2}{*}{ Dynamic efficiency } & Few product innovations & () & () & 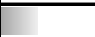 & increase competition \\
\hline & Few process innovations & () & () & - & increase competition \\
\hline \multirow[t]{7}{*}{ Financial market stability } & Procyclicality & () & () & $\overline{-1}$ & (regulate rating methodologies) \\
\hline & Conformity bias & () & () & $\bar{m}$ & (regulate rating methodologies) \\
\hline & Rating Triggers & () & (1) & ]$^{2}$ & increase transparency \\
\hline & Parallel investors behavior & () & $\boldsymbol{\theta}$ & 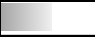 & reduce rating-based regulation \\
\hline & Agency failure & O & () & 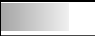 & increase competition \\
\hline & Information provision & () & (1) & $\bar{c}$ & give access to private information \\
\hline & Standardization & () & () & 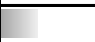 & support standardization \\
\hline \multirow[t]{2}{*}{ Uncompetitive behavior } & Unsolicited ratings & (1) & $\boldsymbol{\theta}$ & & increase transparency \\
\hline & Notching / Tying & (1) & (1) & & increase competition \\
\hline Political power & & $\mathrm{O}$ & O & 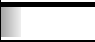 & reduce rating-based regulation \\
\hline $\begin{array}{l}\text { Reputation mechanism } \\
\text { (rating quality) }\end{array}$ & & & () & & $\begin{array}{l}\text { strengthen reputation mechanism, } \\
\text { increase transparency, make official } \\
\text { designation more flexible }\end{array}$ \\
\hline Conflicts of interest & & అ & () & & increase transparency \\
\hline $\begin{array}{l}\text { Rating Inflation } \\
\end{array}$ & & $\overline{\boldsymbol{\theta}}$ & () & 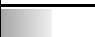 & risk mapping by regulators \\
\hline Timeliness & & (1) & () & 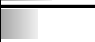 & (regulate rating methodologies) \\
\hline
\end{tabular}

\section{Figure 6.1: Summary of regulatory concerns}

The large number of concerns causes the rating industry to appear prima facie as highly prone to state intervention. However, the analysis has shown that the actual threats are limited. This is especially so because most concerns are just that - concerns. There is very little empirical evidence that things are actually going wrong. The largest threat stems from the reputation mechanism itself. If it is impaired, rating quality might fall without hurting reputation. In this case, many of the described potential problems become much more likely, so the impact is very high. The main measures the state could take are increasing competition and transparency, and changing the system of official recognition.

Not all concerns could be fully dealt with by intervening in the rating industry. Most notably, the danger of rating triggers results from private contracts outside the reach of rating agencies (Nicholls 2005, p. 19). The state would need to increase reporting standards for all fi- 
nancial market participants. Several other issues, mostly structural risks, can either not be directly tackled at all or would require state interference into the rating methodology. This idea should be dismissed right from the beginning since it would effectively mean that the state itself engages in credit ratings. This cannot be the goal of regulatory policies as private ratings are used in rating-based regulation precisely because private actors are superior to the state in assessing credit risk.

Many other concerns pose such a little threat by themselves that it is questionable if there would be a measurable effect on a market intervention. A regulatory regime must always be designed cost-efficiently, considering administrative and compliance costs alike (Rousseau 2005, pp. 41-42). Most low level threats will likely not pass this hurdle in an empirical analysis. Therefore, it is advisable not to concentrate too much on single threats but to look at measures which can improve conditions in many areas.

Figure 6.1 shows that certain measures affect different areas positively, making it easier to implement them cost-efficiently. The state should firstly see that its regulatory legislation increases competition and does not hinder it further. This is by far the single most important measure. Second, official recognition should be not too restrictive in order to encourage market entries and to reduce the status gap between the market leaders and the rest. Third - as long as rating methodologies remain protected - it is advisable to increase transparency in various forms. Eventually of course, all these measures should be directed at strengthening the reputation mechanism, i.e. the market control of the credit rating industry.

While it is simple to suggest to only correct market failures which can be tackled costefficiently, one has to keep in mind that modern regulation theory convincingly points to 'government failure' (e.g., Viscusi et al. 2005, pp. 380-83): "Regulatory legislation redistributes wealth" as its primary purpose (p. 382). Since the profits of rating agencies are great and issuers and investors are strongly affected by rating-based regulation, the stakes are high. Furthermore, investors and issuers have powerful lobbies with good political connections. There is scope for political manipulation through regulation (Schwarcz 2001, p. 303). Also the fact that a state relies on private ratings is not a reason for government intervention per se. There must always be a clear perspective to correct market failures by either improving the rating agencies' performance or by limiting negative influences of ratings on financial markets (pp. 301-302). In addition, one has to avoid short sighted regulatory overreaction in the light of highly visible 'rating failures'. Further, legislation should not focus on Moody's and S\&P alone. The goal should rather be a common high quality standard in the rating industry. Lastly, any regulatory legislation should be coordinated on a worldwide basis. National solutions are often insufficient in dealing with a fully globalized industry. In extreme circumstances, rating agencies might avoid certain national regulation by relocating to a different jurisdiction.

Before moving on the actual assessment of regulatory options, it is useful to point out recent regulatory developments. The question of credit rating agency regulation is discussed from two perspectives. On the one hand, attention focuses on the 2004 Basle II Capital Accord which suggests integrating credit ratings into the international capital adequacy framework a development contrary to the critical attitude of some states. The EU Parliament (2006) was 
the first legislative body to adopt Basle II in its Capital Requirements Directive (CRD) in $2005^{74}$. Among other things, recognition criteria for External Credit Assessment Institutions (ECAIs) are defined. The Committee of European Banking Supervisors CEBS (2006) has specified detailed implementation guidelines to achieve supervisory convergence on the national level. The second reason for public attention to credit rating agencies is an alleged carelessness of the agencies, which harms financial markets and the public at large. This discussion has gained momentum especially because of the weak performance of Moody's, S\&P, and Fitch in the wake of the collapses of Enron and other large companies in 2001 and 2002. There have been numerous national and international regulatory initiatives since.

Regulatory bodies worldwide tend to support international solutions to potential problems in the credit rating industry. The International Organization of Security Commissions (IOSCO) is used as the platform for this process. After more than a year of research and public discussion the IOSCO formulated 'Code of Conduct Fundamentals for the Credit Rating Agencies' in late 2004 (IOSCO 2004). The code provides the credit rating industry with an internationally accepted framework of self-regulation. Most agencies - including the three market leaders - have implemented the code, often literally (e.g., CESR 2006a and CESR 2006b). There are, however, no enforceable rules resulting from the IOSCO framework and important issues such as official recognition have not been covered. The question of national regulation remains largely unanswered.

After the accounting scandals of 2001 and 2002 the US congress launched an inquiry into the role of auditing, investment and rating firms in these scandals. The resulting SarbanesOxley Act of 2002 introduced various substantial changes in financial regulation and several directives for further analysis (US Congress 2002). The Act did not include legislation concerning credit rating agencies directly, but required the SEC to reexamine the role and function of credit rating agencies in the securities markets, a task which was already high on its agenda. Building on prior research, hearings, a concept release, and a substantial amount of public comments, the SEC proposed a rule in early 2005 which, among other things, defines the specifics of the NRSRO process (SEC 2005).

Parallel to the proposed rule, the SEC testified in the third hearing on credit rating agencies before the U.S. House of Representatives Committee on Financial Services that "more explicit regulatory authority from Congress is necessary" (U.S. House 2005c, p. 6). The Committee readily took up the request, rendering the proposed rule obsolete. Congressman Fitzpatrick proposed the 'Credit Rating Agency Duopoly Relief Act' which was controversially debated in the next two Committee meetings on credit rating agencies (U.S. House 2005a,b). It was passed by the House of Representatives in June 2006 in a close vote divided along partisan lines (US Congress 2006a). After certain changes by the Senate Banking and Urban Affairs Committee, however, the final bill was enacted into US law in September 2006 by a virtually unanimous vote as the 'Credit Rating Agency Reform Act of 2006' (US Congress 2006b). From 2008 on it replaces the NRSRO designation with a registration process, introduces SEC oversight, e.g., in the form of disclosure requirements, and increases liability.

74 In other regions the adoption of Basle II has been slower. The USA, e.g., postponed the process for a year and introduced a transition period (Federal Reserve Board 2005). 
Rating agencies are now held accountable for satisfying their own standards filed with the SEC.

Credit rating agencies have also been on the agendas of European institutions after the Enron scandal. In early 2004 the European Parliament adopted a resolution on rating agencies and called on the EU Commission to assess the need for legislative actions (EU Parliament 2004). The Commission received technical advice from the Committee of European Securities Regulators (CESR) in March 2005, which reflects the results of an intensive six month consultation process (CESR 2005). In line with the CESR advice, the EU Commission (2005) announced in December that it would not for the time being introduce any legislative proposals concerning rating agencies, but would rely on existing financial services directives and self-regulation on the basis of the IOSCO code of conduct. The CESR in turn began a dialogue with the big rating agencies to oversee the self-binding implementation process (e.g., CESR 2006a).

One can see that the issue of rating agency regulation is high on the international agenda. However, the process is at an intermediate stage. There are several different approaches and certain areas have been left out by some regulatory bodies. What is needed to appraise the different approaches from an economic perspective is a coherent framework of regulatory options. Rather than analyze state interference in the classic framework of antitrust and regulation, a more specific approach tailored to the credit rating industry will be taken here.

Figure 6.2 indicates five major regulatory options and the approach currently taken in the EU under the Capital Requirements Directive and the USA under the Credit Rating Agency Reform Act. In the remainder of this chapter an economic analysis on the design of the different options will be conducted.

\begin{tabular}{|c|c|c|}
\hline & EU & USA \\
\hline $\begin{array}{l}\text { Use of ratings in } \\
\text { regulation }\end{array}$ & $\begin{array}{l}\text { Use in bank regulation (Basle II); } \\
\text { Further use by some members }\end{array}$ & General rating-based regulation \\
\hline Competition & Neutral position & Strengthen competition \\
\hline $\begin{array}{l}\text { Official } \\
\text { recognition }\end{array}$ & Designation process & Registration process \\
\hline Civil liability & Mostly protected from civil liability & $\begin{array}{l}\text { First Amendment protection, in } \\
\text { tendency increasing civil liability }\end{array}$ \\
\hline $\begin{array}{l}\text { Implementation } \\
\text { method }\end{array}$ & Self-regulation & Direct supervision \\
\hline
\end{tabular}

Figure 6.2: Credit rating agency regulation in the EU and USA 


\subsection{Rating-Based Regulation vs. Market-Based Regulation}

Rating-based regulation has an important influence on the credit rating industry. It increases demand and potentially hinders supply, as not every rating can be used for compliance. Apart from informational quality, official recognition is the single most important factor influencing an agency's perceived status in the market. It might therefore impede the reputation mechanism and advance a quality scope which is the basis for many concerns. Additionally, there are some direct problems such as parallel investor behavior. Quite naturally, it should therefore be one of the first questions of the state whether the additional complexity and problems of rating-based regulation are worth the effort.

The question has been touched upon by several authors, but few discuss the issue in detail. Partnoy (2006, pp. 91-95) makes a strong case for replacing NRSROs with market-based measures in the USA. In a commentary, the investment banker Justin Pettit gives some direct counter argumentation (pp.101-02). Löffler (2004) and Perraudin and Taylor (2004) analyze the issue empirically.

Before evaluating rating-based versus market-base risk measures, one should ask a more fundamental question: Would it make sense to abolish credit risk-sensitive regulation? In this case most the discussed problems will be avoided. Unsurprisingly, the clear economic answer to the question is no. The stability of the financial system can be greatly enhanced by containing risk: confidence increases and certain investors can be protected. It is worth sizeable effort to find a suitable credit risk measure. A second question follows: Should the state use external measures or should it generate its own credit assessments? An internal solution would mean state ratings, the use of which is dictated by law. There are some obvious problems with this solution. Even an independent body (alike some central banks, e.g.) is likely to be influenced by the legislator who in turn is influenced by interest groups. Furthermore, it is questionable if a state agency has the resources and capabilities for accurate risk assessments. Without the profit incentive, a state body is likely to be slow to innovate, too. Although there might also be benefits, it seems rather clear that an external credit risk measure is needed.

The two principal external credit risk measures are credit ratings - as used in rating-based regulation today - and market-based measures such as credit spreads, credit default swaps, or even equity prices. Figure 6.3 contrasts several aspects of credit risk measures and compares how credit ratings and market-based measures compare to a hypothetical optimal risk measure. Both approaches have their strengths and weaknesses. The biggest advantage of market-based measures is their timeliness and flexibility. They can be updated daily, while being smoothed out over any time span through rolling averages. The problems of parallel investor behavior or credit cliffs would be eased since abrupt rating changes would be ruled out. The biggest disadvantage of market-based measures is their limited reach. There are many illiquid securities and new issues cannot be rated at all. Since a full reach is a knockout criterion for any stand-alone risk measure, there is no way to implement a system of purely market-based regulation. 


\begin{tabular}{|c|c|c|c|}
\hline Aspect & Optimal for Use in Regulation & Credit Ratings & Market-Based Measures \\
\hline Breadth & Every debt security & $\begin{array}{l}\text { Every debt security; including } \\
\text { new issues and illiquid junk } \\
\text { debt** }\end{array}$ & Only traded (debt) securities \\
\hline $\begin{array}{l}\text { Informational } \\
\text { quality }\end{array}$ & All available information & $\begin{array}{l}\text { Incorporate public and private } \\
\text { information, no (detailed) audit } \\
\text { of issuer-provided }\end{array}$ & $\begin{array}{l}\text { Include all available information in } \\
\text { the market* (all public, potentially } \\
\text { some private) }\end{array}$ \\
\hline Timeliness & $\begin{array}{l}\text { Timely ratings reflecting mid- } \\
\text { /long-term developments }\end{array}$ & $\begin{array}{l}\text { Through-the-cycle approach, but } \\
\text { not always timely }\end{array}$ & $\begin{array}{l}\text { Timeliness/volatility can be explicitly } \\
\text { chosen through rolling averages* }\end{array}$ \\
\hline Independence & $\begin{array}{l}\text { Independent from all involved } \\
\text { parties }\end{array}$ & $\begin{array}{l}\text { Reputational capital guarantees } \\
\text { independence }\end{array}$ & $\begin{array}{l}\text { Liquid securities: competitive } \\
\text { pricing/no manipulation possible*; } \\
\text { Illiquid securities: price manipulation } \\
\text { possible }\end{array}$ \\
\hline Risk measure & Absolute measure of credit risk & $\begin{array}{l}\text { Relative credit risk measure, } \\
\text { absolute risks can be mapped to } \\
\text { rating classes }\end{array}$ & $\begin{array}{l}\text { Absolute risk measure, but } \\
\text { influenced by other factors than } \\
\text { credit risk such as liquidity or taxes } \\
\text { (less relevant for CDS) }\end{array}$ \\
\hline Clearness & Clear-cut data & $\begin{array}{l}\text { Clear-cut rating classes, but } \\
\text { absolute risk needs to be } \\
\text { mapped to classes }\end{array}$ & $\begin{array}{l}\text { Because of differences in markets, } \\
\text { complex definitions might be } \\
\text { necessary }\end{array}$ \\
\hline Costs & Low costs & $\begin{array}{l}\text { Moderately expensive for } \\
\text { issuers, but freely available to } \\
\text { the public }\end{array}$ & Mostly cheap, easy to calculate \\
\hline $\begin{array}{l}\text { Market } \\
\text { neutrality }\end{array}$ & $\begin{array}{l}\text { No 'unintended' distortion of } \\
\text { capital allocation }\end{array}$ & $\begin{array}{l}\text { Incentives for regulatory } \\
\text { arbitrage, e.g., in CDO markets* }\end{array}$ & No regulatory arbitrage* \\
\hline
\end{tabular}

Figure 6.3: Credit ratings vs. market-based measures in credit risk-based regulation

The scores in Figure 6.3 reflect the results of the analysis in the previous chapters. Critics will likely attack the high scores of informational quality and independence for credit ratings. Empirical research, however, finds that the informational content of credit ratings and marketbased measures is similar (Perraudin and Taylor 2004, p. 2768). Consequently, neither is superior for portfolio governance rules (Löffler 2004, p. 2742) ${ }^{75}$. Furthermore, it has been shown that the issue of rating agency independence is overestimated, especially under a well functioning reputation mechanism. Market-based measures, on the other hand, are prone to manipulation for illiquid securities.

In conclusion one can hold that substituting rating-based regulation is neither possible nor advisable. However, there are clear benefits of market-based ratings. Private rating agencies have in many cases recognized the potential and offer corresponding services. Moody's, e.g., has established an important business field in quantitative credit analysis with the purchase of KMV, today known as 'Moody's KMV' (e.g., Moody's Corporation 2006, p. 24). It is advisable for the state to explore the possibilities of actively utilizing market-based ratings. One promising opportunity is to officially recognize quantitatively oriented rating agencies which translate market data into common ratings. Since such agencies are only one type among several, the liquidity-based selectiveness of their ratings is no problem.

75 Another argument brought forward is that private parties would use market-based measures instead of ratings as legal triggers if the former would be the better instrument (Nicholls 2005, p. 20). This argument can be attacked, however, since rating triggers perfectly measure changes in the regulatory status of bonds which is very important for counterparties. The information value might be second-rate. 
One problem could arise from the business model of quantitatively oriented rating agencies though. Since no data from the issuers is used to compute ratings, it stands to reason that especially new agencies will (initially) chose an investor paid business model. This would conflict with the free availability of ratings needed to comply with rating-based regulation. If the market fails to create free market-based ratings, the state could award subsidies for respective agencies. Alternately, the state might consider setting up a public credit rating agency to provide exclusively market-based ratings. A set of clearly defined mechanical rules (minimum liquidity, exact computation of ratings, etc.) would be needed to guarantee independence. While certainly viable, such an approach hinders private competition in the field, potentially crowding out better solutions.

\subsection{Fostering Competition vs. Restricting Competition}

The credit rating industry is characterized by high entry barriers and limited competition tactical collusion is likely as shown in section 4.3 on strategic interaction. The analysis in chapter 5 has shown, however, that several potential problems of efficiency and anticompetitive behavior would be attenuated by more competition. Given these results, two questions emerge: Why should one consider limiting competition as a policy option in the first place, and, how could the state increase competition given the limiting market forces?

The principal fear of increased competition is a breakdown of the reputation mechanism leading to deteriorating quality. Kranton $(2003, p$. 399) shows in a general model that restricted entry can enhance quality. Butler and Rodgers (2003, p. 2) reason in an empirical study that high rents as a result of limited competition increase the amount of 'relationship rating' which in turn increases overall informational quality since it includes private information. However - even if quality increases in tendency with higher profits - it does not mean that more competition reduces it. In section 3.6 it has been shown that Kranton's assumption on the possibility of strategic pricing does not apply to the rating industry. In the absence of rating-based regulation, the analysis in chapter 4 has shown that there is no incentive for reputable incumbents to reduce their quality, while newcomers, too, have no choice other than to produce high quality.

Nonetheless, the fear has been voiced that "excessive market fragmentation could have adverse consequences", namely "undue pressure to issue favorable ratings in order to attract clients" (EU Commission 2005, p. 7-8). Conflicts of interest might become more significant if the market is less concentrated (Hill 2004, p. 45) ${ }^{76}$. There might be 'a race to the bottom' in rating standards.

The argument takes the perspective of rating agencies trying everything to gain business with issuers. When taking the perspective of the investors, though, it becomes clear that the argument is exclusively based on the existence of rating-based regulation. If the benefits of ratings were purely informational and reputational, a favorable rating has no value at all because it neither carries information nor reputation. Respective agencies would go out of

76 Mariano (2006) tries to theoretically explain how competition can lead rating agencies to deliver low quality. While the model is conclusive, several assumptions such as the two period timeframe and quality believes which are still imperfect ex post do not hold. Therefore, the argumentation is not convincing. 
business. Only if there is a license value of ratings do the voiced concerns make sense in the first place. Practically though, it is doubtful if they are justified. McNamara and Vaaler (2000, pp. 343-44), e.g., find in their empirical study on sovereign ratings that 'insurgent' rating agencies are more conservative than incumbents in order to gain reputation. Increased competition reduces this conservatism bias, but insurgents are still more conservative on an absolute scale. Incumbents, on the other hand, are not significantly affected by the number of competitors.

One can now answer the initial question. It only makes sense to consider limiting competition as a policy option if distortions resulting from rating-based regulation can be expected. Under the traditional restrictive NRSRO designation in the USA this seems not to have been a problem. The analysis in section 4.1.2 on the impact of rating-based regulation on demand, however, provides a theoretical basis for quality concerns. Rating agencies might very well have incentives for sham ratings. Furthermore, the considerations in section 5.2.3.3 on rating inflation show that it is in principal possible for rating agencies to provide a high informational quality for investors and to exploit rating-based regulation at the same time. However, this potential downside of increased competition is not a problem of competition per se. It is a question of the recognition procedure, which will be analyzed in the following section.

Assuming that official recognition prevents any major downside of competition, one can now look at the second question: How could the state increase competition? One tool is again official recognition. It can be a major entry barrier to the industry. However - as summarized in Figure 4.9 - there are also plenty of 'natural' factors limiting competition in the credit rating industry. The part of the competitive process hindered most is market entry - the credit rating industry is not contestable (e.g., Viscusi et al. 2005, p. 172). First, entrants are likely to face high direct entry costs and the users of ratings have a clear preference for incumbents. As it is costly to overcome such preferences (e.g., the two-rating norm), entrants face a disadvantage vis-à-vis incumbents. Second and most importantly, time lags in reputation building make it virtually impossible to enter quickly, no matter how much money is spent. The third condition necessary for contestability is the absence of sunk costs. This condition is met best by the credit rating market, but because of substantial exit costs when cheating it is also missed.

Because there is little outside pressure, the state should focus its efforts on increasing the number of players, i.e. the 'inside pressure'. Economic regulation and antitrust policy are the two tools at hand. Bar official recognition, there is little room for economic regulation though. One of the few possibilities would be to subsidize young rating agencies. In the section immediately above, e.g., supporting innovative investor-paid rating agencies has been considered. In principal, however, subsidies are seldom a good solution to economic problems since they are, among other things, prone to rent-seeking. Further, increasing entries into the credit rating industry will not do. It has been shown in section 4.3 that it is a mutually attractive strategy for small successful entrants and big incumbents to merge with each other.

At this point antitrust considerations come into the game. The state can influence the industry structure by interfering with mergers and acquisitions. Admittedly, this may be in many cases legally difficult as acquisitions of small entrants hardly hinder competitors. Rather, society forgoes benefits from a higher competitive pressure in the mid and long run. Besides this 
technicality, a second question arises: Which mergers are harmful and which increase competition? In section 5.1.1.3 on innovation it was concluded that midsized agencies pose the highest competitive threat for large incumbents, because they still have the flexibility of a young organization while already possessing the needed reputation. It would therefore be a sensible policy to only allow mergers among smaller agencies. This is how Fitch developed into its strong position as third player today. Overall, however, one has to accept that the credit rating industry is framed by exceptionally strong forces hindering competition - it is a natural oligopoly at best. No policy will ever bring about strong competition. But it goes without saying that the state should at least try to foster competition as much as possible.

\subsection{Official Designation vs. Registration}

The issue of official recognition for compliance with rating-based regulation has been discussed in many studies such as CESR (2005, §§ 256-68), Blaurock (2006, pp. 10-13), or Schwarcz (2001, pp. 307-309). Following the argumentation on rating-based regulation in section 3.1.2 it does not wonder that practically all authors see a need for some kind of official recognition. Only Brookfield and Ormrod (2000, p. 326) argue with a large data set that official recognition is duplicative and therefore not needed. However, they base their analysis on the assumption that official recognition perfectly reflects reputation/informational quality and that there are no issuers interested in buying sham ratings. Beaver et al. (2006, p. 332) show empirically that official recognition under the original NRSRO process correlates with rating agency properties.

How should an optimal recognition system look? Should it be a restrictive designation process such as the original NRSRO designation in the USA or should it be a simple registration process as employed under the Rating Agency Reform Act of 2006? It has been concluded already in the previous section that there is an antitrust/competition component and a regulation component to the question. From the perspective of competition, the system should not set additional limits to the already anticompetitive nature of the industry. It would be welcome, on the other hand, if competition is stimulated. The Rating Agency Reform Act of 2006 aims in this direction. The regulation component is important, too. An optimal recognition system must guarantee a high rating quality, neither making possible sham or inflated ratings, nor creating leeway for a quality scope which is in turn the basis for anticompetitive behavior and conflicts of interest. The original NRSRO process has been justified by such argumentation.

Traditionally, official recognition worldwide has been heavily based on market recognition, while lacking transparent operational criteria (BIS 2000, pp. 44-50). Market recognition is equivalent to agency status as described in section 5.2.3.1. The agencies most widely used and praised in the market become recognized (SEC 2005, p. 21312). The principal benefit of the approach is its ease of implementation since there is neither a difficult initial analysis nor much oversight needed. There are, however, deficiencies in the approach. Most importantly, there is a circularity. Market recognition or status is strongly influenced by official recognition. As soon as an agency is officially recognized it receives a boost in its status perceived in the market. Because of the newly acquired license value, the agency's ratings immediately gain more impact. 
This causes two problems. First, it becomes more difficult for new agencies to enter the rating industry. To become accepted in the market, official recognition is needed but to become officially recognized market acceptance is needed. The circularity constitutes a direct entry barrier: newcomers must build up a good reputation by issuing many low-paid ratings for several periods. They have to incur costs which the incumbents - who were 'grandfathered' into their position - never had to incur to such an extent (Beales 1980, p. 135). The second problem is that official recognition itself might increase status to such an extent that rating agencies gain a quality scope $\varepsilon$ (see section 5.2.3.1). Even if informational quality falls, market acceptance stays high because of state recognition, and state recognition remains because of high market acceptance. The rating agencies in turn can come away with lax standards to save costs or even with anticompetitive behavior or the temptation to exploit conflicts of interest, which both become much easier if rating quality can fall a bit without punitive action.

One can conclude that founding official recognition on market recognition/status, although attractive in theory, has turned out to be deficient in practice because status is not fully based on quality. The system neither fulfills the demand of not limiting competition nor of guaranteeing high quality. Therefore, official recognition should be based on other principles. Possible criteria fall into two categories: input measures and output measures.

Input criteria are very common in regulation. Examples are driving licenses, professional qualifications, or capital requirements. The IOSCO code of conduct, e.g., focuses largely on input criteria such as systematic rating methodologies or independence in promoting a high rating quality (IOSCO 2004). Input criteria have the benefit of guaranteeing a minimum quality level. When the basic reputation model has been developed in section 3.1, it has been argued that, e.g., the qualification of employees observed by issuers guarantee a minimum quality $q_{0}$. If the state gives detailed guidelines on input factors, it can likely guarantee also higher quality levels $q_{s}>q_{0}$, not least because it can demand access to confidential internal operations of rating agencies. The analysis of demand in section 4.1.2 has later shown that it is (under normal circumstances) sufficient for the state to only guarantee a medium quality level $q_{s}$. Figure 4.3 shows that sham ratings are effectively prevented. Above a certain quality level the market functions well. Demand 'automatically' concentrates on the high quality levels, which is the goal of the state. From this perspective, input regulation seems to be well suited for official recognition.

On closer inspection, input regulation is deficient though. Figure 4.4 shows a scenario corresponding to the 'regulatory license view'. If the license value is relatively high compared to the information/reputation value, the market might not function above the regulatory threshold $q_{s}$ as intended. In the depicted extreme case, demand would concentrate on the lowest 'allowed' quality. Although this scenario has been rendered implausible, it is not completely irrelevant, as discussed at the end of section 4.1.2.3. The license value might well be high enough so that certain issuers - who do not care at all for the reputation value - buy the cheapest available ratings. A pure input regulation cannot avoid the problem since it reaches its limit at some point. In other words, even if the best inputs are employed, one can never tell if an agency really produces the highest possible informational quality. To lessen the problem, an input oriented recognition system should aim at guaranteeing a quality level $q_{s}$ as high as possible. 
There are further problems with a recognition regime purely based on inputs. As the elasticity of substitution between production factors is partly high, only a comparatively low quality level $q_{s}$ can be guaranteed at best (Beales 1980, pp. 128-29). Highly qualified employees, e.g., might only spend very little time per rating, i.e. analytical thoroughness gets substituted by high qualification. Further, any input control necessarily builds on standards, say on the organizational structure of rating agencies. Such standards limit entrepreneurial freedom which potentially deters new innovative rating methods and business models (White 2002, p. 54). This is especially a problem for newcomers who have little chance to differentiate themselves. Input regulation can be a barrier to entry. An input oriented recognition system should therefore make sure that key areas such as rating methodologies remain flexible.

One sees that input measures cannot guarantee a high rating quality in all circumstances. The obvious solution is measuring output, i.e. rating quality. Contrary to many other areas, rating quality can be measured very well through correlation, transition, and impact studies ${ }^{77}$. Output control is economically preferable to input control, not least because it allows for continuous monitoring (Beales 1980, p. 134). The original NRSRO approach of matching official and market recognition tries to proxy quality, however, with the described problems. It is much more advisable to directly make official recognition dependent on observed rating quality. A major benefit of such a system is that it places no limits whatsoever on rating methodology. Successful quantitatively oriented agencies, e.g., could easily be recognized. Furthermore, the state can map the different rating scales against a common standard so that a rating inflation is impossible. Another benefit specific to the rating industry is the limited downside of output control. Restricting a market to high quality usually creates an economic loss because consumers preferring low quality are hurt (p. 133). But in the rating case there is no demand for low informational quality. Additionally, there is always the possibility to operate a non-recognized rating agency producing any quality level desired.

It seems incomprehensible that states worldwide have never taken a clear and direct output oriented approach. The most likely explanation is the increased efforts needed to define and control quality. However, the efforts are not immense and the potential benefits are large. There are already correlation, transition, and impact studies by the rating agencies themselves which are routinely checked and expanded by independent scholars. The state would in most cases not need to conduct own studies, it would be sufficient to define a set of specific existing variables measuring rating quality. Alternatively, one could take an 'exclusion approach' by making recognition dependent on a continuous track record of independent studies proving high quality.

The Credit Rating Agency Reform Act of 2006 in the USA has been the first attempt worldwide incorporating clear output oriented measures (US House 2006b). Applicants for official registration must provide "credit ratings performance measurement statistics over short-term, mid-term, and long-term periods". Further, applicants confidentially must give proof of their market acceptance by filing a list of paying clients and statements from these clients about the rating quality. This approach is much clearer than the previously used 'market recognition'. The limitation to the 20 largest clients without any further restrictions also leaves room

77 The output of other experts, be it doctors or auditors, is much more difficult to measure - if possible at all. 
for small low cost agencies to register. However, there is still the potential of significant input control, since the registration can be denied if an "applicant does not have adequate financial and managerial resources (...)". As argued, such input oriented measures are an unnecessary limitation, since there are already better output oriented measures in place. There are many further input-oriented requirements. However, they pose no substantial limitation, since they largely aim at transparency regarding conflicts of interest and similar issues. The SEC is asked under section ( $n$ ) to detail several aspects of the Credit Rating Agency Reform Act by new provisions and a review of existing regulations. It should see to it, that the input requirements stay limited. More importantly, it should only very carefully use its power under section (i) to "prohibit any (...) unfair, coercive, or abusive act (...)" of rating agencies. As argued at several points, any direct regulation of rating methodologies is dangerous, since quality might be reduced and innovative business models hindered. It is much better to increase transparency and competition in order to prevent potential misbehavior.

A potential problem of pure output measures is that they can again be an entry barrier for young agencies. Freshly issued ratings can initially just be checked against market data (i.e. for minimum quality $q_{0}$ ) and only after several years meaningful correlation studies are available. Hence, early clients could be wrong in their initial judgment on a new agency - or they might even be biased because of favorable ratings. Hence, the reliance on a client track record is not enough. Since minimum quality ratings are a threat to the effectiveness of rating-based regulation, the state is rightly reluctant to officially recognize unknown agencies. There is a tradeoff between more newcomers and late recognition. More newcomers mean more competition, but older and more reputable agencies are a safer bet for high quality ratings, because they have more to lose from a recognition withdrawal. It is a good solution to recognize new agencies at first conditionally based on input factors. Such a control can guarantee a quality level $q_{s}>q_{0}$, reducing the danger and impact of cheating. Once output oriented measures are available, input oriented regulation can be dropped. Such a regime also limits the disadvantage of innovative rating agencies which employ different or far less resources than traditional rating agencies. They fail qualifying for recognition only during an initial phase. If the input requirements are upheld lastingly, on the other hand, they might never become recognized.

The Credit Rating Agency Reform act strikes a balance between more newcomers and late recognition by allowing official registration only after at least three consecutive years of offering a credit rating service. This is in principal a sensible idea. However, it is a duplication given the input requirements already in place. The time restriction is simply a stricter criterion to prevent mischief by unknown agencies. Therefore, the input restrictions on financial and managerial resources could be dropped, as long as good statistical proof on the rating quality is available after the three years. Alternatively, input restrictions could fully substitute the required time in the market.

Another important point of the registration regime is recognition withdrawal. So far, there has not been a single significant case worldwide, which is consistent with the reputation model (cheating is not attractive). Nonetheless, the state should see that there is a real danger of losing recognition because it is a powerful threat to agencies not to engage in uncompetitive or quality reducing behavior. On the other hand, a recognition system must avoid volatility. Issuers and investors prefer stable rating relationships. A recognition withdrawal - even if 
only partly - will most likely hurt reputation fatally, causing unwanted disruption in the market. There are also social costs, for the investments in reputation are lost once an agency goes out of business. It is most advisable that the state defines clear output oriented benchmarks that automatically lead to a withdrawal procedure. Just being subject to potential withdrawal is already a high threat, while the actual procedure can consider the specific situation preventing any unjustified withdrawal.

The analysis has so far concentrated on the question of how official recognition should be designed to prevent additional entry barriers. But it can also be a tool to foster entry. Analogous to the thoughts in section 3.3, the state can transfer reputation to young agencies. A quick recognition will reduce the needed investments into reputation, making newcomers more competitive against the long time incumbents. Especially the recognition of different agencies in different countries might generate strong national players with a chance to eventually compete internationally. The Japan Credit Rating Agency, e.g., was recognized early on from the Japanese regulator helping the company to quickly gain ground (e.g., Fight 2001, pp. 84-90).

In conclusion, a clear advice on how to design a good recognition system can be given, although there is no perfect solution. The system should be directly based on rating quality and not on proxies such as market recognition. A transparent registration process with continuous oversight and mapping is preferable to an opaque official designation. For young agencies a provisional recognition based on input criteria makes sense. A minimum reputation/time in the market might be considered, too. The Credit Rating Reform Act has rightly identified and abolished several problems of the original NRSRO designation. Given the prior concern for quality, though, it wonders why it is not directly based on statistical quality control. The focus on inputs and the minimum of three years to market should prevent the emergence of new agencies trying to exploit regulatory benefits by issuing sham ratings. Overall, these measures even seem to be a bit overdone, since they make market entry unnecessarily difficult. Overall, however, the Credit Rating Reform Act is a very good piece of legislation, given the results of this study. The EU should use the Act as prototype for its own legislation. The European ECAI guidelines are too much focused on preventing abuse. Rather, the EU should take a clear position to foster rating agency competition. The reliance on 'credibility and market acceptance' is inferior to a pure quality measure as suggested above.

\subsection{Limited Liability vs. Full Liability}

The question of civil liability for credit ratings has been extensively discussed. Husisian (1990) was one of the first scholars to analyze the issue in detail, concluding that economic and legal arguments speak against strong civil liability of rating agencies. Bottini (1993 pp. 609-10), although in principal in support of increased oversight, agrees. On the contrary, Partnoy (2006, pp. 83-89, 95-96) makes a case for increasing liability. Blaurock (2006, pp. 16-25) gives a good neutral overview on civil-law liability issues concerning rating agencies with reference to several different jurisdictions.

Traditionally, rating agencies have enjoyed a high level of protection from civil liability worldwide. They are usually only held accountable for bad faith or recklessness, but not for negligence as most other financial market participants. In the USA, e.g., ratings are considered as 
opinions protected by the First Amendment and rating agencies enjoy exemption from 'Sector 11' on negligence liability under the Securities Act of 1933. Liability has increased somewhat with the Credit Rating Agency Reform Act of 2006 since rating agencies are now held accountable for satisfying their own standards filed with the SEC. But the level of care is still below to what other financial market intermediaries such as equity analysts and especially auditors are held accountable for.

Based on the prior analysis, this section examines whether there are significant economic differences between rating agencies and investment banks or auditors. Without relevant differences, a special legal treatment cannot be justified. For discussions on the general pros and cons of civil liability, on the specific impact of civil liability on the rating industry, and on tools to control liability (e.g., First Amendment Protection, security laws, or burden of proof) see the cited literature. Figure 6.4 displays a rough structure of the business models of rating agencies, equity analysts, and auditors. All three act as information intermediaries. They analyze their clients' information and publish an assessment of the information which is bonded by their reputation ${ }^{78}$. There is no difference between the three business models. However, this structural similarity does not necessarily mean a similarity of economic functions which is decisive.

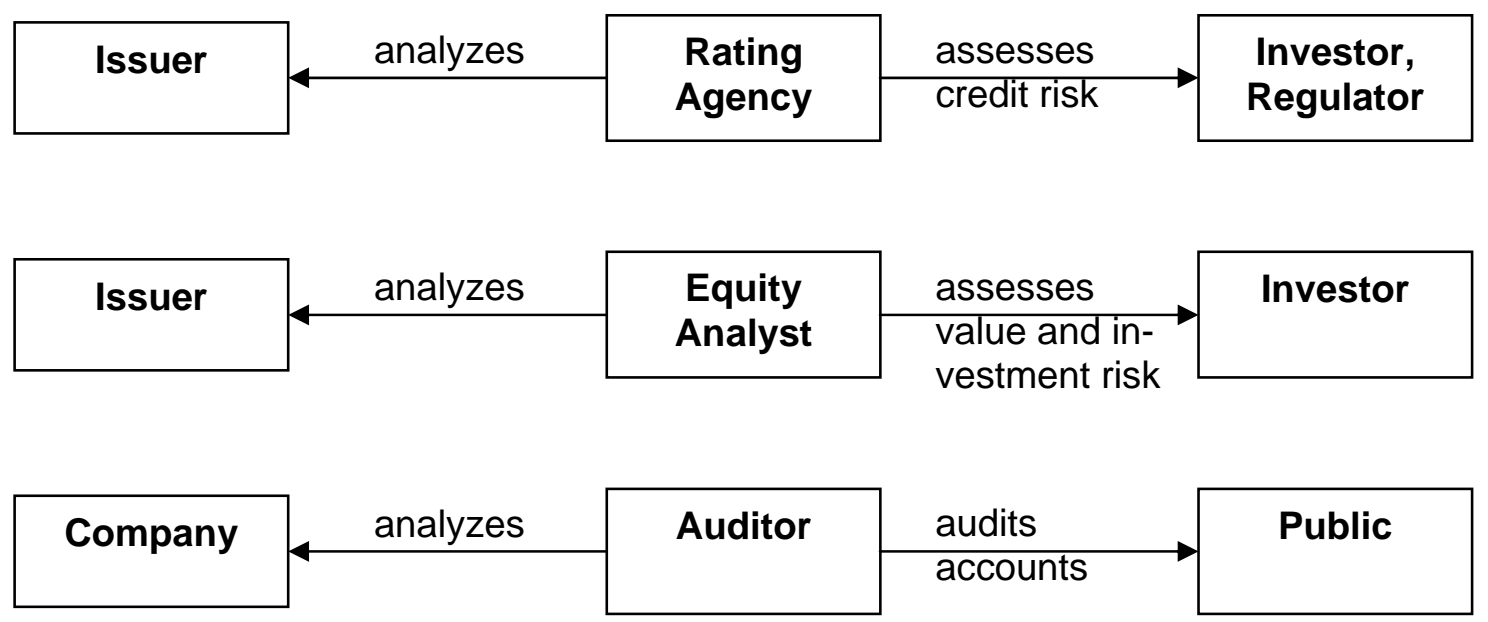

Figure 6.4: Business structure of rating agencies, equity analysts, and auditors

There are two clear differences between rating agencies and equity analysts on the one hand, and auditors on the other. While the former follow individual (i.e. non-standardized) methodologies, the latter gear their analysis strictly to fixed accounting standards. Further, auditors - as their name says - produce an audit with full access to client books, while rating agencies and equity analysts explicitly disclaim taking information as received without audit. Consequently, auditors should be subject to increased liability because of the very nature of their analysis. People rely on audits as true, given a certain set of accounting rules. Most wrongdoings of auditors can be proven against the accounting standards. In contrast, a court would have difficulties to judge the quality of a rating methodology and the importance of its different parts (Husisian 1990, p. 443).

78 Equity analysts of investment banks might also use a financial interest in the issuer as additional bond. 
It is important to look closely at the nature of ratings versus investment recommendations and audits. Audits prove that a company has kept its accounts according to the standards they are absolute statements or facts. Equity analysts do not produce absolute statements in this sense, but their assessments have the nature of an absolute recommendation. Their (fundamental) analysis calculates a fair value of an equity, reflecting the likelihoods of all relevant events. Given the current market price, an equity is either over- or undervalued. Ratings are similar in that they are the outcome of a fundamental analysis reflecting all available information and uncertainties. Because of this similarity, Partnoy says, "credit ratings are not really just opinions any more than fairness opinions of investment banks, audit opinions of accounting firms, [or] buy-sell ratings of security analysts (...)" (U.S. House 2005a, p. 9).This opinion is supported by the fact that ratings substitute private information, e.g., in the USA explicitly under the exemption from regulation FD (Schwarcz 2001, p. 308). Investors cannot prove this information but must rely on it.

However, ratings are in their nature a relative statement, since they primarily aim to give a rank-ordering of default risks. The same debt security might be a good or bad investment for different investors. Further, given all rated securities in the same rating class, a certain number of them must default. Given all buy recommendations, in contrast, none should turn out to be wrong. Nonetheless, Partnoy has a good point because ratings factually also indicate an absolute risk level and thereby point to an over- or undervaluation. On the other hand, ratings are much more specific than equity research. They only display credit risk, while equity research displays all pricing/value relevant factors. An investor could of course buy a bond on a single rating opinion, but he then ignores information on factors such as taxes, currency risks or liquidity. Admittedly, for many investors these factors are at best secondary.

Altogether, the nature of ratings is a decent but not particularly strong basis to argue for less civil liability for rating agencies. In any event, it looks very unpromising to demand compensation on the simple basis of a default because any rating necessarily describes a real chance of default. In other words, a default per se says nothing on the quality of the rating analysis. More relevant is the timeliness of rating reviews which has been a major imputation by critics of the rating agencies. The matter has been discussed in section 5.2.3.4. It leads to a second area where rating agencies potentially differ from other financial information intermediaries. The discussion of timeliness has shown that there are contrary expectations towards ratings. The same can be said for the tenor or general level of ratings. Figure 6.5 displays how the users of ratings differ in their expectations:

\begin{tabular}{|l|c|c|c|c|}
\hline \multirow{2}{*}{ Player } & \multirow{2}{*}{$\begin{array}{c}\text { Tenor on } \\
\text { Ratings }\end{array}$} & Rating & \multicolumn{2}{|c|}{ Tevel } \\
\cline { 4 - 5 } & conservative & low & \multicolumn{2}{|c|}{ Upgrades } \\
\hline State & progressive & high & quick & slow \\
\hline Issuer & progressive & high & quick & slow \\
\hline $\begin{array}{l}\text { Investor - confined by } \\
\text { regulatory restrictions }\end{array}$ & conservative & low & quick & quick \\
\hline $\begin{array}{l}\text { Investor - not subject } \\
\text { to regulatory restrictions }\end{array}$ & & &
\end{tabular}

Figure 6.5: Demands on ratings 
The state employs rating-based regulation and most investors who are interested in the information value of ratings prefer a conservative approach to ratings. Issuers and investors who are subject to rating-based restrictions generally prefer a more progressive approach to ratings, i.e. in doubt the higher rating should be assigned. In the same manner, the different players prefer different levels of timeliness, which are well reflected in survey results (Ellis 1998, p. 41). The benefits of the through-the-cycle approach, namely the decrease of rating induced transactions and the prevention of avoidable negative chain reactions, speak for slow rating revisions. Quick rating reviews, on the other hand, reflect the underlying information much better.

In principal, the demands towards equity analysts are ambivalent, too. Issuers prefer a benevolent analysis, investors prefer a conservative approach. However, there is a key difference: there is no equivalent to rating-based regulation. Ratings carry a much higher impact than recommendations of equity analysts. There will hardly be an investor interested in a delayed update of equity research. Quick information does no harm because there is no distinct serial dependency of equity recommendations. The situation is very different for ratings: a quick rating downgrade may lead to serious disadvantages for issuers and investors. Such ratinginduced disadvantages might well be avoidable if the reasons for the downgrade are only temporary. Importantly, issuers and investors can easily provide 'evidence' for the harm done by the rating in form of falling debt and equity prices and might try to bring a respective liability case. A different scenario would be that a rating agency is slow in downgrading since it assumes that the negative conditions are only temporary. If this belief turns out to be wrong, the negative effects of a downgrade would be especially pronounced. Parties such as the state or active investors might then bring a case because of the sluggishness. Here, too, easy evidence would be available as ratings lack behind market prices.

The example shows that a rating agency might become subject to a justified liability case no matter how it behaves. Ex post - when all information is available - it might appear quite obvious where the agency was wrong, while the respective factors were not as clear ex-ante. This applies to both, the rating level and the timeliness of rating changes. Therefore, one can attest a clear difference between the rating industry and the equity research profession. Issuers, investors, and states are stronger impacted by ratings than by equity research opinions and have at the same time more contrary demands and interests.

In conclusion one can hold that it is justifiable to treat rating agencies legally different from other financial information intermediaries. Auditors clearly differ because of the factual nature of their assessments. The nature of ratings is also different to equity research opinions. But what really matters is the combination of high rating impact and opposed demands on what ratings should be. Rating agencies serve different masters. If more liable, they might become subject to a large number of 'false' litigation cases. The social costs of such a system are likely larger than potential benefits. This conclusion is of course against conventional wisdom which would say rating agencies must be especially liable because they wield so much power. One solution would be to make liability exemption dependent on high quality, a system which could be introduced along with a respective recognition system. Contrary to audits, rating quality can be exactly measured ex-post. If there are serious distortions of average rating data, i.e. if rating quality is low, doubts about a low standard of care or even bad faith are justified. Overall, however, it is difficult to argue for higher rating agency liability, especial- 
ly in an environment which has tended toward reduced liability related to security research and sales in recent years (Fisch 2004). It makes more sense to strengthen the reputation mechanism.

\subsection{Self-Regulation vs. State Regulation}

There are many different substantive suggestions on rating agency regulation - including the ideas developed in chapters 5 and 6 of this study. The Capital Requirements Directive (CRD) in Europe and the Credit Rating Agency Reform Act of 2006 in the USA are important pieces of recent legislation implementing several ideas. In this last section it will be analyzed how a good implementation policy should be constructed. The focus is again on the principal economic arguments and not on a detailed analysis of specific legislation. Most authors concerned with the regulation of the rating industry have put forward more or less specific implementation ideas. The CESR (2005, $\S \S 187-245)$ discusses in detail four regulatory options concerning rules of conduct and registration. Rousseau (2005, pp. 50-62) critically analyses implementation options concerning accountability, rules of conduct, and entry. Blaurock (2006, pp. 28-36) looks at different regulation issues and implementation methods against the background of individual national approaches.

The question of regulatory implementation is most important for the area of official recognition. But it is also relevant for several other issues, especially business conduct. There are two basic implementation methods: self-regulation and regulation by a state authority. The meaning of state regulation has already been touched in the introduction to this chapter. The state can impose limitations on the rating agencies such as certain minimum input requirements or restrictions on business behavior, e.g., the use of unsolicited ratings. These limitations are supported by a threat of sanctions. Self-regulation, on the other hand, means that the rating agencies directly or indirectly set their own rules. It is similar to state regulation in that it also limits the discretion of the rating agencies. However, it differs in two points. First, there is no coercive power. Instead of state sanctions, self-regulation relies on supervision by the rating agencies themselves and outside parties such as market participants or the media. Secondly, self-regulation is less strict. If a rating agency departs from self imposed restrictions, it can often please outside parties by clarifying its action. One speaks of a 'comply or explain' mechanism.

Concerning state regulation, a general danger of government failure has already been pointed out in the chapter introduction, because there are strong interests among the well organized parties in the rating industry. This is a first reason why a far-reaching regulation is problematic. Secondly, it was argued that the state can hardly manage the core rating process efficiently. To decide on the best methods, the state would need to be a better rater than the rating agencies themselves. Thirdly, the credit rating industry has an exceptional position compared to other industries because of the dual interest of the state. On the one hand, the state employs credit ratings in rating-based regulation and is concerned with the general impact of ratings on financial markets; on the other, it is subject to ratings itself. This second point makes the difference: alike rated private parties, rated public bodies might have an incentive to avoid negative ratings. In contrast to private players, though, public bodies can indeed exert influence by means of regulation. All three reasons, but especially the second and third, speak for a light touch of state regulation. The core rating methodology or, 
even worse, single ratings must not be subject to state regulation. Deviating demands of some authors do not withstand principal economic arguments (e.g., Bottini 1993, p. 613, demanding SEC influence on 'wrong' ratings).

The described problems - except of government failure - are far less relevant in those areas of rating agency regulation which do not deal with the core business. Most notable this is true for official recognition, especially if it is based on rating quality. Here, the state has no inherent self interest but wants to design a system which maximizes welfare. It is in principal the right body to implement oversight. Nonetheless, potential costs of state regulation must be considered. The recognition system suggested in section 6.3, e.g., needs a substantial amount of oversight in measuring rating quality. Additionally, the financial markets are complex and fast changing, so there are either inefficiency costs of outdated regulatory procedures or administrative costs of constantly implementing new ones.

After this short appraisal of state regulation self-regulation needs to be looked at. As described, self-regulation has the major deficiency of being voluntary. The success of any self regulatory regime stands or falls with the question of control. First, there needs to be effective supervision that reveals deviations from the self entailed rules. Secondly, there must be a mechanism which sanctions deviations. Self-regulation in the credit rating industry can only be considered if it fulfills both requisites. The obvious supervision tool is rating quality. Contrary to many comparable industries, the output of rating agencies is very well measurable. As described in chapter 5 , many practices and effects disliked by the state go along with a deteriorating quality. Additionally, rating agencies are well observed by scholars, financial market participants, and the media, because of their high visibility and perceived power. The big accounting scandals have brought an additional advance of public scrutiny which is likely to even uncover deviations from self imposed rules which are not reflected in quality, e.g., pressuring issuers with the mere threat of negative rating actions. The second requisite is also met in form of the reputation mechanism. Rating agencies are highly sensitive to a reduced informational quality and to proven anticompetitive behavior, since both lower the issuers' willingness to buy ratings. A loss of reputation endangers the very business of any rating agency, so it is a highly effective sanctioning mechanism.

In sum, the credit rating industry is particularly well suited for self-regulation. Above all, this result is important for regulating the core business of rating agencies. It has been shown that there is no natural outside party to do the job - the state is neither neutral nor capable. The rating agencies, on the other hand, are certainly capable of defining a sensible business behavior, and the market is by definition a neutral supervisor. Therefore, the state is well advised to encourage the implementation of a business code of conduct for rating agencies. The IOSCO Code of Conduct is exemplary: it was developed in a broad consultation process including many rating agencies themselves and then implemented de facto internationally as part of the European CRD. The benefit of such a code of conduct is not only the direct control of specific business behavior - it has been shown that several problems are in fact overstated. Much more important is the reinforcement of the reputation mechanism. By committing themselves to a business code the rating agencies further raise their stake in the game. On the one hand, they become even more scrutinized, on the other, they set very specific rules to be judged against. Reputation will not only fall when quality drops, but also when the rules of conduct are violated. 
Apart from controlling business conduct, self-regulation could play a role in the recognition process as well. It has been argued that the state is the natural body to administer recognition, but there are costs in establishing and supervising the standards. If recognition is based on an objective ex post quality measure, this part of the process might be outsourced to rating agency self-regulation, too. The agencies have traditionally kept very well track of statistical rating quality. Instead of direct control, the state could rely on such data - not least because it is difficult to manipulate - and content himself with crosschecks from independent scholars. The state would still grant the actual recognition, but employ data directly delivered from the rating agencies. In such surroundings the suggestion of employing a credit rating industry association makes a lot of sense (Rousseau 2005, pp. 51-55). An industry association could develop and update common rating quality standards. This would ensure consistency while at the same time guaranteeing flexibility and minimizing costs for the state. Further, an industry association would guarantee an international solution, preventing regulatory fragmentation or even a regulatory 'race to the bottom'.

In a survey of 41 issuers and 51 investors about of 80-90 percent answered that the rating agencies kept their level of scrutiny or even increased their performance in 2005 in every single area the survey asked about (TBMA 2006, p. 22). The agencies scored the best results for the 'transparency of processes and methodologies' which was criticized most after the big accounting scandals in the prior years. The rating agencies are obviously very responsive to criticism - the reputation mechanism is working. These anecdotal findings go along well with the recommended implementation of regulation. The state should build on the self regulatory potential of the industry with a focus on further strengthening the reputation mechanism.

Figure 6.6 summates the recommendations on the five regulatory options discussed:

\begin{tabular}{|c|c|}
\hline & Recommendation \\
\hline $\begin{array}{l}\text { Use of ratings in } \\
\text { regulation }\end{array}$ & $\begin{array}{l}\text { Yes: Rating-based regulation creates benefits. Market-based risk meas- } \\
\text { ures are not sufficient }\end{array}$ \\
\hline Competition & Strengthen competition \\
\hline $\begin{array}{l}\text { Official } \\
\text { recognition }\end{array}$ & Registration process based on rating quality \\
\hline Civil liability & Limit civil liability \\
\hline Implementation & Self-regulation \\
\hline
\end{tabular}

Figure 6.6: Regulatory recommendations 


\section{Summary}

Credit rating agencies are widely discussed because of their importance in financial markets, but the economics of the industry are not always well understood. In principal, rating agencies serve as information intermediaries between debt issuers and investors. They scrutinize issuers and specific debt-securities resulting in a simple letter rating certifying their credit worthiness on a relative scale. This is done for a rating fee paid by the issuer. The investors value this information and accept a lower interest rate since the rating agencies are believed to be honest and capable. The reduction in borrowing costs more than offsets the rating fee. Apart from the information function, credit rating agencies have two additional major roles. On the one hand, rating agencies fulfill a certification function since their ratings are used as a benchmark for complying with rating-based regulations and similar private arrangements. On the other hand, credit ratings have a standardization function. They are an important convention in the process of issuing debt and allow the global comparability of credit risks among all kinds of debt instruments.

A lot of the attention to the credit rating industry stems from the use of ratings in state rules and regulations which are designed to protect different financial market participants against too much risk and to increase overall confidence. Many states worldwide employ ratingbased regulation, because ratings have proven to be a good measure of credit risk, are readily available, and can easily be monitored. Historically, regulatory systems employing ratings have restricted the number of recognized agencies. In the USA, only ratings from 'Nationally Recognized Statistical Rating Organizations' (NRSROs) were allowed to be used for compliance since 1973. The opaque NRSRO designation has only recently been replaced by a more open registration system under the Credit Rating Agency Reform Act of 2006.

The credit rating industry has been dominated by two agencies throughout its history. Moody's and S\&P hold a nearly duopolistic position with about 77 percent of worldwide credit rating revenues. The remaining business is dominated by Fitch holding another 15 percent. Despite the enormous growth of the industry - which has multiplied its revenues many times to over $\$ 4$ billion in 2005 - no significant new player managed to enter the global rating market. Meanwhile, Moody's and S\&P are highly profitable with operating margins well above 50 percent.

The multiplicity of rating functions paired with their importance for financial markets and the agencies' obvious market power as a matter of principle give rise to concerns. This explains the wide attention of researchers and regulatory bodies to the credit rating industry. To generate well-founded conclusions, a thorough analysis of the credit rating economics is necessary. As a starting point, credit ratings are classified as experience goods. On issuance it is only possible to see if they are of a minimum quality, either by comparing them to market data such as stock quotes or by analyzing the inputs of the rating process such as the qualifications of the involved personnel. The true quality of an agency's ratings, however, can only be checked after a substantial amount of time by statistically correlating the ratings with actual defaults. Because of the relative nature of the rating scale, the highest rating category should have the lowest default probability and the bottom category the highest. This, in turn, means that the quality of a single rating cannot be judged against the fact of default, since there are - and must be - defaults in any rating class. 
Agencies with a strong correlation build up reputation with issuers and investors for their accurate risk assessments. Reputation is the single most important economic concept for understanding the credit rating industry. Because of the good reputation, investors believe in the rating quality ex ante and value the agencies' analysis highly. The issuers in turn seek ratings from agencies with high reputation, because their ratings promise the largest reduction in borrowing costs. Thus, reputable rating agencies can demand a high price for their rating assessment, generating above market returns compared with a situation without reputation. In any period, rating agencies could deceive issuers and investors by an unsound analysis, either to save costs or to generate extra fees through favorable ratings. The rating agency would earn an extra profit in the period of deceit, but would lose the rents generated from its reputation in the following periods. If this one-time gain cannot offset the reduced profits in the future, rating agencies will always produce high quality ratings in order to keep and strengthen their reputational capital. The equilibrium price is capped by potential entrants. They could initially sell high quality ratings below cost in order to build up a reputation. These losses offset the discounted future gains in equilibrium so entry is not attractive below a certain price.

In principal, reputation does not need to carry market power. In the credit rating reality, however, it does. There is not a distinct equilibrium price, but the incumbents enjoy a price scope. One likely reason is the changing informational environment over time. While ratings of minimum quality had value at the inception of the industry in the early $19^{\text {th }}$ century, unknown newcomers today have a harder time to compete against free market data from company reports or stock exchanges. It is also likely that the costs to generate high quality ratings have risen over time with the increasing complexity of financial markets. While all rating agencies benefit from increased prices reflecting the increased costs, incumbents are advantaged, because they built up their reputation with comparably smaller investments.

A key aspect of reputation is its transferability. Incumbents can use their good reputation in one segment of the rating market to enter another segment. In this case, issuers and investors believe in a quality higher than the minimum quality, because the agency has proven capable in a very similar field. New entrants to the rating market - even those with a background in related fields - have a more difficult time to leverage their general reputation for analytical thoroughness. They face high conflicts of interest and it is questionable if their existing services are similar enough to ratings. The transfer of reputation creates a competitive advantage, since it reduces the investments into reputation when expanding. The largest agencies can expand fastest, since they have the most difficult time to hide a cheating strategy. For them it is not an option to offer minimum quality in a new market segment at a relatively high price. Although they would generate one time profits, they cannot easily milk the reputation of their incumbent businesses, because such deceit could be detected prematurely. This risk makes cheating so expensive that investors are safe to believe in honest high quality ratings. Such reasoning even applies in existing market segments. Many issuers do not demand an initial discount at all when buying first time ratings from one of the market leaders. Hence, the rating agencies become more profitable with increasing size, because they can spread their fixed investments into reputation to more units.

The stability of the reputation mechanism in principal opens up a broad quality spectrum. However, demand for credit ratings concentrates exclusively on the very high quality level. 
This is because issuers use ratings as a signal to financial markets which is free for investors. In order to get attention in the widths of investment opportunities, they need to be as professional as possible. Investors only choose among the best investment alternatives which feature a high quality rating. Likewise, the debt securities compete against each other in efficient financial markets. Since most issuers have similar informational asymmetries to overcome, they value ratings equally. This translates into a low price elasticity of demand in the relevant range. The same is true for the cross-price elasticity between different quality levels. Low quality ratings are no substitute for high quality ratings.

A key question of the demand analysis is the impact of rating-based regulation. Generally, state recognition adds a quality independent license value to ratings. Issuers have less reporting costs and the debt-securities become eligible for a large number of regulated investors. Some issuers have incentives to buy sham ratings at very low cost certifying their debt securities the best possible credit risk. To prevent this, the state must make recognition dependent on a certain higher quality level. If the license value is small compared to the information value of a rating, the market will automatically swing into a high quality equilibrium. If the license value is substantive compared to the information value, however, the market might settle at a lower quality close to the quality necessary for state recognition. The discussion on the importance of the license value is still open, but the arguments are strongest for a limited impact.

Large rating agencies enjoy a boost in demand because of network effects. Investors value the comparability of many different debt securities. In a wider framework, network effects are part of the 'two-rating norm'. It describes the fact that today most debt securities have two ratings: one from Moody's and one from S\&P. The two-rating norm is a de facto standard based on a host of factors. Therefore, it is very stable and constitutes a substantive competitive advantage of the two market leaders.

Important economic forces on the supply side of the rating industry are first mover advantages and lock-in effects. The first agency in a market segment can acquire customers early on so that entrants face a smaller number of unserved clients and would need to reduce their price in order to lure away some of the first mover's clients. In the long run, lock-in effects become even stronger. Issuers that put themselves under the scrutiny of the best rating agencies - which usually are Moody's and S\&P - face a loss of trust in financial markets when changing to an equally or even less reputable agency, because such a move looks like 'shopping' for a better rating. Agencies with a low reputation, on the other hand, are less protected by lock-in effects, since financial markets do not disregard an issuer changing to an agency of higher reputation.

Also relevant for the supply of credit ratings are economies of scale. From a pure production point of view size does not matter much, but it is beneficial in reputation building and risk diversification. Larger rating agencies can leverage their reputation when growing in existing market segments or entering new ones. Smaller agencies have to invest more to gain a comparable position. Additionally, smaller agencies could be hit by random credit events that distort rating quality statistics as there might be only a small number of ratings in a given rating class. For large agencies such effects average out, so rating quality measures are more 
precise. Size also matters in internal monitoring efforts which become relatively cheaper in larger organizations.

In terms of market segmentation the credit rating industry offers few strategic options. Contrary to other industries, there is only demand for a very high service quality and it is no option to concentrate on debt issues with a certain level of credit risk. A plausible differentiation can only happen in terms of geography or product class. However, such strategies face obstacles, too. Along with financial markets, credit ratings are addressed to a global audience. Further, ratings explicitly make the credit risk of all kinds of debt securities comparable. Moody's and S\&P quite successfully claim competence in any market and for any debt instrument. Nonetheless, the only successful entrants over time followed a niche strategy focusing on a region and/or industry.

In sum, the analysis of the credit rating economics confirms and explains the market power of Moody's and S\&P. Large credit rating agencies have cost advantages over small agencies and face higher demand. Further, long established rating agencies with the highest reputation have advantages over newer competitors. Lastly, factors such as official recognition and the structure of demand limit the strategic options of rating agencies. As a result, the competition within the rating industry is limited - it can best be described as a collusive oligopoly. Potential newcomers have little chance to break into the oligopoly because of the high entry barriers. In case a newcomer none the less manages to build up a reputation and client base, it is mutually beneficial for the incumbents and the newcomer to merge with each other.

The market power and importance of rating agencies raise regulatory concerns which can be grouped into unwanted allocation effects and, more directly, harmful behavior. Against popular opinion, the economic analysis provides few strong starting points for regulatory interference, although many topics pose at least a certain threat.

Efficiency in the classic sense should be no major issue for the state. Despite the mostly anticompetitive environment there is little welfare lost due to monopoly power since issuers are willing to pay high prices. The potential effect of lower rating fees on the number of debtissues is impossible to quantify. There are some social costs in connection with the build-up of reputation, but there is no basis on which to argue for any specific antitrust measure. The structure of the business model as information intermediary is a guarantee for necessary product innovations. In sum, monopoly power in the credit rating industry does little harm compared to traditional (non-natural) monopolies. There are, however, at least some benefits of competition to Moody's, S\&P, and Fitch by smaller agencies. Since such competition could hardly do any harm from the allocation perspective, it is certainly sensible for the state to take competition increasing measures, even if there is no single reason justifying a specific action.

There are several concerns on the effect of ratings on financial market stability. Some problems such as the potential for a pro-cyclical impact on the credit cycle or a limited breadth of information because of overly similar ratings could only be dealt with by directly regulating rating methodologies. Other threats such as the spreading use of rating-triggers and parallel investor behavior can be tackled by increased transparency and less rating-based regulation. 
The structural risk with the highest impact is a potential breakdown of Moody's or S\&P which would cause disruption in financial markets. Although very unlikely, the state should pay attention and aim to increase competition. Overall, however, there is no concern posing a substantial threat for financial market stability.

One of the key allegations against Moody's and S\&P, especially in the USA, is anticompetitive behavior. The economic analysis is ambiguous, though. First of all, there are no contractual relations manifesting an anticompetitive behavior. The objected practice of notching is part of the rating methodology, and rating agencies have not been found to have exclusivity or tying agreements with issuers. Further, the scope of anticompetitive behavior is generally limited because rating agencies are very well scrutinized by the public. Additionally, the threat of too low ratings cannot be executed since rating quality is statistically measurable. Therefore, it is hard to effectively pressure issuers to do something 'against their will'. In sum, there is no strong basis for the state to interfere despite the practical allegations. Especially any direct regulation of rating methodologies is inappropriate without proven wrongdoing of the rating agencies. Instead, potential measures should aim to increase transparency and competition in general.

Many practitioners and scholars translate the rating agencies monopoly power into a form of political power in that rating agencies can directly affect decisions of rated issuers. From an economic perspective, the concept of political power is empty, though. The credit rating agencies simply make visible the demands and standards of international capital markets they have no discretionary power. The analysis falls back to the potential for anticompetitive behavior. With a bad rating analysis, rating agencies can move markets at maximum in the short run, while prices will revert in the long run and the agencies' reputation falls. A good example of the fallacy of political power are sovereign ratings, which have traditionally been highly criticized although their impact on market prices is limited. The only way that rating agencies indeed have discretionary power over issuers is a quality scope.

If it is possible to punish issuers by giving them low ratings or to reward them by giving artificially high ratings without losing reputation, rating agencies can profitably engage in anticompetitive behavior. The rating quality should therefore be at the center of state concern, not least because rating-based regulation is directly dependent on a high informational quality. While the reputation mechanism is very robust in itself, market participants are likely to derive reputation not only from the perfectly measurable informational quality, but also from softer factors. Investors and issuers rank rating agencies based on their perceived 'status'. State recognition or the relationships to high profile issuers, e.g., make up for a limited deterioration of quality. Overall, however, the quality scope is limited in the credit rating industry since reputation is too much dependent on quality in the long run. The state should nonetheless try to minimize the existing grey zone by increasing transparency and strengthening the reputation mechanism.

An important aspect connected to rating quality are conflicts of interest of which there are many within the credit rating industry. However, the practical impact of conflicts of interest is limited by the narrow scope for actually assigning favorable ratings. Further, few businesses are scrutinized as closely as rating agencies, so it is hard to hide any wrongdoing. Although the problem of conflicts of interests is generally overstated, the state does no damage by 
helping increasing transparency. Another potentially harmful behavior concerning rating quality is a rating inflation, i.e. all ratings rise while the relative ranking remains constant. To prevent a negative impact on the effectiveness of rating-based regulation, the state should map the different rating scales against absolute default levels. A third issue on rating quality is the timeliness of rating changes. Rating agencies are often blamed for slow downgrades. However, there are good reasons for a certain sluggishness. The state should therefore not intervene.

The large number of concerns let the rating industry appear prima facie as highly prone to state intervention. However, the actual threats are limited. This is especially so because most concerns are just that - concerns. There is very little empirical evidence that things are actually going wrong. The largest threat stems from the reputation mechanism itself. If it was impaired, rating quality might fall without hurting reputation. In this case, many potential problems become much more likely. The main measures the state should take are increasing competition and transparency, and installing a registration system for the compliance with rating-based regulation. $A$ far reaching intervention into the business of rating agencies is not justified, though.

The state must decide on five policy areas. The most basic decision is between rating-based regulation and the use of market-based risk measures. Both methods have their strength and weaknesses. However, if the state decides to use risk-based regulation in principal, there is hardly a way to avoid a form of ratings, since market based measures are limited to traded securities. A second basic decision concerns competition between rating agencies. Since the fear of a downward spiral of quality standards in a highly competitive environment is economically unfounded, the state serves its interests best by fostering competition. Regulatory entry barriers should be reduced; it makes also sense to closely study the effects of rating agency mergers.

The stance on competition is an important input for the decision on the process of state recognition for the regulatory use of ratings. In principal, recognition can be based on a designation regime or the free registration of rating agencies. Since competition is good for the industry, a registration regime is the best choice. It should explicitly be dependent on statistical rating quality and not on input measures. The US 'Credit Rating Agency Reform Act of 2006' - although still relying on factors other than rating quality - is broadly in accordance with the economic recommendations. On the other hand, the European recognition approach under the 'Capital Requirements Directive' implementing Basle II is too restrictive and leaves room for improvement.

A controversially discussed policy option is the stance on civil liability. Rating agencies are special compared to similar businesses such as auditors or equity analysts, because ratings bear an enormous influence while the demands on rating properties such as timeliness and conservativeness are opposed between different affected groups. Increased civil liability of rating agencies would do more harm than good.

The last decision of the state is between explicit regulation and self-regulation. Explicit regulation suffers from the potential of 'government failure' because of the strong interest groups involved. Secondly, the state is subject to ratings itself, so any direct influence on the agen- 
cies could be misused. Rating agencies themselves are far more efficient in setting rating methodologies than the state. Therefore, explicit regulation is only advisable in areas that do not touch the core business conduct - most notably official recognition. On a general level, the state should better count on international self-regulation such as the 'IOSCO code of conduct'. Rating agencies are particularly well suited for self-regulation, since their output is statistically measurable and the industry receives a lot of attention. 


\section{Appendix: Literature Review}

There is a vast literature on credit ratings and their role in international financial markets, mostly focusing on quantitative, empirical methods. More relevant to this work is theoretical research on the industrial organization and regulation of the credit rating industry. In the following, major contributions will be briefly reviewed. The largest group consists of studies by law and economics scholars. There are also relevant articles from a sociological and political perspective. Several surveys among investors and issuers provide practical insights. There is also a large amount of relevant governmental research and legislation. Furthermore, individual publications from rating agencies as well as student papers are reviewed.

\begin{tabular}{|l|l|l|}
\hline \multicolumn{2}{|l|}{ Type } & \multicolumn{2}{l|}{ Contents/Conclusions } \\
\hline Scientific Research: Law \& Economics
\end{tabular}

79 The national reports are available at http://www2.law.uu.nl/priv/AIDC/index1.asp 


\begin{tabular}{|c|c|c|}
\hline ECB 2004 & Paper & $\begin{array}{l}\text { - Examination of the credit rating literature available in } \\
\text { mid } 2003 \text { (consideration of numerous empirical stu- } \\
\text { dies) } \\
\text { - The increased significance of credit ratings and their } \\
\text { impact on market dynamics } \\
\text { - } \quad \text { Discussion of the challenges for rating agencies }\end{array}$ \\
\hline Fight 2001 & Book & $\begin{array}{ll}\text { - } & \text { Extensive profiles of eight big rating agencies, limited } \\
\text { information on several more } \\
\text { - } & \text { Methodologies and characteristics of the rating proc- } \\
& \text { ess } \\
\text { - } & \text { Discussion of several surveys } \\
\text { - } & \text { Analysis of regulatory issues (especially NRSRO) }\end{array}$ \\
\hline Fisch 2004 & Paper & $\begin{array}{ll}\text { - } & \text { Discussion of calls for regulatory reform after the } \\
\text { Enron and WorldCom scandals. } \\
\text { - } \quad \text { Role of rating agencies, valuation of their services by } \\
\text { market participants } \\
\text { - } \quad \begin{array}{l}\text { Conclusion: immediate action only on NRSRO } \\
\text { designation and agency liability advisable }\end{array} \\
\end{array}$ \\
\hline Frost 2006 & $\begin{array}{l}\text { Working } \\
\text { Paper }\end{array}$ & $\begin{array}{l}\text { Validation of widespread criticisms of rating agencies } \\
\text { on the basis of existing empirical evidence } \\
\text { - Issues: Disclosure practices, conflicts of interest, anti- } \\
\text { competitive practices, diligence and competence }\end{array}$ \\
\hline Hill 2004 & Paper & 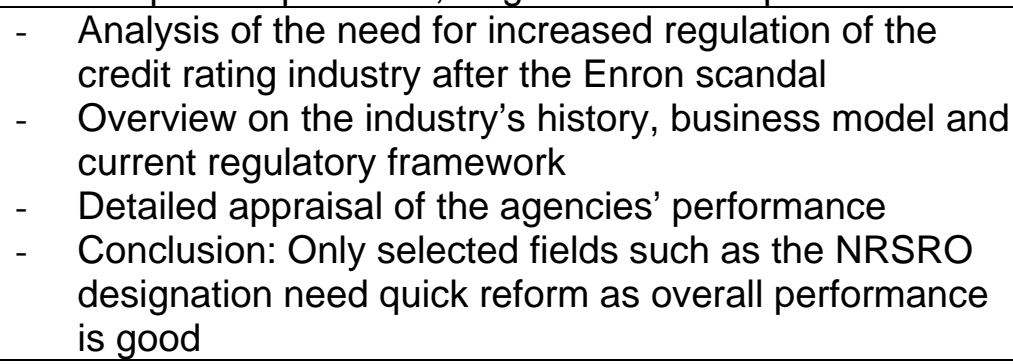 \\
\hline Husisian 1990 & Paper & $\begin{array}{ll}\text { - } & \text { Function of credit rating agencies } \\
\text { - } & \text { Detailed economic and First Amendment evaluation of } \\
& \text { expanding liability } \\
\text { - } & \text { Conclusion: extending liability is problematic from ei- } \\
\text { ther perspective }\end{array}$ \\
\hline Jackson 2001 & $\begin{array}{l}\text { Book Chap- } \\
\text { ter }\end{array}$ & $\begin{array}{l}\text { - Analysis and critique of the role of ratings in the Basle } \\
\text { II proposals } \\
\text { - Possible alternatives to credit ratings in capital ade- } \\
\text { quacy }\end{array}$ \\
\hline $\begin{array}{l}\text { Levich et al. } \\
2002\end{array}$ & Anthology & $\begin{array}{ll}\text { - } & \text { History, value, and structure of the rating industry } \\
\text { - } & \text { Empirical evidence on pricing and regulatory aspects } \\
\text { - } & \text { Empirical evidence on performance } \\
\text { - } & \text { Policy issues facing rating agencies and regulators } \\
\text { - } & \text { Includes: Sylla 2002, White 2002, Smith and Walter } \\
& 2002\end{array}$ \\
\hline Nicholls 2005 & $\begin{array}{l}\text { Conference } \\
\text { Paper }\end{array}$ & $\begin{array}{ll}\text { - } & \text { Background information on industry and current dis- } \\
& \text { cussions } \\
\text { - } & \text { Analysis of public and private uses of credit rating } \\
\text { - } & \text { Alternatives to credit ratings and liability issues } \\
\text { - } & \text { Detailed overview on rating-based regulations in Can- } \\
\text { ada } \\
\text { - Conclusion: No significant regulation should be intro- } \\
\text { duced in Canada }\end{array}$ \\
\hline
\end{tabular}




\begin{tabular}{|c|c|c|}
\hline Partnoy 1999 & Paper & $\begin{array}{ll}\text { - } & \text { Detailed description of the industry's history } \\
\text { - } & \text { Empirical findings casting doubt on the reputation me- } \\
\text { chanism as main driver of the rating business } \\
\text { - } & \text { Rating-based regulation as major industry driver } \\
\text { - } & \text { Proposals: substitute ratings through market-based } \\
& \text { measures in regulation, increase liability }\end{array}$ \\
\hline Partnoy 2006 & $\begin{array}{l}\text { Book Chap- } \\
\text { ter }\end{array}$ & 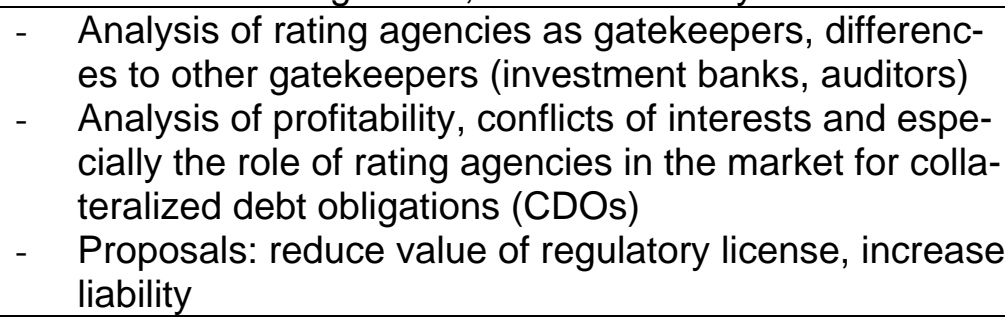 \\
\hline $\begin{array}{l}\text { Rajeshwer and } \\
\text { Jutur } 2005\end{array}$ & Anthology & $\begin{array}{ll}- & \text { Anthology of mostly published papers/working papers } \\
& \text { such as Sylla } 2002 \text { or Reisen } 2003 \\
\text { - } & \text { Introduction on the rating industry } \\
\text { - } & \text { Sovereign ratings } \\
\text { - } & \text { Corporate ratings } \\
\end{array}$ \\
\hline Rousseau 2005 & $\begin{array}{l}\text { Conference } \\
\text { Paper }\end{array}$ & $\begin{array}{l}\text { - } \quad \text { Canadian report to the } 2006 \text { Congress of the Interna- } \\
\text { tional Academy of Comparative Law, Utrecht } \\
\text { - } \quad \text { Short overview on the rating industry } \\
\text { - } \quad \text { Accountability concerns: potential market failures, legal } \\
\text { and institutional control mechanisms } \\
\text { - } \quad \text { Regulation to increase accountability: regulatory goals, } \\
\text { the IOSCO and the SEC proposals, implementation } \\
\text { - } \quad \text { Proposal: disclosure strategy }\end{array}$ \\
\hline Schwarcz 2001 & $\begin{array}{l}\text { Book Chap- } \\
\text { ter }\end{array}$ & $\begin{array}{l}\text { - Identification of "a de facto control of rating agencies } \\
\text { over international debt markets" (p. 301) } \\
\text { - Analysis if regulatory bodies should try to actively curb } \\
\text { and control this power } \\
\text { - Conclusion: States should only focus on optimizing the } \\
\text { existing NRSRO designation }\end{array}$ \\
\hline $\begin{array}{l}\text { Smith and Wal- } \\
\text { ter } 2002\end{array}$ & $\begin{array}{l}\text { Book Chap- } \\
\text { ter }\end{array}$ & $\begin{array}{l}\text { - } \quad \text { Conflicts of interest in the credit rating industry } \\
\text { - } \\
\text { Focus on the structure of the major industry players } \\
\text { and their relation to each other and the state } \\
\text { - Conclusion: reputation mechanism is a strong deter- } \\
\text { rent of misbehavior }\end{array}$ \\
\hline Sylla 2002 & $\begin{array}{l}\text { Book Chap- } \\
\text { ter }\end{array}$ & $\begin{array}{ll}- & \text { Extensive analysis on the rating industry's history } \\
\text { - } & \text { The very origins } \\
\text { - } & \text { The early phase from } 1909 \text { to the } 1960 \text { s } \\
\text { - } & \text { The globalization of the industry since the } 1970 \text { s }\end{array}$ \\
\hline White 2002 & $\begin{array}{l}\text { Book Chap- } \\
\text { ter }\end{array}$ & $\begin{array}{l}\text { - Short but comprehensive industrial economics analysis } \\
\text { of the credit rating industry in the 'structure, conduct, } \\
\text { performance' framework } \\
\text { - Discussion of several policy issues such as the } \\
\text { NRSRO designation and the Basle II proposal }\end{array}$ \\
\hline \multicolumn{3}{|c|}{ Scientific Research: Sociology/Political Economy } \\
\hline Kerwer 2002a & $\begin{array}{l}\text { Book Chap- } \\
\text { ter }\end{array}$ & $\begin{array}{ll}\text { - } & \text { Analysis of rating agencies as private standard setters } \\
\text { for creditworthiness } \\
\text { - } \quad \text { The role of rating-based regulation } \\
\text { - } \quad \text { Result: systematic deficit in rating agency accountabili- } \\
\text { ty ('accountability gap') }\end{array}$ \\
\hline
\end{tabular}




\begin{tabular}{|c|c|c|}
\hline Kerwer 2005 & Paper & $\begin{array}{ll}\text { - } & \text { Analysis of rating agencies as informal 'non- } \\
\text { majoritarian regulators' } \\
\text { - } \quad \text { Lack of rating agency accountability modeled in a } \\
\text { modified principal agent framework } \\
\text { - } \quad \text { Conclusion: limit scope of rating agency operations }\end{array}$ \\
\hline $\begin{array}{l}\text { King and Sinclair } \\
2003\end{array}$ & Paper & 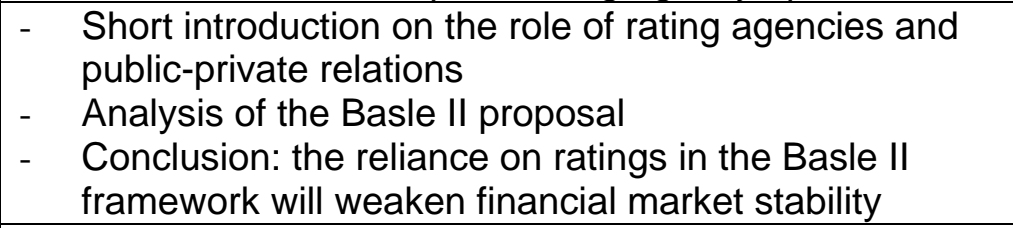 \\
\hline Sinclair 2000 & Paper & $\begin{array}{ll}\text { - } & \text { Analysis of rating agencies as 'embedded knowledge } \\
& \text { networks' } \\
\text { - } & \text { Short history of rating market } \\
\text { - } & \text { Epistemic authority of rating agencies } \\
\text { - } & \text { Government relations }\end{array}$ \\
\hline Sinclair 2005 & Book & 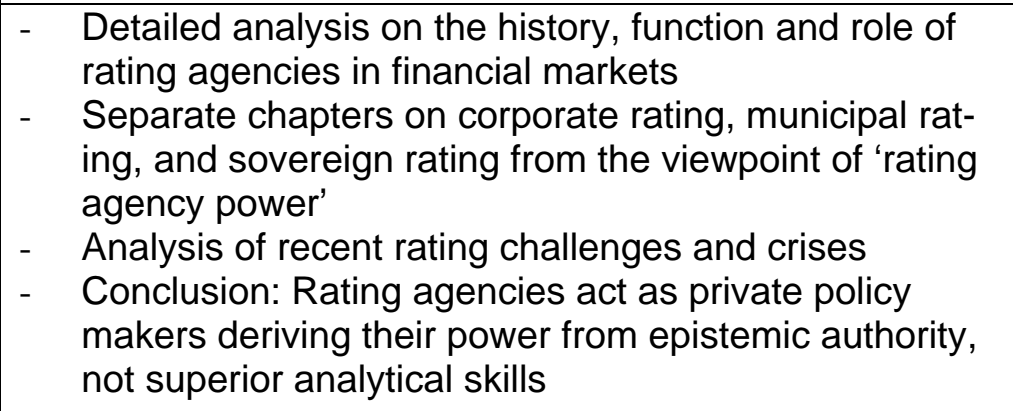 \\
\hline \multicolumn{3}{|l|}{ Surveys } \\
\hline AFP 2002, 2004 & Paper & $\begin{array}{ll}\text { - } & \text { Participants: senior level corporate practitioners and } \\
\text { financial professionals } \\
\text { - } & \text { Sets between } 9 \text { and } 17 \text { questions } \\
\text { - } & 715 \text { surveys received in } 2002 \text { and } 230 \text { in } 2004 \\
\text { - } & \text { Focus: accuracy and timeliness of ratings, the state's } \\
& \text { role }\end{array}$ \\
\hline $\begin{array}{l}\text { Baker and Mansi } \\
2002\end{array}$ & Paper & 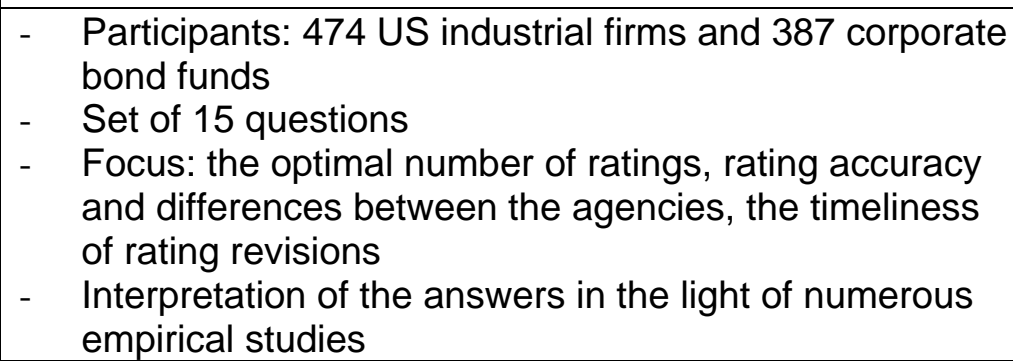 \\
\hline Cantwell 1998 & Paper & $\begin{array}{ll}\text { - } & \text { The last of several surveys on credit ratings since } 1996 \\
\text { - } & \text { Participants: } 300-400 \text { international issuers } \\
\text { - } & \text { Focus: issuer-agency relationship centered on the rat- } \\
\text { ing process } \\
\text { - } \quad \text { Reprinted in Fight } 2001, \text { pp. } 151-172\end{array}$ \\
\hline Ellis 1998 & Paper & $\begin{array}{l}\text { - First survey of issuers and investors at the same time. } \\
\text { - Participants: } 102 \text { rated utilities and } 205 \text { institutional } \\
\text { fixed income investors } \\
\text { - Focus: the number of ratings, unsolicited ratings, rating } \\
\text { accuracy, factors influencing ratings }\end{array}$ \\
\hline
\end{tabular}




\begin{tabular}{|c|c|c|}
\hline $\begin{array}{l}\text { JCIF 2001, } \\
\text { 2000, } 1999\end{array}$ & Paper & $\begin{array}{ll}\text { - } & \text { Surveys of Japanese issuers and institutional investors } \\
\text { - } & \text { Around } 250 \text { participants per year } \\
\text { - } & \text { Questions on rating agencies recognized in Japan and } \\
\text { major international agencies } \\
\text { - Focus: the uses of ratings by Japanese market } \\
\text { participants, assessment of several performance }\end{array}$ \\
\hline TBMA 2006 & Paper & $\begin{array}{ll}\text { - } & \text { Poll of } 41 \text { issuers and } 51 \text { investors } \\
\text { - } & \text { Set of } 28 \text { questions } \\
\text { - } & \text { Focus: industry regulation } \\
\text { - } & \text { Single questions covering a broad array of other issues }\end{array}$ \\
\hline \multicolumn{3}{|c|}{ Governmental Research, Legislation } \\
\hline AFTE 2004 & $\begin{array}{l}\text { Code of } \\
\text { Conduct }\end{array}$ & $\begin{array}{l}\text { - Code of Standard Practices for Participants in the } \\
\text { Credit Rating Process, introduced by several private } \\
\text { financial professional associations } \\
\text { - Similar to the IOSCO code, based on work from the } \\
\text { Association Française des Trésoriers d'Entreprise } \\
\text { - } \quad \text { Includes guidelines for states and issuers }\end{array}$ \\
\hline AMF 2005 & Report & $\begin{array}{ll}\text { - } & \text { International rating business, market impact, regulatory } \\
& \text { environment } \\
\text { - } & \text { French market for financial ratings } \\
\text { - } & \text { Value of the agencies from the different players' points } \\
& \text { of view } \\
\text { - } & \text { Rules of conduct and transparency }\end{array}$ \\
\hline BIS 2004 & $\begin{array}{l}\text { Policy } \\
\text { Framework }\end{array}$ & $\begin{array}{l}\text { - } \quad \text { Basle II Capital Accord } \\
\text { - } \quad \text { First incorporation of credit ratings into worldwide } \\
\text { banking regulation } \\
\text { - } \quad \text { Minimum capital requirements can be calculated under } \\
\text { the 'standardized approach' of the first pillar from credit } \\
\text { ratings } \\
\text { - } \quad \text { Technical detail on individual claims and credit risk } \\
\text { mitigation } \\
\text { - Implementation considerations (consistently use of } \\
\text { ratings from officially recognized 'External Credit } \\
\text { Assessment Institutions' (ECAls) }\end{array}$ \\
\hline CEBS 2006 & Guideline & $\begin{array}{l}\text { Committee of European Banking Supervisors Guide- } \\
\text { lines on the recognition of External Credit Assessment } \\
\text { Institutions for implementing the CRD on the national } \\
\text { level } \\
\text { - Focus: the general recognition process, the specific } \\
\text { implementation of the CRD recognition criteria, and the } \\
\text { criteria for mapping external credit assessments to the } \\
\text { CRD }\end{array}$ \\
\hline
\end{tabular}




\begin{tabular}{|c|c|c|}
\hline CESR 2005 & Report & 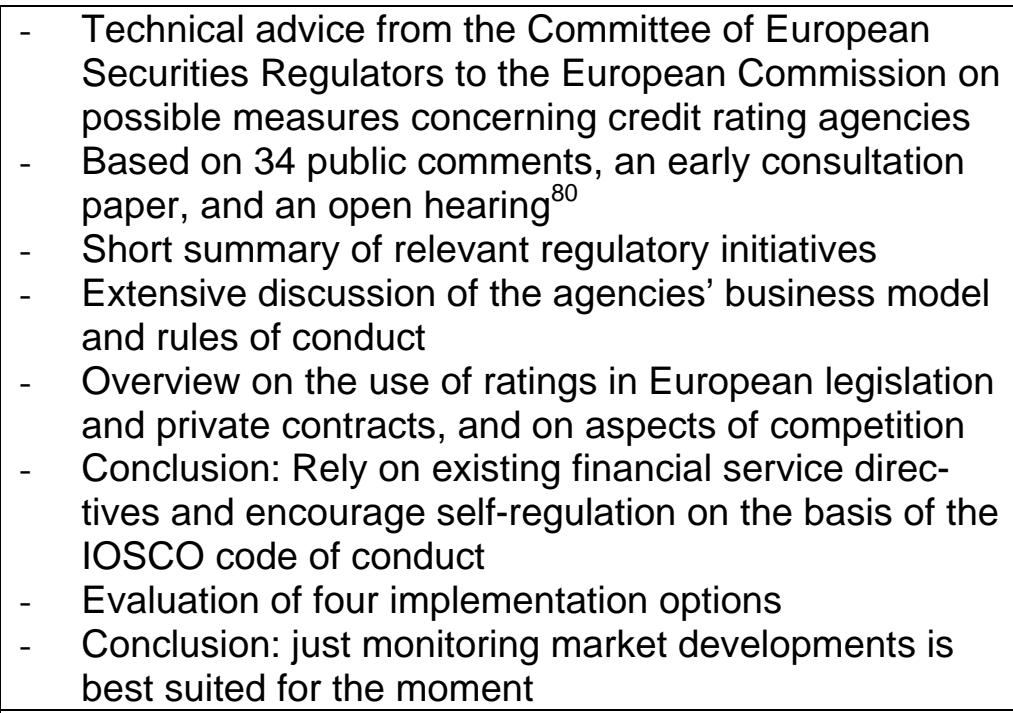 \\
\hline $\begin{array}{l}\text { EU Commission } \\
2005\end{array}$ & Report & $\begin{array}{l}\text { - } \text { Report in response to the European Parliament re- } \\
\text { quest for an industry assessment } \\
\text { - } \\
\text { Adoption of the CESR proposal, no introduction of any } \\
\text { new legislation } \\
\text { - } \\
\text { Reference to existing financial services directives and } \\
\text { the IOSCO code of conduct (implementation was mo- } \\
\text { nitored by the CESR, e.g., CESR 2006a) }\end{array}$ \\
\hline $\begin{array}{l}\text { EU Parliament } \\
2004\end{array}$ & Resolution & $\begin{array}{l}\text { - } \begin{array}{l}\text { European Parliament resolution on credit rating agen- } \\
\text { cies }\end{array} \\
\text { - List of concerns and acknowledgements towards rating } \\
\text { agencies } \\
\text { - Calls on the EU Commission to assess the need for } \\
\text { legislative actions }\end{array}$ \\
\hline $\begin{array}{l}\text { EU Parliament } \\
2006\end{array}$ & Directive & $\begin{array}{ll}\text { - } & \text { European Parliament Capital Requirements Directive } \\
\text { (CRD) } & \\
\text { - } & \text { Transfer of Basle II proposals into EU law } \\
\text { - } & \text { Section } 3 \text { outlines the use of ratings from External } \\
& \text { Credit Assessment Institutions (ECAIs) and respective } \\
\text { regulatory procedures, annex IV goes into detail } \\
\text { - } \quad \text { Part } 1 \text { of the annex deals with risk weights, part } 2 \text { with } \\
\text { recognition criteria for ECAls, and part } 3 \text { with imple- } \\
\text { mentation details for credit institutions }\end{array}$ \\
\hline IOSCO 2003a & Report & 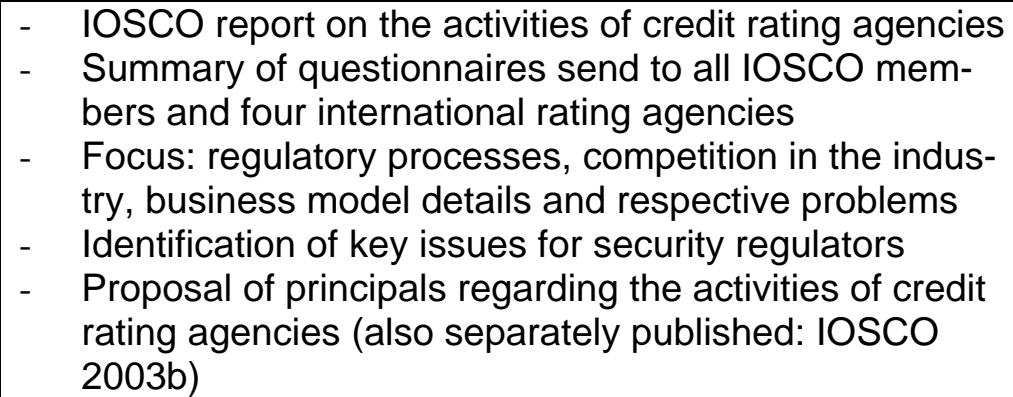 \\
\hline
\end{tabular}

80 Consultation paper: CESR (2004), comments: http://www.cesr-eu.org/index.php?page=responses\&id=53 


\begin{tabular}{|c|c|c|}
\hline IOSCO 2004 & $\begin{array}{l}\text { Code of } \\
\text { Conduct }\end{array}$ & $\begin{array}{l}\text { - } \quad \text { IOSCO Code of Conduct Fundamentals for Credit Rat- } \\
\text { ing Agencies } \\
\text { - } \quad \text { Based on the IOSCO report and comments } \\
\text { - Guidelines on the quality and integrity of the rating } \\
\text { process, on agency independence and responsibility, } \\
\text { and on disclosure/market communication } \\
\text { - Enforcement is left to national regulators and rating } \\
\text { agencies themselves }\end{array}$ \\
\hline SEC $2003 a$ & Report & $\begin{array}{l}\text { - Comprehensive SEC report as requested by section } \\
702 \text { of the Sarbanes-Oxley Act } \\
\text { - History of the NRSRO designation process and details } \\
\text { on recent inquiries and initiatives concerning credit rat- } \\
\text { ing agencies } \\
\text { - Discussion on the role and importance of rating agen- } \\
\text { cies in financial markets } \\
\text { - Information dissemination, entry barriers, conflicts of } \\
\text { interest }\end{array}$ \\
\hline SEC 2003b & $\begin{array}{l}\text { Concept } \\
\text { Release }\end{array}$ & 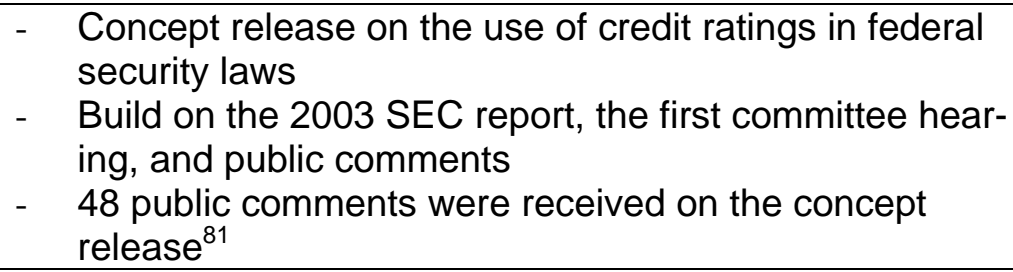 \\
\hline SEC 2005 & $\begin{array}{l}\text { Proposed } \\
\text { Rule }\end{array}$ & $\begin{array}{ll}\text { - } & \text { Proposed rule on the NRSRO Definition build on the } \\
\text { concept release, hearings and comments } \\
\text { - } & \text { Detailed history on the NRSRO process } \\
\text { - } & \text { Explicit definition of what a credit rating is and what } \\
\text { market acceptance means } \\
\text { - } \quad \text { Guidelines on the rating agencies business conduct } \\
\text { - } 32 \text { public comments were received on the proposed } \\
\text { rule }\end{array}$ \\
\hline $\begin{array}{l}\text { U.S. House } \\
2005 a, b, c, 2004 \\
2003 \text {, }\end{array}$ & $\begin{array}{l}\text { Hearing } \\
\text { Notes }\end{array}$ & 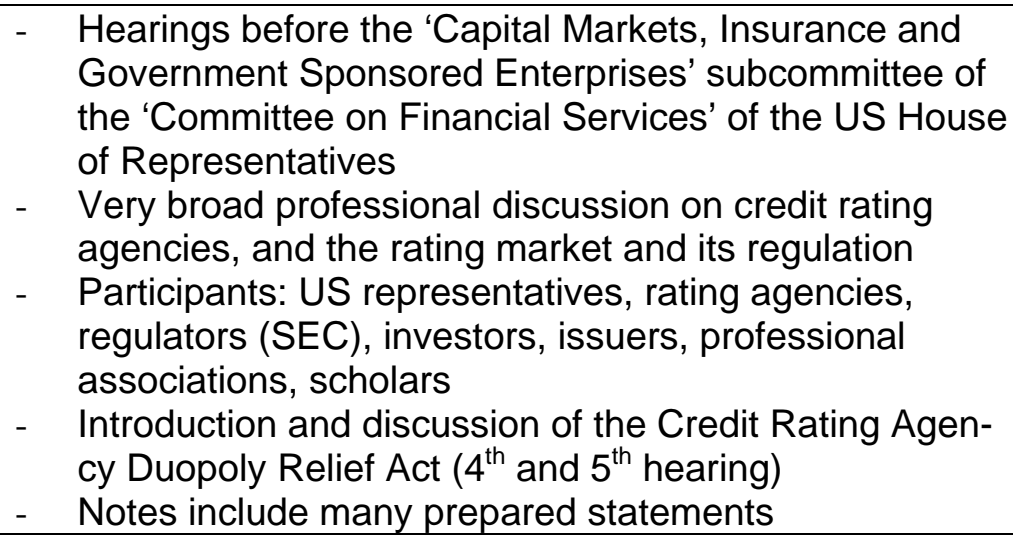 \\
\hline $\begin{array}{l}\text { US Congress } \\
2002\end{array}$ & Legislation & $\begin{array}{ll}\text { - } & \text { Sarbanes-Oxley Act of } 2002 \\
\text { - } & \text { Result of a US congress survey on the role and } \\
\text { possible failures of auditing, investment and rating } \\
\text { firms after the Enron, WorldCom and other scandals in } \\
2001 \text { and } 2002 \\
\text { - } \quad \begin{array}{l}\text { No details concerning credit rating agencies } \\
\text { - Section } 702 \text { demands a commission study and report } \\
\text { regarding credit rating agencies }\end{array}\end{array}$ \\
\hline
\end{tabular}

81 http://www.sec.gov/rules/concept/s71203.shtml

82 http://www.sec.gov/rules/proposed/s70405.shtml 


\begin{tabular}{|c|c|c|}
\hline $\begin{array}{l}\text { US Congress } \\
2006 a, b\end{array}$ & Legislation & $\begin{array}{ll}- & \text { Credit Rating Agency Duopoly Relief Act of 2006; Cre- } \\
\text { dit Rating Agency Reform Act of } 2006 \\
\text { - } & \text { In force from } 2008 \text { on } \\
\text { - } & \text { Replaces the NRSRO designation with a registration } \\
& \text { process } \\
\text { - } & \text { Introduces SEC oversight } \\
\text { - } & \text { Increases liability }\end{array}$ \\
\hline \multicolumn{3}{|c|}{ Rating Agency Publications } \\
\hline Moody's 1991 & Book & $\begin{array}{ll}\text { - } & \text { In depth description of Moody's rating methodology } \\
\text { - } & \text { Details on nine different industries/security classes } \\
\text { - } & \text { Introduction on the role of ratings and the industry } \\
\end{array}$ \\
\hline S\&P 2006 & Report & $\begin{array}{ll}- & \text { In depth description of S\&P's rating methodology } \\
\text { - } & \text { Updated yearly }\end{array}$ \\
\hline \multicolumn{3}{|l|}{ Student Papers } \\
\hline Asgharian 2005 & $\begin{array}{l}\text { Master The- } \\
\text { sis }\end{array}$ & $\begin{array}{ll}\text { - } & \text { Theoretic framework: extended Principal-Agent model } \\
\text { - } & \text { Overview on business model and market } \\
\text { - } & \text { Short analysis of several issues concerning regulation } \\
\text { - } & \text { Specific reform proposals }\end{array}$ \\
\hline $\begin{array}{l}\text { Champsaur } \\
2005\end{array}$ & LL.M. Paper & $\begin{array}{ll}- & \text { Credit rating market and business model } \\
- & \text { Multiple values of credit ratings } \\
- & \text { Regulatory intervention (reasons plus specific options) }\end{array}$ \\
\hline
\end{tabular}




\section{References}

Adams, Charles, D. J. Mathieson, and G. Schinasi, 1999: "International capital markets: developments, prospects, and key policy issues". Washington, DC.

AFP (Association for Financial Professionals), 2002: "Rating Agencies Survey: Accuracy, Timeliness, and Regulation": http://www.afponline.org/pub/pdf/ratings_survey.pdf.

AFP (Association for Financial Professionals), 2004: "2004 Credit Rating Agency Survey": http://www.afponline.org/pub/pdf/2004_10_research_cra_report.pdf.

AFTE (Association Française Des Trésoriers D’Entreprise), 2004: "Code of Standard Practices for Participants in the Credit Rating Process": http://www.afponline.org/pub/pdf/CSP_final.pdf.

AMF (Autorité des Marchés Financiers), 2005: "2004 AMF Report on Rating Agencies": http://www.amf-france.org/documents/general/5891_1.pdf.

Aaker, David A., 1992: "Strategic Market Management", $3^{\text {rd }}$ ed. New York, NY.

Afonso, Antonio, 2003: "Understanding the Determinants of Sovereign Debt Ratings: Evidence for the Two Leading Agencies". Journal of Economics and Finance, 27 (1): 56-74.

Alpert, Frank H. and Michael A. Kamins, 2004: "Corporate Claims as Innovator or Market Leader: Impact on Overall Attitude and Quality Perceptions and Transfer to Company Brands". Corporate Reputation Review, 7 (2): 147-160.

Altman, Edward I. and Herbert A. Rijken, 2004: "How Rating Agencies Achieve Rating Stability". Journal of Banking \& Finance, 28 (11): 2679-2714.

Amato, Jeffrey D. and Craig H. Furfine, 2004: "Are Credit Ratings Procyclical?". Journal of Banking \& Finance, 28 (11): 2641-2677.

Ammer, John M. and Frank Packer, 2000: "How Consistent Are Credit Ratings? A Geographic and Sectoral Analysis of Default Risk". FRB International Finance Discussion Paper No. 668 (June 2000): http://ssrn.com/abstract=232909.

Artus, Patrick, Jean Garrigues, and Mohamed Sassenou, 1993: "Interest Rate Costs and Issuer Ratings: The Case of French CP and Bonds". Journal of International Securities Markets, 7 (autumn): 211-218.

Asgharian, Hossein, 2005: "Reformation of the Credit Rating Industry - Is There a Need?". Lund University School of Economics and Management (June 2005): http://ftp.sec.gov/rules/proposed/s70405/mchartwall6956.pdf.

BIS (Bank for International Settlements, Basle Committee on Banking Supervision), 2000: "Credit Rating and Complementary Sources of Credit Quality Information". Basle Committee on Banking Supervision - Working Papers No. 3 (August 2000): http://www.bis.org/publ/bcbs_wp3.pdf. 
BIS (Bank for International Settlements, Basle Committee on Banking Supervision), 2004: "International Convergence of Capital Measurement and Capital Standards - A Revised Framework" (Basle II): http://www.bis.org/publ/bcbs107.pdf.

Baker, Kent H. and Sattar A. Mansi, 2002: "Assessing Credit Rating Agencies by Bond Issuers and Institutional Investors". Journal of Business Finance and Accounting, 29 (9/10): 1367-1398.

Baliga, Sandeep and Benjamin Polak, 2004: "The Emergence and Persistence of the Anglo-Saxon and German Financial Systems". Review of Financial Studies, 17 (1): 129-163.

Balling, Morten, 2004: "Objectives and Theoretical Foundations of the European Commission's 1999 Action Plan Concerning the Framework for Financial Markets". Journal of International Banking Regulation, 5 (3): 256-286.

Baumol, William J. and Wallace E. Oates, 1998: "The Theory of Environmental Policy", $2^{\text {nd }}$ ed. Cambridge.

Beales, J. Howard III, 1980: "The Economics of Regulating the Professions", in Roger D. Blair, and Stephen Rubin, eds., "Regulating the Professions: a Public-Policy Symposium". Lexington, MA: 125-142.

Beaver, William H., Catherine Shakespeare, and Mark T. Soliman, 2006: "Differential Properties in the Ratings of Certified vs. Non-Certified Bond Rating Agencies". Journal of Accounting and Economics, 42 (3): 303-334.

Behr, Patrick, and André Güttler, 2006: "Does the Stock Market React to Unsolicited Ratings?". Universität Frankfurt, Working Paper Series Finance and Accounting No. 163 (April 2006): http://ssrn.com/abstract=724881.

Blaurock, Uwe, 2006: "Control and Responsibility of Credit Rating Agencies - General Report". XVIIth Congress of the International Academy of Comparative Law Utrecht, 16 - 22 July 2006: http://www2.law.uu.nl/priv/AIDC/index1.asp.

Blume, Marshall E., Felix Lim, and Archie C. MacKinlay, 1998: "The Declining Credit Quality of US Corporate Debt: Myth or Reality?". Journal of Finance, 53 (4): 1389-1413.

Boot, Arnoud W. A., Todd T. Milbourn, and Anjolein Schmeits, 2006: "Credit Ratings as Coordination Mechanisms". Review of Financial Studies, 19 (1): 81-118.

Bottini, Francis A., 1993: "An Examination of the Current Status of Rating Agencies and Proposals for Limited Oversight of Such Agencies". San Diego Law Review, 30: 579-620.

Brookfield, David and Phillip Ormrod, 2000: "Credit Agency Regulation and the Impact of Credit Ratings in the International Bond Market". European Journal of Finance, 6 (4): 311331.

Butler, Alexander W. and Kimberly J. Rodgers, 2003: "Relationship Rating: How Do Bond Rating Agencies Process Information?". EFA 2003 Annual Conference Paper No. 491 (June 
27, 2003): http://ssrn.com/abstract=345860.

CEBS (Committee of European Banking Supervisors), 2006: "Guidelines on the Recognition of External Credit Assessment Institutions". (20 January 2006): http://www.cebs.org/pdfs/GL07.pdf.

CESR (Committee of European Securities Regulators), 2004: "CESR's Technical Advice to the European Commission on Possible Measures Concerning Credit Rating Agencies - Consultation Paper". Ref: 04-612b (November 2004): http://www.cesr-eu.org/.

CESR (Committee of European Securities Regulators), 2005: "CESR's technical advice to the European Commission on possible measures concerning credit rating agencies". Ref: 05139b (March 2005): http://www.cesr-eu.org/.

CESR (Committee of European Securities Regulators), 2006a: "Public Statement - Update on CESR's Dialogue with Credit Rating Agencies to Review how the IOSCO Code of Conduct is Being Implemented". Ref: 06-220 (6 July 2006): http://www.cesr-eu.org/.

CESR (Committee of European Securities Regulators), 2006b: "Public Statement - Update on CESR's Dialogue with Credit Rating Agencies to Review how the IOSCO Code of Conduct is Being Implemented (Annexes)". Ref: 06-220 Annexes (6 July 2006): http://www.cesreu.org/.

Campbell, Tim S., 1979: "Optimal Investment Financing Decisions and the Value of Confidentiality". Journal of Financial and Quantitative Analysis, 14 (5): 913-925.

Campbell, Tim S. and William A. Kracaw, 1980: "Information Production, Market Signaling, and the Theory of Financial Intermediation". Journal of Finance, 35 (4): 863-883.

Cantor, Richard and Frank Packer, 1994: "The Credit Rating Industry". Federal Reserve Bank of New York Quarterly Review, 19 (2): 1-27.

Cantor, Richard and Frank Packer, 1995: "Sovereign Credit Ratings". Current Issues in Economics and Finance, 1 (3): 1-6.

Cantor, Richard and Frank Packer, 1996: "Multiple Ratings and Credit Standards: Differences of Opinion and Selection Bias in the Credit Rating Industry". Federal Reserve Bank of New York Staff Reports No. 12 (April 1996): http://ideas.repec.org/p/fip/fednrp/9527.html.

Cantwell, Joseph, 1998: "Managing Credit Ratings and Rating Agency Relationships". Treasury Management Association Journal, (November/December): 1-22.

Champsaur, Amélie, 2005: "The Regulation of Credit Rating Agencies in the U.S. and the E.U.: Recent Initiatives and Proposals". Seminar in International Finance, LL.M. Paper, Under the Supervision of Professor Howell E. Jackson (May 2005): http://www.law.harvard.edu/programs/pifs/pdfs/amelie_champasaur.pdf.

Chemmanur, Thomas J. and Paolo Fulghieri, 1994: "Investment Bank Reputation, Information Production, and Financial Intermediation". Journal of Finance, 49 (1): 57-79. 
Chen, Zhaohui, 2004: "Buy-Side and Sell-Side: The Industrial Organization of Information Production in the Securities Industry". EFA 2004 Maastricht Meetings Paper No. 4073 (March 2004): http://ssrn.com/abstract=557074.

Cook, Douglas O., Carolin D. Schellhorn, and Lewis J. Spellman, 2003: "Lender Certification Premiums". Journal of Banking \& Finance, 27 (8): 1561-1579.

Covitz, Daniel M. and Paul Harrison, 2003: "Testing Conflicts of Interest at Bond Ratings Agencies with Market Anticipation: Evidence that Reputation Incentives Dominate". FEDS Working Paper No. 2003-68 (December 2003): http://ssrn.com/abstract=512402.

Crockett, Andrew D., 1997: "Why is Financial Stability a Goal of Public Policy?". Economic Review, 82 (4): 5-22.

Deephouse, David L., 1996: "Does Isomorphism Legitimate?". Academy of Management Journal, 39 (4): 1024-1039.

Diamond, Douglas W., 1984: "Financial Intermediation and Delegated Monitoring". Review of Economic Studies, 51 (3): 393-414.

Dodd, Randall and Gautam Setty, 2003: "Credit Rating Agencies: Their Impact on Capital Flows to Developing Countries". Financial Policy Forum, Derivatives Study Center, Special Policy Report 6 (April 7 2003): http://www.financialpolicy.org/FPFSPR6.pdf.

Dumez, Hervé and Alain Jeunema, 1997: "Financial Regulation: From Economic Analysis to Practical Experience", in Alain Jeunemaître, ed., "Financial Markets Regulation: A Practitioner's Perspective". Basingstoke: 3-24.

ECB (European Central Bank), 2004: "Market Dynamics Associated with Credit Ratings: a literature review". Occasional Paper Series No. 16 (June 2004): http://www.ecb.int/pub/pdf/scpops/ecbocp16.pdf.

EU Commission (European Commission), 2005: "Communication from the Commission on Credit Rating Agencies". 2005/11990 (23.12.2005): http://ec.europa.eu/internal_market/securities/docs/agencies/communication_en.pdf.

EU Parliament (European Parliament Committee on Economic and Monetary Affairs), 2004: "Report on Role and Methods of Rating Agencies (Session Document)". A5-0040/2004 (29. January 2004): http://www.europarl.europa.eu/.

EU Parliament (European Parliament), 2006: "Directive 2006-48-EC Relating to the Taking up and Pursuit of the Business of Credit Institutions (recast) - Capital Requirements Directive (CRD) part 1". Official Journal of the European Union, L 177.

Economides, Nicholas S., 1996: "The Economics of Networks". International Journal of Industrial Organization, 14 (6): 673-699.

Economist, 1997: "Risk Beyond Measure". The Economist, 345 (8047): 68-69. 
Ellis, David M., 1998: "Different Sides of the Same Story: Investors' and Issuers' View of Rating Agencies". Journal of Fixed Income, 7 (4): 35-46.

Federal Reserve Board, 2005: "Banking Agencies Announce Revised Plan for Implementation of Basle II Framework". Press Release (September 30, 2005): http://www.federalreserve.gov/boarddocs/press/bcreg/2005/20050930/default.htm.

Ferri, Giovanni and Li-gang Liu, 2003: "How Do Global Credit-Rating Agencies Rate Firms From Developing Countries?". Asian Economic Papers, 2 (3): 30-56.

Fight, Andrew, 2001: "The Ratings Game". Chichester.

Fimalac Group, 2006: "Annual Report 2005": http://www.fimalac.com/.

Fisch, Jacob, 2004: "Rating the Raters". Davis Business Law Journal, 5 (3): http://blj.ucdavis.edu/article/549/.

Fishman, Arthur and Rafael Rob, 2002: "Is Bigger Better? Investing in Reputation". (August 2, 2002): http://www.econ.ucla.edu/iobara/seminar/biggerisbetter1.pdf.

Fitch Ratings, 2002: "Survey Shows Majority of Structured Finance Executives Oppose Notching as Practiced by Moody's and S\&P (press release)". (March 27, 2002): http://www.greenbergresearch.com/articles/1616/1409_FitchRatings_pr.pdf.

Frost, Carol Ann, 2006: "Credit Rating Agencies in Capital Markets: A Review of Research Evidence on Selected Criticisms of the Agencies". (June 27, 2006): http://ssrn.com/abstract=904077.

Gerke, Wolfgang, Ferdinand Mager, and Alexander Röhrs, 2005: "Pension Funding, Insolvency Risk and the Rating of Corporations". Schmalenbach Business Review, Special Issue 2: 35-64.

Gerke, Wolfgang and Ferdinand Mager, 2005: "Die Macht der Ratingagenturen? Der Fall ThyssenKrupp AG". Betriebswirtschaftliche Forschung und Praxis, 57 (3): 203-214.

Gilbert, Richard J., 1989: "Mobility Barriers and the Value of Incumbency". Handbook of Industrial Organization, 1: 475-535.

Gras, Isabelle, 2003: "The Power to Rate. Eine Untersuchung zur Rolle der Ratingagenturen auf den Internationalen Finanzmärkten.". REGEM Analysis No. 6 (May 2003): www.chinapolitik.de/studien/regem/regem_no6.pdf.

Grundmann, Stefan and Wolfgang Kerber, 2001: "Information Intermediaries and Party Autonomy - The Example of Securities and Insurance Markets", in Stefan Grundmann, Wolfgang Kerber, and Stephen Weatherill, eds., "Party Autonomy and the Role of Information in The Internal Market". Berlin, New York: 264-310.

Herring, H. C. and J. M. Reeve, 1986: "An Examination of Nonrated Municipal Bond". Journal of Economics and Business, 38: 65-76. 
Hill, Claire A., 2003: "Rating Agencies Behaving Badly: The Case of Enron". Connecticut Law Review, 35: 1145-1155.

Hill, Claire A., 2004: "Regulating the Rating Agencies". Washington University Law Quarterly, 82: 42-95.

Hsueh, L. P. and D. S. Kidwell, 1998: "Bond Ratings: Are Two Better Then One?". Financial Management, 17 (1): 46-53.

Hull, John C., Mirela Predescu, and Alan White, 2004: "The Relationship Between Credit Default Swap Spreads, Bond Yields, and Credit Rating Announcements". Journal of Banking \& Finance, 28 (11): 2789-2811.

Husisian, Gregory, 1990: "What Standard of Care Should Govern the World's Shortest Editorials?: An Analysis of Bond Rating Agency Liability". Cornell Law Review, 75 (2): 411-461.

Hörner, Johannes, 2002: "Reputation and Competition". American Economic Review, 92 (3): 644-663.

IOSCO (International Organization of Security Commissions, Technical Committee), 2003a: "Report on the Activities of Credit Rating Agencies". IOSCO Public Document 153 (September 2003): www.iosco.org/library/pubdocs/pdf/IOSCOPD153.pdf.

IOSCO (International Organization of Security Commissions, Technical Committee), 2003b: "Statement of Principles Regarding the Activities of Credit Rating Agencies". IOSCO Public Document 151 (25 September 2003): www.iosco.org/library/pubdocs/pdf/IOSCOPD151.pdf.

IOSCO (International Organization of Security Commissions, Technical Committee), 2004: "Code Of Conduct Fundamentals For Credit Rating". IOSCO Public Document 173 (October 2004): http://www.iosco.org/library/pubdocs/pdf/IOSCOPD173.pdf.

JCIF (Japan Center for International Finance), 1999: "Characteristics and Appraisal of Major Rating Companies". (December 1998): http://www.jcif.or.jp/e/report/rating.html.

JCIF (Japan Center for International Finance), 2000: "Characteristics and Appraisal of Major Rating Agencies". (January 2000): http://www.jcif.or.jp/e/report/rating.html.

JCIF (Japan Center for International Finance), 2001: "Characteristics and Appraisal of Major Rating Companies". (February 23, 2001): http://www.jcif.or.jp/e/report/rating.html.

Jackson, Howell E., 2001: "The Role of Credit Rating Agencies in the Establishment of Capital Standards for Financial Institutions in a Global Economy", in Eilís Ferran, and Charles A. E. Goodhart, eds., "Regulating Financial Services and Markets in the Twenty First Century". Oxford: 311-322.

Jappelli, Tullio and Marco Pagano, 2000: "Information Sharing in Credit Markets: A Survey". CSEF Working Paper No. 36 (March 2000): http://www.csef.it/WP/wp36.pdf.

Jendges, Thomas, 1996: "Wettbewerbsstrategien bei Rückläufigen Märkten". Wiesbaden. 
Jewell, Jeff and Miles Livingston, 1999: "A Comparison of Bond Ratings from Moody's S\&P and Fitch IBCA". Financial Markets Institutions \& Instruments, 8 (4): 1-45.

Jewell, Jeff and Miles Livingston, 2000: "The Impact of a Third Credit Rating on the Pricing of Bonds". Journal of Fixed Income, 10 (3): 69-85.

Johnson, Richard, 2004: "Rating Agency Actions Around the Investment-Grade Boundary". Journal of Fixed Income, 13 (4): 25-37.

Jorion, Philippe, Zhu Liu, and Charles Shi, 2005: "Informational Effects of Regulation FD: Evidence From Rating Agencies". Journal of Financial Economics, 76 (2): 309-330.

Kerwer, Dieter, 2002a: "Standardising as Governance: The Case of Credit Rating Agencies", in Adrienne Héritier, ed., "Common Goods: Reinventing European and International Governance". Lanham, MD: 293-315.

Kerwer, Dieter, 2002b: "Rating Agencies Setting a Standard for Global Financial Markets". Economic Sociology European Electronic Newsletter, 3 (3): 40-46.

Kerwer, Dieter, 2005: "Holding Global Regulators Accountable: The Case of Credit Rating Agencies". Governance, 18 (3): 453-475.

Kim, Moshe, Doron Kliger, and Bent Vale, 2003: "Estimating Switching Costs: the Case of Banking". Journal of Financial Intermediation, 12 (1): 25-56.

King, Michael R. and Timothy J. Sinclair, 2003: "Private Actors and Public Policy: A Requiem for the New Basle Capital Accord". International Political Science Review, 24 (3): 345362.

Klein, Benjamin and Keith B Leffler, 1981: "The Role of Market Forces in Assuring Contractual Performance". Journal of Political Economy, 89 (4): 615-641.

Klemperer, Paul, 1995: "Competition When Consumers have Switching Costs: an Overview with Applications to Industrial Organization, Macroeconomics, and International Trade". Review of Economic Studies, 62 (4): 515-539.

Kliger, Doron and Oded H. Sarig, 2000: "The Information Value of Bond Ratings". Journal of Finance, 55 (6): 2879-2902.

Kranton, Rachel E., 2003: "Competition and the Incentive to Produce High Quality". Economica, 70: 385-404.

Kreps, David M., 1990: "Corporate Culture and Economic Theory", in James E. Alt, and Kenneth A. Shepsle, eds., "Perspectives on Positive Political Economy". Cambridge: 90-143.

Kroeber-Riel, Werner and Peter Weinberg, 1996: "Konsumentenverhalten". München.

Kräussl, Roman, 2003a: "Do Changes in Sovereign Credit Ratings Contribute to Financial Contagion in Emerging Market Crises?". CFS Working Paper Series 2003/22: 
http://ssrn.com/abstract=473262.

Kräussl, Roman, 2003b: "Do Credit Rating Agencies Add to the Dynamics of Emerging Market Crises?" CFS Working Paper Series 2003/18: http://www.ifk-cfs.de/papers/03_18.pdf.

Kuhner, Christoph, 2001: "Financial Rating Agencies: Are They Credible?: Insights into The Reporting Incentives of Rating Agencies in Times of Enhanced Systemic Risk". Schmalenbach Business Review, 53 (1): 2-26.

Lane, Charles, 2005: "Justices Overturn Andersen Conviction". Washington Post: http://www.washingtonpost.com/wp-dyn/content/article/2005/05/31/AR2005053100491.html.

Leibenstein, Harvey, 1966: "Allocative Efficiency vs. 'X-Efficiency"'. American Economic Review, 56 (3): 392-415.

Levich, Richard M., Giovanni Majnoni, and Carmen M. Reinhart, 2002: "Ratings, Rating Agencies and the Global Financial System", Boston, MA.

Löffler, Gunter, 2004: "An Anatomy of Rating Through the Cycle". Journal of Banking \& Finance, 28 (3): 695-720.

Mann, Ronald J., 1999: "Verification Institutions in Financing Transactions". Georgetown Law Journal, 87: 2225.

Mariano, Beatriz, 2006: "Conformity and Competition in Financial Certification", EFA 2006 Zurich Meetings (March): http://ssrn.com/abstract=906462.

McAfee, R. Preston, Hugo M. Mialon, and Michael A. Williams, 2004: "What is a Barrier to Entry?". American Economic Review, 94 (2): 461-465.

McGraw-Hill Companies, 2006: "Annual Report 2006": http://www.mcgraw-hill.com/.

McNamara, Gerry and Paul M. Vaaler, 2000: "The Influence of Competitive Positioning and Rivalry on Emerging Market Risk Assessment". Journal of International Business Studies, 31 (2): 337-347.

McNamara, Gerry and Paul M. Vaaler, 2004: "Crisis and Competition in Expert Organizational Decision Making". Organization Science, 15 (6): 687-703.

Microsoft Corporation, 2005: "Annual Report 2005": http://www.microsoft.com/.

Micu, Marian, Eli M. Remolona, and Philip Wooldridge, 2006: "The Price Impact of Rating Announcements: which Announcements Matter?". BIS Working Papers No. 207 (June 2006): http://www.bis.org/publ/work207.pdf

Milgrom, Paul and John Roberts, 1982: "Predation, Reputation and Entry Deterrence". Journal of Economic Theory, 27: 280-312.

Millon, Marcia H. and Anjan V. Thakor, 1985: "Moral Hazard and Information Sharing: a 
Model of Financial Information Gathering Agencies". Journal of Finance, 40 (5): 1403-1422.

Moody's Corporation, 2006: "Annual Report 2005": http://www.moodys.com/.

Moody's (Moody's Investor Service), 1991: "Global Credit Analysis". London.

Moody's (Moody's Investor Service), 1999: "Designation of Unsolicited Ratings in which the Issuer has not Participated". Moody's Special Comment (November 1999): http://www.moodys.com/.

Moody's (Moody's Investor Service), 2001a: "Revised Country Ceiling Policy". Rating Methodology (June 2001): http://www.moodys.com/.

Moody's (Moody's Investor Service), 2001b: "The Unintended Consequences of Rating Triggers". Special Comment (December 2001): http://www.moodys.com/.

Moody's (Moody's Investor Service), 2002: "Moody's Analysis of US Corporate Rating Triggers Heightens Need For Increased Disclosure". Special Comment (July 2002): http://www.moodys.com/.

Moody's (Moody's Investor Service), 2003: "The Role and Function of Rating Agencies: Evolving Perceptions and the Implications of Regulatory Oversight: Special Report". Special Comment (February 2003): http://www.moodys.com/.

Mora, Nada and Sebouh Aintablian, 2005: "A Fabricated Ceiling? The Information Contribution of Bond Ratings". (February 24, 2006): http://ssrn.com/abstract=886739.

Mora, Nada, 2004: "Sovereign Credit Ratings: Guilty Beyond Reasonable Doubt?". EFA 2004 Maastricht Meetings Paper No. 1982 (March 5): http://ssrn.com/abstract=561141.

NERA, 2003: "Credit Ratings for Structured Products: A Review of Analytical Methodologies, Credit Assessment Accuracy, and Issuer Selectivity among the Credit Rating Agencies". (6 November 2003): http://www.nera.com/Publication.asp?p_ID=119.

Nelson, Phillip, 1970: "Information and Consumer Behavior". Journal of Political Economy, 78 (2): 311-329.

Nicholls, Christopher, 2005: "Public and Private Uses of Credit Ratings", Credit Rating Agencies: Need for Reform in Canada? (August 2005): http://www.rotman.utoronto.ca/cmi/papers/CRA_Study_Nicholls.pdf.

Norden, L. and M. Weber, 2004: "Informational Efficiency of Credit Default Swap and Stock Markets: the Impact of Credit Rating Announcements". Journal of Banking \& Finance, 28 (11): 2813-2843.

Partnoy, Frank, 1999: "The Siskel and Ebert of Financial Markets?: Two Thumbs Down for the Credit Rating Agencies". Washington University Law Quarterly, 77 (3): 619-714.

Partnoy, Frank, 2006: "How and Why Credit Rating Agencies are Not Like Other Gatekee- 
pers", in Yasuyuki Fuchita, and Robert E. Litan, eds., "Financial Gatekeepers: Can They Protect Investors? ". Washington, DC: 59-102.

Perraudin, William R. M. and Alex P. Taylor, 2004: "On the Consistency of Ratings and Bond Market Yields". Journal of Banking \& Finance, 28 (11): 2769-2788.

Podolny, Joel M., 1993: "A Status-Based Model of Market Competition". American Journal of Sociology, 98 (4): 829-872.

Poon, Winnie P. H., and Michael Firth, 2005: "Are Unsolicited Credit Ratings Lower? International Evidence From Bank Ratings". Journal of Business Finance \& Accounting, $32(9,10)$ : 1741-71.

Poon, Winnie P. H., 2003: "Are unsolicited credit ratings biased downward?". Journal of Banking \& Finance, 27 (4): 593-614.

Posner, Richard A., 1975: "The Social Costs of Monopoly and Regulation". Journal of Political Economy, 83 (4): 807-827.

Radelet, Steven and Jeffrey Sachs, 1998: "The East Asian Financial Crisis: Diagnosis, Remedies, Prospects". NBER Working Paper 6680 (August 1998): http://papers.nber.org/papers/w6680.pdf.

Ramakrishnan, Ram T. S. and Anjan V. Thakor, 1984: "Information Reliability and a Theory of Financial Intermediation". Review of Economic Studies, 51: 415-432.

Rajeshwer, Ch and Sharath Jutur, 2005: "Credit Rating Agencies - Emerging Issues", Andhra Pradesh, India.

Reisen, Helmut, 2003: "Ratings Since the Asian Crisis". OECD Development Centre Working Papers 214 (November 2003): http://www.oecd.org/dataoecd/22/8/1934625.pdf

Rousseau, Stephane, 2005: "Enhancing the Accountability of Credit Rating Agencies: The Case for a Disclosure-Based Approach", Credit Rating Agencies: Need for Reform in Canada? (August 2005): http://ssrn.com/abstract=797325.

S\&P (Standard and Poor's Rating), 2006: "Corporate Ratings Criteria": www.corporatecriteria.standardandpoors.com.

SEC (Securities and Exchange Commission), 2003a: "Report on the Role and Function of Credit Rating Agencies in the Operation of the Securities Markets". (January 2003): www.sec.gov/news/studies/credratingreport0103.pdf.

SEC (Securities and Exchange Commission), 2003b: "Concept Release: Rating Agencies and the Use of Credit Ratings under the Federal Securities Laws". Release Nos. 33-8236; 34-47972: www.sec.gov/rules/concept/33-8236.htm.

SEC (Securities and Exchange Commission), 2005: "Definition of Nationally Recognized Statistical Rating Organization". Federal Register, 70 (78): 21306-21323. 
Samuelson, Paul Anthony and William D. Nordhaus, 1998: "Economics", $16^{\text {th }}$ ed. Boston, MA.

Schmalensee, Richard, 1982: "Product Differentiation Advantages of Pioneering Brands". American Economic Review, 72 (3): 349-365.

Schwarcz, Steven L., 2001: "The Role of Rating Agencies in Global Market Regulation", in Eilís Ferran, and Charles A. E. Goodhart, eds., "Regulating Financial Services and Markets in the Twenty First Century". Oxford: 297-309.

Schwarcz, Steven L., 2002: "Private Ordering of Public Markets: The Rating Agency Paradox". University of Illinois Law Review, (1): 1-28.

Shapiro, Carl, 1983: "Premiums for High Quality Products as Returns to Reputations". Quarterly Journal of Economics, 98 (4): 659-679.

Shapiro, Carl, 1986: "Investment, Moral Hazard, and Occupational Licensing". Review of Economic Studies, 53 (5): 843-862.

Shefrin, Hersh M., 2000: "Beyond Greed and Fear". Boston, MA.

Shy, Oz, 2001: "The Economics of Network Industries". Cambridge.

Sinclair, Timothy J., 2000: "Reinventing Authority: Embedded Knowledge Networks and the New Global Finance". Environment and Planning C: Government and Policy, 18 (4): 487502.

Sinclair, Timothy J., 2001: "The Infrastructure of Global Governance: Quasi-Regulatory Mechanisms and the New Global Finance". Global Governance, 7: 441-451.

Sinclair, Timothy J., 2005: "The New Masters of Capital: American Bond Rating Agencies and the Politics of Creditworthiness". Ithaca, NY.

Smith, Roy C. and Ingo Walter, 2002: "Rating Agencies: Is There an Agency Issue?", in Richard M. Levich, Giovanni Majnoni, and Carmen M. Reinhart, eds., "Ratings, Rating Agencies and the Global Financial System". Boston, MA: 289-318.

Stigler, George Joseph, 1968: "The Organization of Industry". Homewood, III.

Strausz, Roland, 2005: "Honest Certification and the Threat of Capture". International Journal of Industrial Organization, 23 (1/2): 45-62.

Sylla, Richard, 2002: "A Historical Primer on the Business of Credit Rating", in Richard M. Levich, Giovanni Majnoni, and Carmen M. Reinhart, eds., "Ratings, Rating Agencies and the Global Financial System". Boston, MA: 19-40.

TBMA (The Bond Market Association), 2006: "Rate the Raters. Investors' and Issuers' Polls". Rating Industry Day (23. February 2006). 
Tirole, Jean, 1998: "The Theory of Industrial Organization", $10^{\text {th }}$ printing. Cambridge, MA.

Train, Kenneth, 1991: "Optimal Regulation: the Economic Theory of Natural Monopoly". Cambridge, MA.

U.S. House (Capital Markets, Insurance and Government Sponsored Enterprises subcommittee of the Committee on Financial Services of the U.S. House of Representatives), 2003: "Rating the Rating Agencies: the State of Transparency and Competition". No. 108-18, 1st rating agency hearing (April 2, 2003)": http://financialservices.house.gov/media/pdf/10818.pdf.

U.S. House (Capital Markets, Insurance and Government Sponsored Enterprises subcommittee of the Committee on Financial Services of the U.S. House of Representatives), 2004: "The Ratings Game: Improving Transparency and Competition Among the Credit Rating Agencies". No. 108-110, 2nd hearing on rating agencies (September 14, 2004): http://financialservices.house.gov/media/pdf/108-110.pdf.

U.S. House (Capital Markets, Insurance and Government Sponsored Enterprises subcommittee of the Committee on Financial Services of the U.S. House of Representatives), 2005a: "Legislative Solutions for the Rating Agency Duopoly". No. 109-42, 4th hearing on rating agencies (June 29, 2005): http://financialservices.house.gov/media/pdf/109-42.pdf.

U.S. House (Capital Markets, Insurance and Government Sponsored Enterprises subcommittee of the Committee on Financial Services of the U.S. House of Representatives), 2005b: "H.R. 2990 The Credit Rating Agency Duopoly Relief Act of 2005". No. 109-66, 5th rating agency hearing (November 29, 2005): http://financialservices.house.gov/media/pdf/10966.pdf.

U.S. House (Capital Markets, Insurance and Government Sponsored Enterprises subcommittee of the Committee on Financial Services of the U.S. House of Representatives), 2005c: "Reforming Credit Rating Agencies: The SEC's Need for Statutory Authority." No. 109-14, 3rd rating agency hearing (April 12, 2005): http://financialservices.house.gov/media/pdf/041205ox.pdf.

US Congress, 2002: "Sarbanes-Oxley Act of 2002". Public Law 107-204 (July 30, 2002): http://www.sec.gov/about/laws/soa2002.pdf.

US Congress, 2006a: "Credit Rating Agency Duopoly Relief Act of 2006". H.R. 2990: http://www.govtrack.us/congress/bill.xpd?bill=h109-2990.

US Congress, 2006b: "Credit Rating Agency Reform Act of 2006". S. 3850: http://www.govtrack.us/congress/bill.xpd?bill=s109-3850.

US Senate (Senate Committee on Governmental Affairs), 2002: "Financial Oversight of Enron: The SEC and Private-Sector Watchdogs". Report of the Staff (October 8, 2002): www.senate.gov/ govt-aff/100702watchdogsreport.pdf.

Viscusi, W. Kip, John M. Vernon, and Joseph E. Harrington, 2005: "Economics of Regulation and Antitrust", $4^{\text {th }}$ ed. Cambridge, MA. 
Wendorf, Gabriele, 1994: "Umweltzeichen im Spannungsfeld Zwischen Konsumenten und Unternehmen". Frankfurt am Main.

West, Richard R., 1973: "Bond Ratings, Bond Yields and Financial Regulation: Some Findings". Journal of Law \& Economics, 16: 159-168.

White, Lawrence J., 2002: "The Credit Rating Industry: An Industrial Organization Analysis", in Richard M. Levich, Giovanni Majnoni, and Carmen M. Reinhart, eds., "Ratings, Rating Agencies and the Global Financial System". Boston, MA: 41-65. 